\title{
Trends in the timing of first marriage among men and women in the developing world [Arabic]
}

\author{
Barbara Mensch \\ Population Council \\ Susheela Singh \\ John B. Casterline
}

Follow this and additional works at: https://knowledgecommons.popcouncil.org/departments_sbsr-pgy

Part of the Demography, Population, and Ecology Commons, Family, Life Course, and Society Commons, International Public Health Commons, and the Maternal and Child Health Commons How does access to this work benefit you? Let us know!

\section{Recommended Citation}

Mensch, Barbara, Susheela Singh, and John B. Casterline. 2005. "Trends in the timing of first marriage among men and women in the developing world," Policy Research Division Working Paper no. 202 [Arabic]. New York: Population Council. Version of record: https://doi.org/10.17226/11524 


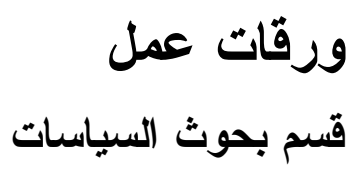

$$
\text { بين الجاهات حول توقيت الزواج الأول }
$$

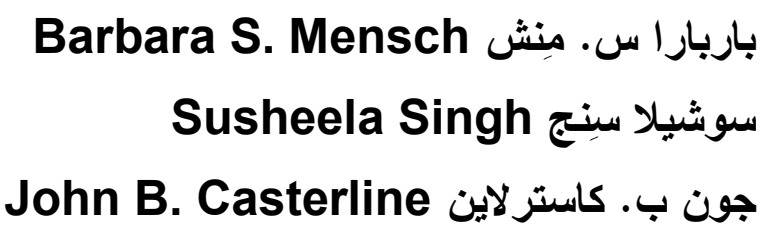

2005 رقم 202

مجلس السكان 
One Dag Hammarskjold Plaza New York, New York 10017 USA www.popcouncil.org pubinfo@popcouncil.org

لا يجوز إعادة إنتاج هذه المادة العلمية دون الموافقة الخطية للمؤلفين. للحصول على قائمة بورقات العمل الصادرة

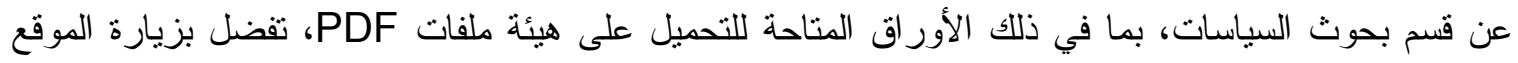

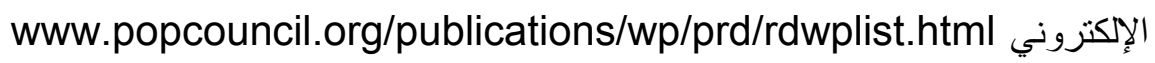

ISSN: $1554-8538$

( 2005 حقوق الطبع محفوظة لمجلس السكان 


\section{اتجاهات حول توقيت الزواج الأول \\ بين الرجال و النساء في العالم النامي}

باربار اس. مينش Barbara S. Mensch، وسوشيلا سِنج Susheela Singh، وجون ب. كاستر لاين John B. Casterline

باربار اس. منش Barbara S. Mensch هي مشارك أول Senior Associate بقسم بحوث السياسات في

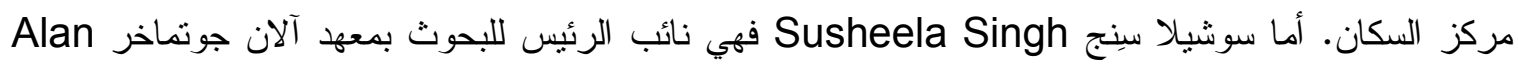
Guttmacher Institute

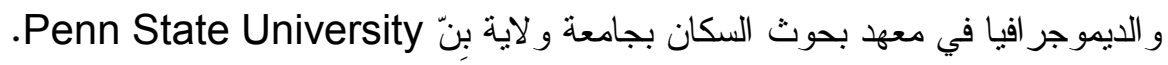

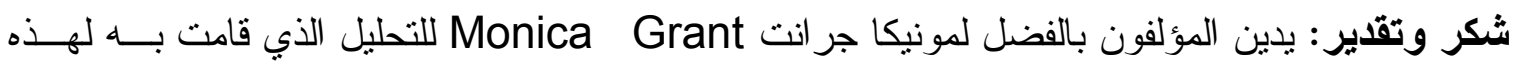

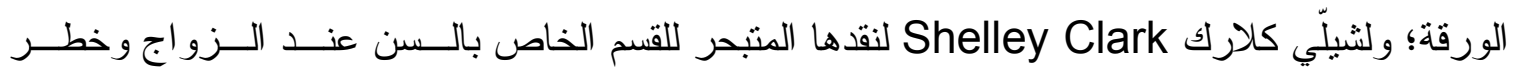

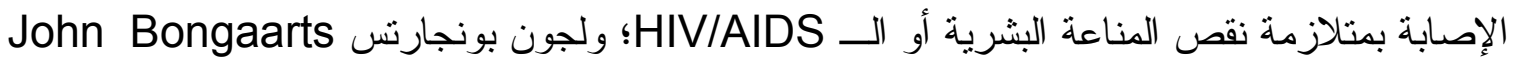

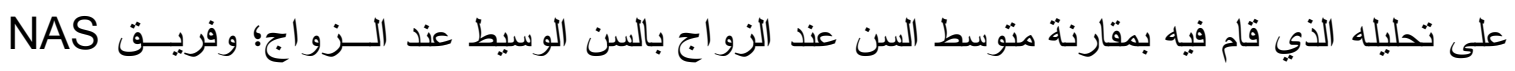

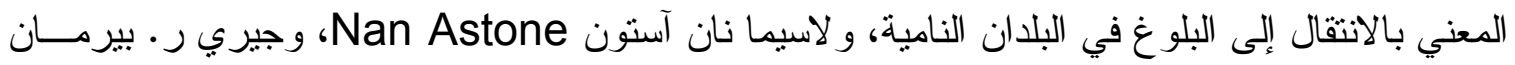

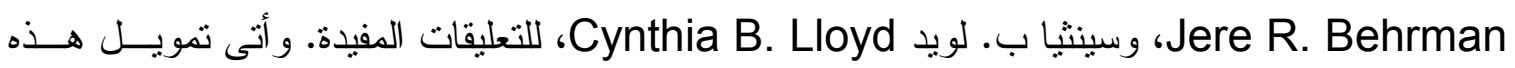

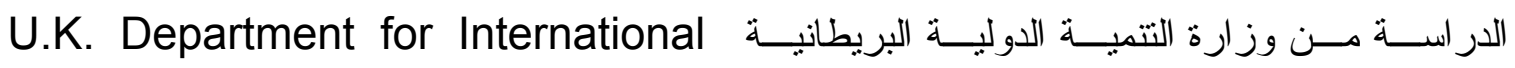
the William and Flora Hewlett Development

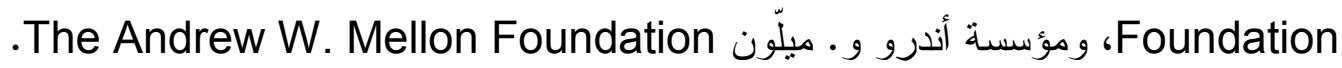

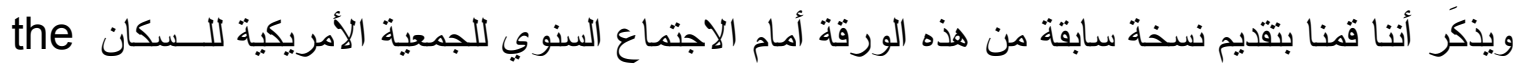
Population Association of America وسيتم نشر ها كللك كالفصل 5 من المجلد اللاحق لمطابع الأكاديميات الوطنية، الانتقالات المتغيــرة إلـى الـى البلو غي البلان النامية، دراسات مختارة، أو : The Changing Transitions to Adulthood in Developing Countries: Selected

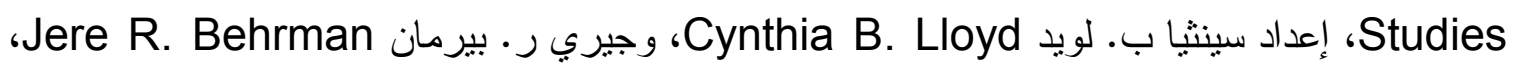

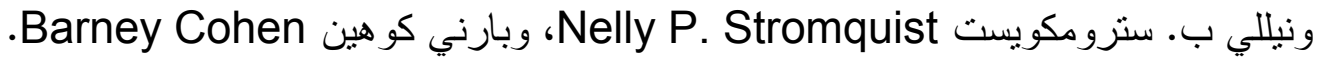


يستحق توقيت أول اقتران في حياة الإنسان البحث، ليس فقط بسبب العلاقة الوقتية الوثيقة بين

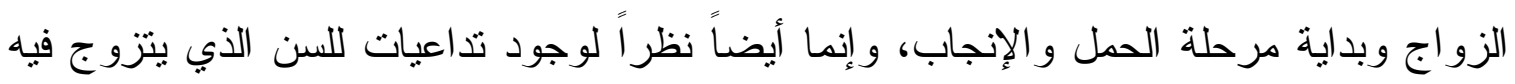

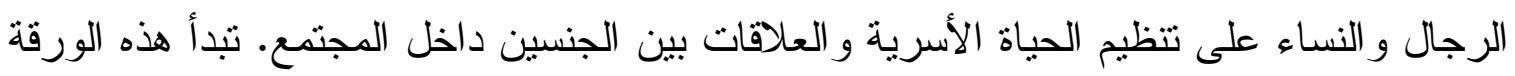

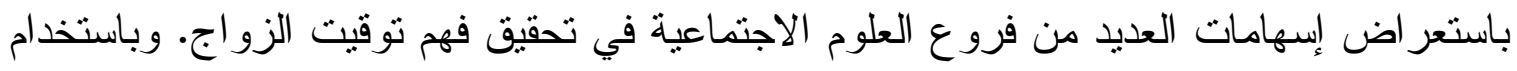

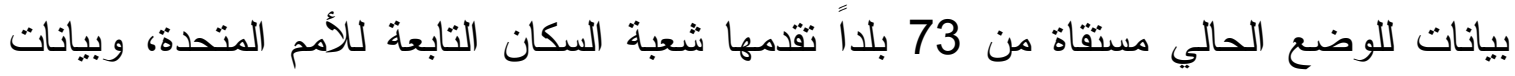

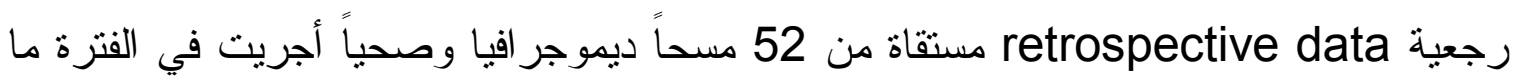

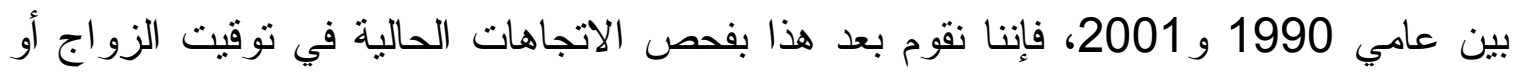

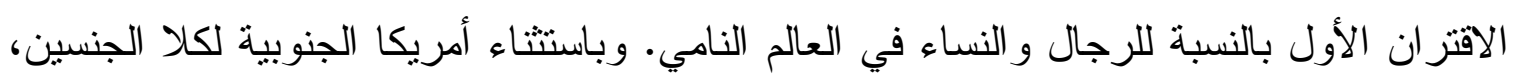
وجنوب شرق آسيا بالنسبة للرجال، ظهر نر اجع ضخم في نسبة الثباب و الثنابات المتزوجين.

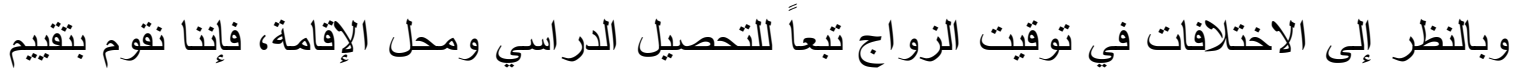
ما إذا كانت هنالك علاقة بين تر اجع نسبة الثباب الذين يتزوجون وبين الارتفاع في مستوى النعليم

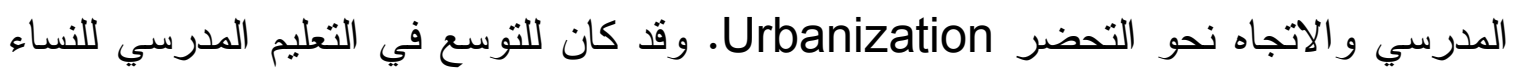
بعض التأثثر، بيد أن نسبة كبيرة من نراجع ظاهرة الزواج المبكر لا تفسرها التغيرات في

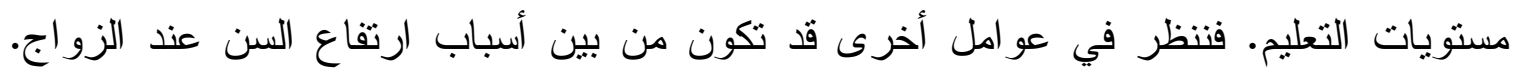

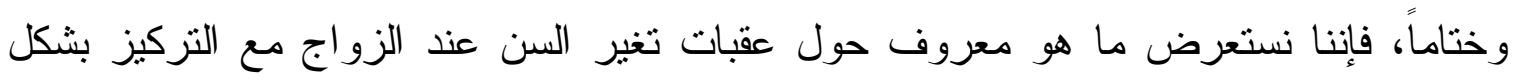

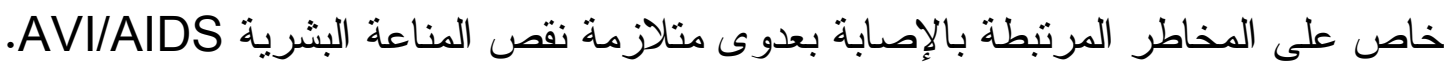


بالنسبة لكثير من الأخصائيين الديموجر افيين، يعتبر السن عند أول اقتران أمراً يستحق الالتفات

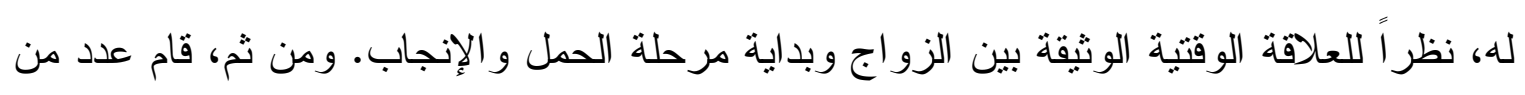

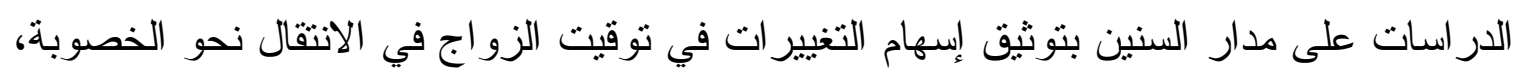

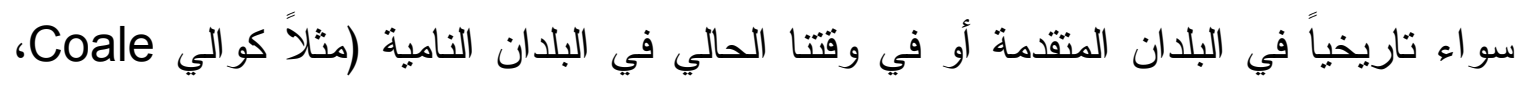
وتريدواي Treadway، 1986؛ وكاستر لاين Casterline، Rosero-Bixby

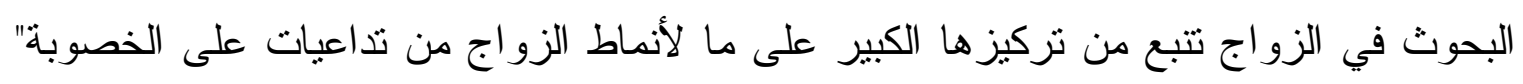

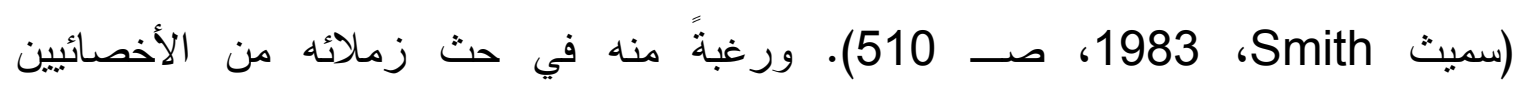

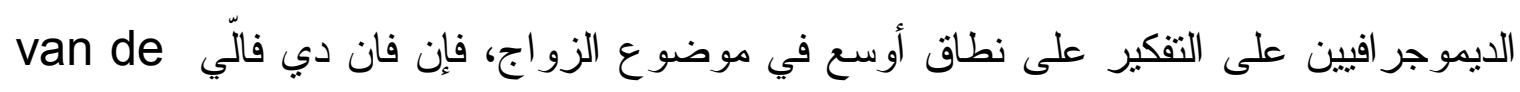
(1993) Walle

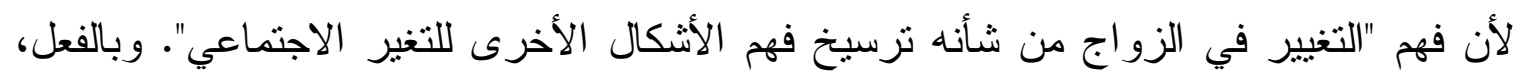

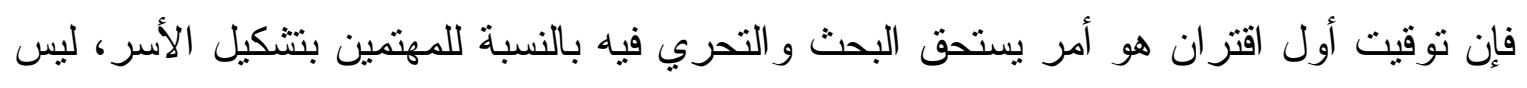

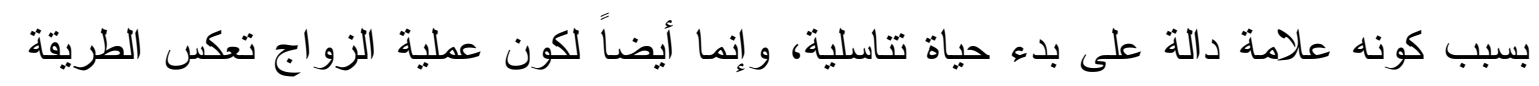

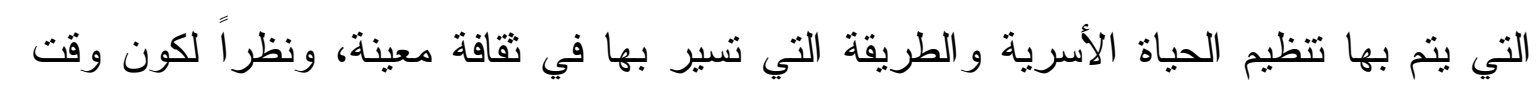

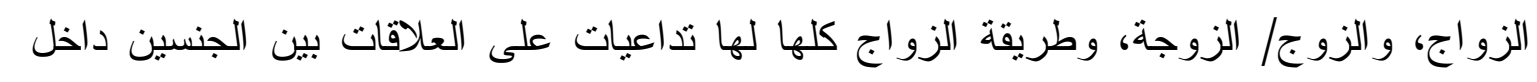

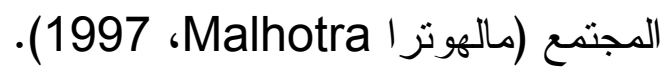

يتأثر السن التي يقترن فيها الرجال و النساء للمرة الأولى في إطار الزواج بالأعراف و التوقعات

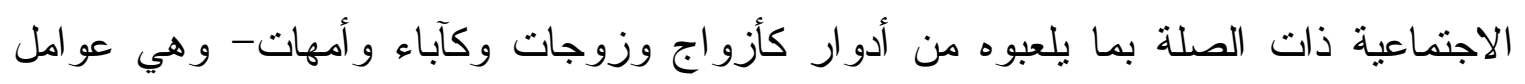

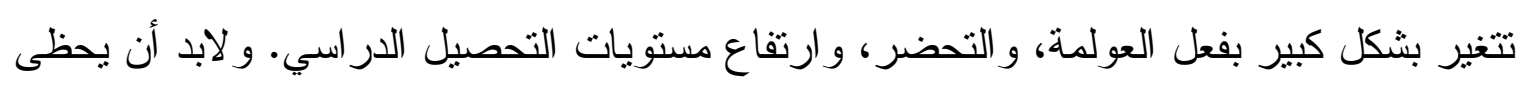

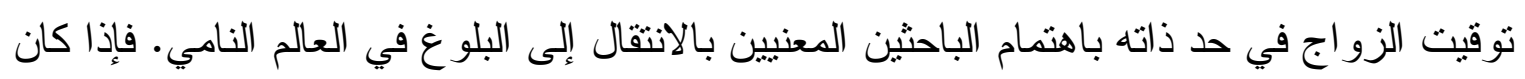

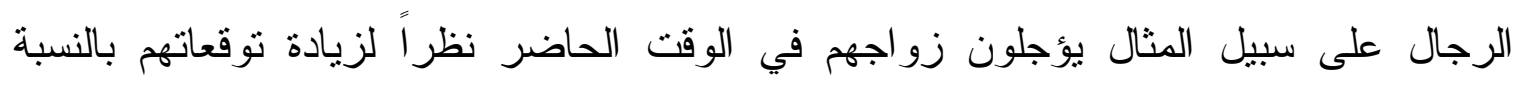

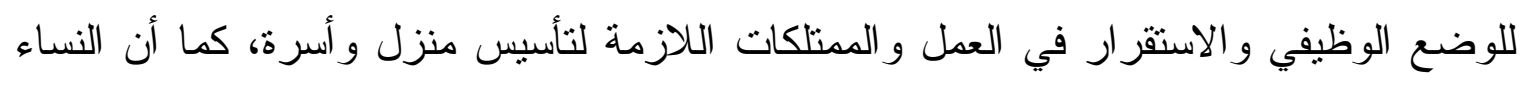
ترجئن الزواج بسبب تحول الأدوار القائمة على النوع، فإنه يكون من الأهمية بمكان توتثيق هذه

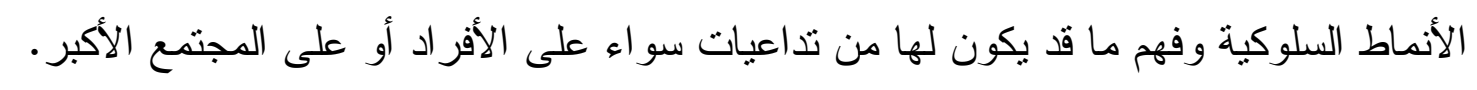


ففي السنوات الأخيرة، لم تلتقت سوى قلة من الأخصائيين الديموجر افيين إلى دعوة فان دي فالّي

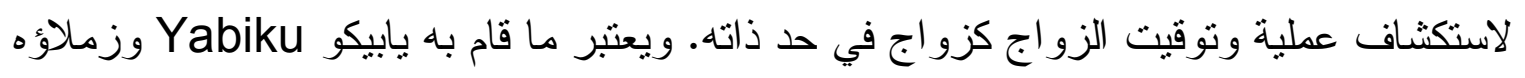

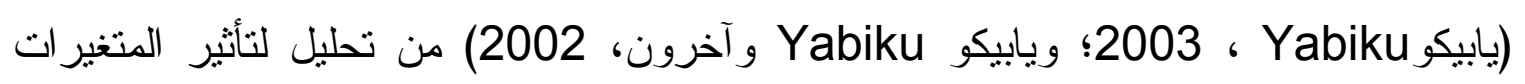

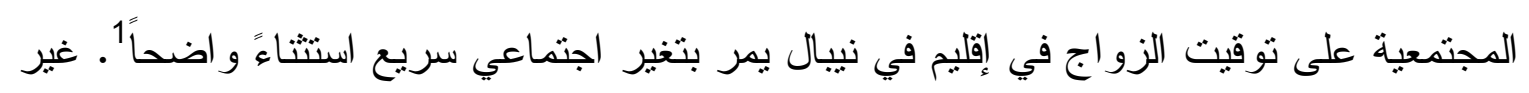

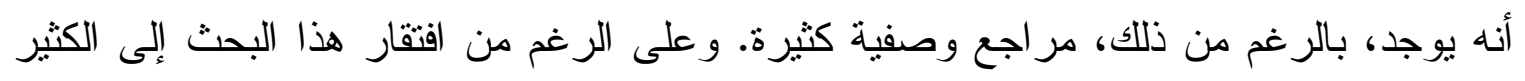

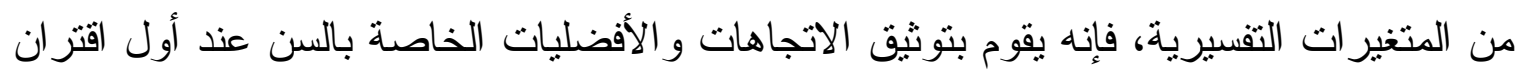

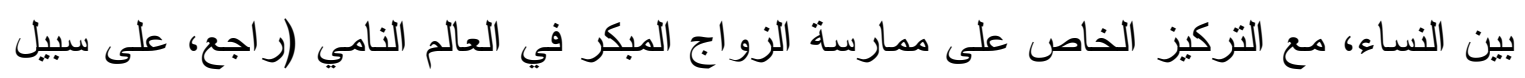

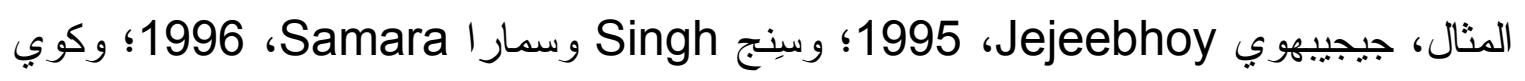

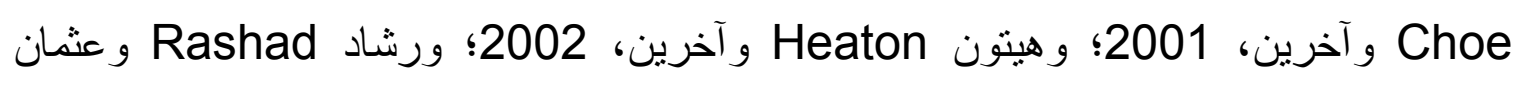

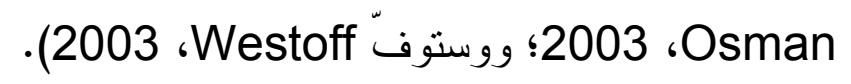

ويعكس هذا الاهتمام بالزواج المبكر اهتمام مناصري حقوق الإنسان والصحة الإنجابية، و الذين

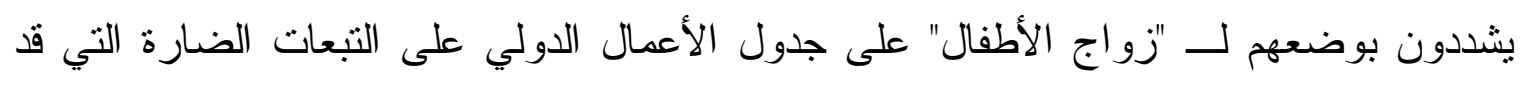

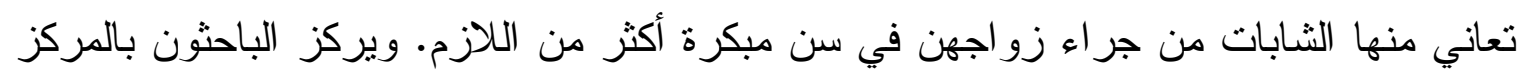

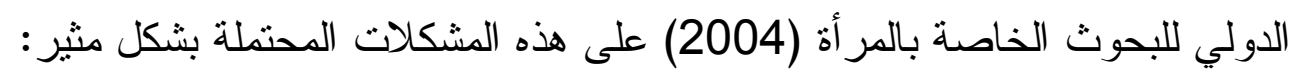

تحرَم العر ائس الأطفال من تجارب الحياة العادية التي يأخذها الثباب الآخرون

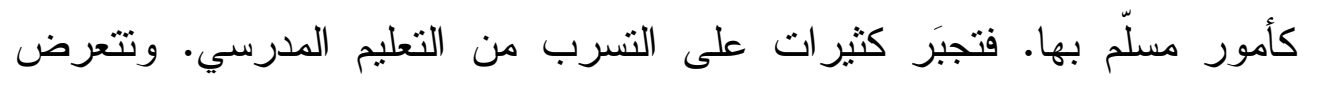

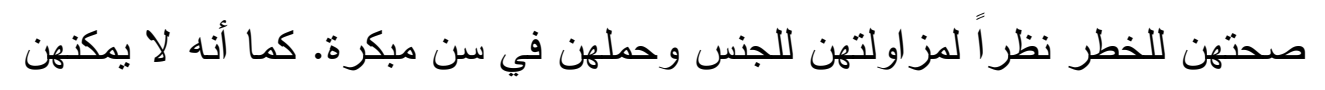

1 $1{ }^{1}$ Fricke Lestaeghe

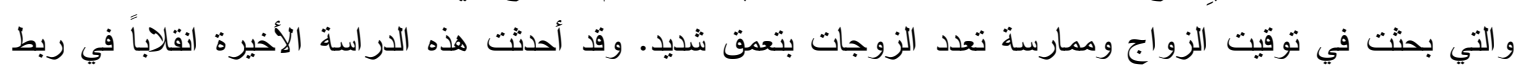

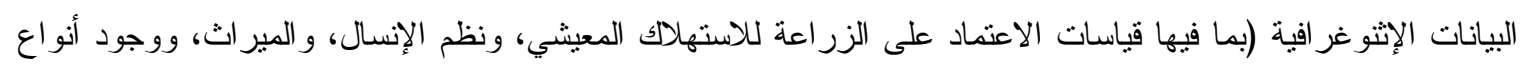

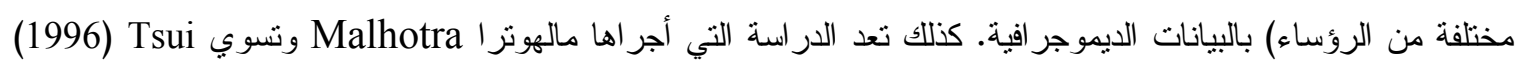

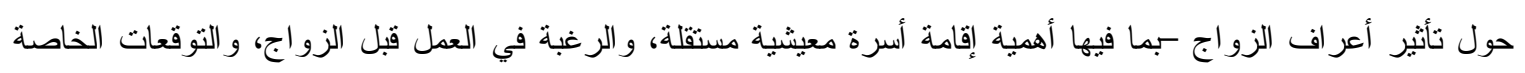

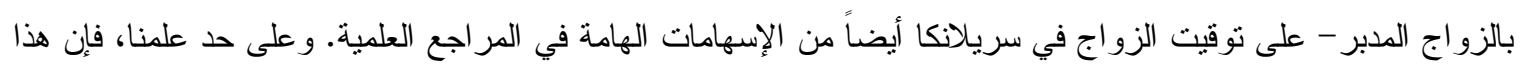

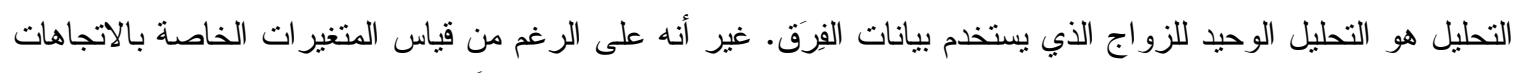

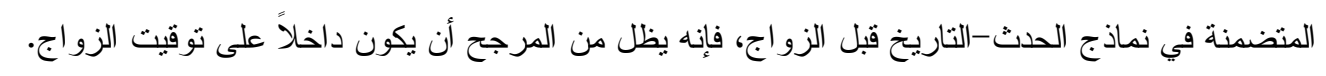


الاستفادة من الفرص الاقتصادية المتاحة. وعادة ما يتم تحجيم صداقاتهن مع

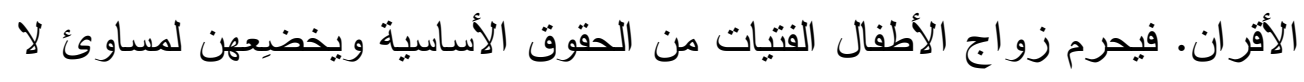

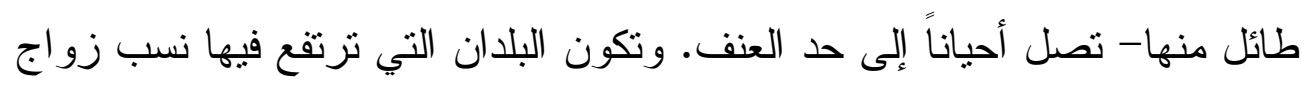

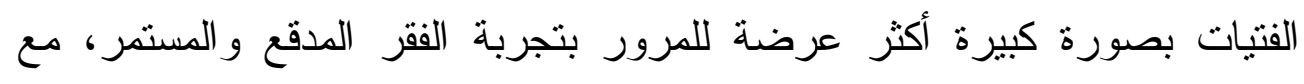

$$
\text { ارتفاع معدلات وفيات الأمهات و الأطفال. }
$$

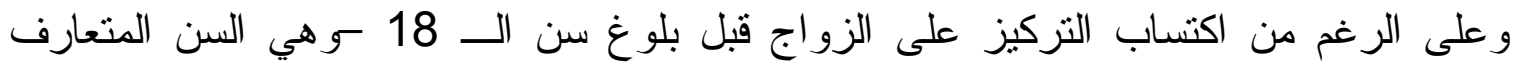

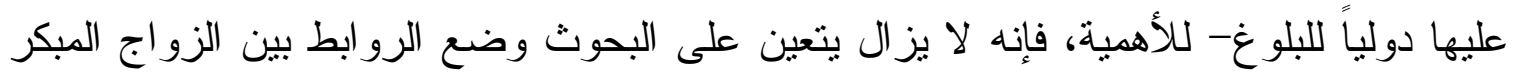

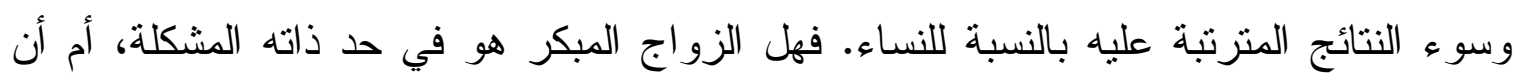

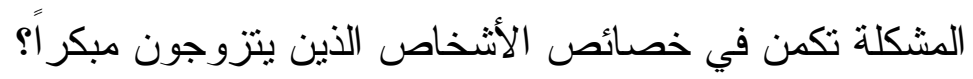

و على عكس الثوثيق الثامل لسن الإناث عند الزواج، فإن المؤلفات المعنية بالرجال تتسم بالندرة

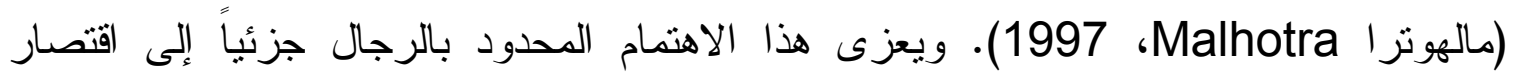

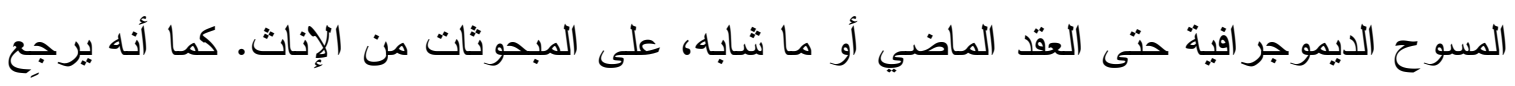
كذللك إلى عدم شيوع زو اج الرجال خلال سنوات مر اهقتهم، وذللك في نطاق و اسع من البلدان

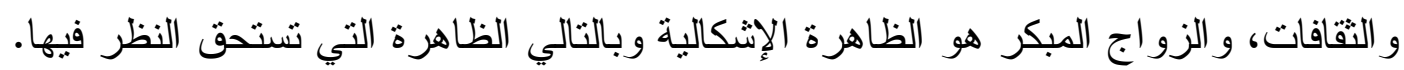
في هذه الورقة، نقوم ببحث الاتجاهات الخاصة بتوقيت الزواج أو الاقتران الأول بالنسبة للرجال

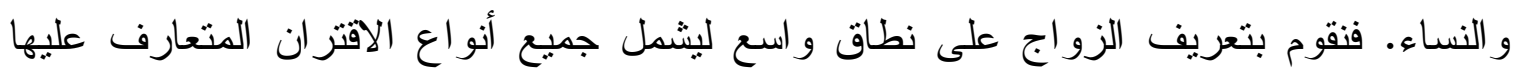

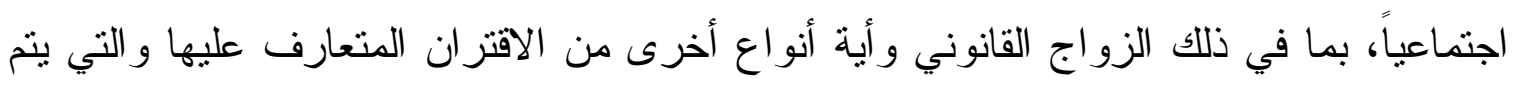

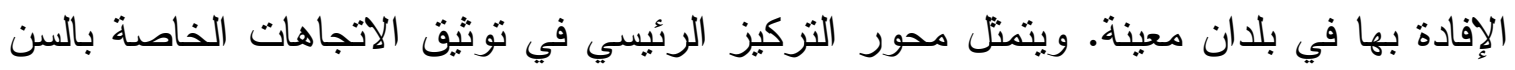
عند الزواج بالنسبة للمناطق الكبرى من العالم النامي. كما نقوم بفصص النطاق الحالي للزوباج

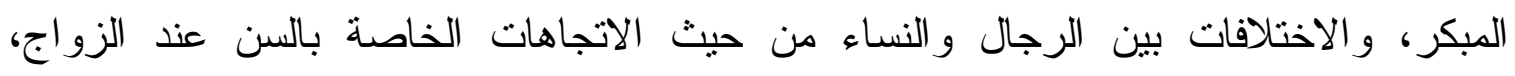
و العلاقة بين السن عند الزو اج و الخصائص الديموجر افية الاجتماعية، وبخاصة النعليم و الإقامة في لئي الريف أو الحضر، و السن عند الزواج وخطر النقاط عدوى متلازمة نقص المناعة البشرية.

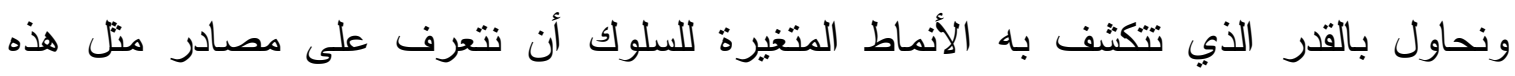
التحو لات ونعتمد على المر اجع الديموجر افية من أجل تقديم رؤى متعمقة. 


\section{فهم توقيت الزواج}

قام عدد من العلماء ببحوث حول توقيت الزواج. فنبدأ باستعر اض موجز لإسهامات العديد من فروع العلوم الاجتماعية في تحقيق فهم للسن عند الزو اج.

\section{ديموجر افيا تاريخية}

على الرغم من قيام الأخصائيين في ديموجر افيا التاريخ بعمل جدير بالثناء فيما يتصل بتوثيق

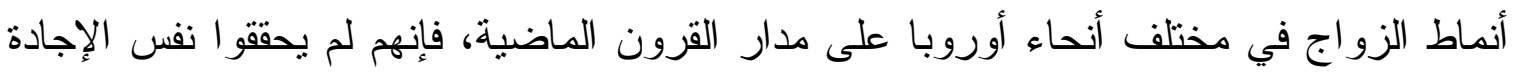

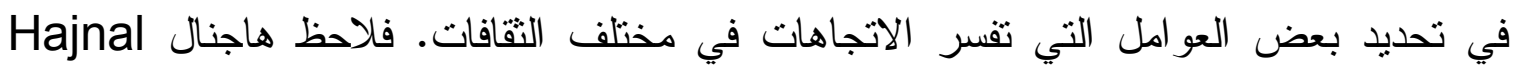

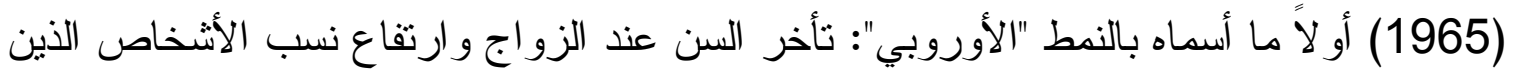

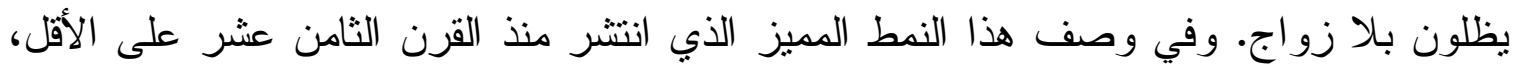

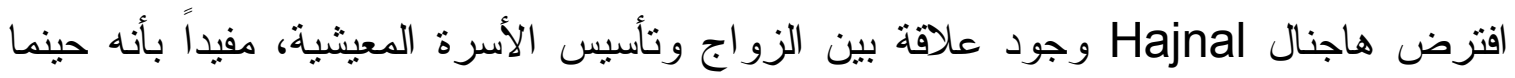

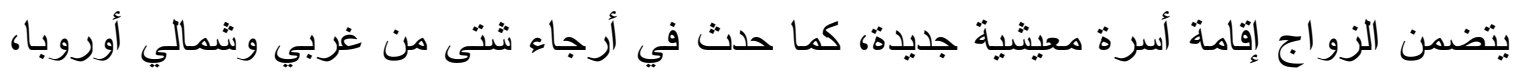

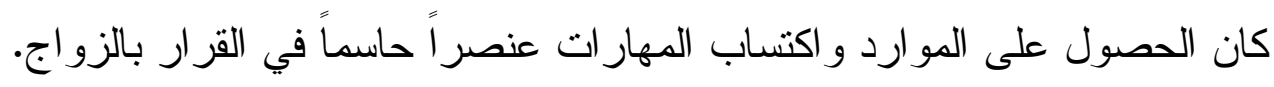

ويدعم ريجلي Wrigley وزملاؤه (1997، صـ 122)، في تاريخه للنشب الإنجليزي اعتبارً من أو اخر القرن السادس عشر وحتى بداية القرن التاسع عشر، هذا الرأي، حيث أنهم لم يخلصوا

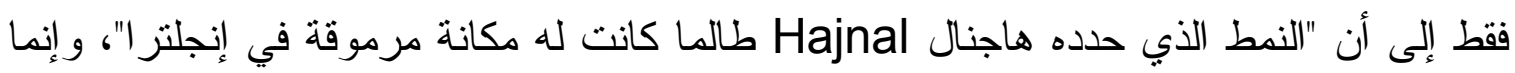
أيضاً إلى أن القرار بالزو اج يقوم على القدرة على إرساء دعائم أسرة معيشية مستقلة.

و على الرغم من ملاحظة الكثثرين لما لها من "تأثير بالغ على الدراسة التاريخية للزواج

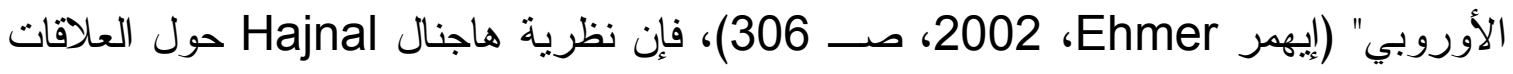

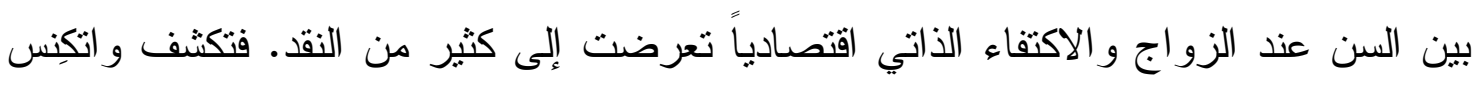
1870)Watkins

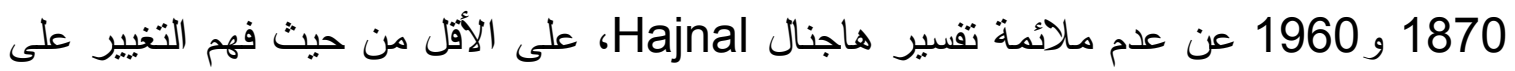

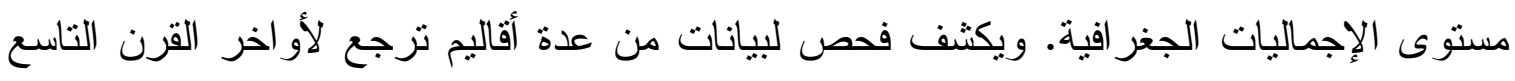

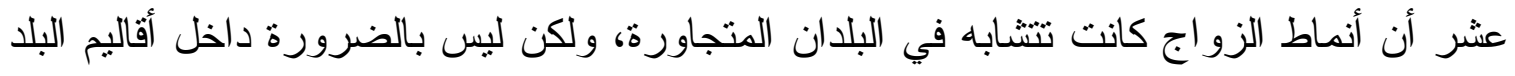

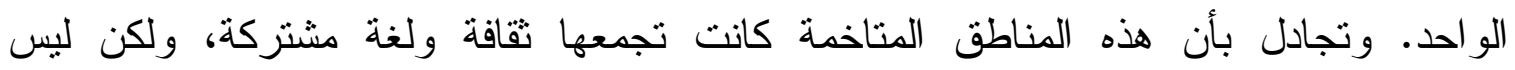

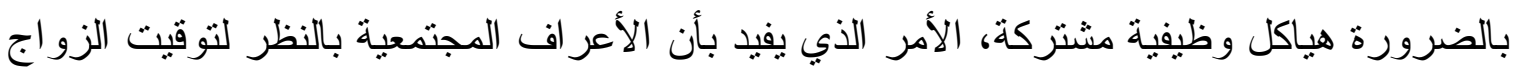


كانت قائمة بصورة مستقلة عن الظروف الاقتصادية. كذلك تقبد دراسات أخرى بأن القرار

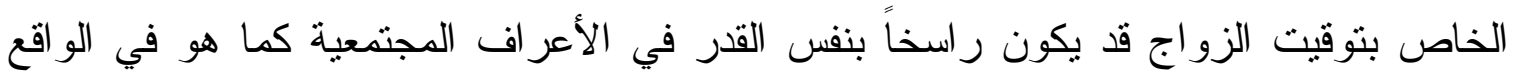

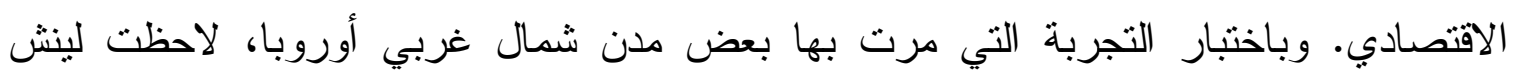
الزوا Lynch

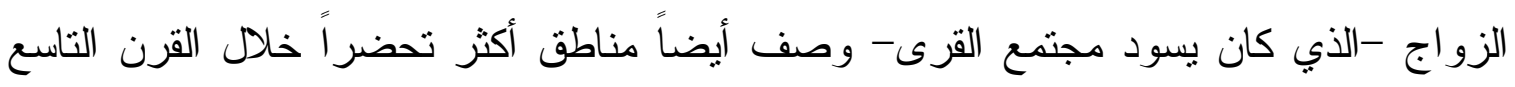

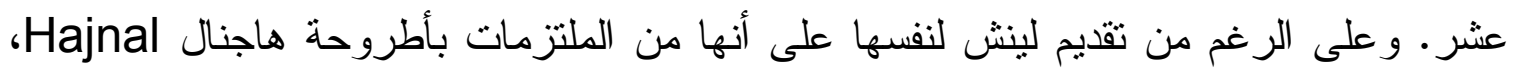

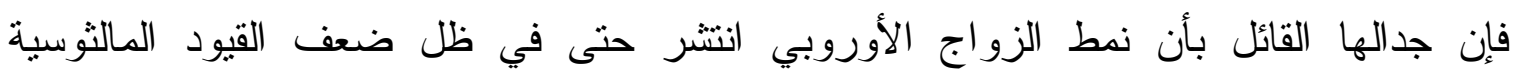
Malthusian

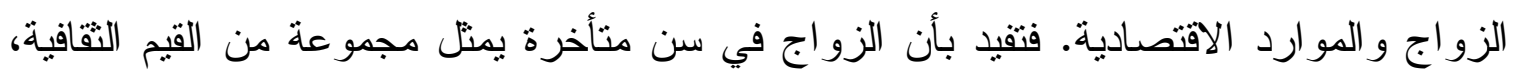
حتى مع القيم التي نثأت، جزئياً، عن الحقائق الاقتصادية للأزمنة الفيائتة.

كذلك تكثف دراسات ركزت على كل بلد على حدة أيضاً على عدم كفاية التفسير الذي بربط بين

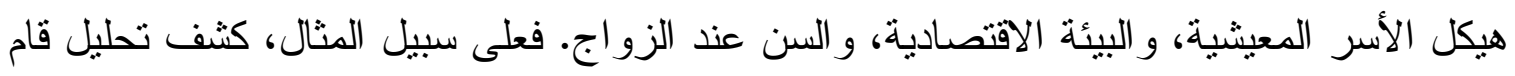

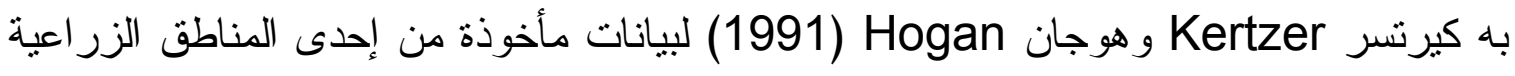

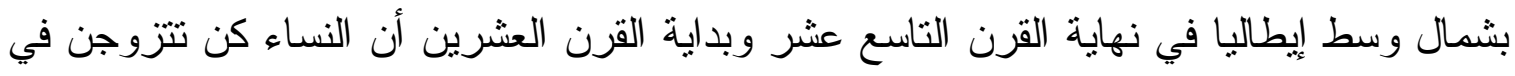

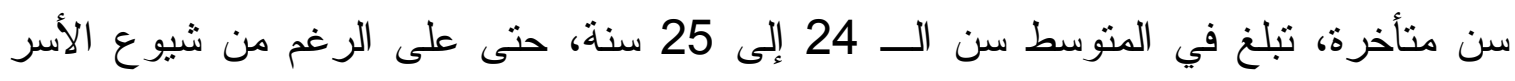

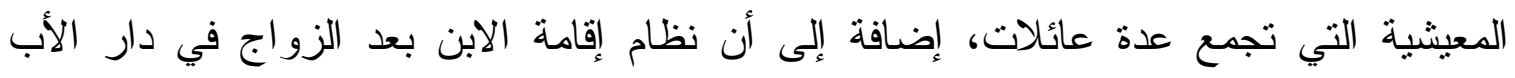

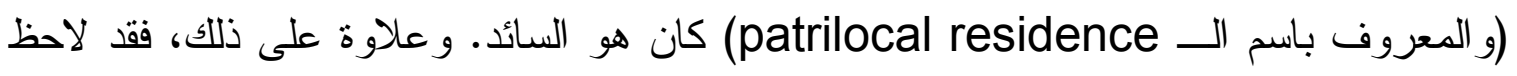

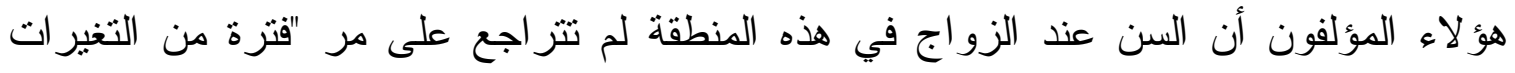

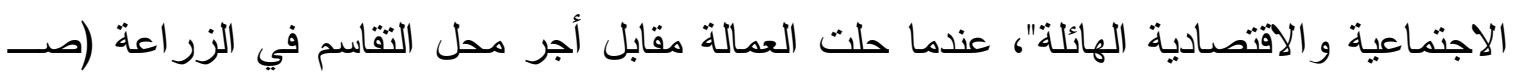

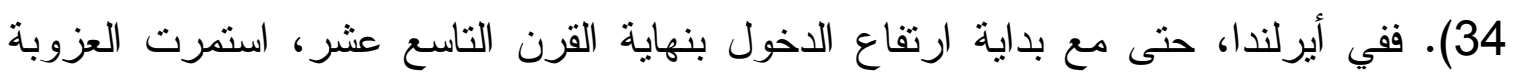

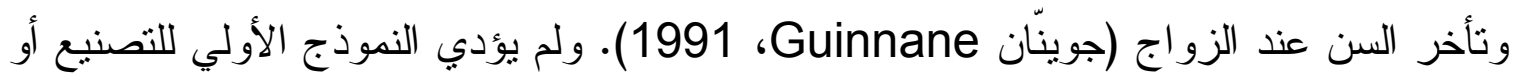

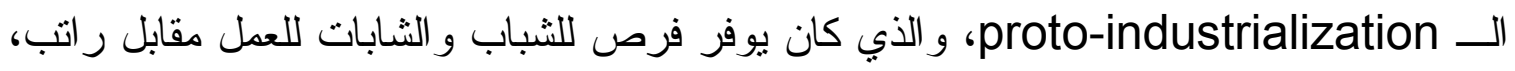

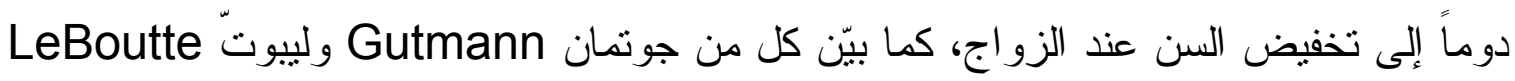

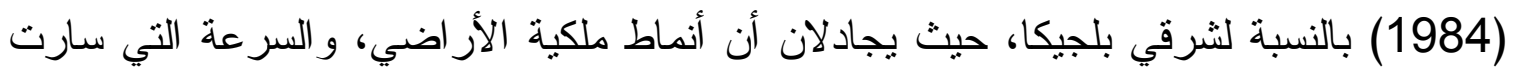

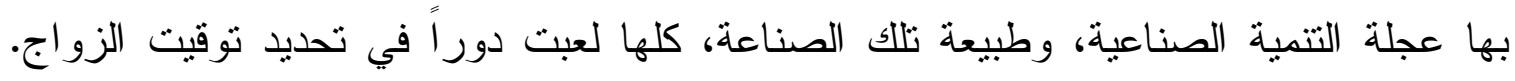


وبالإضافة إلى ذلك، فإن دراسات حالة أتت من مناطق أخرى في أوروبا لا نبين علاقة قوية بين

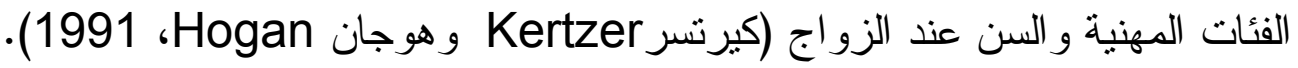

وتعتبر هذه الدراسات الديموجر افية لأوروبا التاريخية مفيدة للعلماء الذين يبحثُون في الزواج في

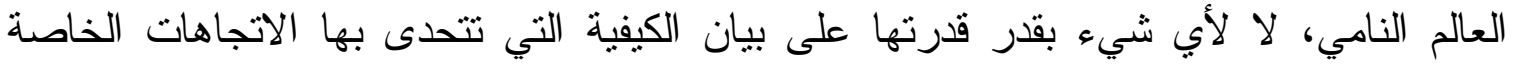

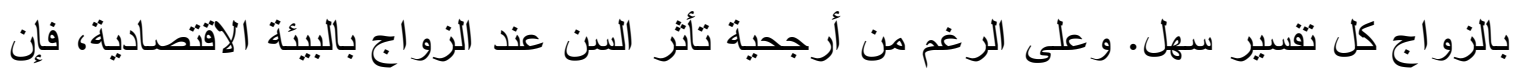

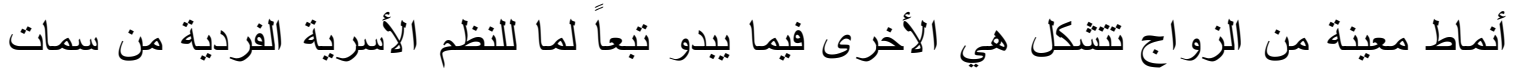

ميزة0

علم الإنسان الاجتماعي

بالنسبة لعلماء الإنسان (الأنثروبولوجيين الاجتماعيين، تكون نظم القر ابة

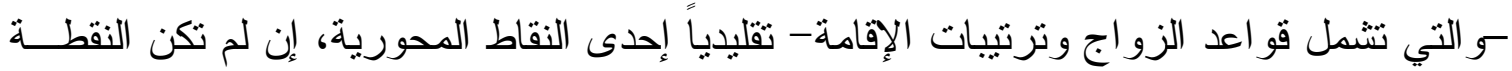

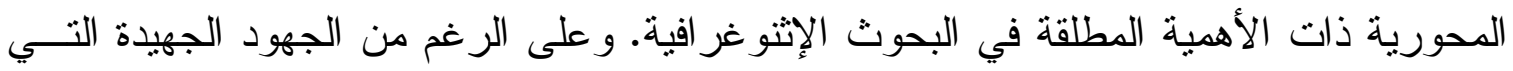

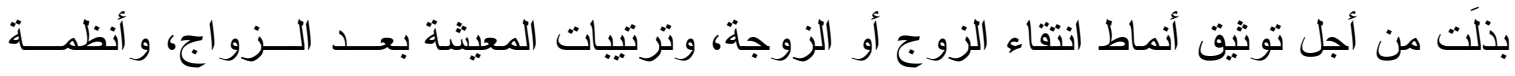

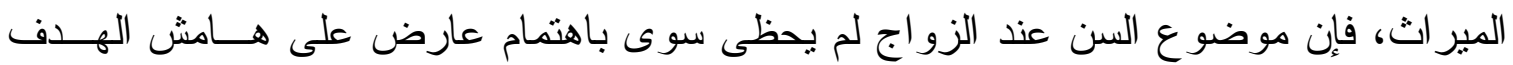
الأكبر المتمثل في وصف الطريقة التي تعمل بها نظم القرابة وقو اعد الزو اج للحفاظ على بلى النظــام الاجتماعي.

وقد هيمن المنحى الوظيفي الهيكلي للقرابة على علم الإنسان الثقافي خلال فترة طويلة من القرن

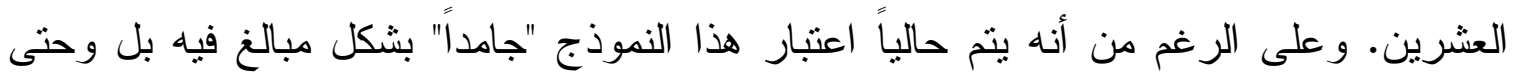

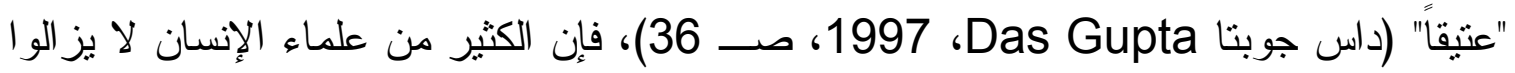

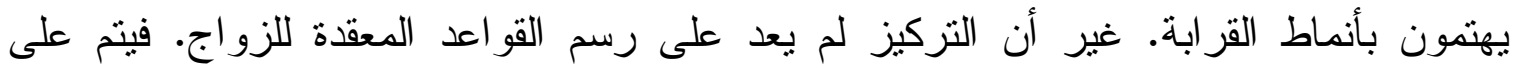

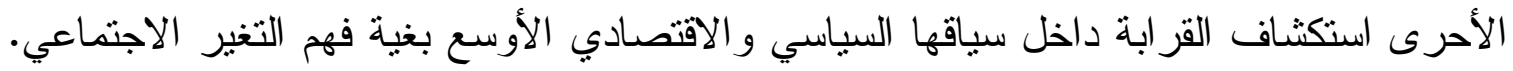
وتعدّ الدراسة الإثتوغر افية التي أجرتها أهيارن Ahearn (2001) حول الطريقة التي أدت فيها

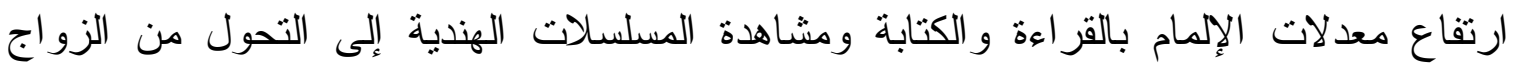

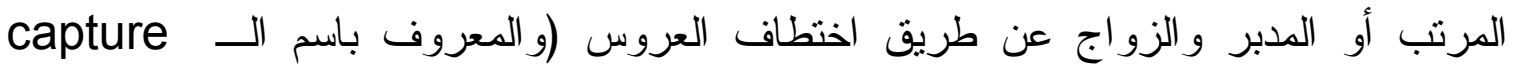
(marriage 
القر ابة. غير أنها لا تلي أي اهتمام إلى ما إذا كان هذا التحول في عملية الزواج كان له تأثيثر على الثى

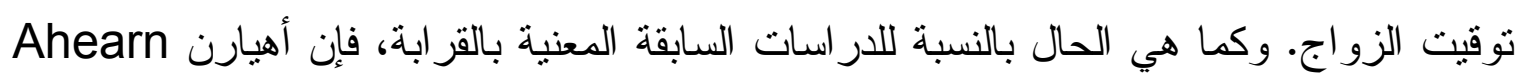
لا تلقوم بمناقثة السن عند الزواج.

وتركز دراسة تعاونية بين علماء الإنسان والأخصائيين الديموغر افيين، أجريت هي الأخرى على دالى

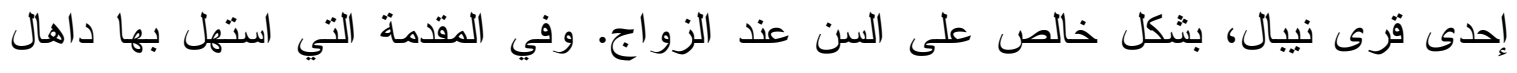

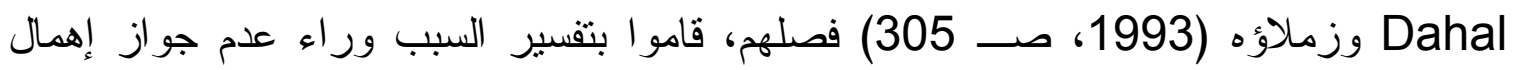

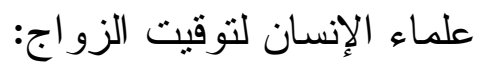

إذا كانت أثنكال معينة للزو اج دليلاً على وجود استر اتيجيات أوسع نطاقاً في مجال النتاسل

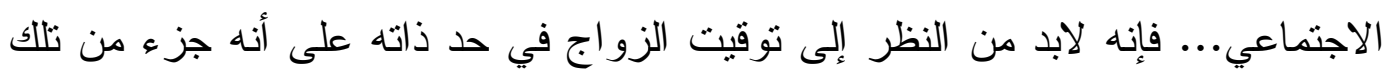

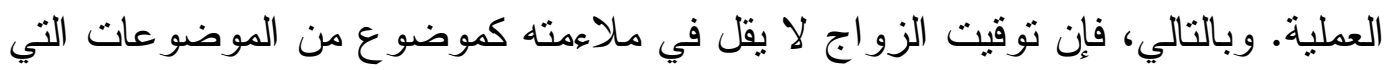

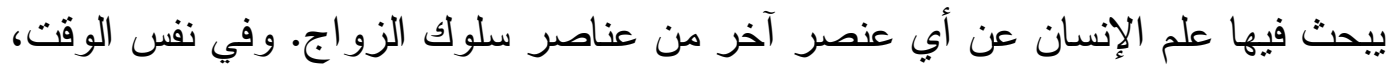

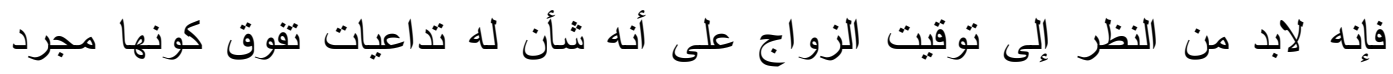

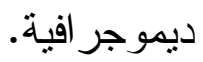

ويتوجه داهال Dahal وزملاؤه بالنقد حتى "لأكثر الأخصائيين الديموغر فيين إطلاعاً بعلم

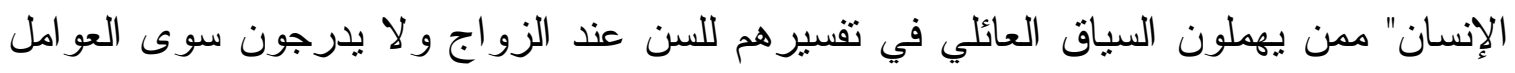

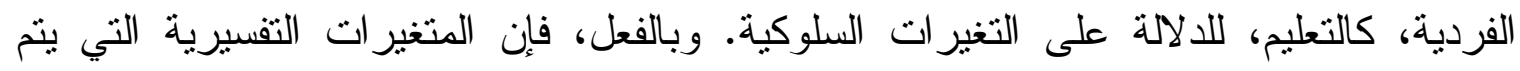

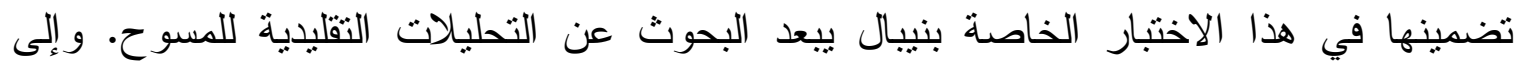

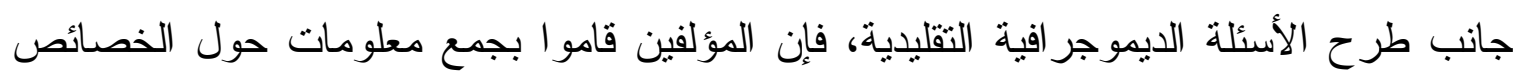

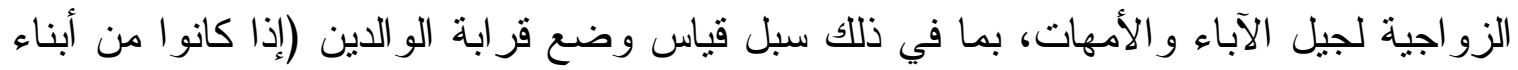

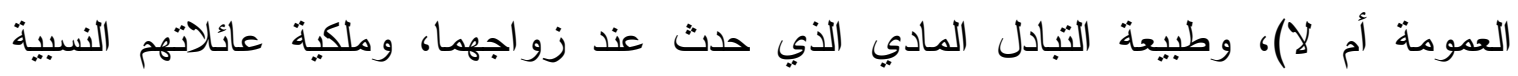

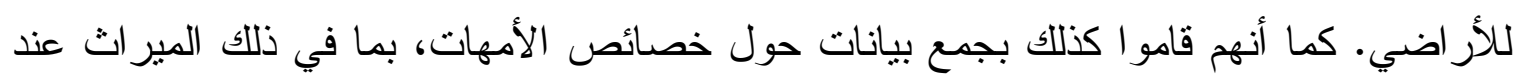

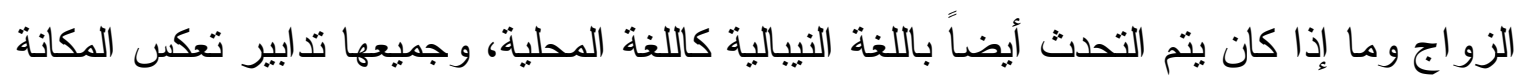

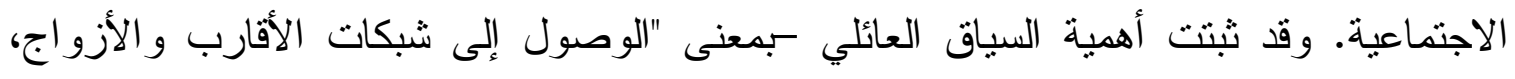


و الرقابة بين الأجيال، والمكانة التي تحظى بها الجماعات الني ولدوا فيها وينتمون إليها"- في

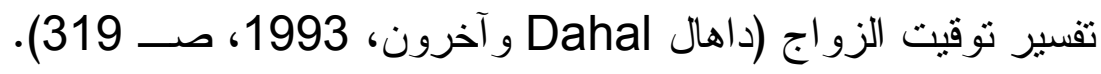

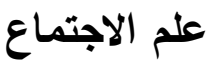

لا يعتبر علماء اجتماع الأسرة، على عكس أخصائيي علم الإنسان الاجتماعي، بشكل عام أن الأن

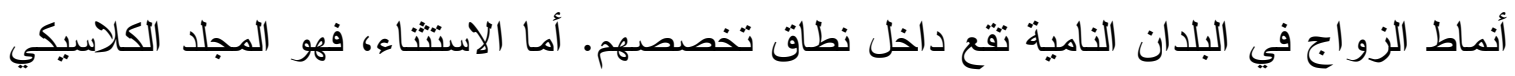

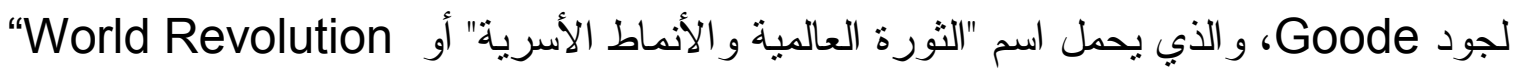
and Family Patterns" ويركز جود على "التوافق Fit" بين الأسرة الزواجية و المجتمع الصناعي الحديث، وما يحتاجه من

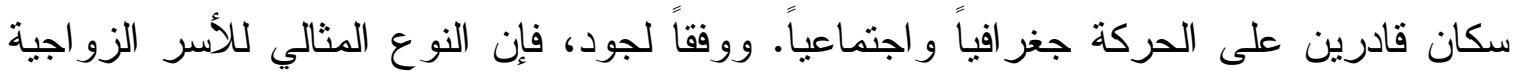

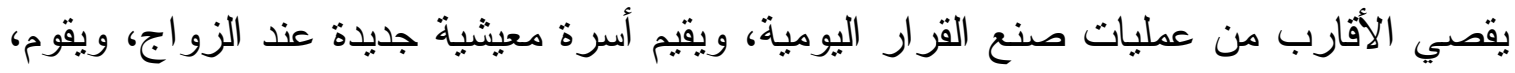

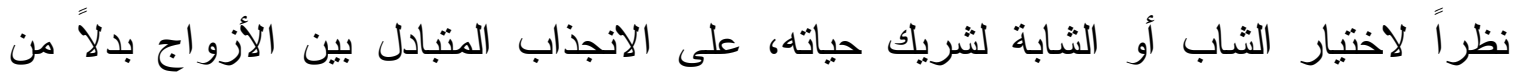

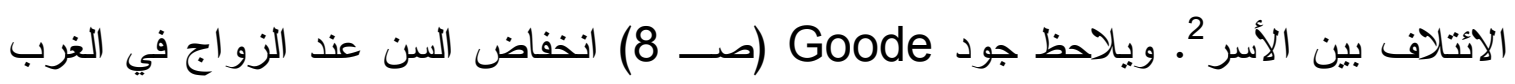
بالنسبة لكل من الرجال و النساء خلال القرن العشرين، الأمر الذي جعله يخلص إلى إثكالية التتبؤ

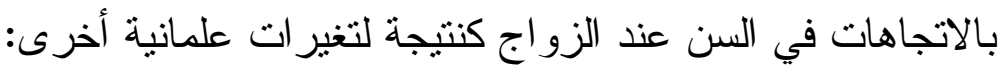

عندما يبدأ مثل هذا النظام [الزواجي] في الظهور في مجتمع ما، فإنه يحتمل أن تتغير

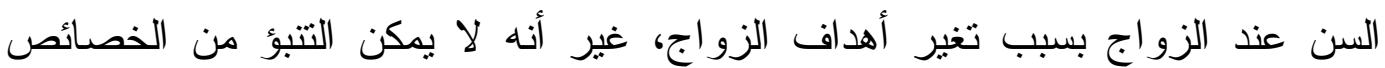

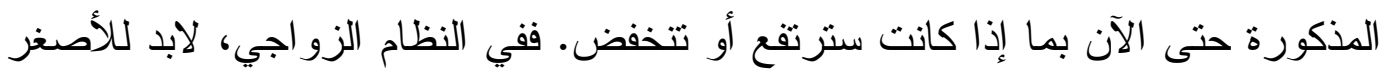

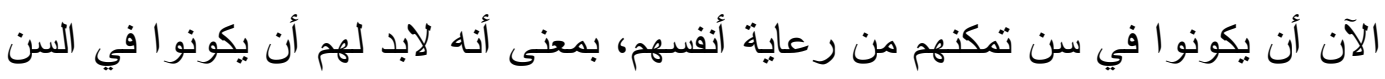

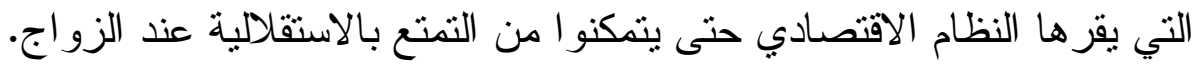

و لا يجادل جود Goode في أن التصنيع و التحضر "تسبيا" في حدوث تغيير في الأنماط الأسرية في الغرب. وبدلاً من ذلك، فإنه يلاحظ أن الأسرة كان لها تأثيثر مستقل في تطوير التصنيع. ويفيد

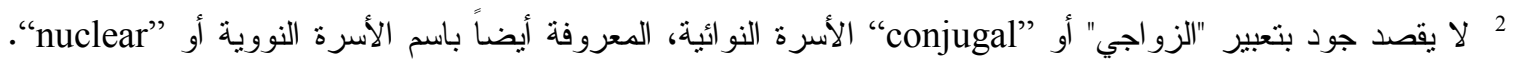
فبالنسبة له، فإن نظام الأسرة النو ائية هو نظام لا يحدث فيه تثاعل بين الأقارب. 
بأنه "لم ينجح أحد بعد في بيان العوامل المحددة بين النظم الأسرية و النظم الاقتصادية أو

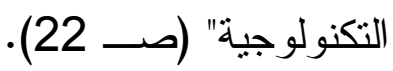

و على الرغم من أن جود Goode كان يكتب منذ ما يربو على 40 عاماً، فإن النجاح لا يز ال لم

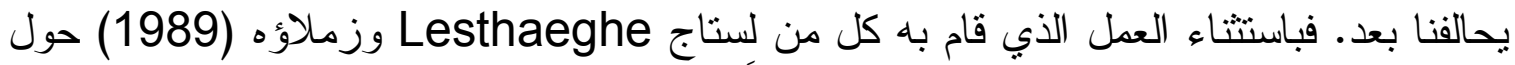

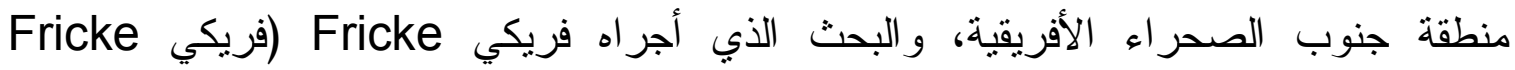

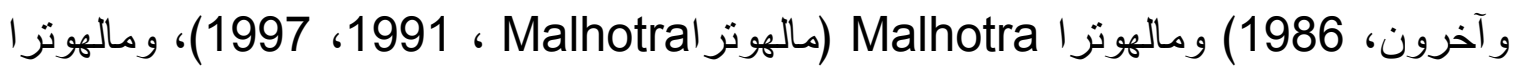
Malhotra ويابيكو Yabiku ، 2003) حول جنوب آسيا، فإن قليل من الدراسات الديموجر افية تبحث في

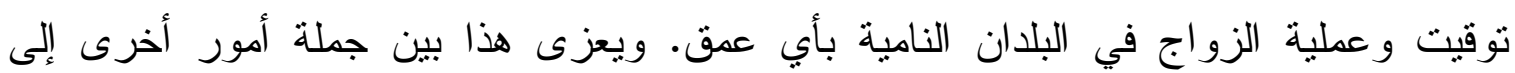

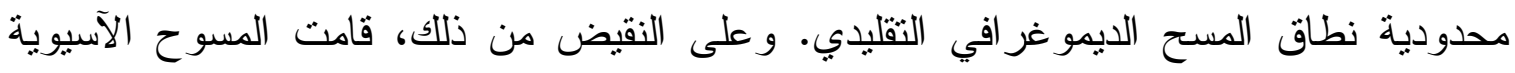

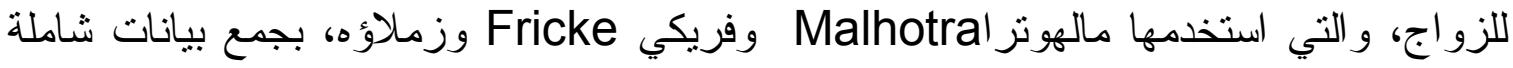
حول عملية الزواج. غير أن لهذه المسوح استخدام محدود في نحليل نوقيت الزواج نظراً

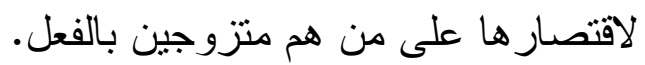

الاقتصاديات لم يكن الاقتصاديون على نفس القدر من الاهتمام بتفسير السلوك المرتبط بالزواج في العالم النامي

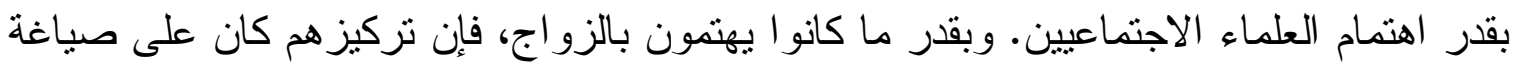

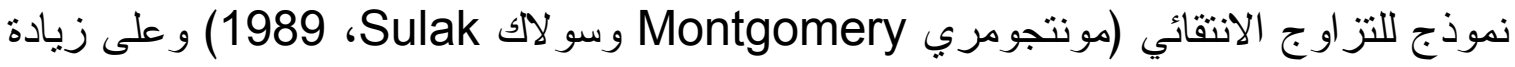

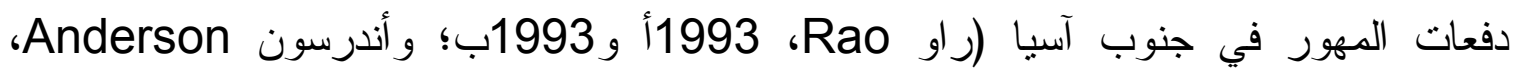

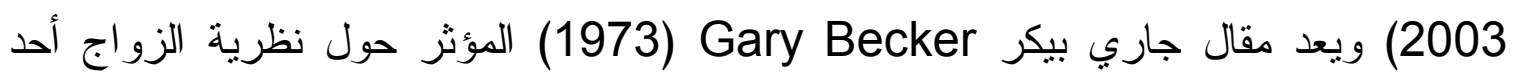

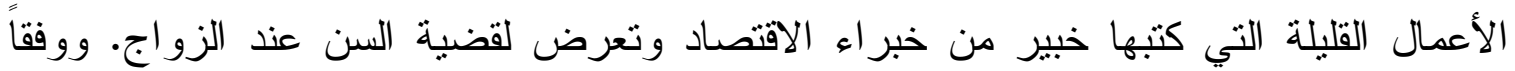
لبيكر Becker ، فإن الزواج هو مظهر من مظاهر السلوك الذي يقوم بتعظيم المنفعة: فيتزوج

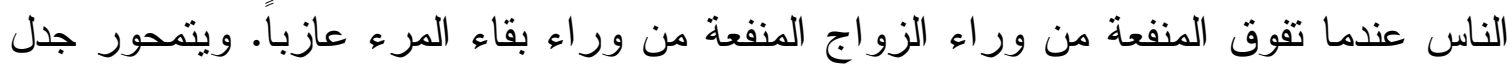

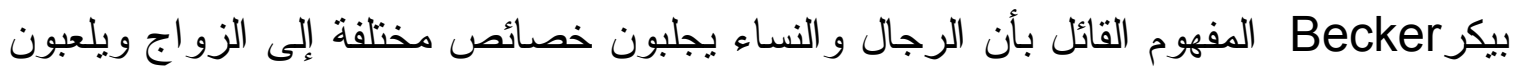

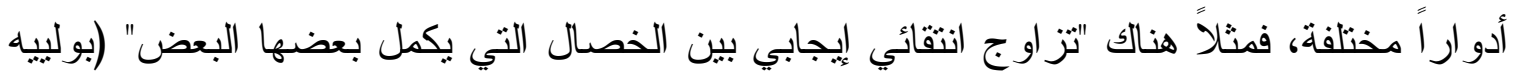

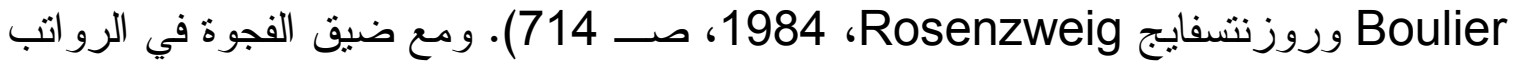


شيئاً فنيء بين الرجال والنساء، ومع تحقيق النساء والرجال للمزيد من المساواة الاقتصادية

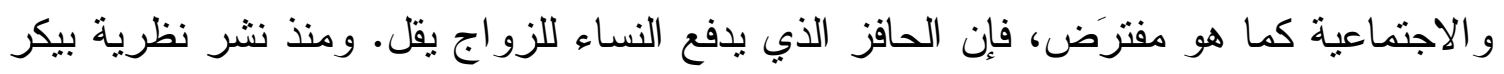
Becker وبالاستعانة بيانات نرجع إلى مستهل السبعينات في الفلبين، يقدم بولييه وروزنتسفايج Rosenzweig

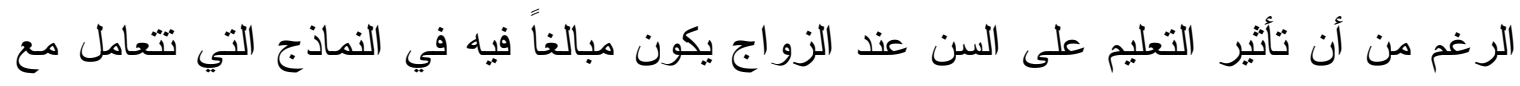

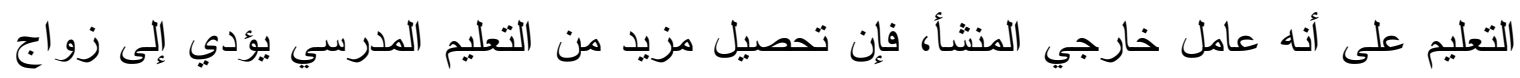

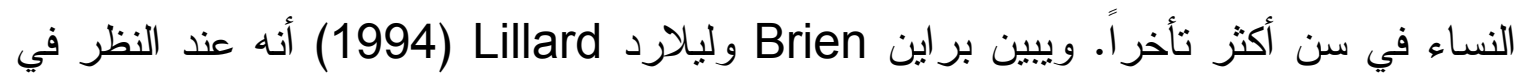
تأثير تأخير الزواج على التعليم -بمعنى احتمال أن يصبح التعليم شأناً محلياً داخلي المنشأ- فانان تأخر سن زو اج النساء في ماليزيا يفسره إلى حد كبير ارتفاع نسب التسجيل التهيل بالمدارس و والتحصيل

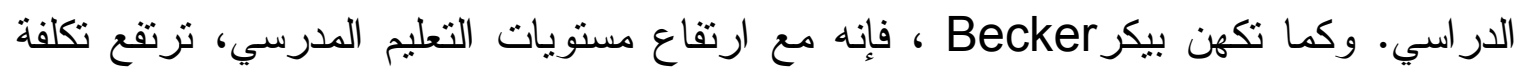
فرص الزو اج بالنسبة للنساء.

وباستثناء ما قام به بيكر Becker من عمل، فإنه لا يوجد لدينا سوى نظريات قلائل نتتاول بشكل

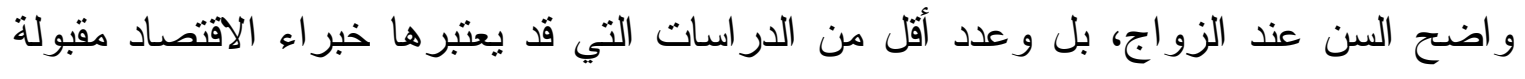

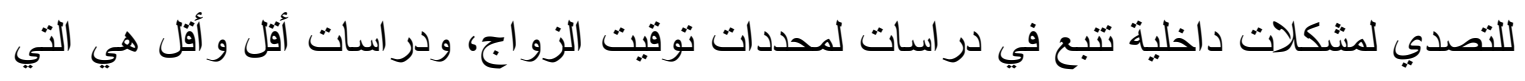

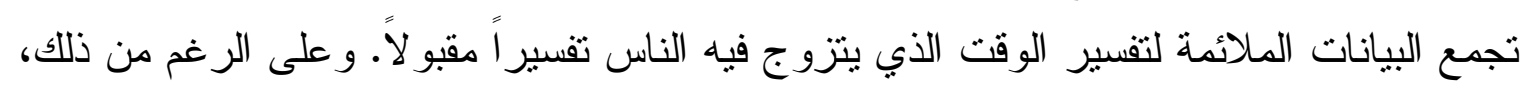

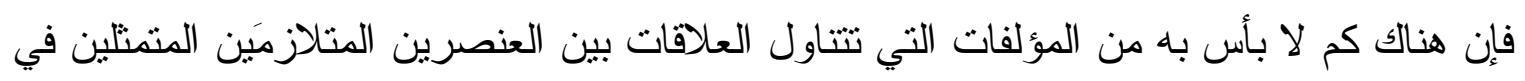

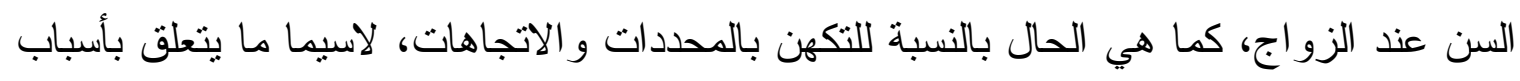

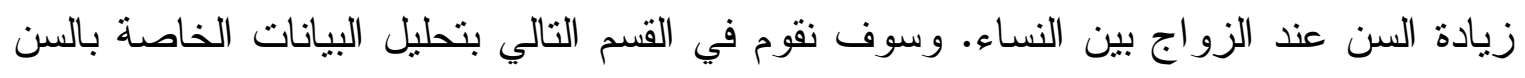

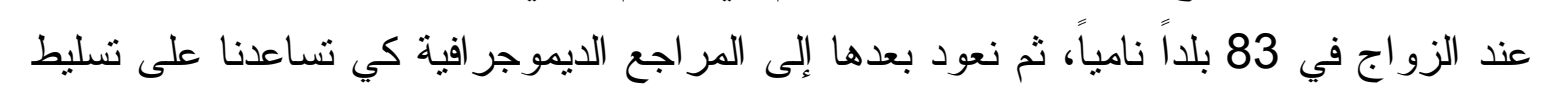
الضوء على الاتجاهات التي نلحظها.

\section{مصادر البيانات}

تم الحصول على البيانات الخاصة بالسن عند الزو اج الأول من مصدرين: (1) قاعدة بيانات قامت

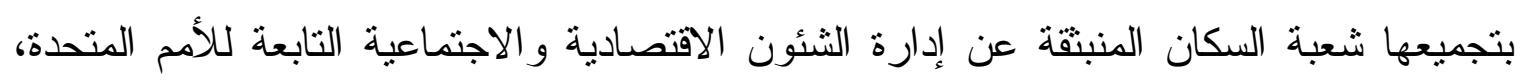
و المأخوذة جزئياً من الإحصاءات السكانية، و (2) مسوح ديموجر افية وصحية ممثلة وطنياً. 
تقدم قاعدة البيانات الخاصة بالأمم المتحدة نسبة السكان الذين تزوجو ا فــي مجموعــات عمريــة تغطي كل منها خمس سنوات وتتمل أغلب البلدان النامية (إدارة الثئون الاقتصادية و الاجتماعية

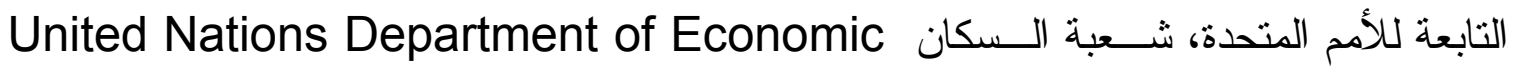
and Social Affairs, Population Division,

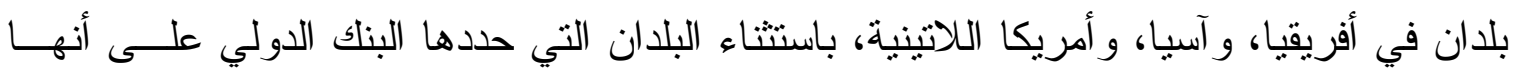

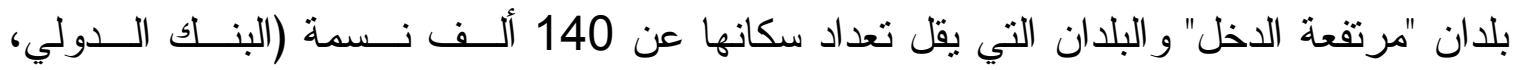

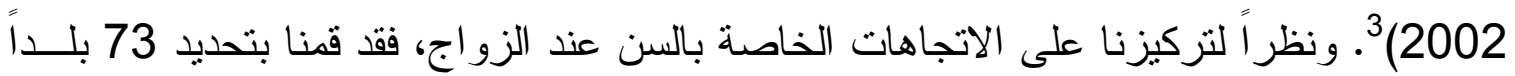

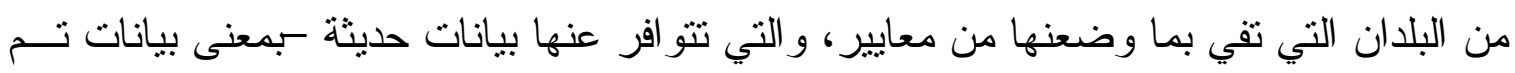
جمعها في عام 1990 أو ما بعده- و التي تثو افر عنها معلومات مستقاة من تعدادين أو مـسحين

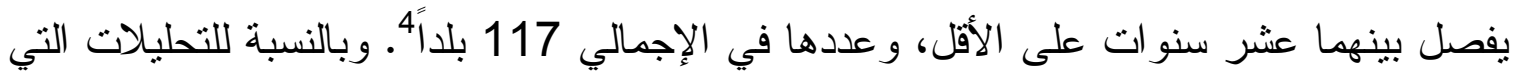

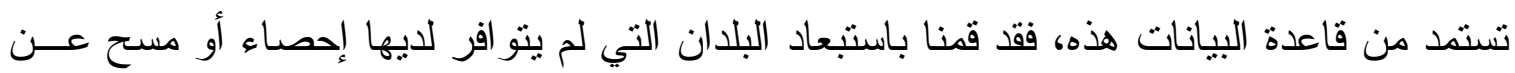
كلا الجنسين. وبالإضافة إلى هذا، فإننا قمنا باستخدام نفس مجموعة البيانات مع كل من الرجــال

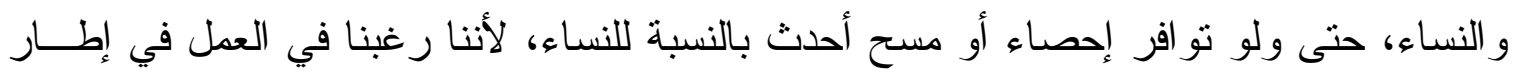

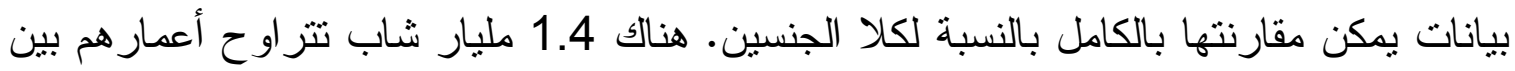

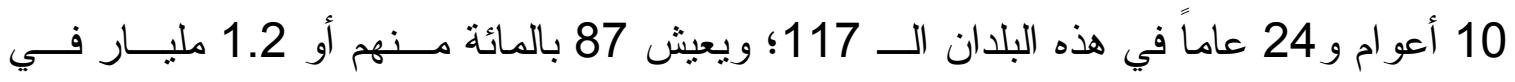

3ُ لم تقدم الأمم المتحدة بيانات عن البلدان التي يقل تعداد السكان فيها عن 140 ألف نسمة. ونم الحصول على بيانــات الـــذخل الخاصـــة

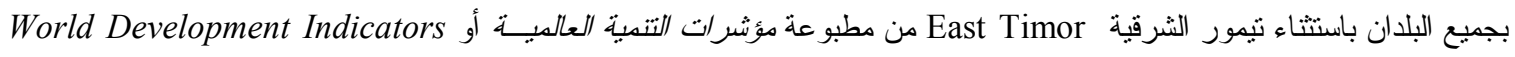

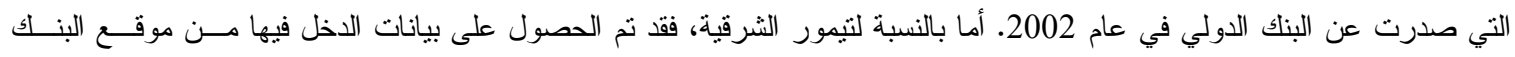

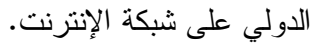
4 لا تتو افر بيانات حول الأشخاص الذين تتراوح أعمار هم بين 15 و 19 عاماً في الأرجنتين أو الذين تتراوح أعمارهم بين 20 و29 عاماً في البحرين بسبب استخدام مجموعات عمرية غير قياسية هناك. غير أنه نم على الرغم من ذلك تضمين

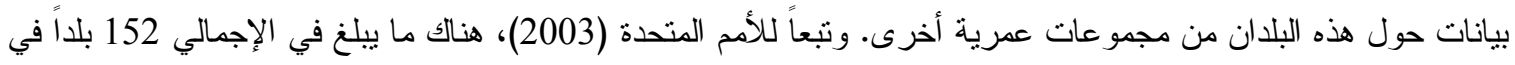
آسيا، و أفريقيا، و أمريكا اللاتينية. ويقل عدد السكان في 13 منها عن 140 ألف نسمة، صنف البنان البك الدولي 16 منها على أنها بلدان مرتفعة الدخول، و لا يوجد لدى البنك الدولي بيانات عن دخول خمسة منها. وقد أدت البيانات المحدثة لمجموعات

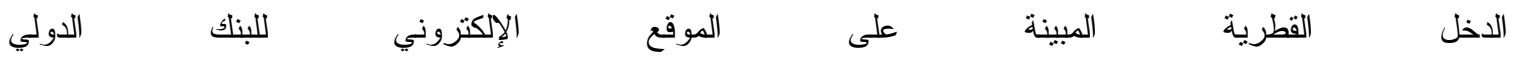

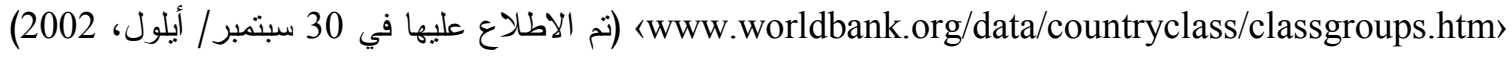
إلى قيامنا ببعض التعديلات على هذه المجموعات القطرية، منها نقل كوريا إلى مجموعة البلدان مرتفعة الدخل وبالتالي إخر اجها من مجموعة البلدان النامية، الأمر الذي جعل إجمالي البلدان التي تفي بالمعايير التي وضعناها يصبح 117 بلداً. 


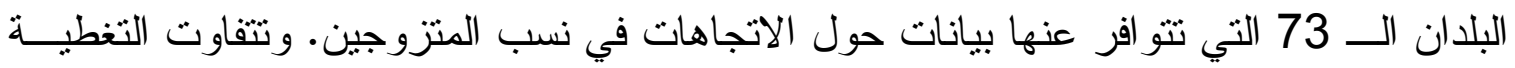
تفاوتاً بالغاً من منطقة إلى أخرى.

تمثل هذه البيانات حوالي 90 بالمائة أو أكثر من سكان شرقي وجنوبي أفريقيا، وجنوب وسط

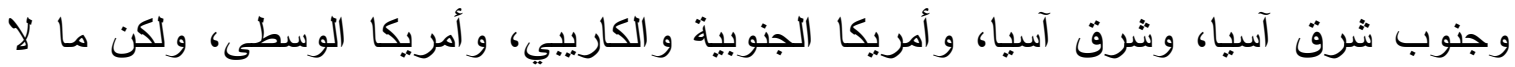
يتجاوز 63 بالمائة من سكان الثرق الأوسط، و 31 بالمائة من سكان غرب وبندئ ووسط أفريقيا، و38 بالمائة من سكان آسيا السوفييتية السابقة. وتتكون النتائج الخاصة بمنطقة شرق آسيا دون الإقليمية

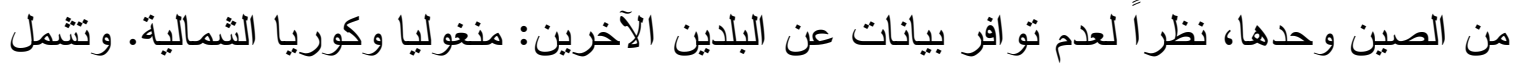
البلدان كثثفة السكان والتي لا تتو افر عنها بيانات من قاعدة بيانات الأمم المتحدة أفغانستان، و الجزائر، وجمهورية الكونغو الديمقراطية، و وغانا، والعراق، ونيجيريا، و المملكة العربية السعودية، وأوزبكستان، وفيتتام.

Macro ونستقى بيانات المسوح من مسوح ديموجر افية وصحية أجرتها هيئة ماكرو الدولية International عند الزواج من مقابلات شخصية مع مبحوثين في سن الإنجاب وهم جزء من استنيان شامل

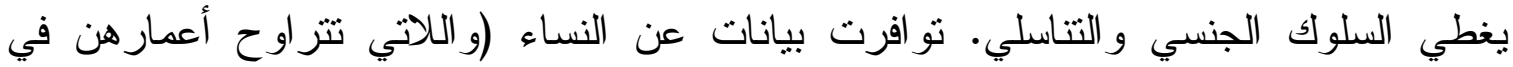

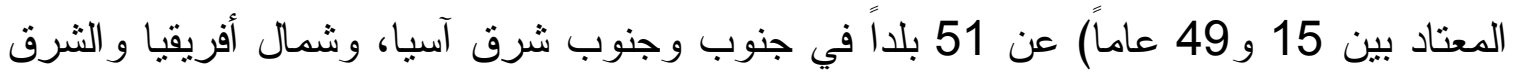

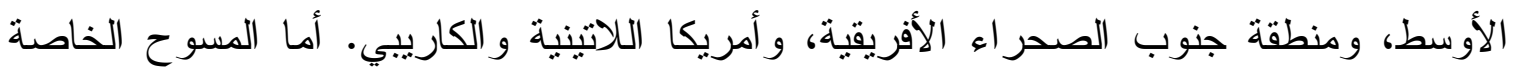

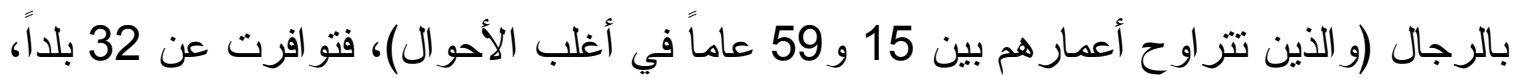

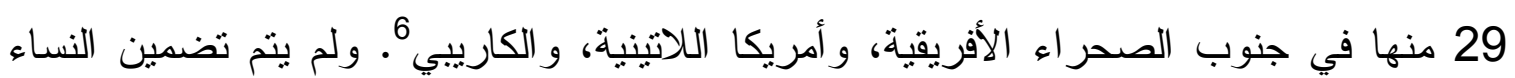

5 يقتصر المسح الديموغر افي والصحي على تعداد سكان الأسر المعيثية. ولا تقوم المسوح ديموجر افيةالديموجرافية

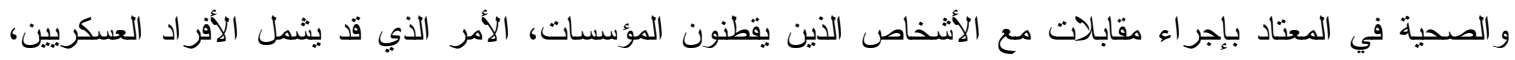

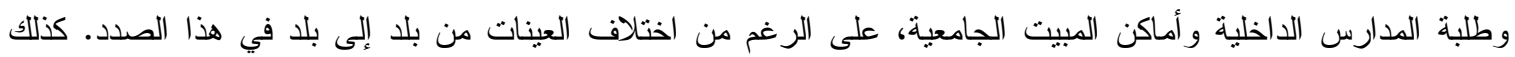
تخضع البيانات لخطأ عدم الاستجابة. وتعد معدلات عدم الاستجابة في المسوح ديموجر افيةالديموجر افية و الصحية منخفضة لـانة مقارنةً بمعدلات المسوح في البلدان مرتفعة الدخول. و وعلى الرغم من هذا، يمكن افتراض اض أن يكون المعدل أكثر ارتفاعاً بين شباب البالغين غير المتزوجين، لاسيما الثباب الذكور، عنه بئه فين البالغين الأكبر سناً. 6 تم تمثيل منطقتين (آسيا السوفييتية السابقة و الثرق الأوسط) من خلاد ثلاثية بلدان فقط، هي أرمينيا، وكاز اخستان، وتركيا، ومن ثم، فإنه لم يتم تضمينها في الإجماليات الإقليمية. وكما ورد عاليه، فإن التحليلات القائمة على بيانات الأمم المتحدة لا

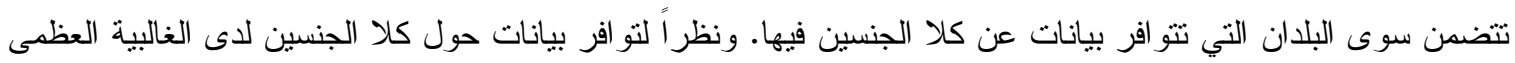


غير المتزوجات في المسح الخاص بالنساء على المستوى الفردي بالنسبة لعدد من المسوح

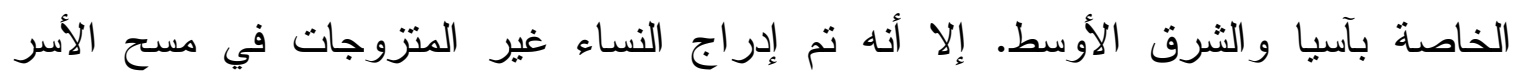

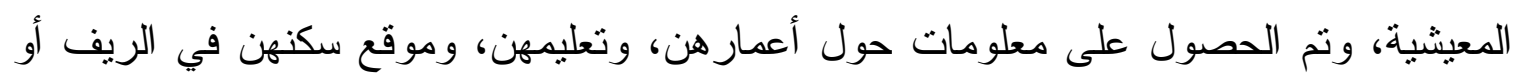

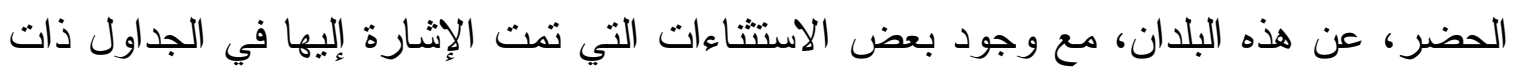

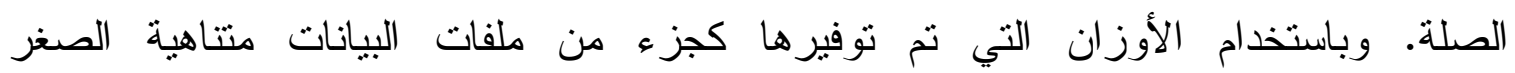
microdata files للسن، ومحل الإقامة، و التعليم، بحيث تتضمن مقامات نسب المتزوجات بشكل صحيح جميع النساء لهاء لهاء في كل مجموعة من المجموعات الفرعية.

ويتم تجميع البيانات الخاصة بكل بلد في منوسطات عــن المنــاطق دون الإقليميــة (باســتخدام

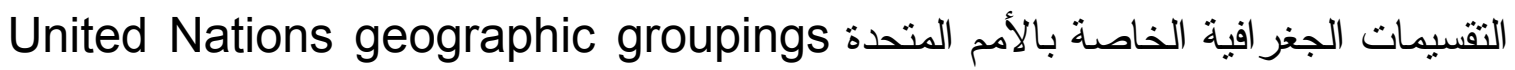

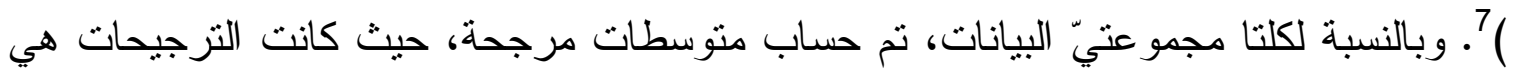

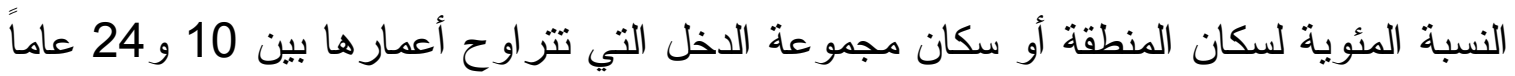

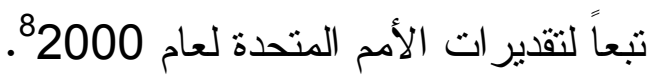

وبالنسبة لعدد قليل من البلدان، تتو افر بيانات المسوح الديموجر افية والصحية وإن كانت لا تتو افر

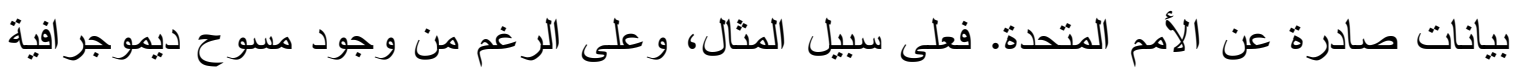
وصحية عن نيجيريا -أكثر بلدان منطقة جنوب الصحراء الأفريقية كثافة سكانية- فإن الأمم المتحدة لا توفر بيانات حول الرجال و النساء عن الفترتين الزمنيتين اللازمنين. ويدرج الجدول الملحق أ-1 كل بلد من كل مصدر تبعاً للمنطقة.

من البلدان، فإن هذا الثرط لا يكون مقيداً بنسبة كبيرة. إلا أنه بالنسبة للتحليلات التي تقوم على بيانات المسوح

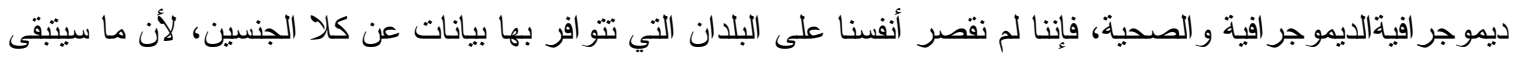
لنا كان سيقتصر على عدد قليل للغاية من البلدان. 7 تتو افر البيانات الفردية الخاصة بكل بلد لاند لإى المؤلفين.

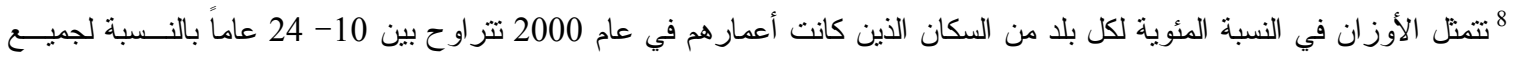

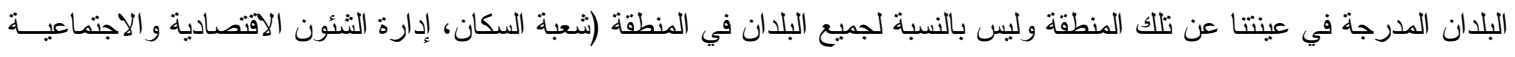

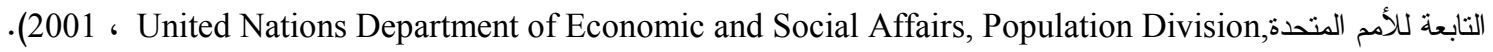


أما بيانات الإحصاءات، و التي تعتبر المصدر الرئيسي لقاعدة البيانات التي جمعتها شعبة الـسكان

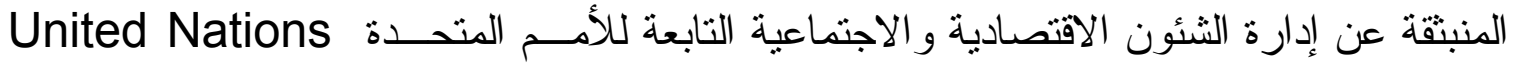
، Department of Economic and Social Affairs, Population Division, عنها في المعتاد رب الأسرة المعيشية، وليس تبعاً لكل فرد داخل تلك الأسرة. فإذا ما قارنّا هـــا بييانات المسوح الديموجر افية و الصحية حول الوضع بالنسبة للزو اج و السن عند الزو اج، فإنه يتم

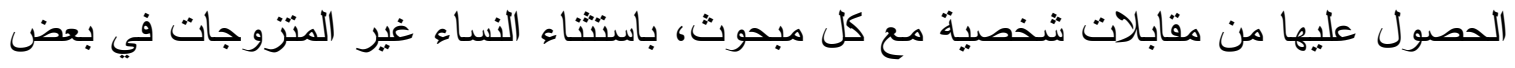
البلدان الآسيوية وبلدان الثرق الأوسط.

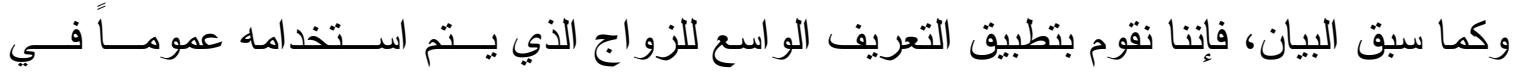

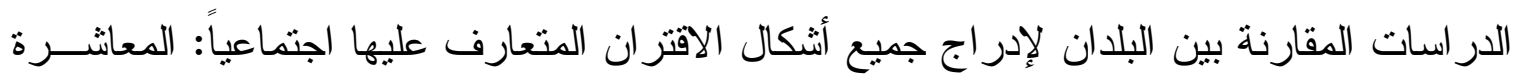

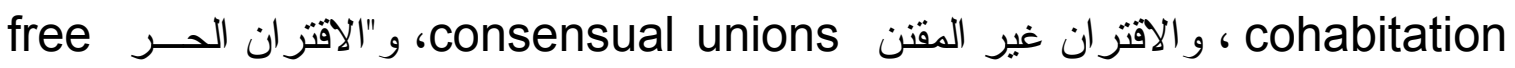

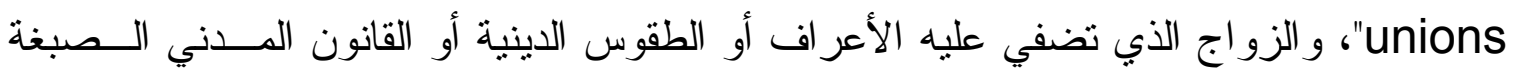
الثرعية marriage legitimated by custom, religious rites, or civil law . غير أن تعريف الزواج المستخدم في الإحصاءات قد يكون أكثر تغير اً من التعريـــ المسـتخدم فـي المسوح القياسية. فبالنسبة للمسح الديمو غر افي و الصحي، يعتبر الزو اج حالة تعرف نفسها بندئ بنفسها.

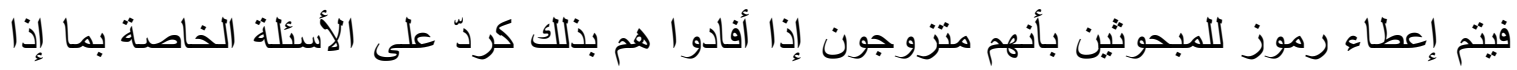

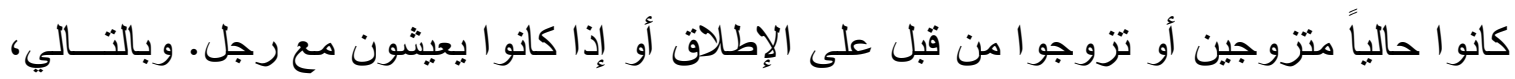

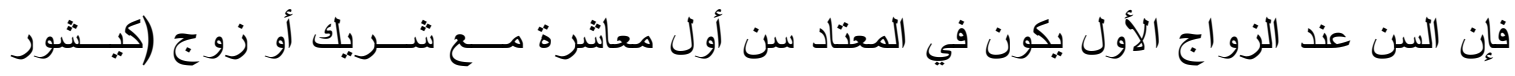
Kishor

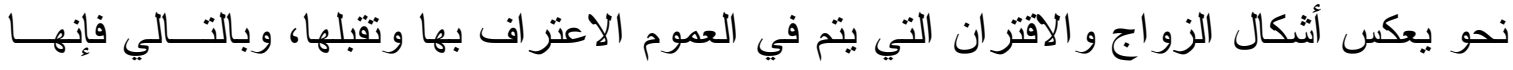
تحصل على المعلومات بنفس الطريقة. وكنتيجة لهذا، فإنه يمكن في أغلب الأحيان مقارنة البيانات

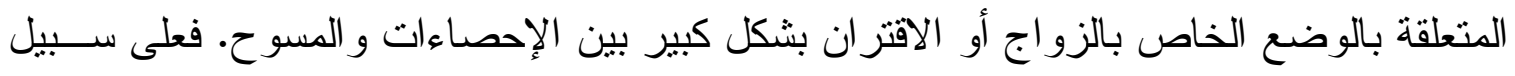

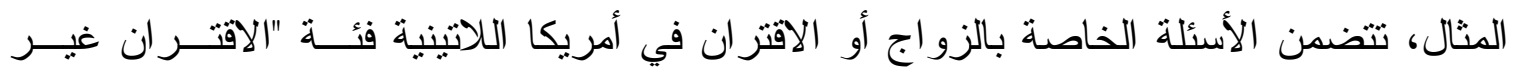

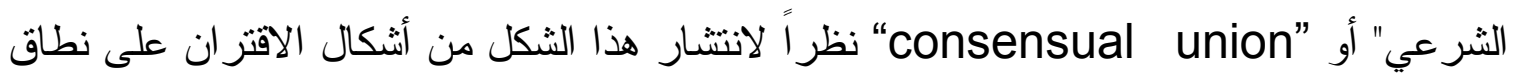
و واسع في هذه المنطقة حيث تحظى بالقبول. بيد أنه في البلدان التي تكون فيها المعانشرة بلا زو اج

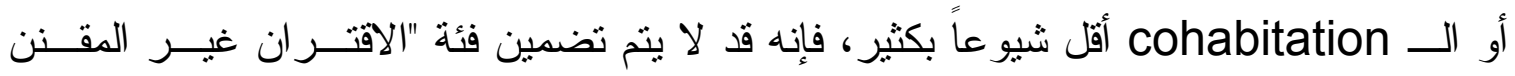


consensual union عن منل هذا الوضع بالققر الو اقعي.

وتحقيقاً لأغراض هذا التحليل، فإننا نفترض دقة الإبلاغ عن السن والحالة الاجتماعية في

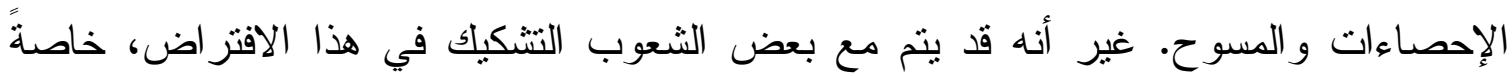

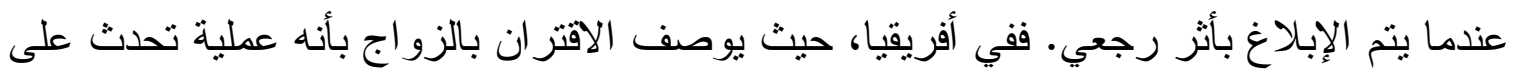

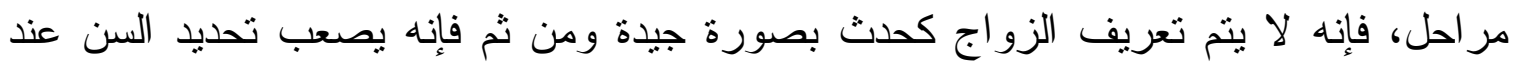

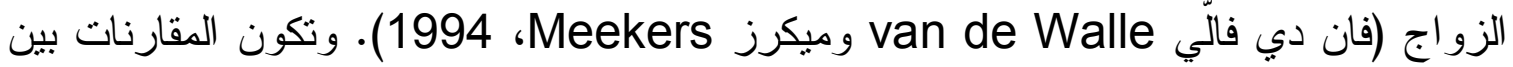

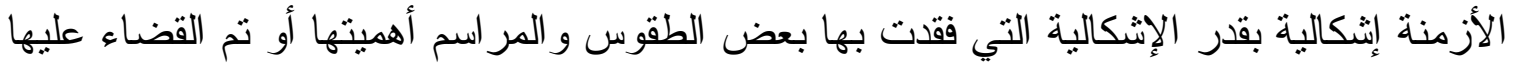

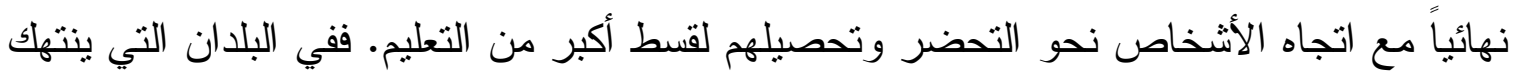

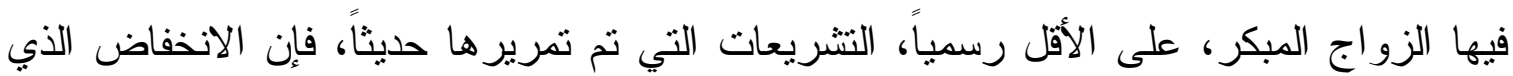

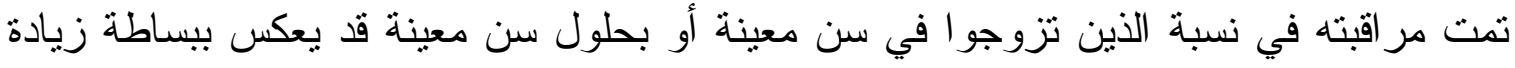

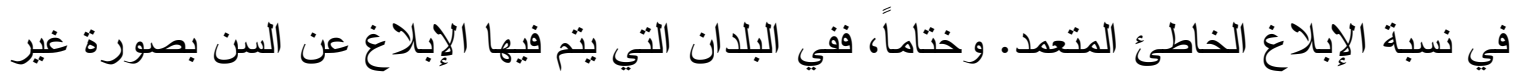

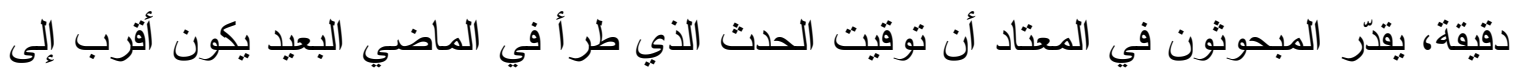

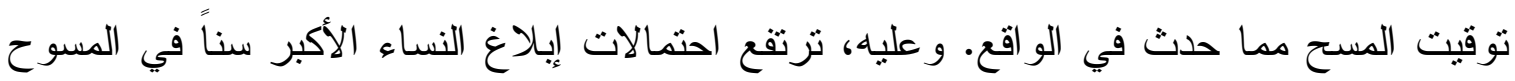

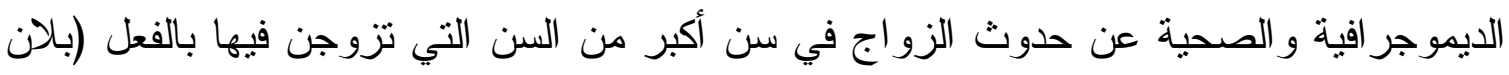
Blanc

\section{اتجاهات في السن عند الزواج}

إلى أي مدى تغير السن عند الزواج في السنوات الأخيرة؛ هل كانت الاتجاهات الخاصة بالرجال

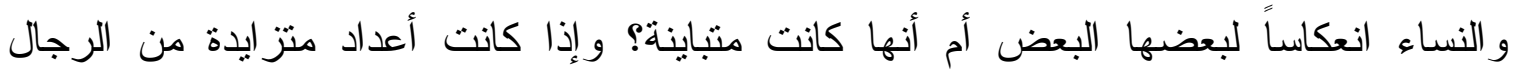

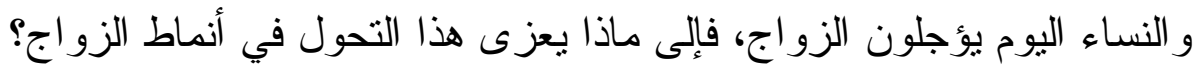

في هذا القسم، نقوم بتحليل طريقتين مختلفتين لقياس السن عند الزواج، بغية وصف الاتجاهات الخاصة بـ: (1) نسبة المجموعات العمرية الدحدة التي تنزوج، و التي تقوم على تثقارير حول الوضع الحالي، و(2) نسبة النساء والرجال الذين بتزوجون ببلوغهم أعمار معينة، وتقوم على لهي 
تقارير رجعية. ونقوم بتضمين هذه القياسات، حيث أنه يشيع استخدامها، ونريد تحديد ما إذا

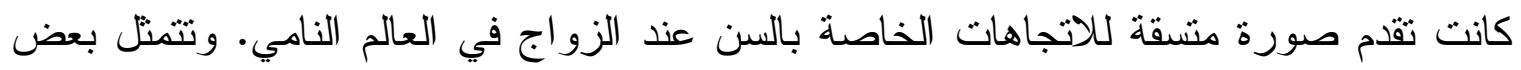
الاختلافات في مدى التغطية الجغر افية للقياسين. فيشمل القياس الأول، و المأخوذ من قاعدة بيانات الأمم المتحدة، 73 بلداً، ويتضمن معلومات حول كل من الفترات الزمنية التي تحظى بالاهنمام (1970- 1989 و1990- 2000) بالنسبة للرجال و النساء، وتمنل بطريقة أو بأخرى كل إقليم

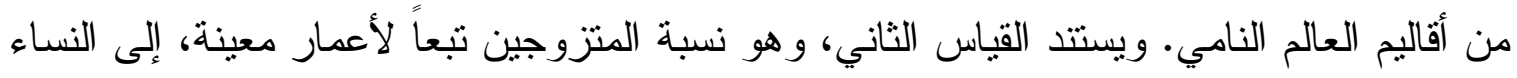

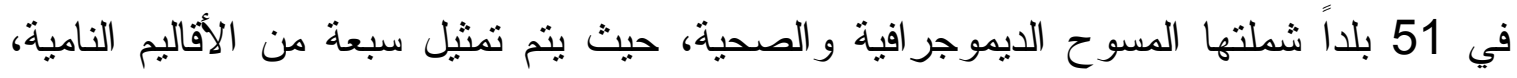

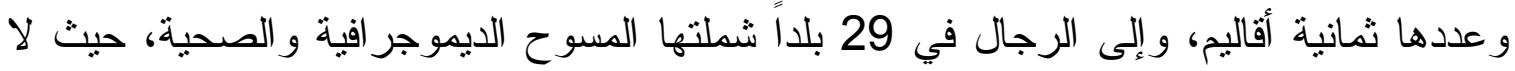

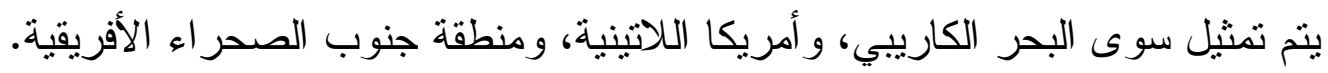

وتقوم شعبة السكان التابعة للأكم المتحدة بمر اقبة الاتجاهات الخاصة بالزو اج، باستخدام متوسـطـ السن عند الزواج (SMAM)، وهو وسيلة قياس مركبة يـتم حسـابها علــى أســاس بيانسات

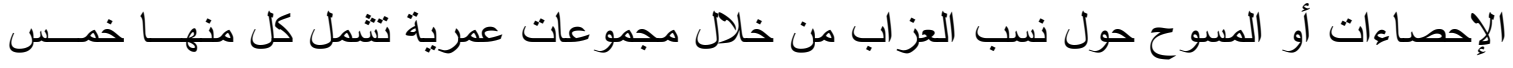
سنوات (الأمم المتحدة United Nations، الأس 2004). و على الرغم من أنه يشار إلى هذا القياس

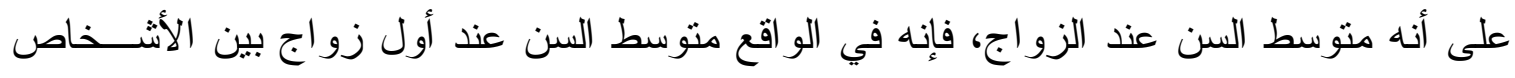

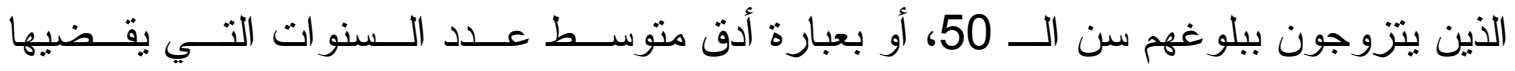
الأشخاص الذين يتزوجون قبل سن الــ 50 عزاباً (إدارة الثئون الاقتصادية و الاجتماعية الدولية

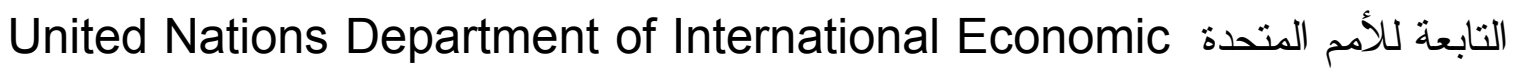
(and Social Affairs

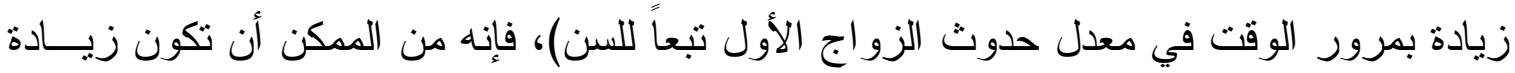

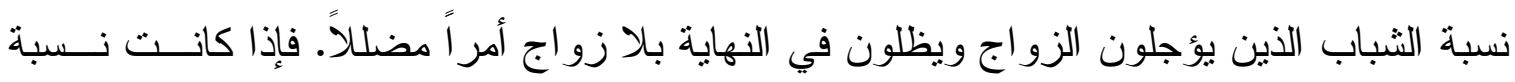

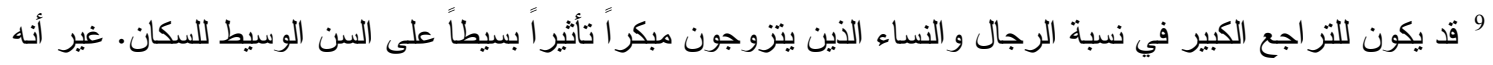

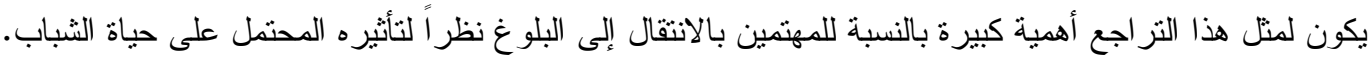

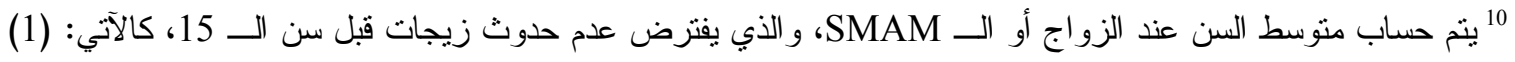

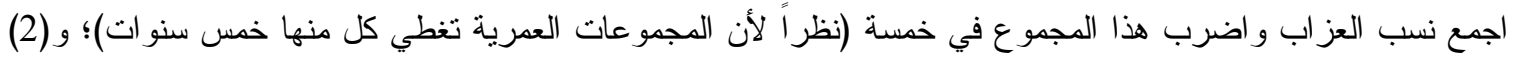

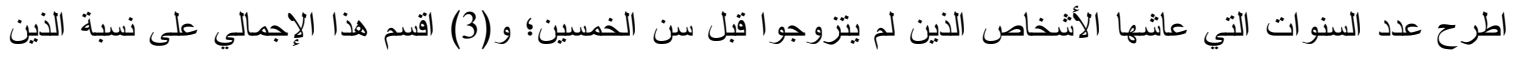

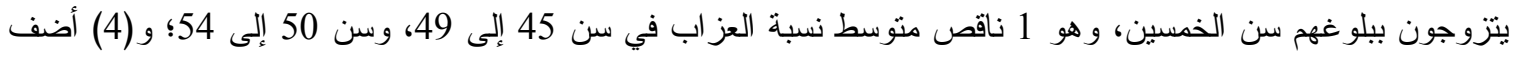

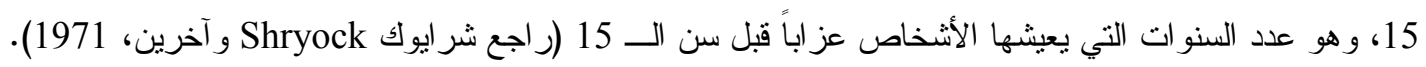


الثباب الذين يتزوجون في نهاية المطاف أقل من النسبة الحالية للذين يبلغون من العمر 50 عاماً وتزوجو ا، فإنه سيتم تضخيم منوسط السن عند الزواج بصورة اصــطناعية. ويحـذر بريـستون Preston وزملاؤه (2001، صـ 89) من استخدام منوسط السن عند الزواج في حالة تغيــر

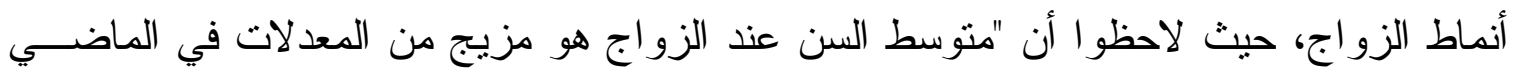
القريب و البعيد". و على الرغم من ذللك، فإنهم لا يبينون كيفية هذا التشويه و لا مداه. فتكثف مقارنة

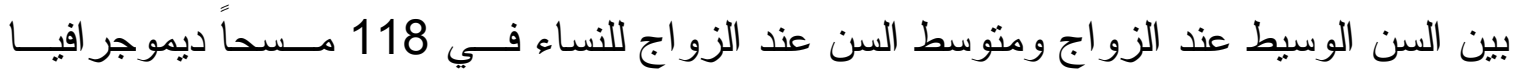

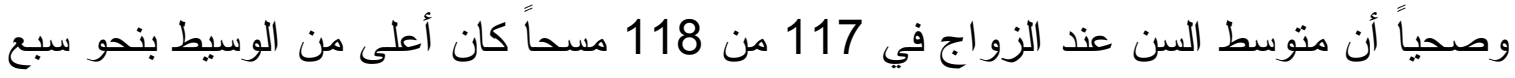

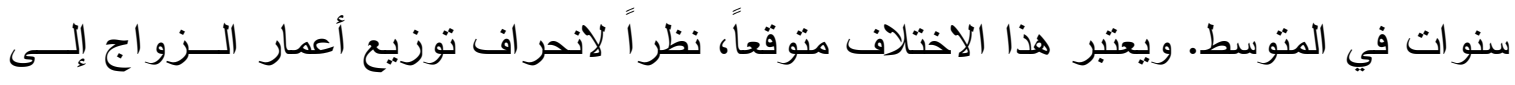

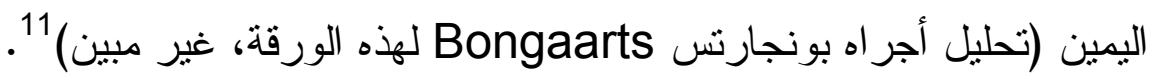

اتجاهات في النسبة المئوية للمتزوجين بين الثباب الذين تتراوح أعمارهم بين 15 و29 عاماً يقام الجدولان (1 و2) بيانات حول الوضع الحالي للبيانات تبعاً للمنطقة حول النسبة المئوية

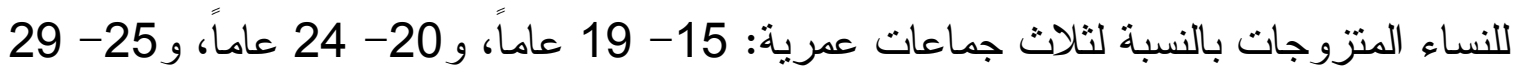
عاماً، ونسبة الرجال (و الذين يكون الزواج بينهم خلاه سنوات المر اهقة أمراً أكثر ندرة) بالنسبة لجماعتين عمريتين: 20- 24 عاماً، و25- 29 عاماً. وبالنظر لتباين المسافة الزمنية بين الإحصاءات أو المسوح تبعاً للبلد، فإنه ينم حساب معدل سنوي للتغيير .

وبالنسبة لجميع الأقاليم باستثناء آسيا السوفييتية السابقة وأمريكا الجنوبية، حيث لم يكن الزواج المبكر شائعاً حتى من 10 سنوات - 20 سنة مضت، انحسر زواج المباء المر اهقين بشكل بالغ بين النساء. ويتجلى هذا الانخفاض بصورة خاصة في أفريقيا. كذلك هبطت نسبة المتزوجات بين

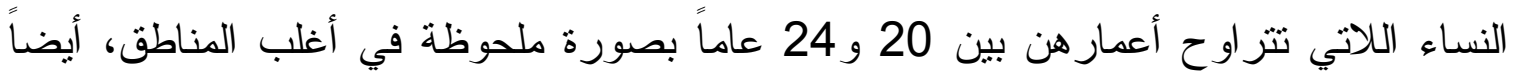

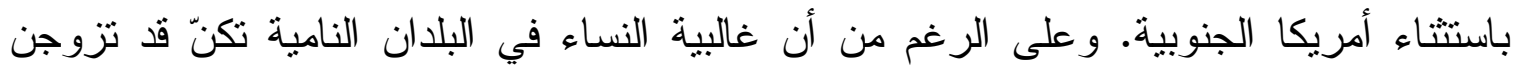

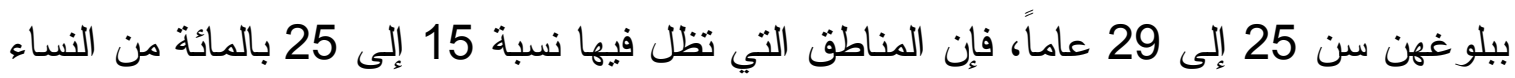
بلا زواج لاى بلوغهن أواخر العشرينات من أعمار هن تشمل أمريكا الجنوبية، والكاريبي وأمريكا

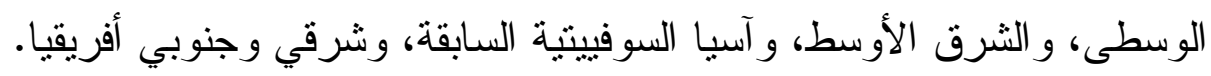

11 لا يكون الوسيط أعلى من متوسط السن عند الزواج إلا في المو اقف الني لا تنزوج فيها نسبة كبيرة من النساء. 


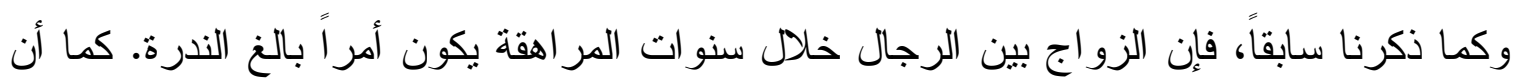

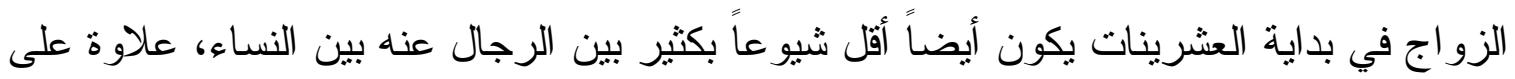

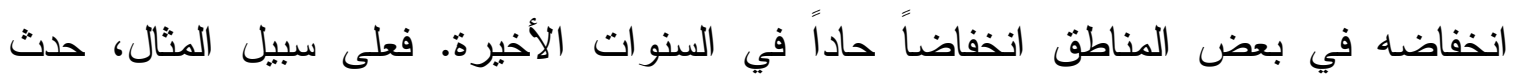

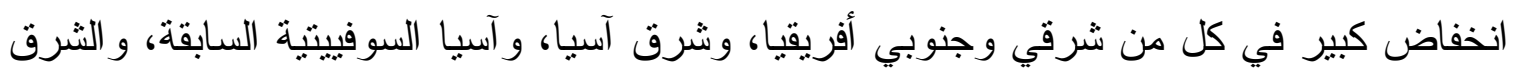

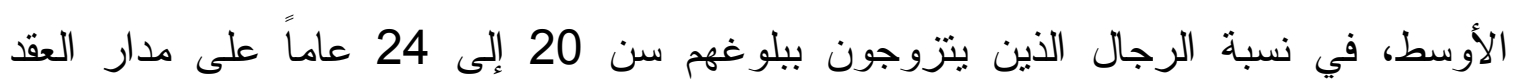

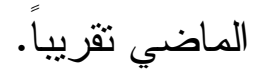

وبيلوغ سن الـ 25 وحتى الـ 29، تكون أعداد كبيرة من الثباب في البلان النامية قد تزوجت.

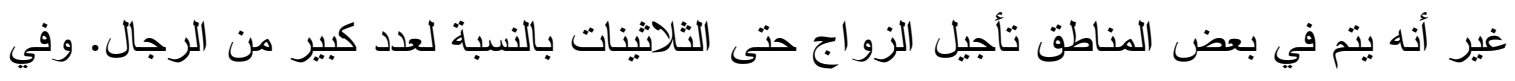

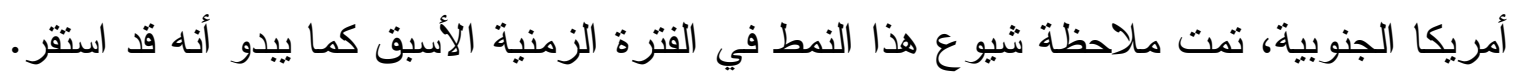

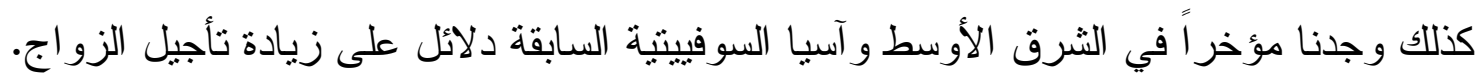

وباختصار، يكثف الجدولان (1, و) عن انخفاض في نسبة الدتزوجين من كلا الجنسين في

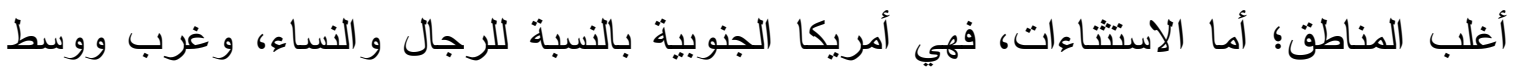

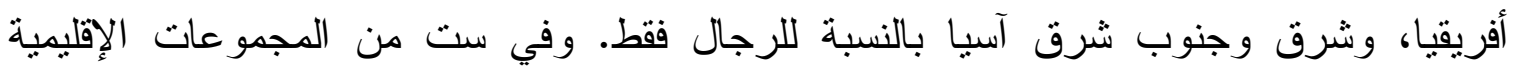

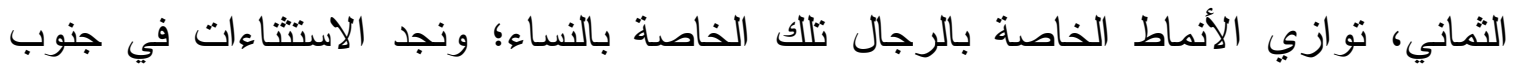

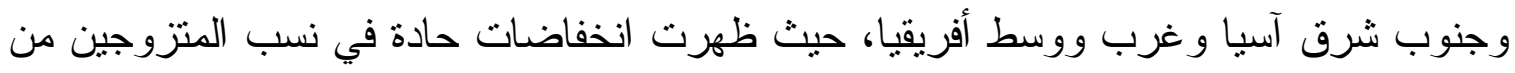

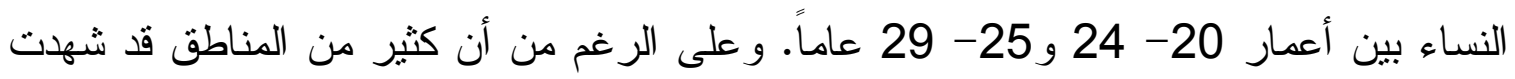

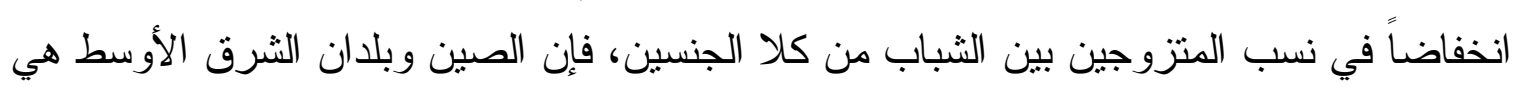

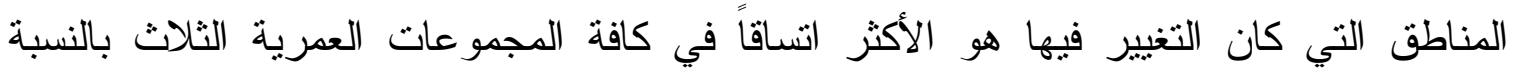
للنساء وفي مجمو عتين عمريتين بالنسبة للرجال.

\section{اتجاهات في نسبة النساء اللاتي تتزوجن بين سن 18 و20 و25 عاماً}

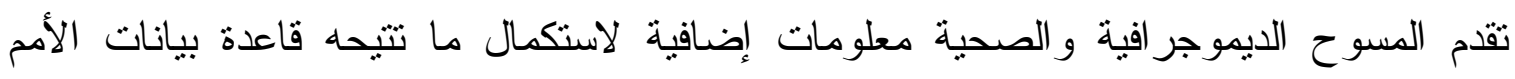

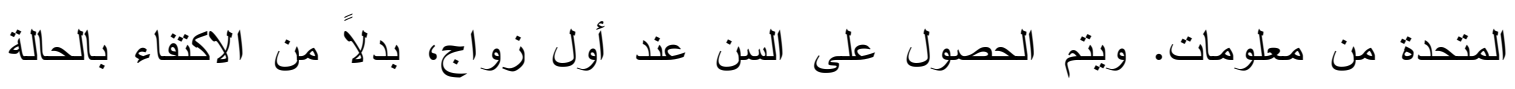

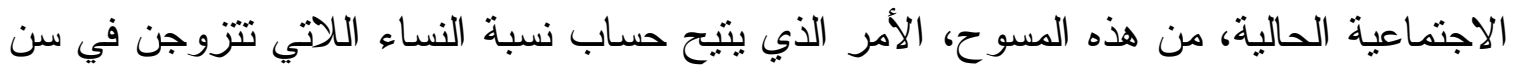
معينة وليس مجرد النسبة المئوية لفئة عمرية معينة تكون متزوجة. والعيب الوحيد فئي في هذه 
المسوح هو أنه تم إجر اؤها في عدد من البلان يقل عن البلدان التي شملتها قاعدة بيانات الأمم

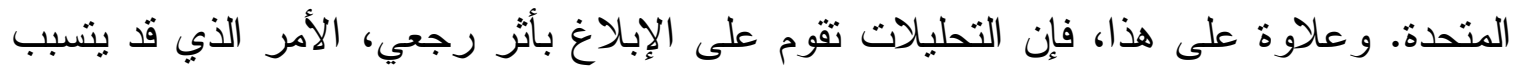

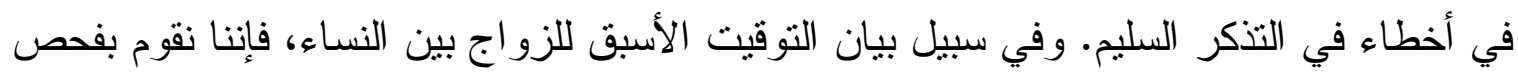

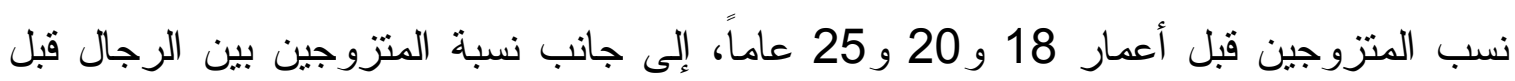

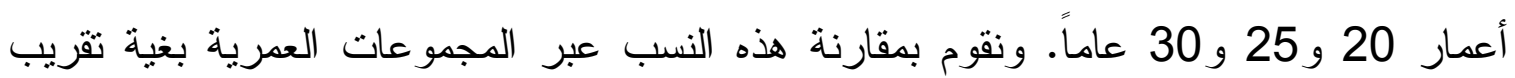

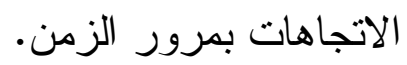

وتتوفر البيانات الخاصة بنسبة النساء اللاتي تنزوجن في سن معينة في الجدول (3). فيبين العمود الأول النسبة المئوية لسكان كل منطقة تنظاها المسوح الديموجر افية و الصحية.

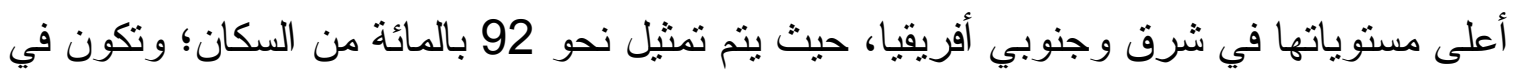

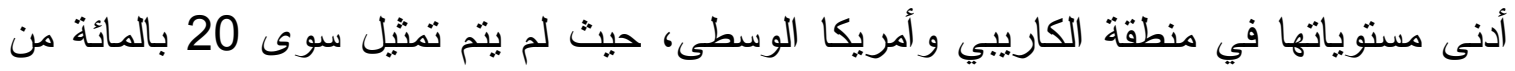

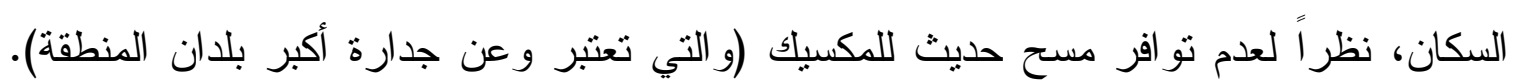

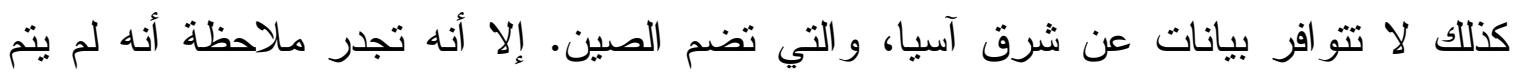

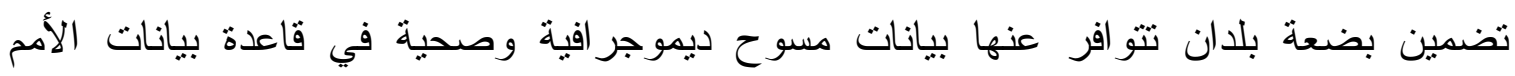
المتحدة، وهي: أرمينيا، و غانا، وغينيا، ومدغشقر ، ونيجيريا، وتوجو، و وأوزبكستان، وفيتنام،

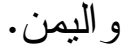

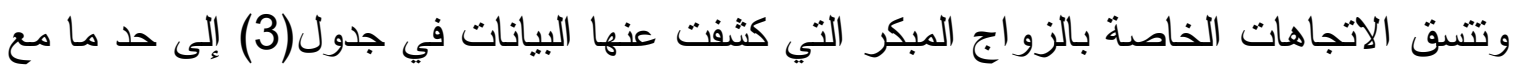

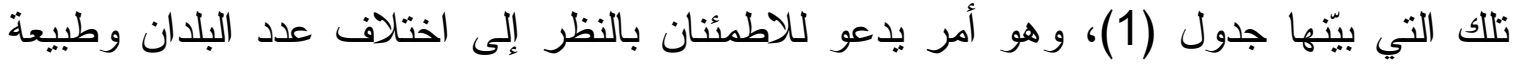

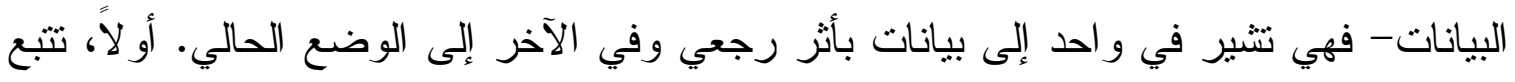

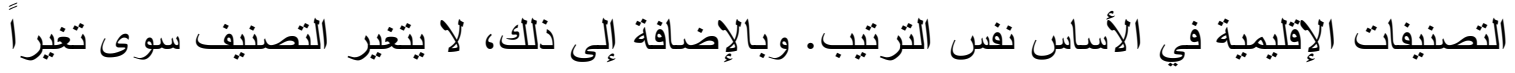

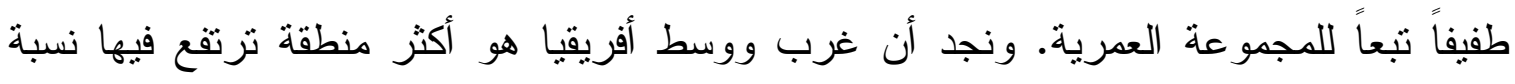

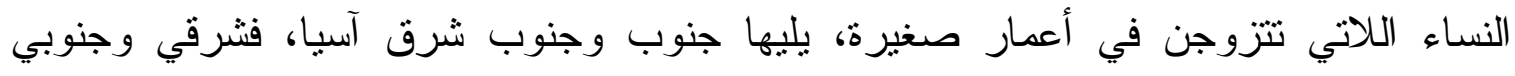

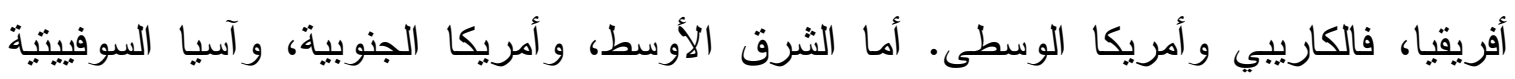

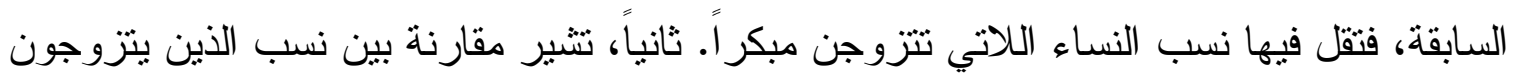

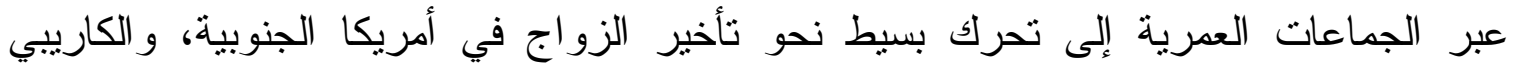
وأمريكا الوسطى، وآسيا السوفيبية السابقة. وبالفعل، تزوجت نسية نسبة أكبر من النساء اللاتي تتراوح 
أعمارهن بين 20 و و30 عاماً في آسيا السوفييتية السابقة في سن أسبق من سن زواج اللاتي

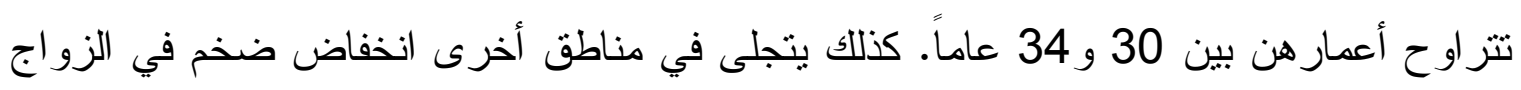

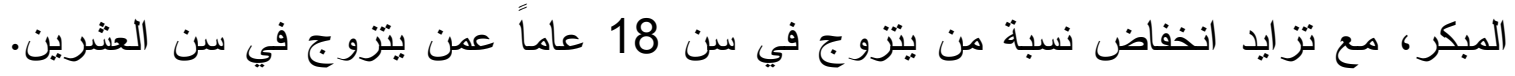

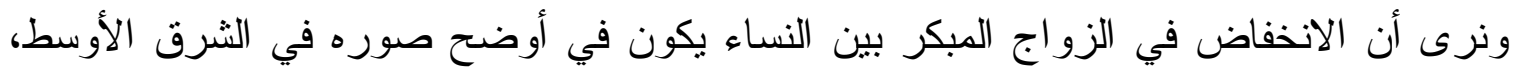

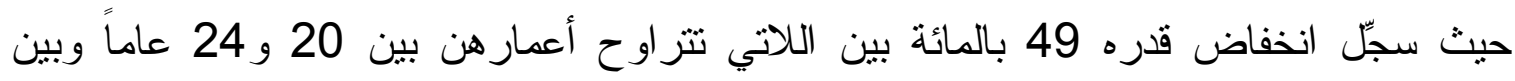

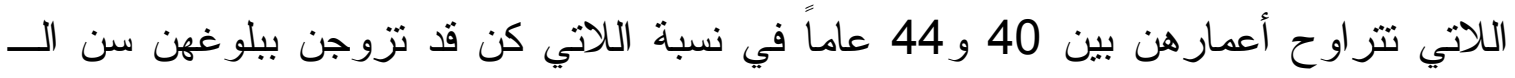

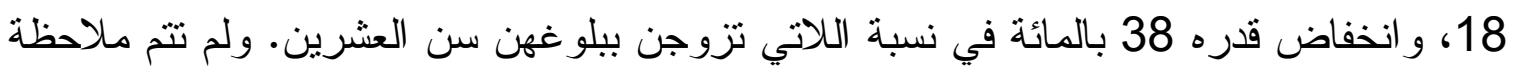

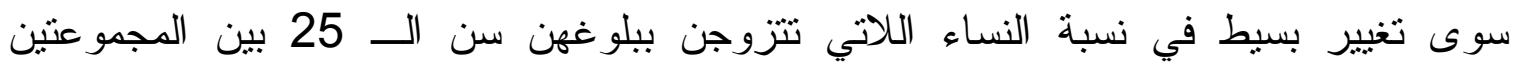

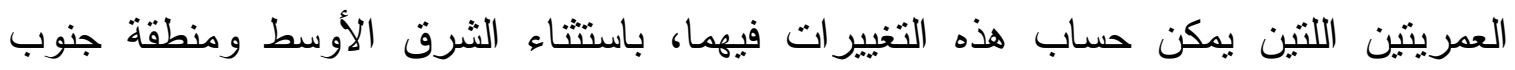

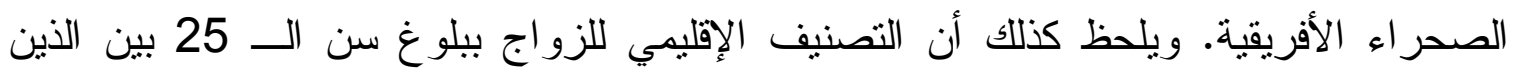

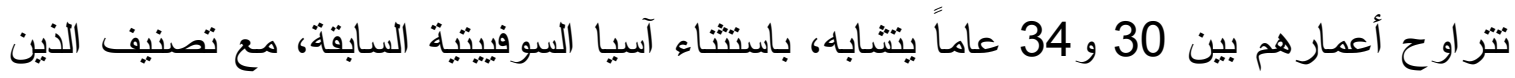

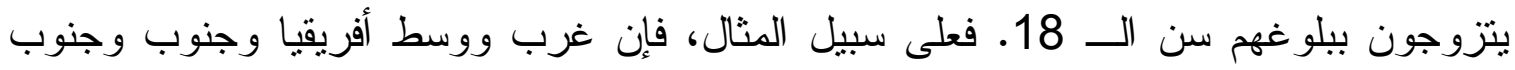
شرق آسيا هي المناطق التي تكون فيها نسب النساء اللاتي تتزوجن بليلوغهن سن الـ الــ 18 إلى 25 عاماً هي الأعلى.

ولتلخيص البيانات المتعلقة بالاتجاهات الخاصة بالسن عند الزواج بين النساء، فعلى الرغم من فئر

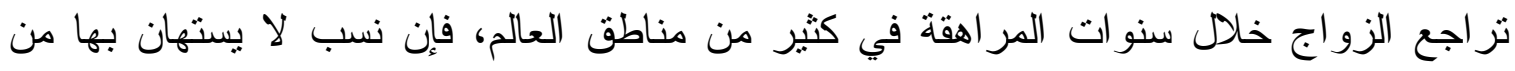

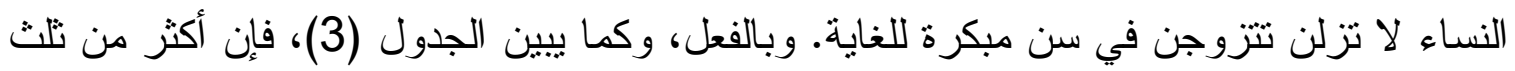

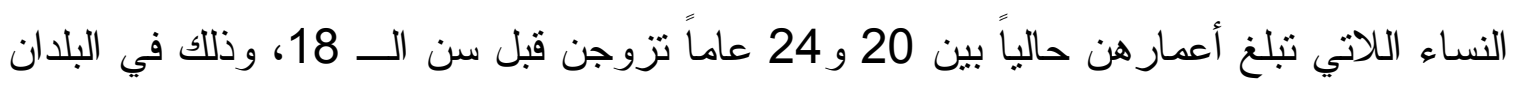
التي تنو افر عنها بيانات مسوح ديموغر اغية وصحية.

\section{اتجاهات في نسبة الرجال الذين يتزوجون بين سن 20 و25 و30 عاماً}

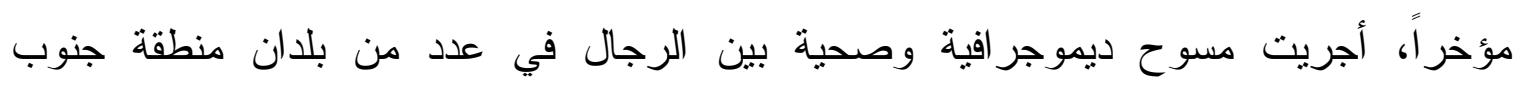

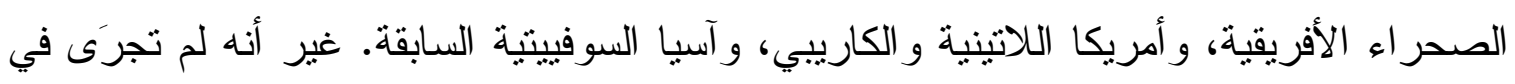

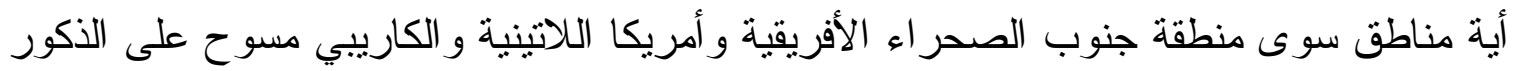

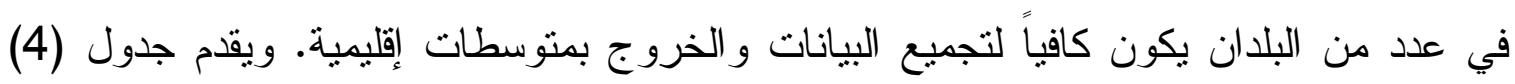

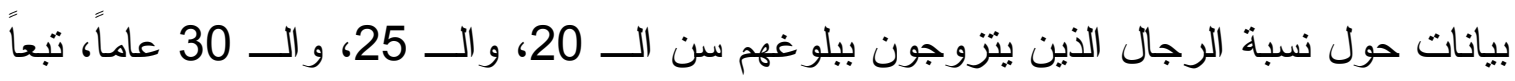


للمجموعة العمرية في وقت المسح، عن 29 بلداً أجريت فيها مسوح في الفترة ما بين عاميّ

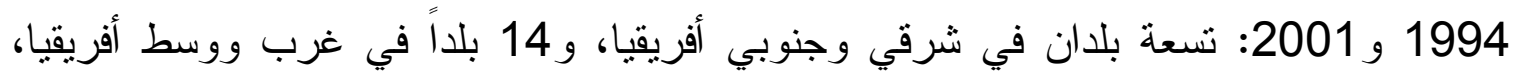
وثلاثة بلدان في أمريكا الجنوبية، وثلاثة بلدان في الكاريبي وأمريكا الوسطى.

وعلى الرغم من عدم بيان هذا الجدول سوى لقليل من التغيير المنسق في أمريكا اللاتينية و الكاريبي، فإنه تمت ملاحظة تز اجع طفيف في نسبة الرجال الذين يتزوجون في كلتا منطقتي" جنوب الصحراء الأفريقية. غير أن التراجع يقل بصورة ملحوظة عما نراه بالنسبة للنساء.

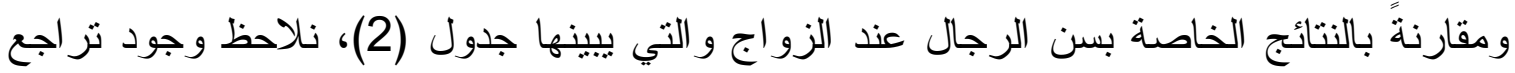

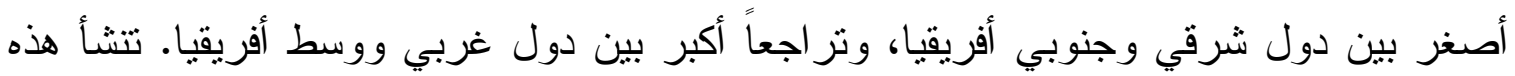
التفاوتات بسبب الاختلافات في البلدان التي تم تضمينها في التحليلات. ولم يتم إدراج نيجيريا،

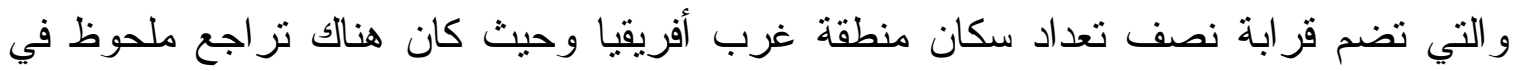
الزواج المبكر بين الثباب الذكور (تزوجت نسبة 10.8 بالمائة ببلوغهم سن الــ 20 بين الأشخاص الذين نتز اوح أعمار هم بين 20 و 24 عاماً، مقارنةً بـ 19.5 بالمائة بين الأشخاص

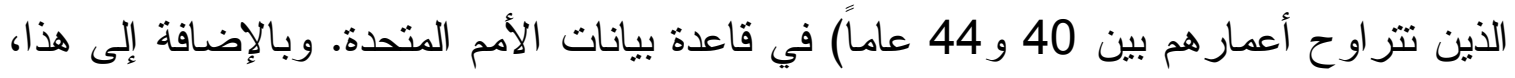

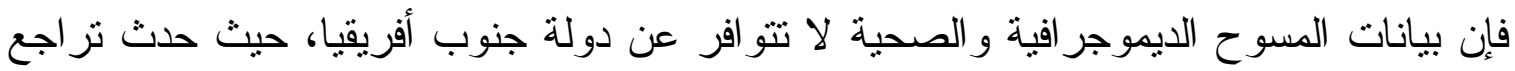
كبير في نسبة الرجال الذين يتزوجون في العشرينات من أعمار هم. ونظر أ لعدم إدر اج نسبة كبيرة من الذكور في تحليلنا القائم على المسوح الديموجر افية والصحية، فإن النقديرات الإقليمية ربما تكون مشوشة. وبالفعل، يلاحظ وستوف” Westoff (2003، صـ

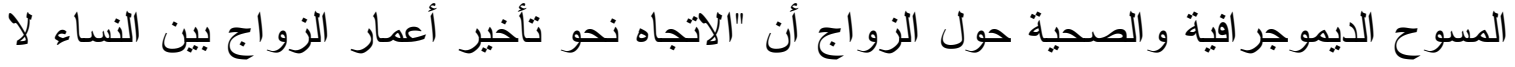
يظهر بوضوح بين الرجال الذين شملهم المسح بمنطقة جنوب الصحر اء الأفريقية"، وهو تأكيد كان أنساه من الممكن تغييره إذا كانت هنالك بيانات منوفرة عن عدد أكبر من البلدان.

\section{تفاوتات في السن عند الزواج} من الممكن لاختبار التفاوتات في توقيت الزواج تبعاً للتحصيل الدراسي ومحل الإقامة، والذي يمكن القيام بها بالاستعانة بييانات المسوح الديموجر افية و الصحية، أن يقدم رؤى متعقة داخل القوى التي تقف وراء الاتجاهات التي لاحظناها. ويقتصر الجدولان (5 و6) على النساء اللاتي

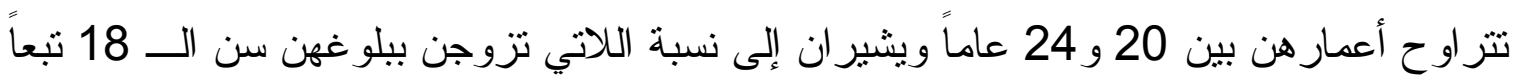


لسنوات التعليم المدرسي التي نم تحصيلها وللإقامة في الريف أو الحضر، على التوالي. أما

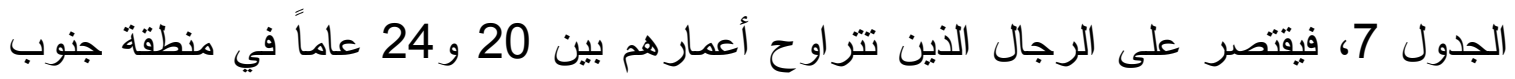

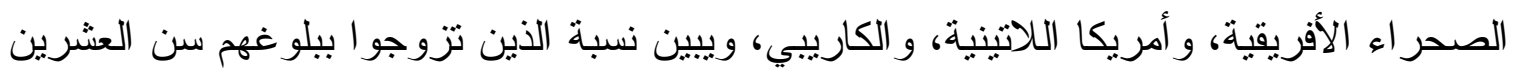

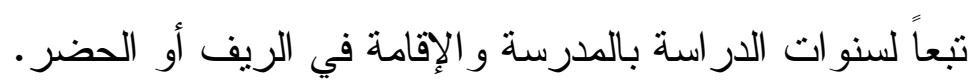

وكما هو متوقع، تمت ملاحظة اختلافات ضخمة تبعاً للتعليم والإقامة بالنسبة لكلا الجنسين. فتبين أن النساء و الرجال الذين تلقوا ثماني سنوات أو أكثر من التعليم المدرسي يكنّ أقلى عرضة بكة بكثير

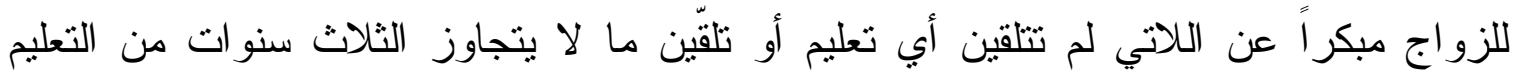

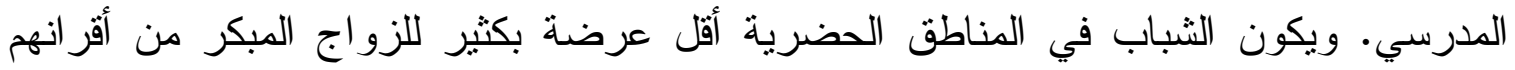
الذين يعيشون في الريف. و على الرغم من ضخامة هذه الاختلافات، فإن التباين في توقيت الزوراج

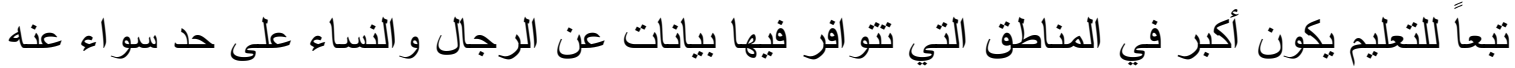
تبعاً للإقامة. فنجد أن هنالك عدد من النساء في شرقي وجنوني الفي أفريقيا على سبيل المثال، يتر اوح

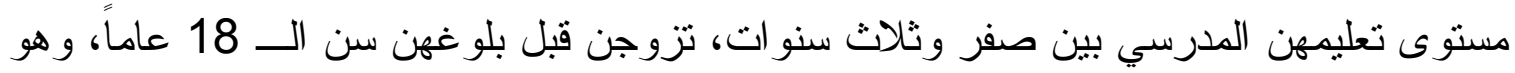
عدد يفوف بأكثر من أربعة أضعاف عدد النساء اللاتي حصلن على قسط أوفر من التعليم بيلغ الثماني سنوات أو يزيد ممن تزوجن في نفس السن، بينما تبلغ نسبة النساء في المناطق الريفية

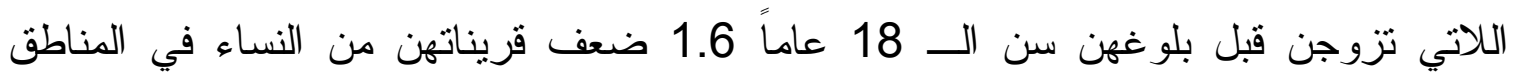

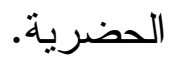

\section{تفسير الاتجاهات في السن عند الزواج}

كما سبق وأن وثِّنا، يتزوج الثباب في أغلب بقاع العالم النامي في سن أكثر تأخراً من أقر انهم

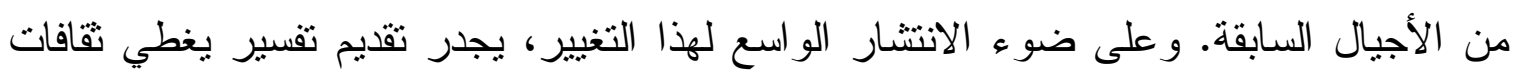

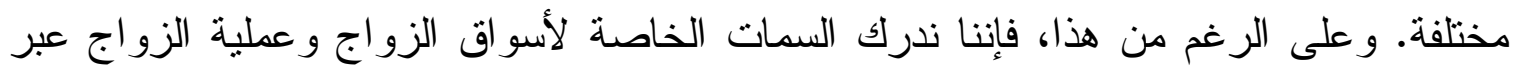
الأزمان و الأمكنة. فعلى سبيل المثال، قد تساعد التغيرات التي حدثت في ممارسة تعدد الزورجات في غرب أفريقيا، وهي ممارسة مميزة بتلك المنطقة، في تفسير سبب زيادة سن زواج النساء

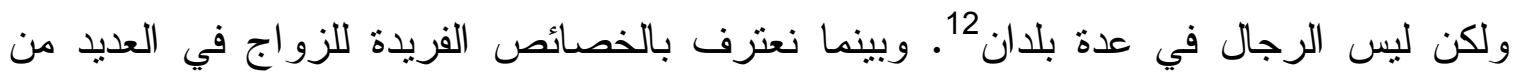

12 في غانا وتوجو على سبيل المثال، حدث انخفاض في نسبة الثابات التي تعشن في إطار نظام تعدد الزوجات. ويشسم هذا

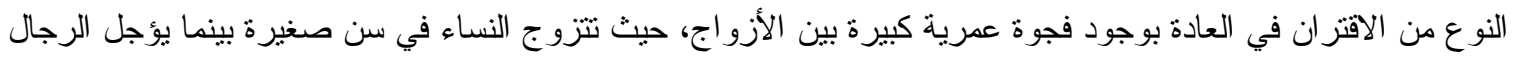


البلدان، فإننا نسعى للحصول على بعض التفسيرات العامة للسبب وراء قلة شيوع الزواج المبكر الآن عما كان في الماضي.

\section{تفسير الاتجاهات بين النساء}

ارتفاع التحصيل الاراسي. هنالك اعتقاد بأن ارتفاع معدلات التعليم الددرســي كــان مــن بـين

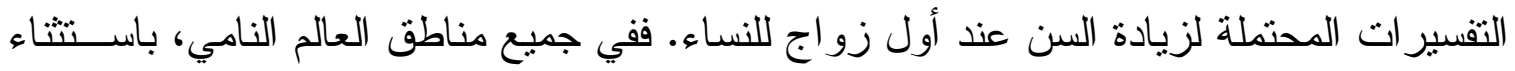

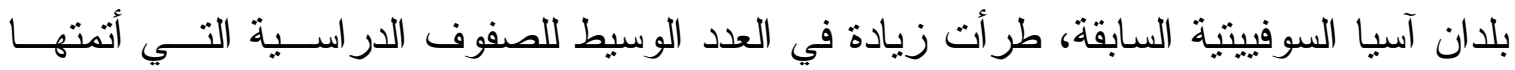

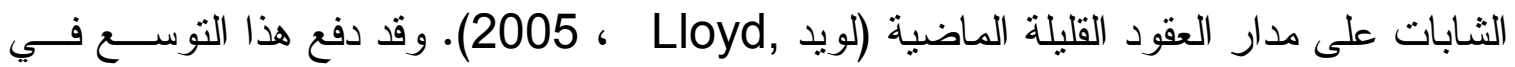

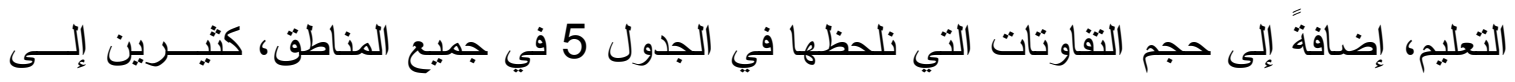

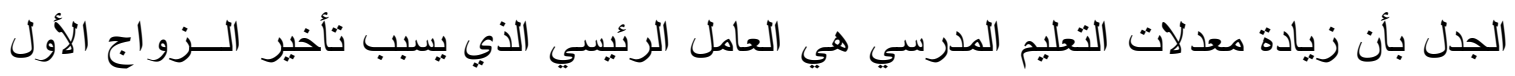

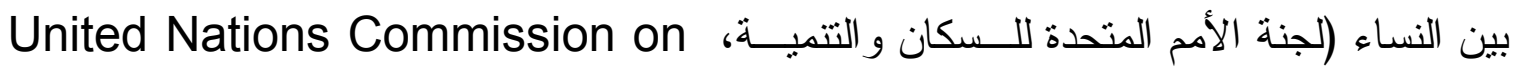
.(2002Population and Development

فإذا ما تععقا في النظر في البيانات المتاحة، لأثثرت لدينا شكوك حول الدور المهيمن لزيادة

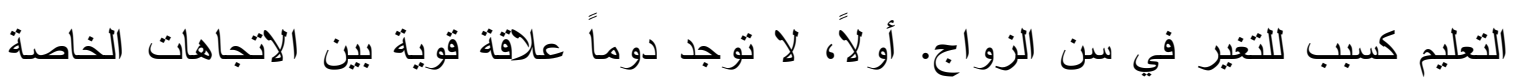

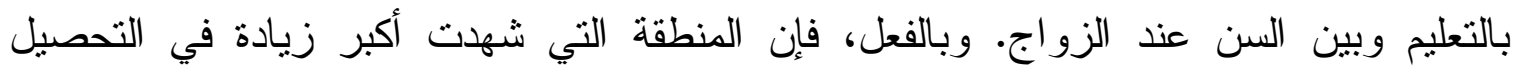
الدراسي بين الثباب، ألا و هي منطقة جنوب وجنوب شرق آسيا- ليست هي نفس المنطقة التي

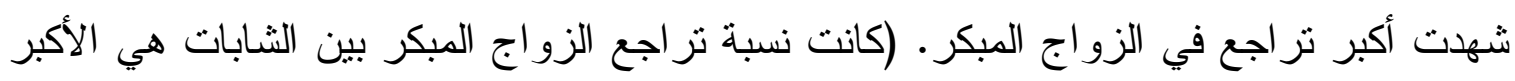
في منطقة الثرق الأوسط). وبالإضافة إلى هذا، وعلى الرغم من ارتفاع عدد سنوات التعليم

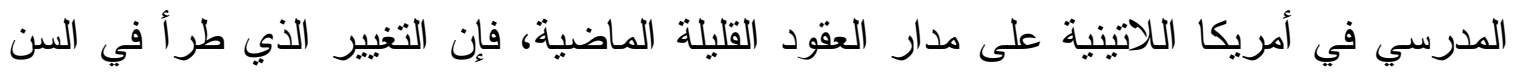

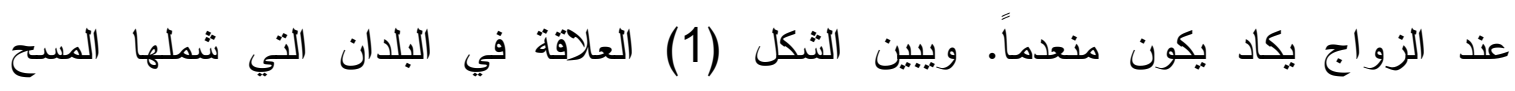
الديمو غر افي و الصحي، و عددها 49 بلداً، بين التغير المطلق بين الجماعات (الجماعتان العمريتان

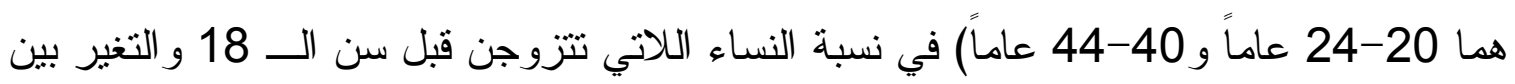

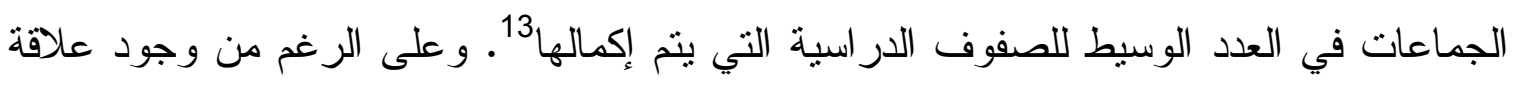

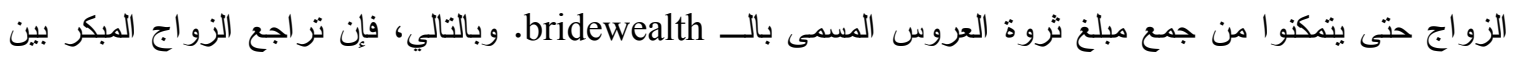

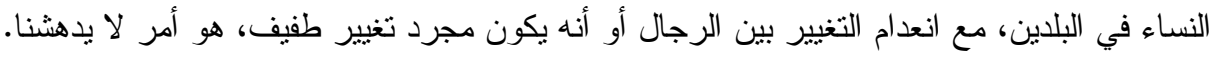

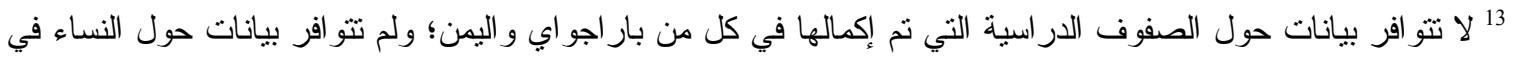
الجابون في وقت إجر اء هذا التحليل. 
و اضحة بين التغيير ات التي حدثت فيما يتم تحصيله من تعليم مدرسي وبين الزو اج - حيث شهدت

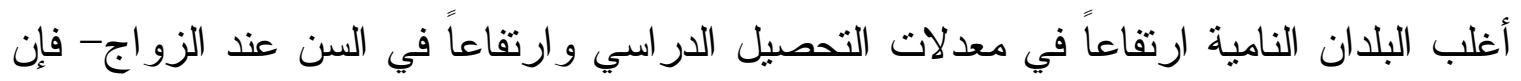
الشكل (1)يكثف عن علاقة أضعف مما كان متوقعاً، بالنظر إلى كون القوة المحددة تعزى في العادة إلى التغير التعليمي.

و هناك منحى بديل لهذا السؤال، يتمنل في اتخاذ العلاقة التي تمت ملاحظتها على المستوى الفردي بين الزو اج و التحصيل الدراسي كنقطة انطلاق، والنظر إلى مدى النغير الذي يحتمل أن ينتج في هذه العلاقة في الزواج المبكر بين الجماعات عن التغير بين الجماعات في التحصيل الدراســي.

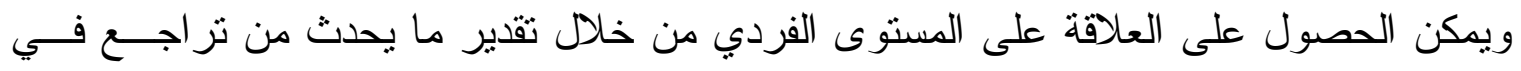

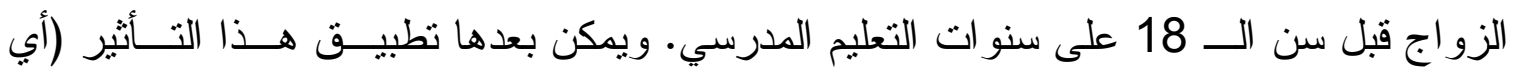

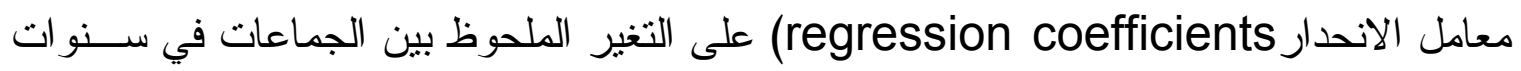
التعليم المدرسي لحساب "التغير المنوقع expected change " في احتمال الزواج المبكر الذي يمكن أن يخلقه التغير في التعليم المدرسي. ويمكن وصف هذه المنهجية بإيجاز فيما يلي: يمكـن فئن

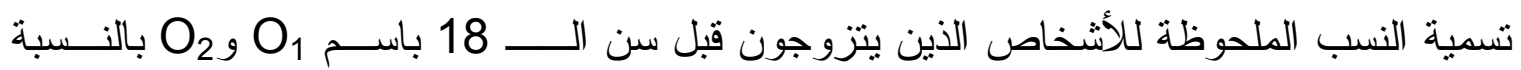

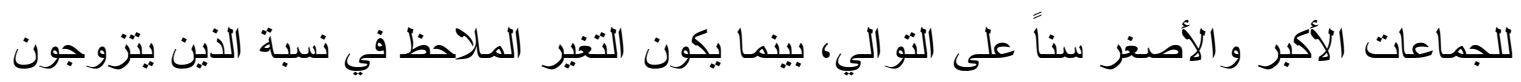
صغار اً هي:

$$
\Delta \mathrm{O}=\mathrm{O}_{1}-\mathrm{O}_{2}
$$

للحصول على "التغير المنوقع expected change " بسبب تغيرات في التعليم المدرسي، يتم تقدير معادلتى انحدار ، و احد عن كل جماعة:

حيث تكون P(M(18) هي احتمال الزواج قبل سن الــ 18 عاماً؛ وS هي التحصيل الدراسي (التعليم المدرسي) لكل امر أة؛ و و a هي المعامل المقدرة؛ و 1 و و2 هي الرموز التحنية التي تشير إلى جماعات (1) الأكبر سناً و (2) الأصغر سناً. 
ويتم حساب النسبة "الكنوقعة" للذين يتزوجون قبل سن الــ 18 عاماً بالنسبة للهجموعة الأصغر

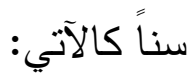

$$
E_{2}=\left(a_{1}+b_{1} S_{2}\right)
$$

يمتل هذا النسبة المتنباً بها للأشخاص الذين بتزوجون مبكراً في جماعة الأشخاص الأصغر سناً

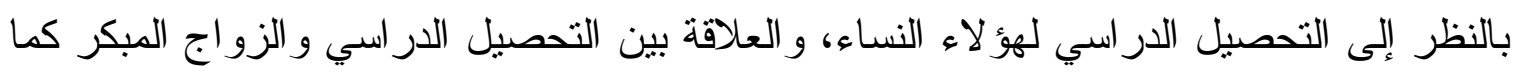

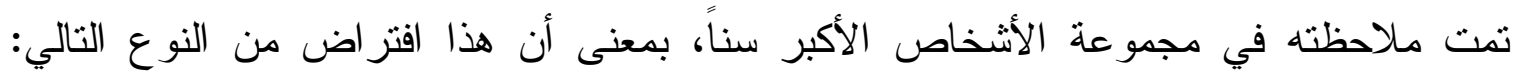

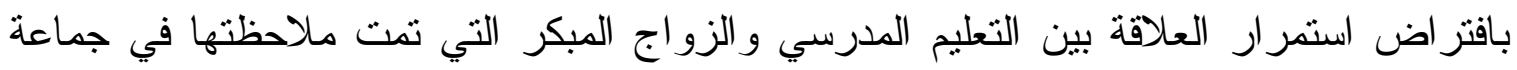

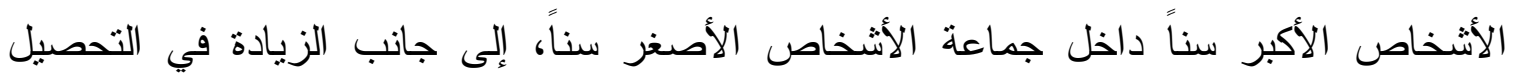

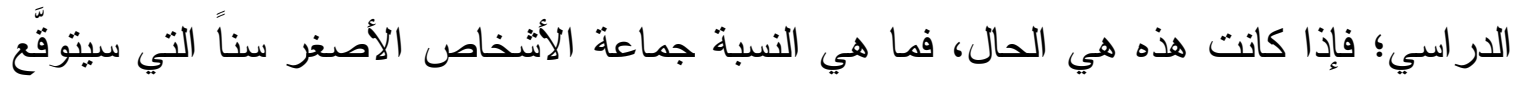

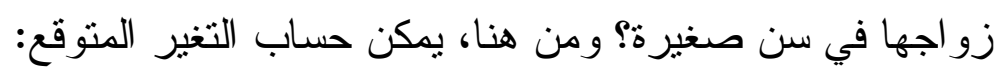

(4)

$$
\Delta \mathrm{E}^{*}=\mathrm{E}_{2}-\mathrm{O}_{1}
$$

ويمكن حساب افتر اض على نفس القدر من الصلاحية عن طريق عكس الجماعات كما يلي:

$$
E_{1}=\operatorname{~وسيط~}\left(a_{2}+b_{2} S_{1}\right)
$$

يمثل هذا النسبة المتتبأ بها من الأثخاص الذين يتزوجون مبكراً في جماعة الأثخاص الأكبر سناً

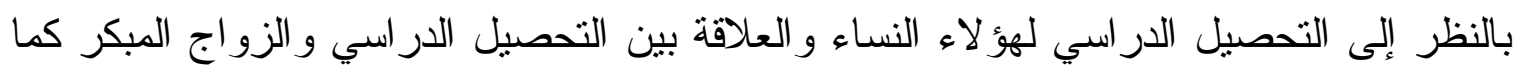

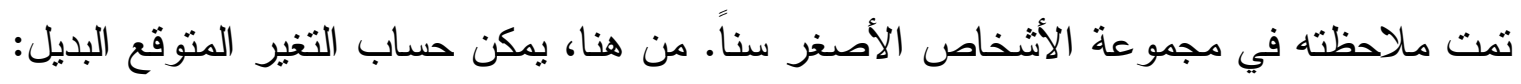

(6)

$$
\Delta \mathrm{E}^{+}=\mathrm{E}_{1}-\mathrm{O}_{2}
$$

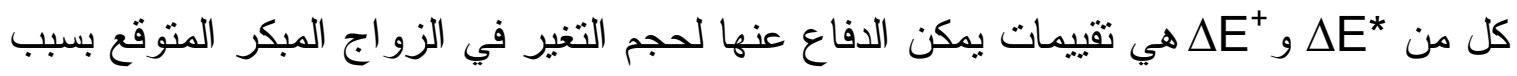

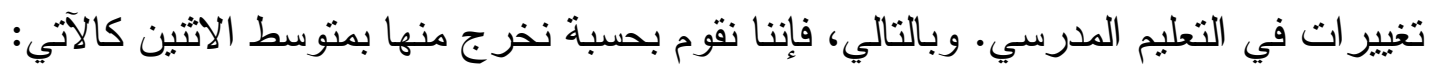


و هE هي "التغير المنوقع expected change " في نسبة الذين بتزوجون صغارًا في المناقثنة التالية وفي الجدول (8) و الثكل (2) 14 . وقد أجري هذا التحليل فقط للبلدان التي أجرت المسوح الديموجر افية والصحية فيها مقابلات مع جميع النساء، وليس فقط النساء المتزوجات أو الكاتلتي

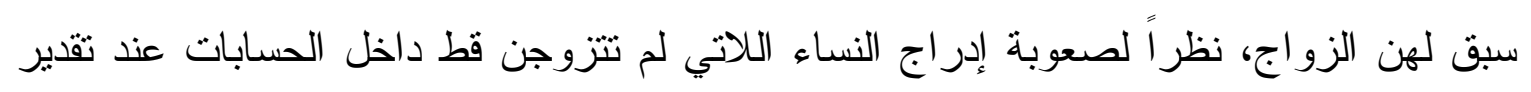

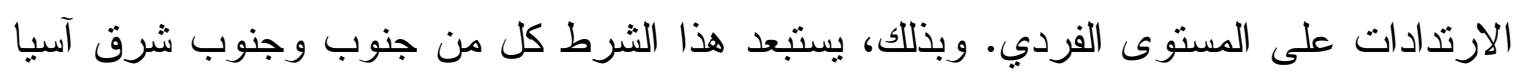
و الثرق الأوسط من هذا التحليل.

ويتم تقديم شكل بياني متفرق أو scatter plot للتغير المتوقع و الملاحَظ في الزواج المبكر في

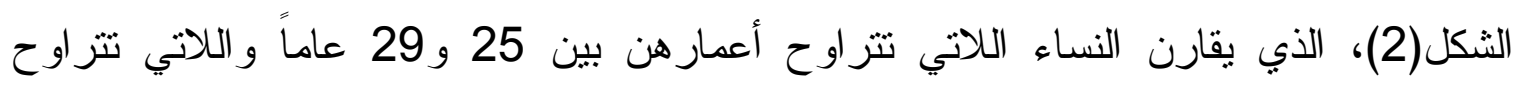
أعمارهن بين 45 و49 عاماً في وقت إجراء المسح. ويمنل الخط المائل في هذا الثكل النقاط

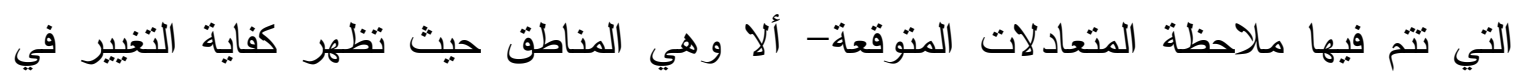

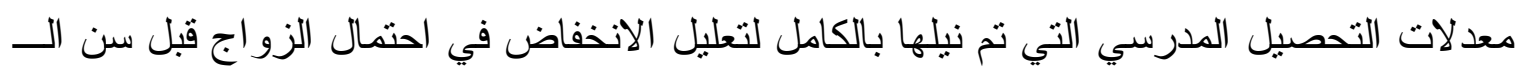

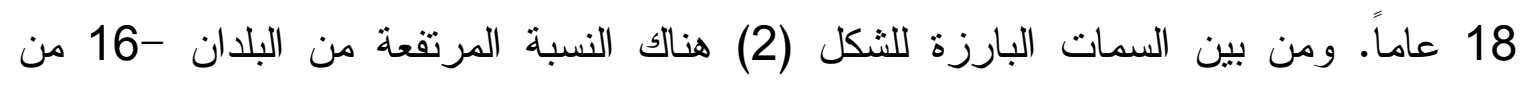
إجمالي 39 بلداً- يفوق فيها التغير المنوقع التغير الملاحَظ (الذي تمثله النقاط الكائنة إلى يمين

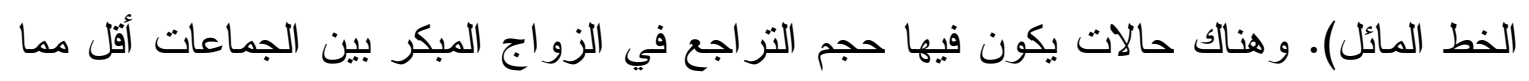

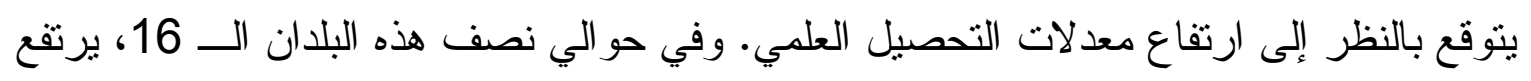

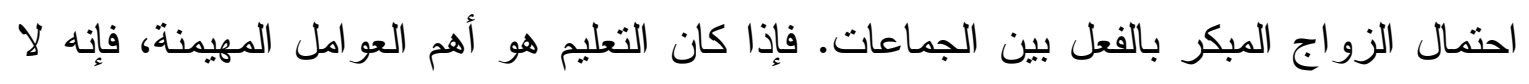

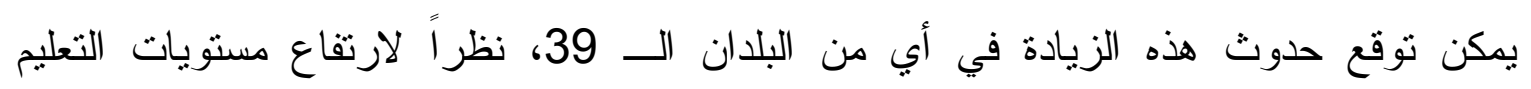

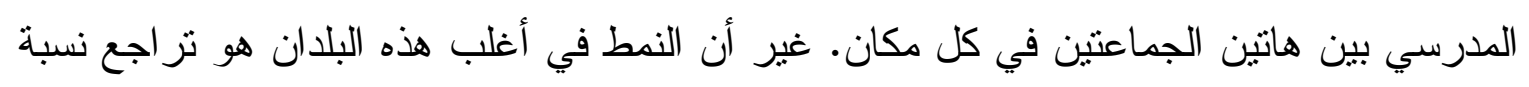

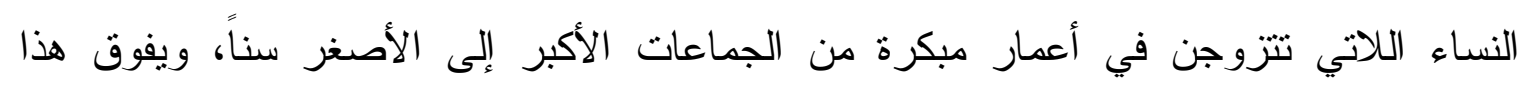

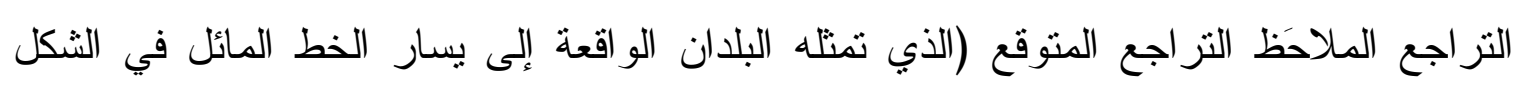

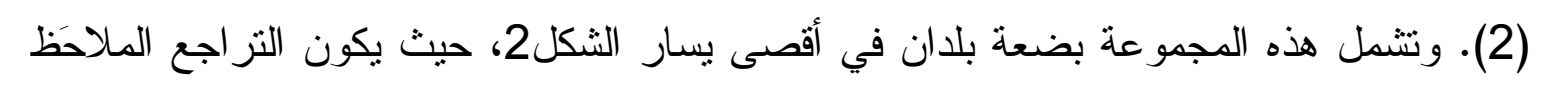

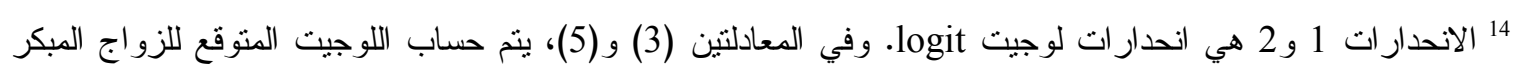

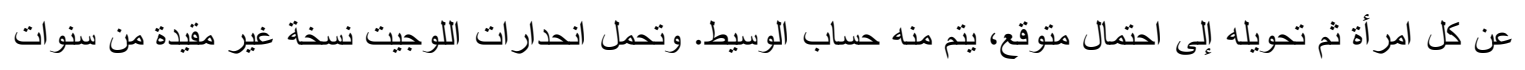

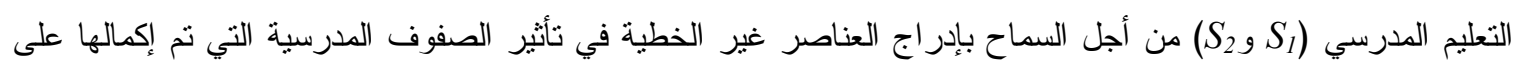

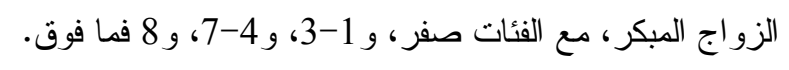


في الزواج المبكر أكبر بكثير من التراجع المتوقع. وفي هذه الحالات، سوف يبدو أن عوامل أخرى بخلاف التعليم المدرسي تدفع التغيير في نوقيت الزئر الزواج الأول.

ويتم إيجاز نطاق الخبرة الإقليمية الموضحة في الثكل(2) في جدول 8، حيث تم توضيح

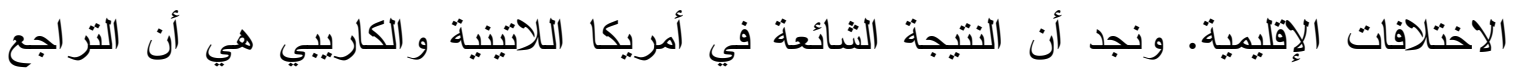

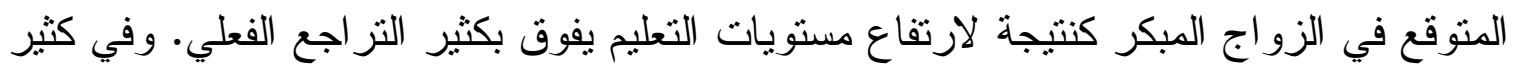

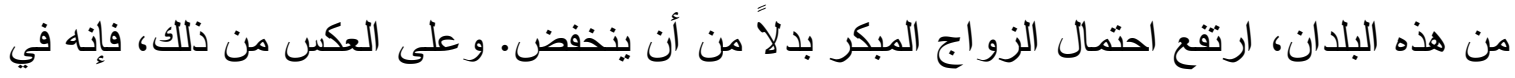

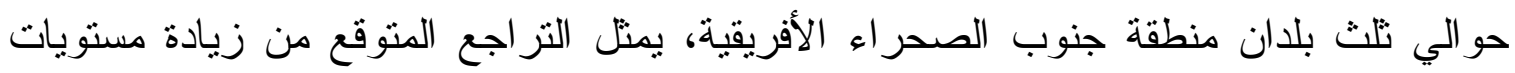

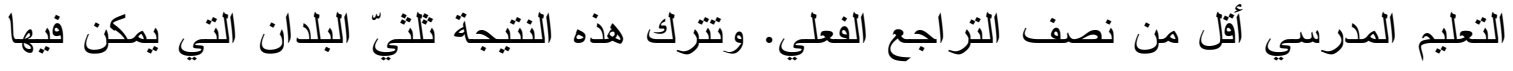

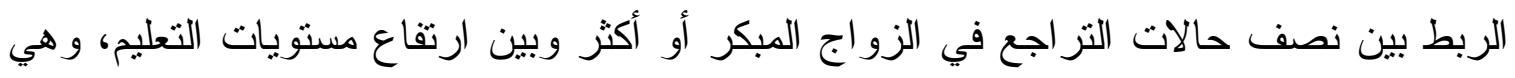
نتيجة جديرة بأن توضع في الحسبان 15. وتبين البلدان الأربعة الو اقعة في آسيا السوفييتية السابقة

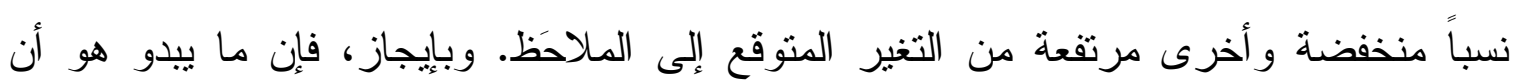

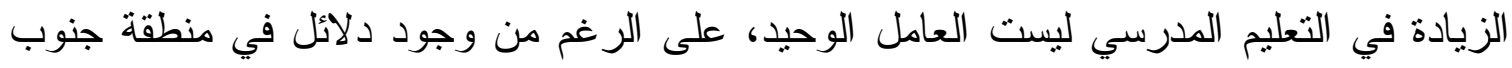

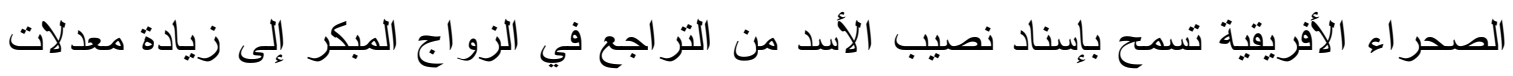

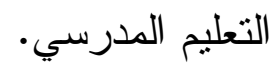

و لا يتحكم النحليل المقدم في الثنكل(2) والجدول (8) في علاقة التعليم الدرسي بالمحددات

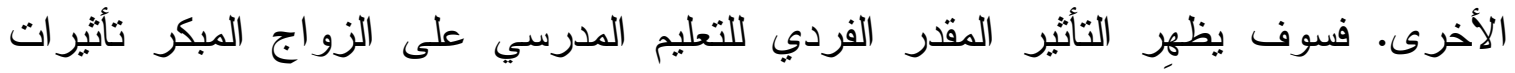

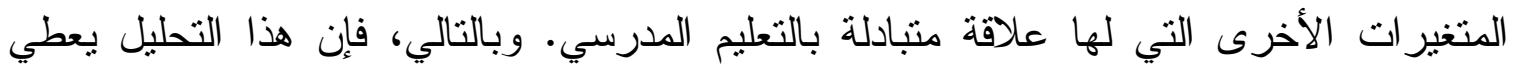

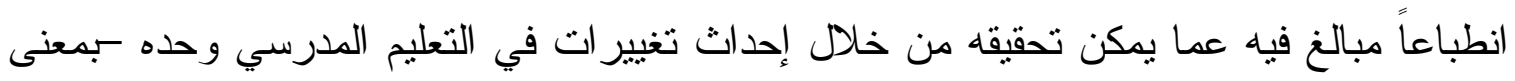

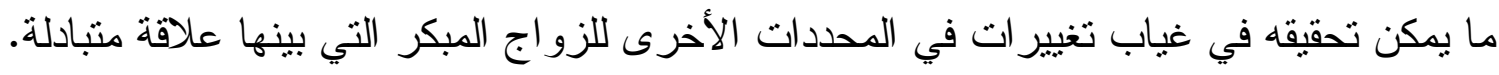

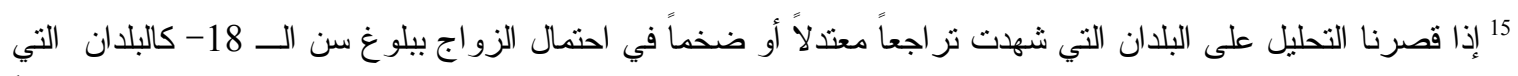

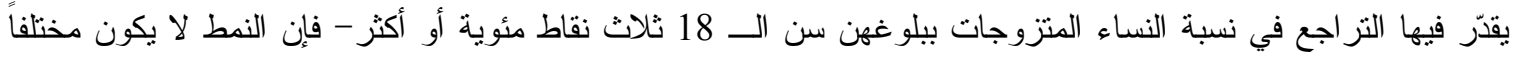

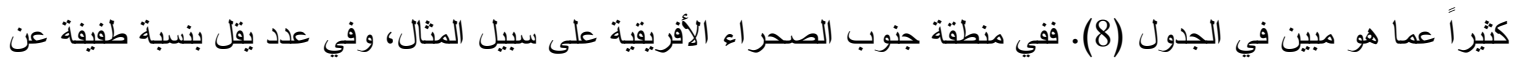

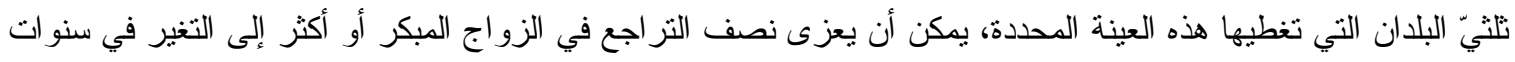
التعليم المدرسي، وهي نتيجة تتبه ما يظهره الجدول (8). 
وحتى في ظل هذه المبالغة المحتملة حول تأثثر زيادة مستويات التعليم المدرسي على تغير أنماط

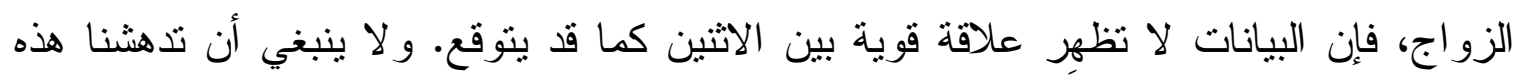

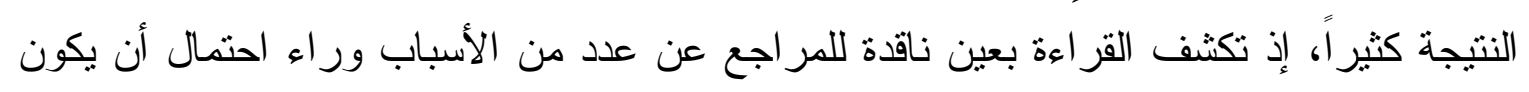

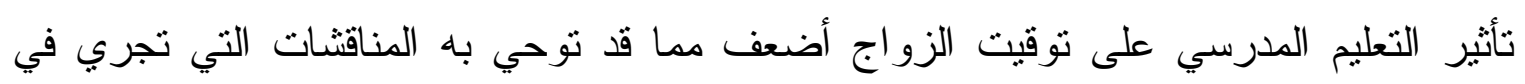
دو ائر السياسات.

ويمكن وضع أسباب وجيهة لتوقع وجود علاقة إيجابية بين التعليم المدرسي ونوقيـــ الـزور اج.

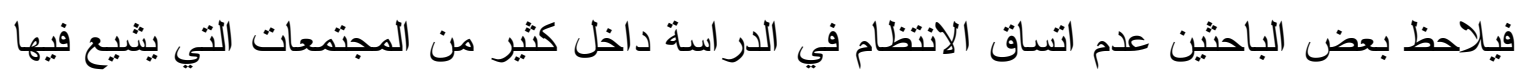

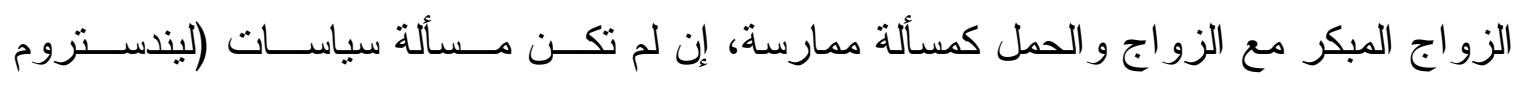

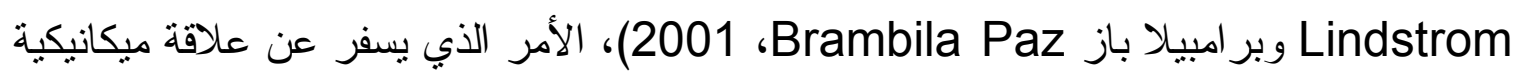

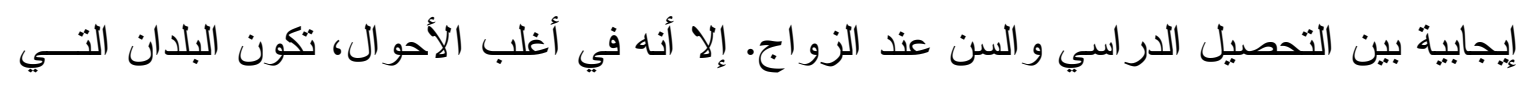

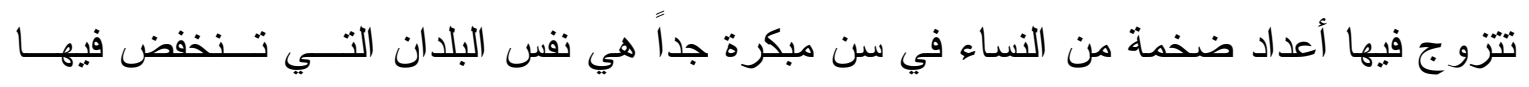

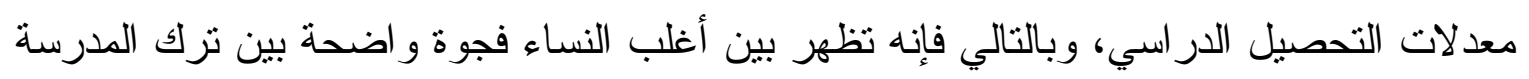

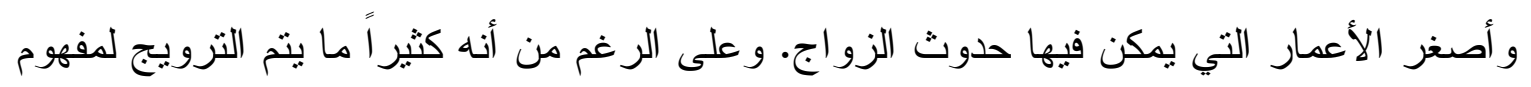

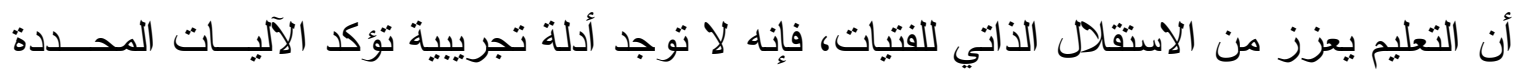

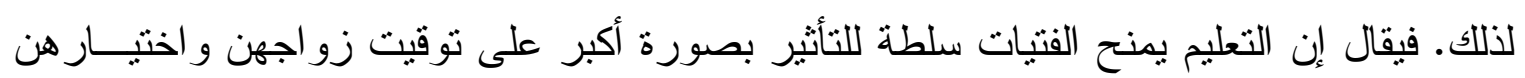

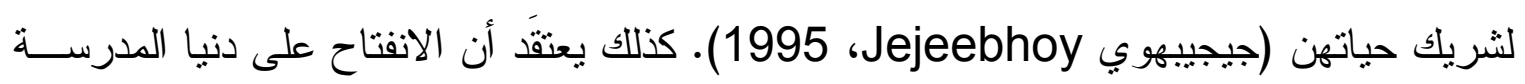

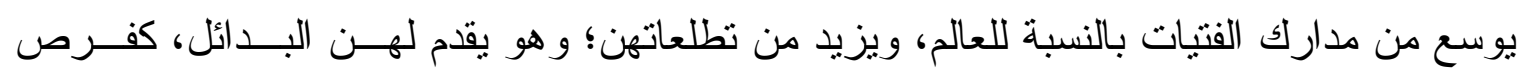

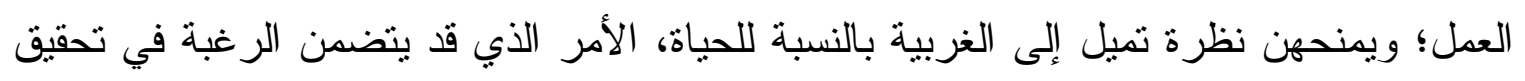

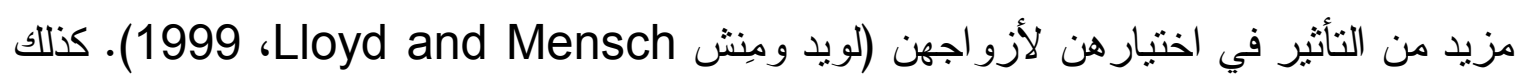

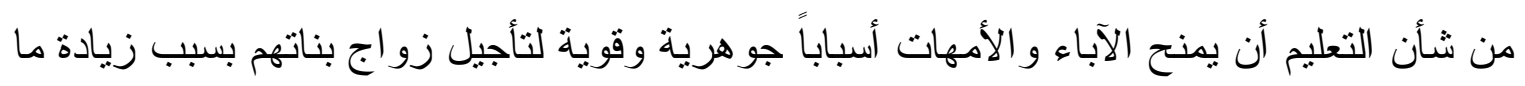

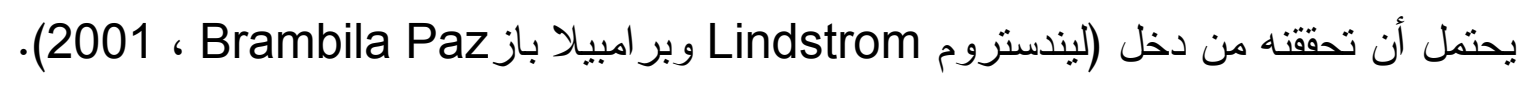

و على الرغم من كون هذه أسباب وجيهة لإثبات أن السن عند أول زو اج يتأجل مع زيادة سنوات أبهات

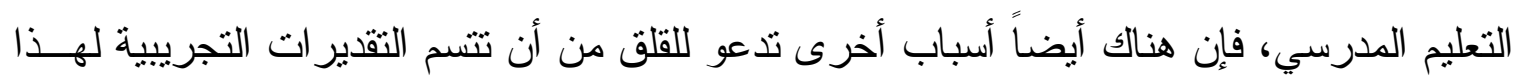

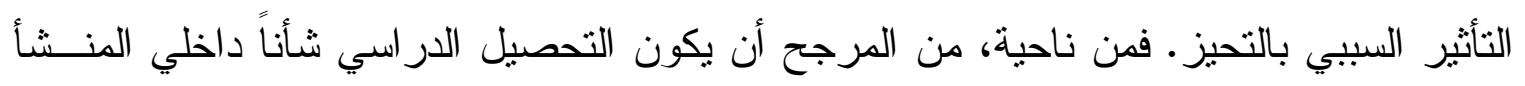

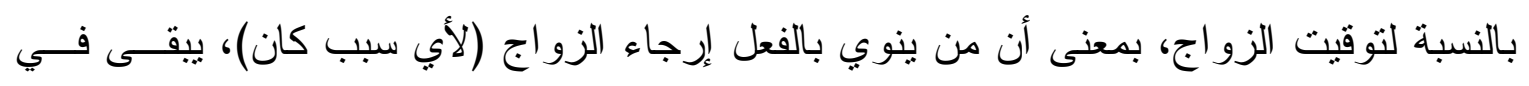


المدرسة لفتر ات أطول، أما من بعتزم الزواج مبكر اً، فيترك المدرسة مبكر اً كي يتزوج. ويتغاضي

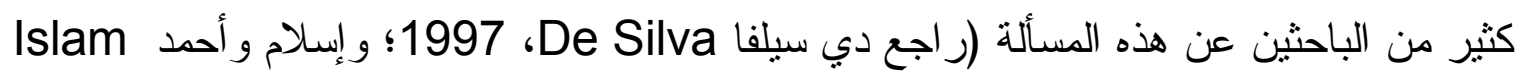
1998، and Ahmed

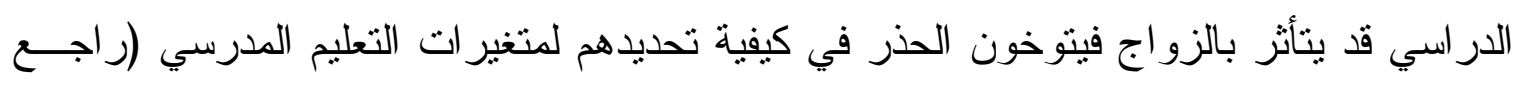

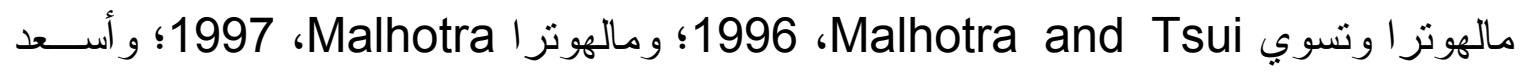
Assaad وزواري Zouari

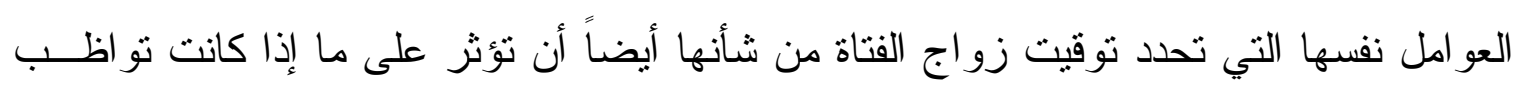

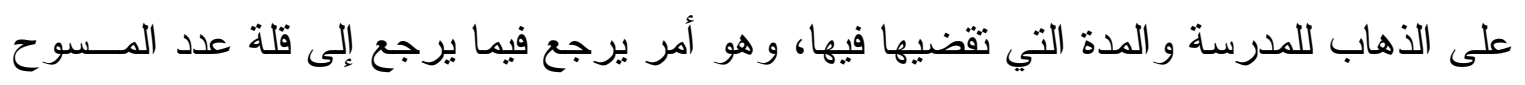

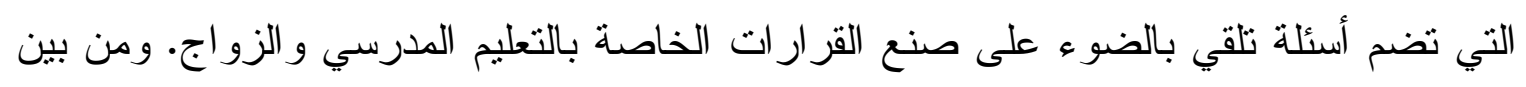

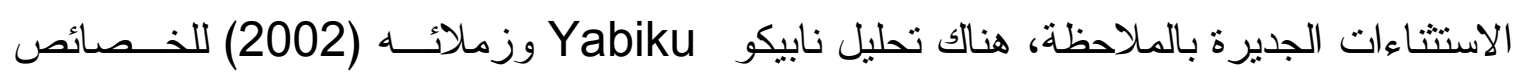

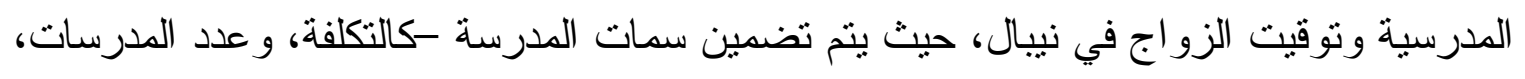

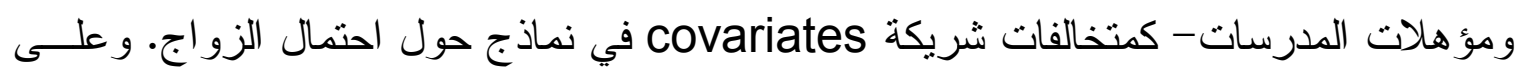

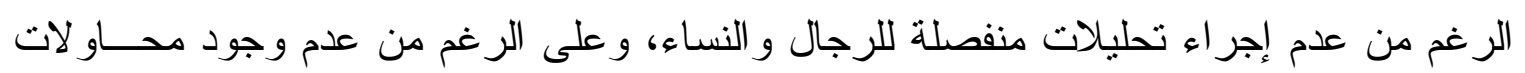

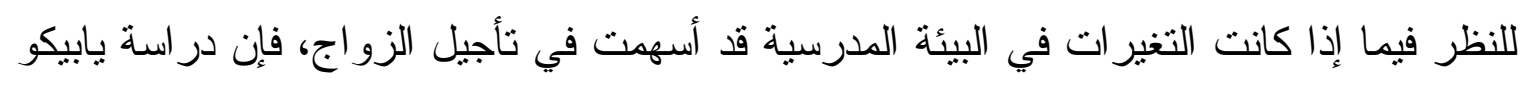
Yabiku الدر اسي.

وفي النهاية، هناك أسباب تدعو للنساؤل حول التعليم المدرسي في حد ذاته و القدر الذي يتوقع أن

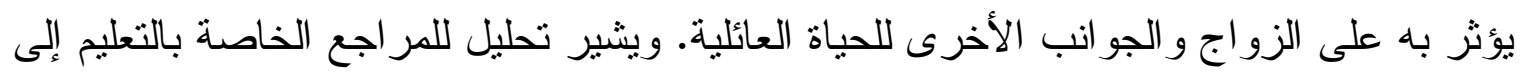

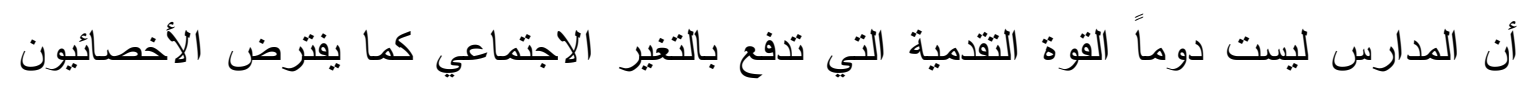

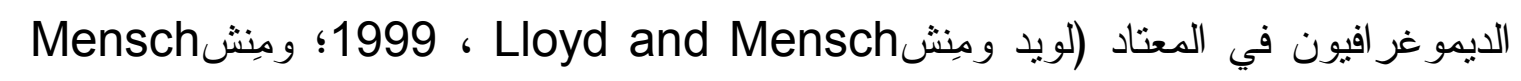
و آخرون، 2003). وعليه، تتمتل الحاجة لإجر اء تحليل أكثر دقة و انتباهاً للتفاصيل حول التعليم

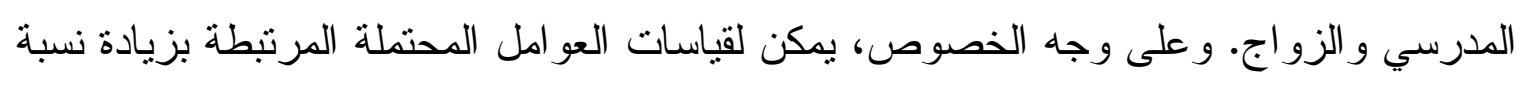

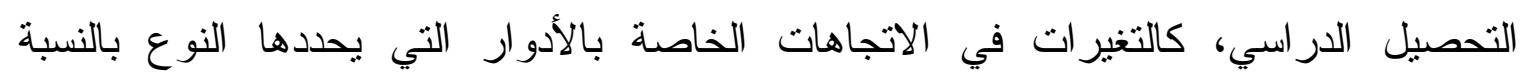

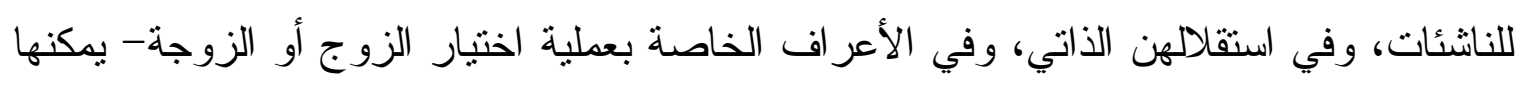

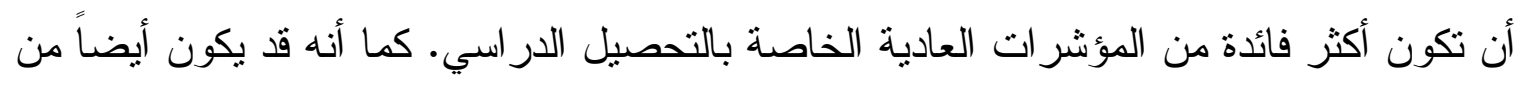

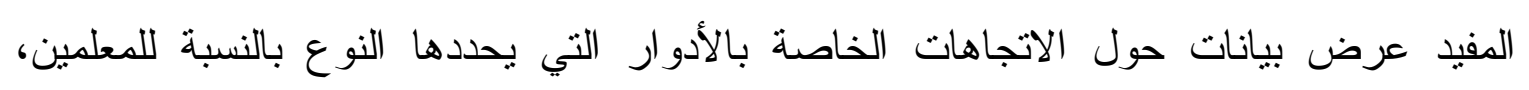


و الاختلافات في المناهج التي يدرسها الأولاد و البنات، وتحليلات للتحيز القائم على أساس النوع داخل الكتب الدراسية. وسيكون الهـف من جمع هذه البيانات هو التمييز بين المجتمعات ذات ولات النظم التعليمية التي نرسخ الوضع القائم وبين المجتمعات التي بها نظم تعليمبة تتحدى الأعراف لفئن

زيادة التحضر Growth in urbanization : في نفس الوقت الذي ارتفع فيه الــسن عنـــ

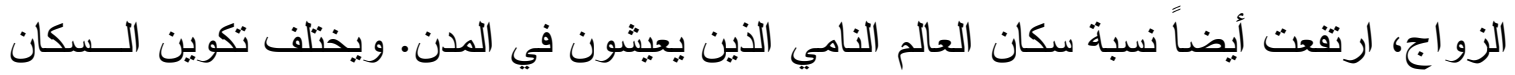

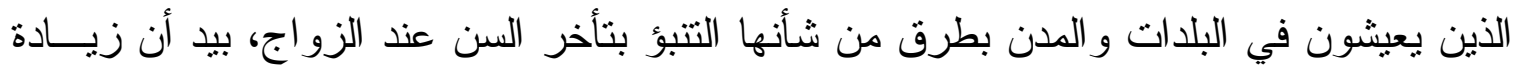

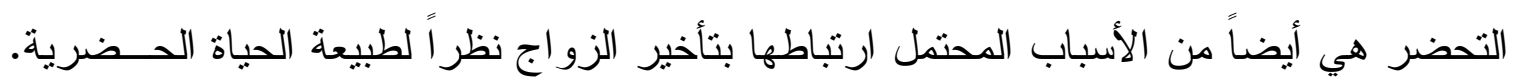
وكما يقتر ح كل من سينج وسمار ا Singh and Samara (1996)، فئن النساء في المنــاطق الحضرية تتفتحن على القيم الحديثة التي تشجع على الزواج في سن أكبر ، كما أنه يقل خضوعهن

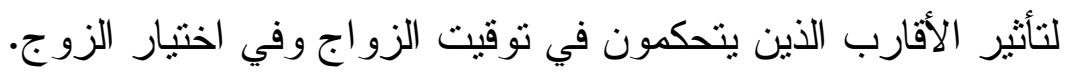

وعلى الرغم من عدم تو افر سبل مباشرة لدينا لقياس خصال الحياة الحضرية التي تتجع على

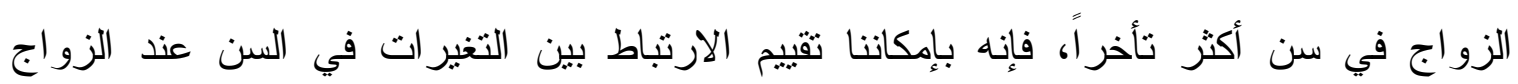
و النغير ات في نسبة السكان الذين يعيشون في المناطق الحضرية. و إلى جانب هذا، فإنه بإمكاننا

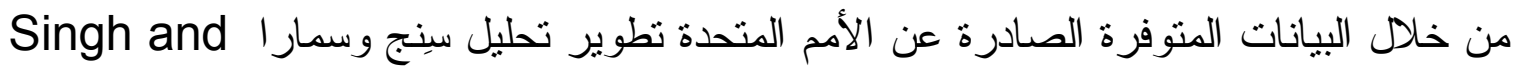
Samara

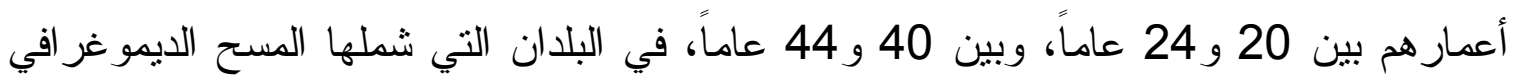

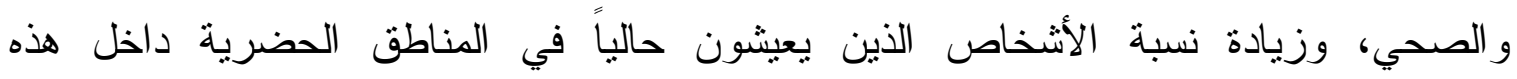
الجماعات. أما ما يعيب تحليلهما، فهو احتمال هجرة النساء اللاتي تبلغن من العمر بين 40 و 44 عاماً منذ زو اجهن الأول. وييين الثكل(3) العلاقة بين التغير في نسبة النساء المنزوجات اللاتي

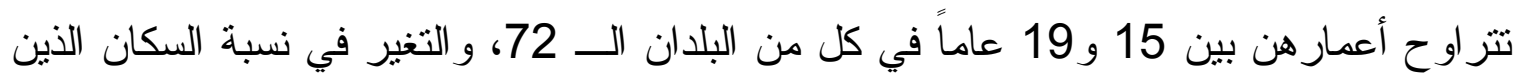

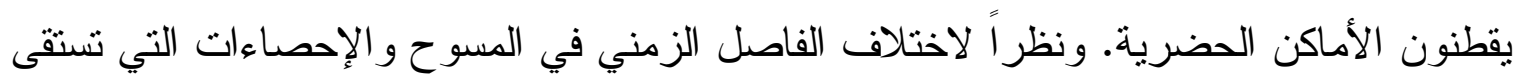

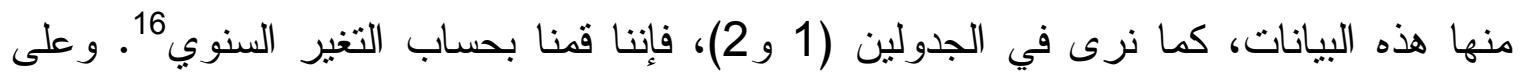

16 تحقيقاً لسهولة التفسير ، قمنا في الثكلين(3 و 5) بضرب التغيير السنوي في 10، وخرجنا بالتغير الهنوسط على مدار عثر

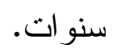


الرغم من عدم معرفتنا بنسبة السكان الذين يعيشون في المناطق الحضرية في التاريخ المحدد لكل

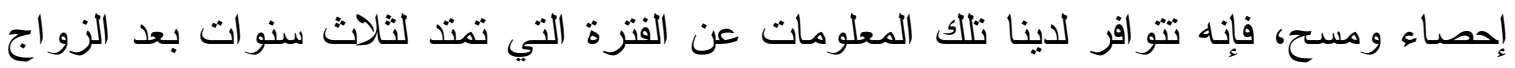

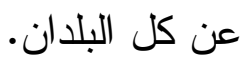

و المثير لبعض الدهشة هو أن الثكل (3) لا يبين وجود علاقة بين زيادة التحضر ونر اجع نسبة

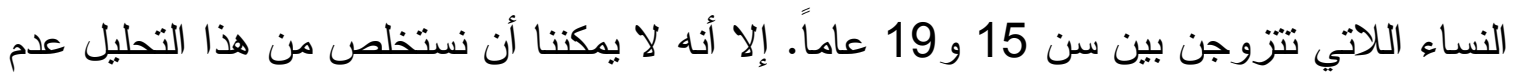

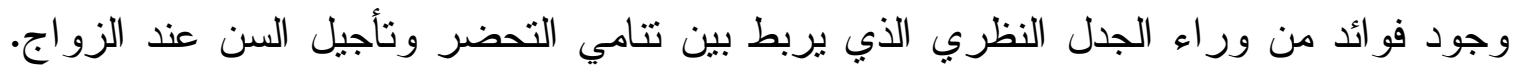

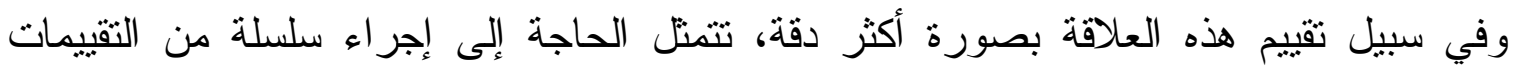

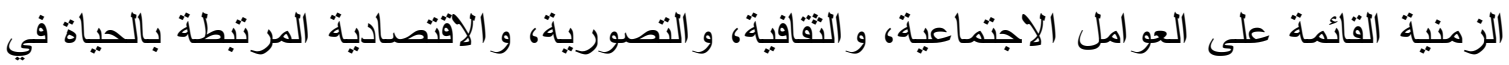
المدن، إضافةً إلى تدابير قياس شاملة للتحضر . لزئل

و على ضوء النتائج المقدمة أعلاه، تكون التغييرات في العو امل الأخرى بخلاف التعليم المدرسي

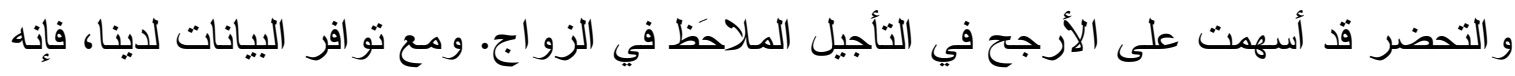

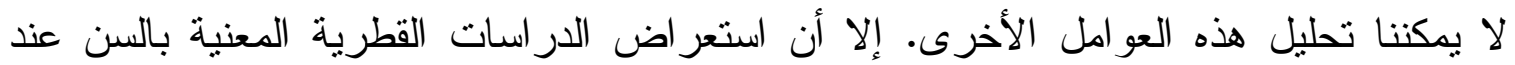

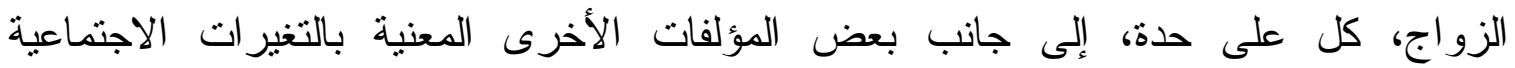

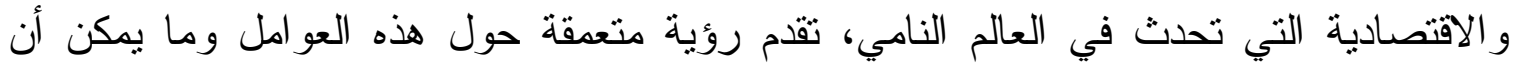
تكون. كما أنه يستبعد كذللك بعض العوامل التي كان من الممكن توقع وجود علاقة بينها وبين

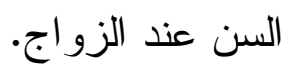

تراجع الزيجات المدبرة The decline in arranged marriages. أرجع كثيــر مـن الأخصائيين الديموغر افيين ممن درسوا نوقيت الزواج في آسيا زيادة أعمار النساء عند الــزواج

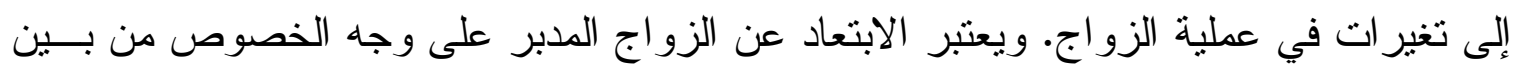

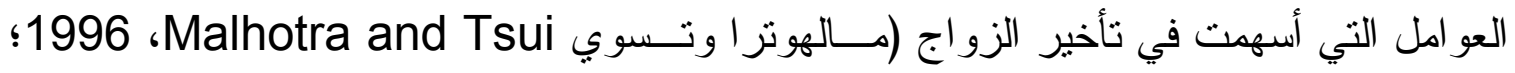

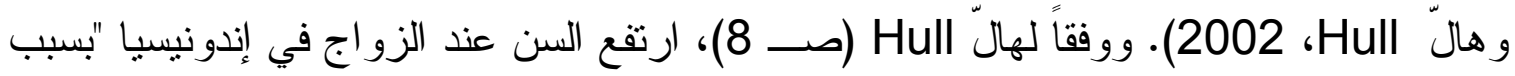

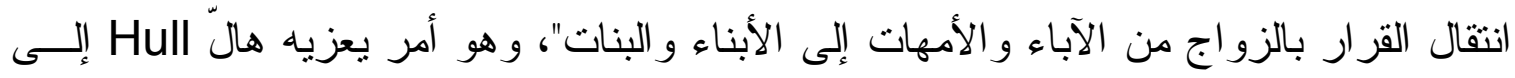

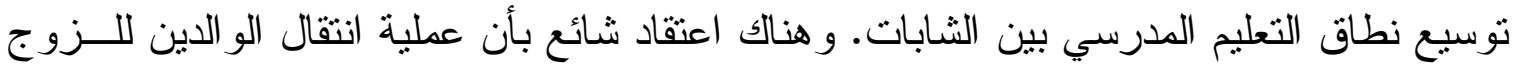
تستغرق وقتاً أقل من بحث الأبناء و البنات بأنفسهر وبصورة فئن فردية عن شريك. و وعلاوة على هذا، 


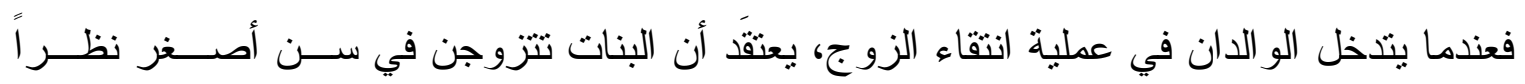

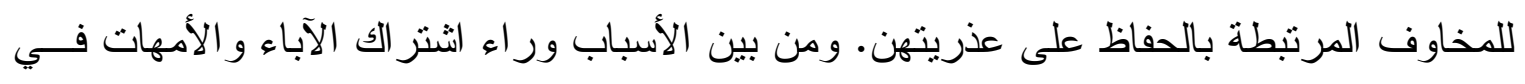

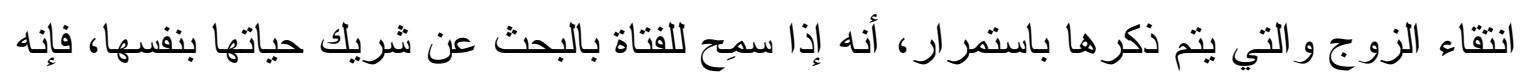

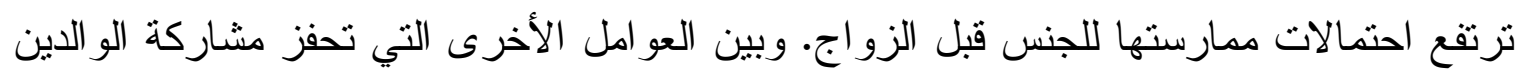

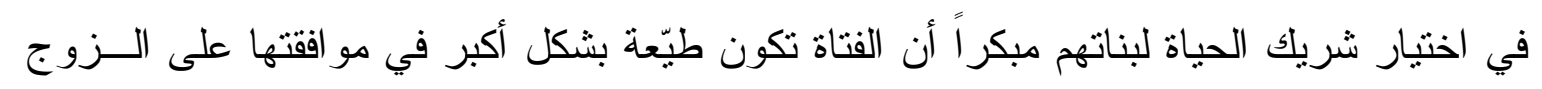

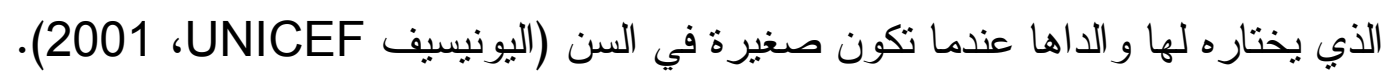

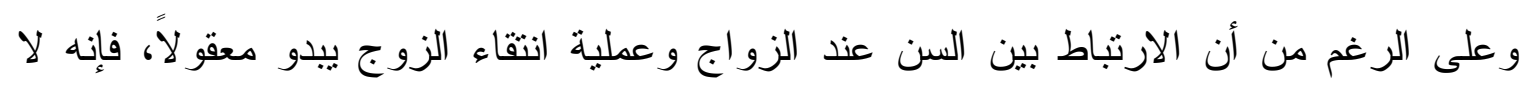

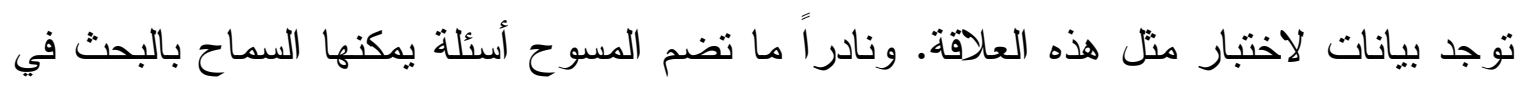

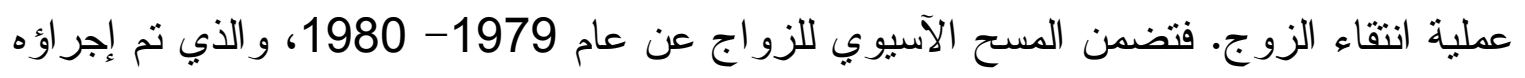

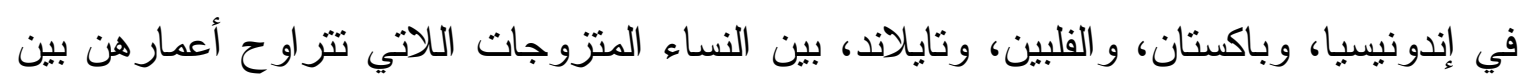

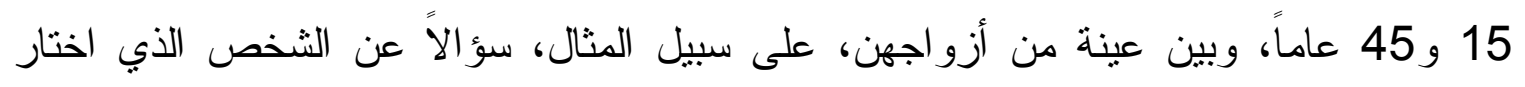

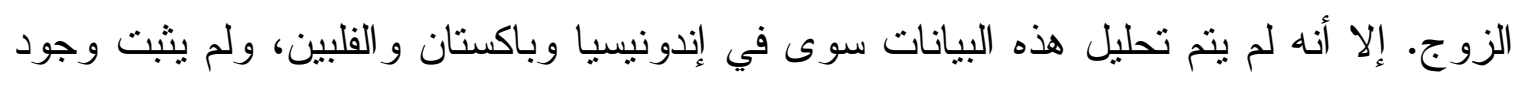
نسب ضخمة من الزيجات المدبرة -بأي شكل من أثنكالها- سوى في إندونيسيا وباكستان.

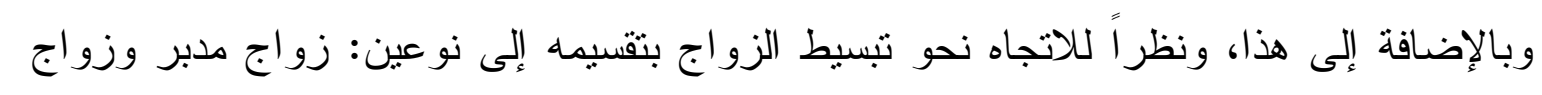

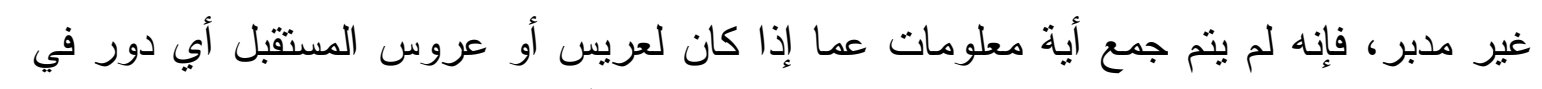

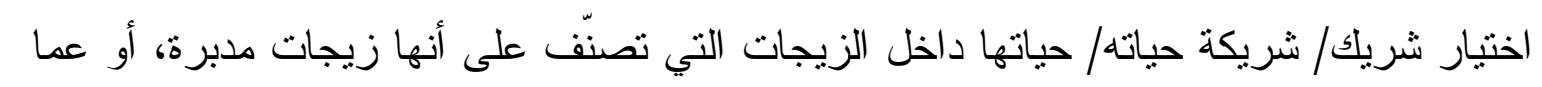

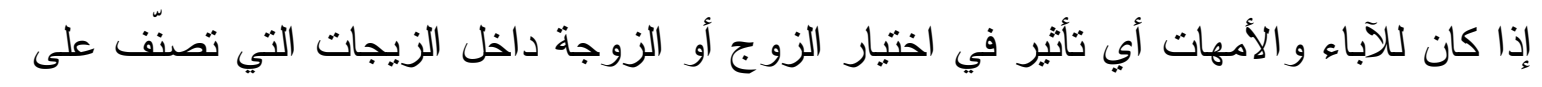

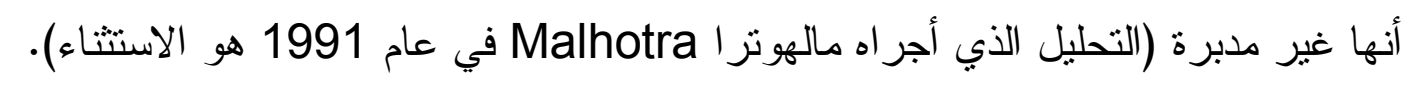

وتقيد البيانات المتاحة حول المشاركة النسبية للآباء و الأمهات و الثباب في اختيار أزواج المستقبل

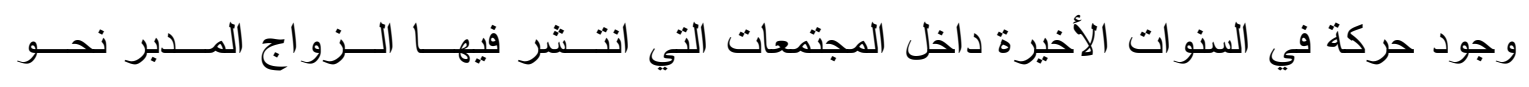

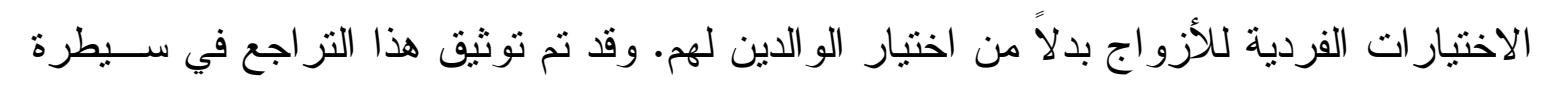

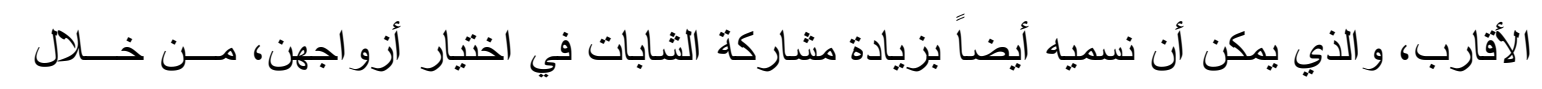

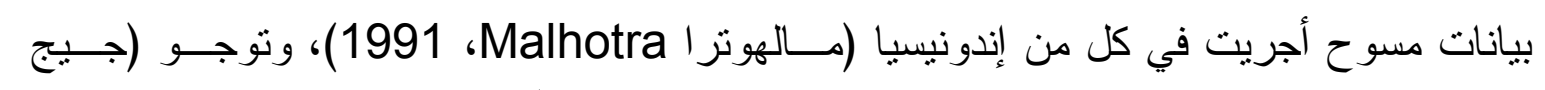

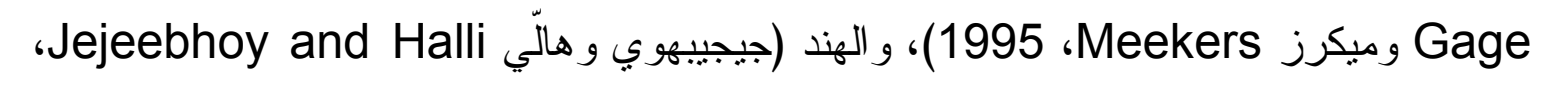

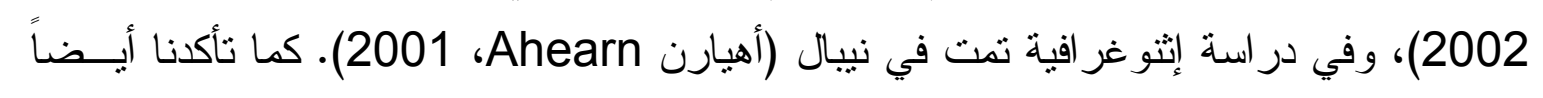


Lesthaeghe من حدوث ذلك في مختلف أنحاء منطقة جنوب الــصحر اء الأفريقيــة (لـــتاج

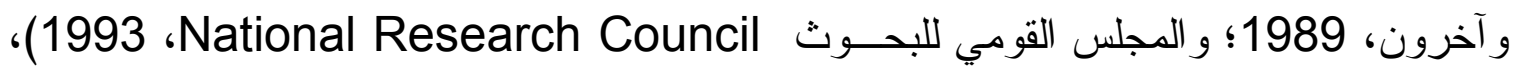
و آسيا (كوي Choe و آخرون، 2002). و على الرغم من قلة عدد الدراسات التي تقدم بيانـات

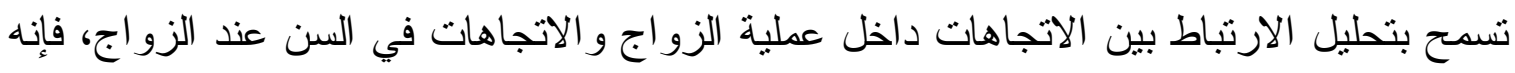
يحتمل وجود علاقة بين الاثتين 17.

The cost of marriage: dowry and تكلفة الــزواج: المهــر وأسـواق الــزواج . نادراً ما قام الباحثون المهتمون بسن المر أة عند الـزوراج بالبحـــ : marriage markets. فيما إذا كانت هناك علاقة بين وقت زواج النساء وظروفهن الاقتصادية أو الظروف الاقتـــــادية

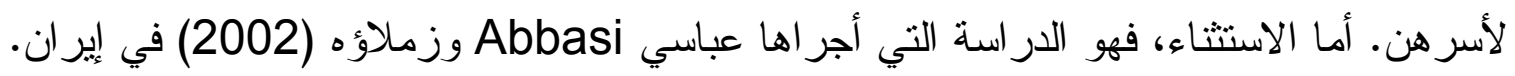

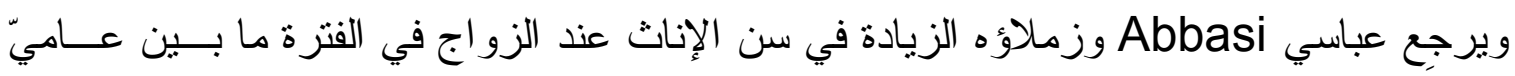

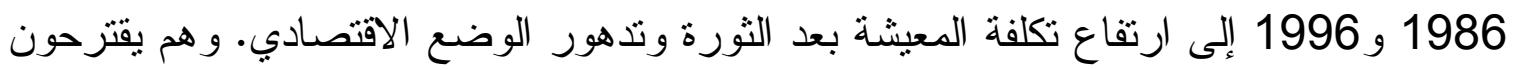

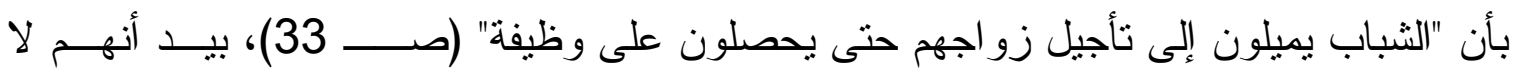

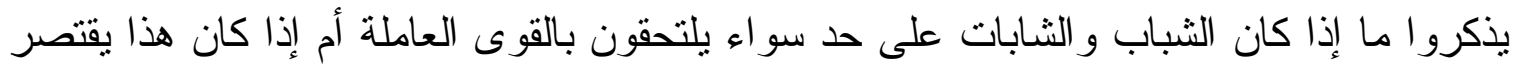
على الثباب الذكور دون سو اهم.

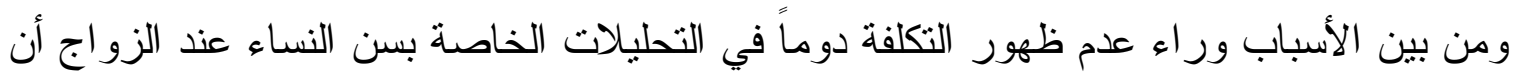
أسرة العريس تحمل العبء المادي الأكبر في الزواج في أغلب البلدان النامية. وبالنسبة للهدايا،

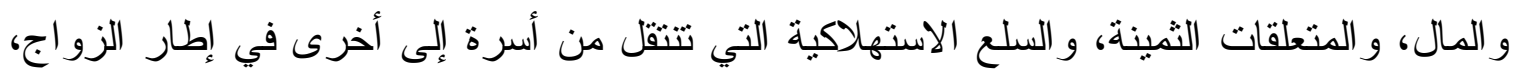

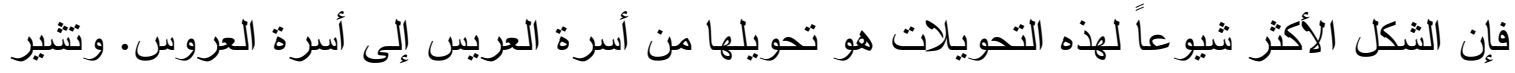

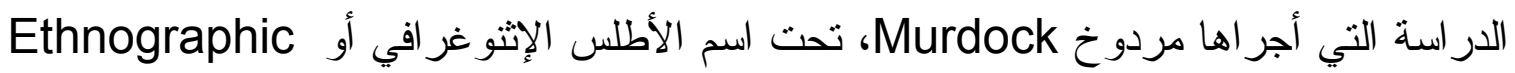
Atlas و التي نشيرت لأول مرة في أو اخر ستينات القرن الماضي وروجعت حوالي عام 1980،

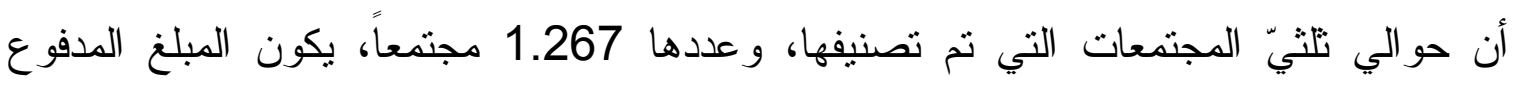
للعروس معيارياً، بينما تتنتر المهور في 7 بالمائة منها فقط، على الرغم من الارتفاع الكبير في لهاني

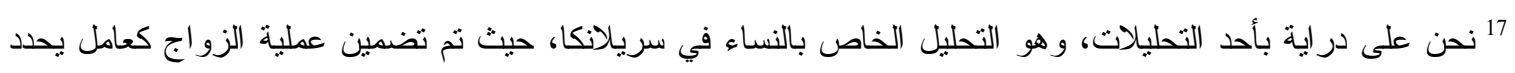

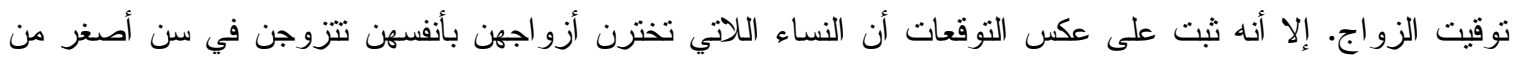

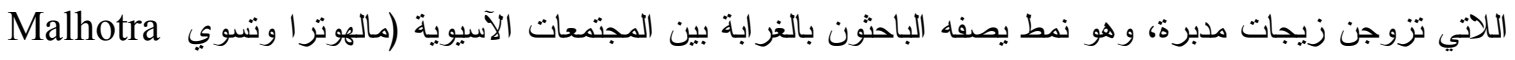
.). 1996 and Tsui 
تعداد شعوب جنوب آسيا التي تعتبر المهر من الطقوس الثائعة فيها (ورد في بات Bhat وهالّي (1999 ، Halli

اقتصرث البحوث التي اختبرث العلاقات بين سن النساء عند الزواج وتكلفة الزواج على الهند

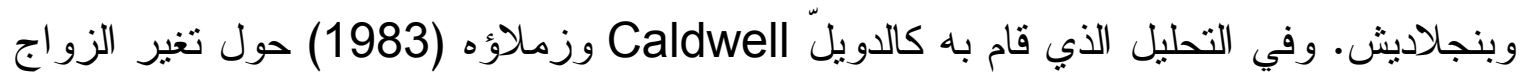

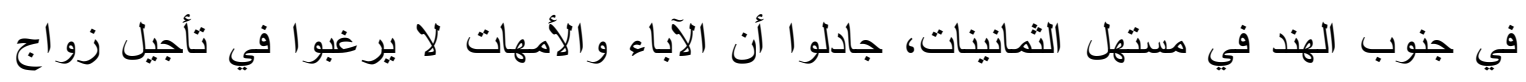

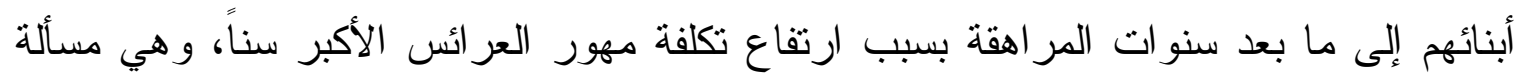

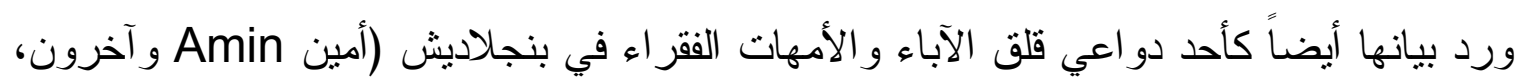

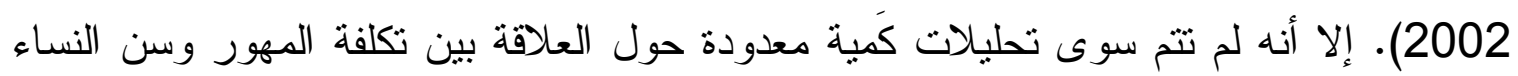

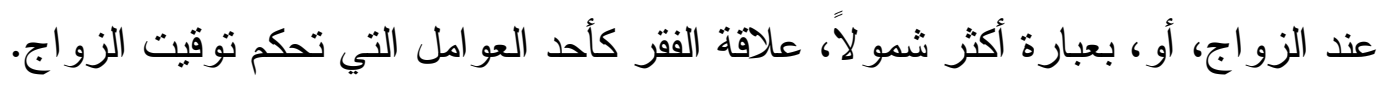

غير أن كثير من البحوث تركز على تقديم أسباب وراء زيادة معدلات انتثار المهور وقيمتها

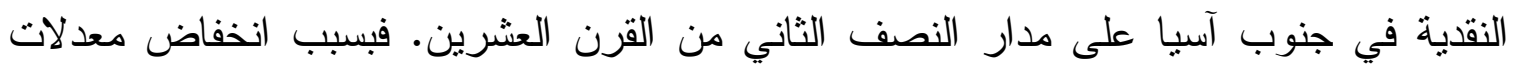

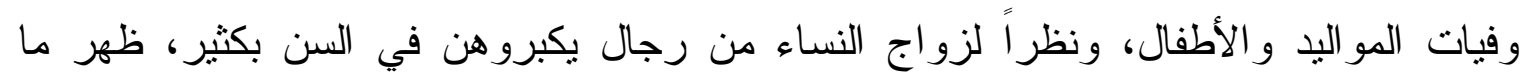

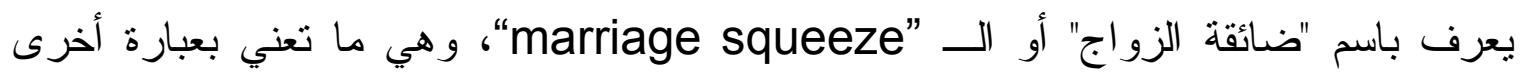

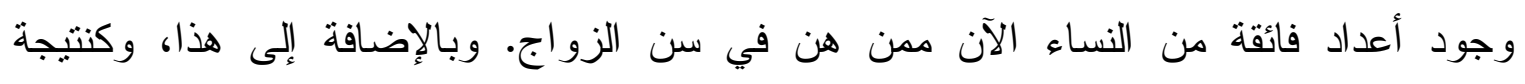

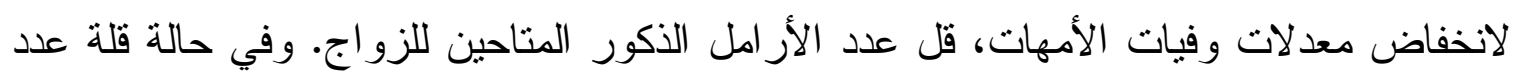

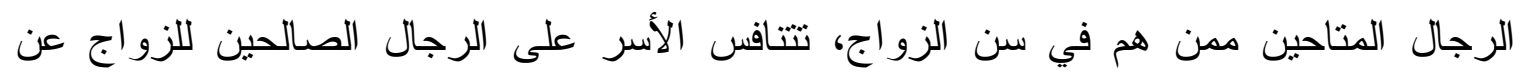

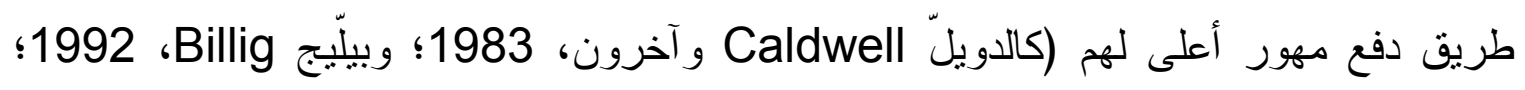

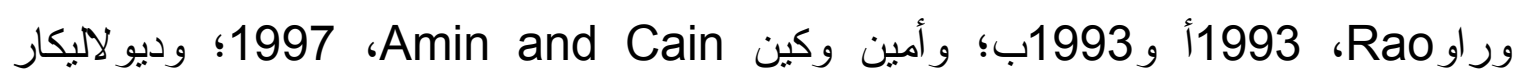
Deolalikar (1999)Bhat and Halli

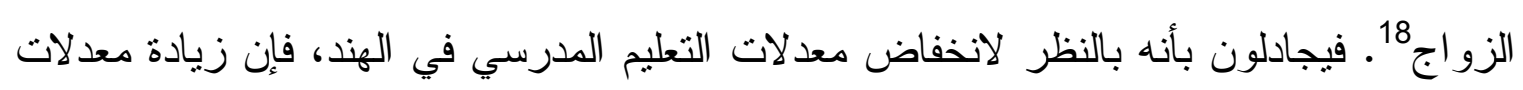

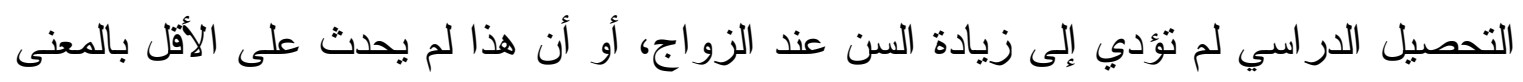

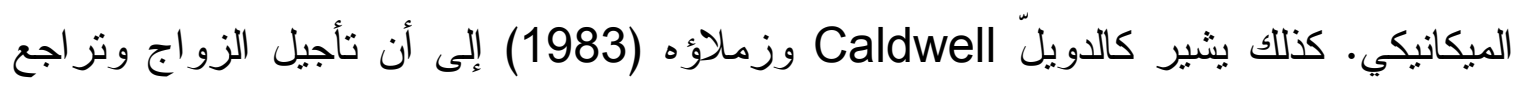

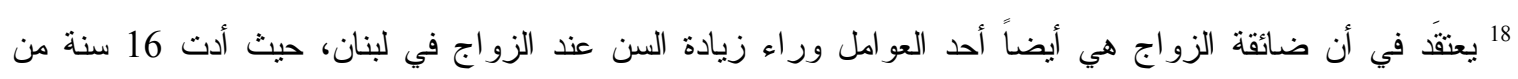

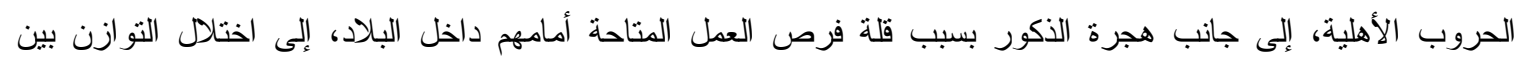

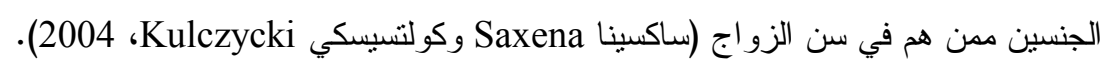


الفوارق العمرية بين الأزواج في جنوب الهند جاءت كنتيجة لضائقة الزواج سابقة الذكر. وهم

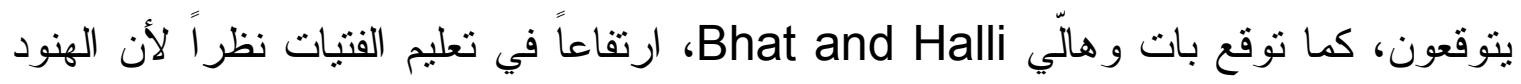

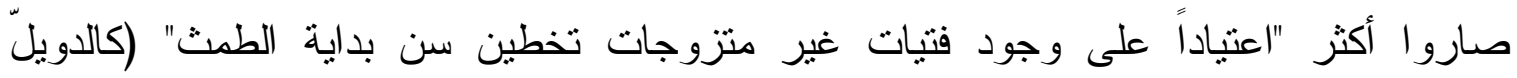
Caldwell

ونظر ألوجود علاقة بين ارتفاع السن عند الزواج بين النساء وزيادة معدلات التعليم المدرسي

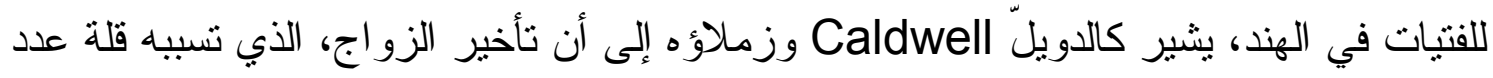

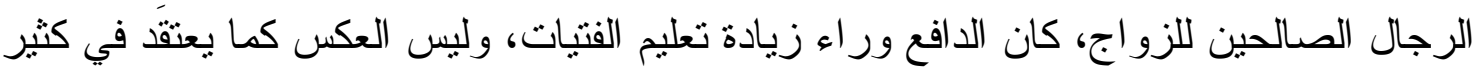

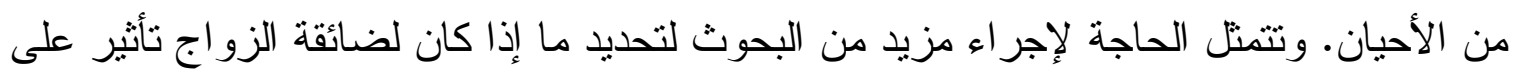
السن عند الزو اج، و الاختلافات العمرية بين الأزو اج، و المطالب الخاصة بالمهور ، و التحصيل

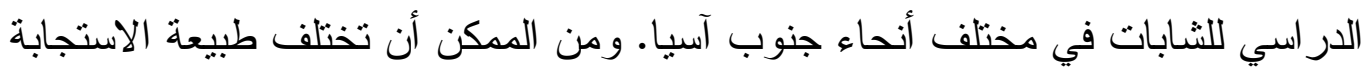

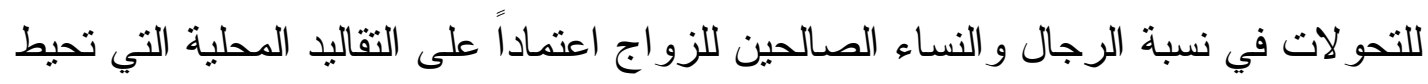

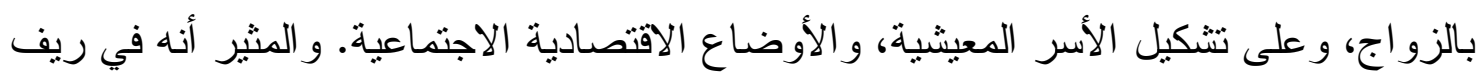

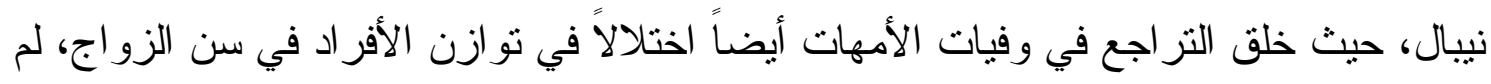
يظهر المهر حتى الآن كممارسة شائعة، على الرغم من "انتشاره على نحو نحو متتامي في إقليم

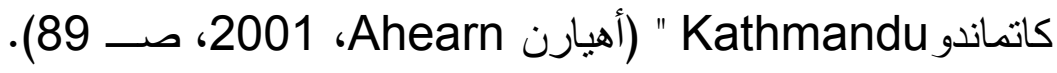

تغير القوانين، وتغير الأعراف Changing laws, changing norms. على حد علمنا،

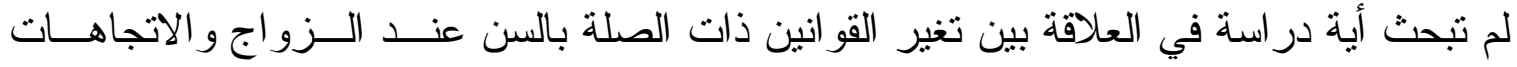
الخاصة بالسن عند الزواج عبر البلدان. فعادة ما يتم إعمال القو انين بصورة غير دير دنسقة دئ، ويمكنها

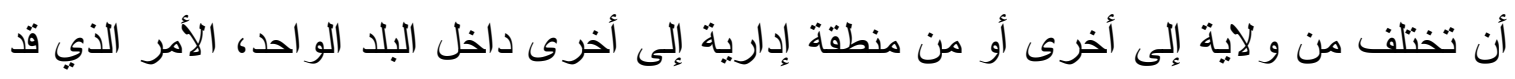

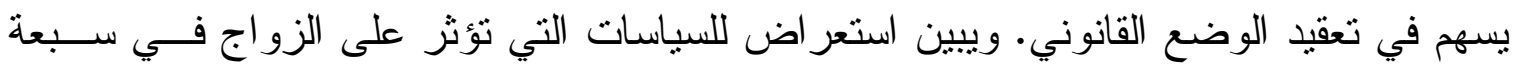

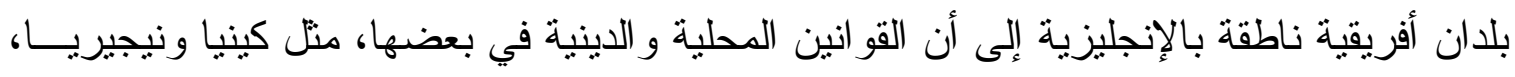

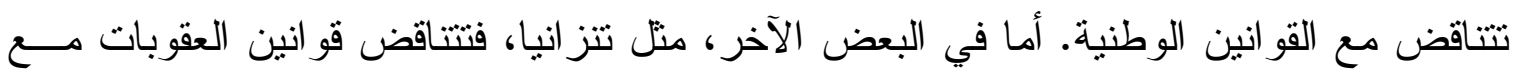

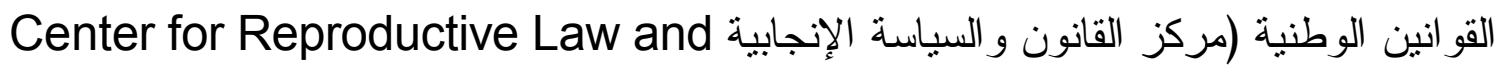
Policy

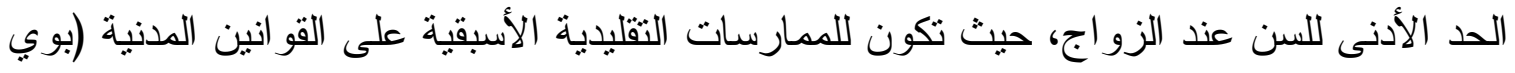


Boye و آخرون، 1991). وييدو أن البيانات الخاصة بالسن عند الزواج تدعم وجهة النظر هذه.

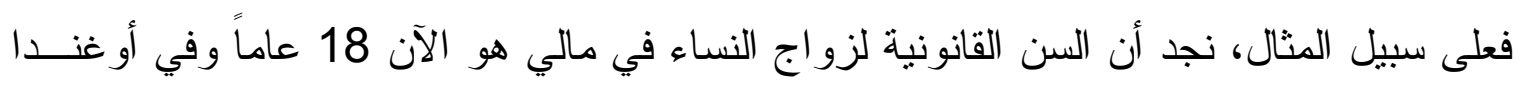

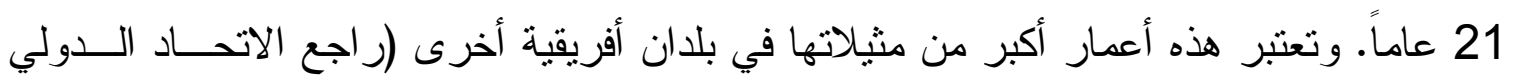

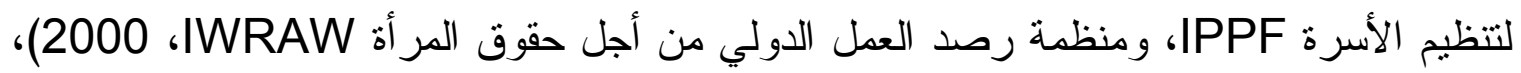

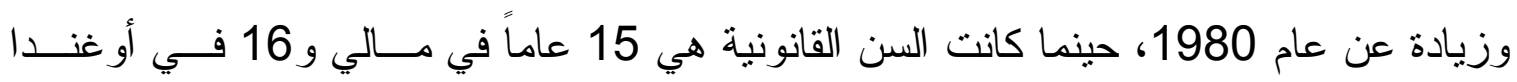
(المجلس القومي للبحوث وزئ عational Research Council،

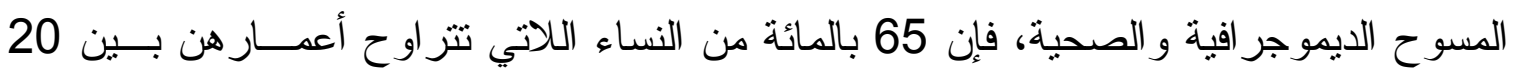

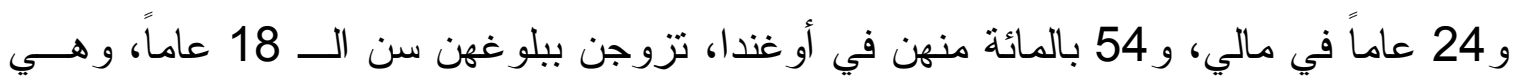

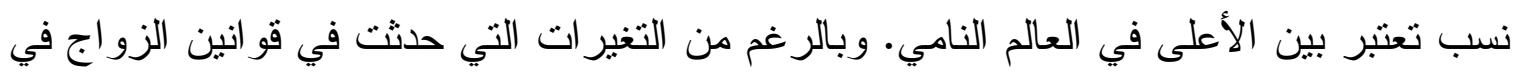
هذين البلدين، تكثثف المقارنة بين نسب المتزوجين ببلوغ سن الـــ 18 في الفئة العمرية بين 24

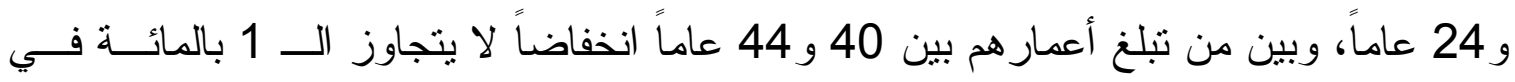

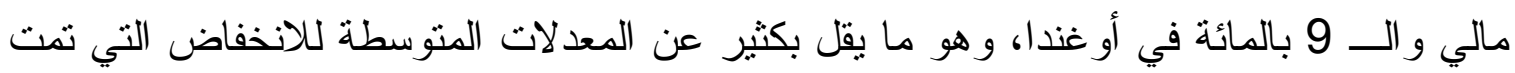

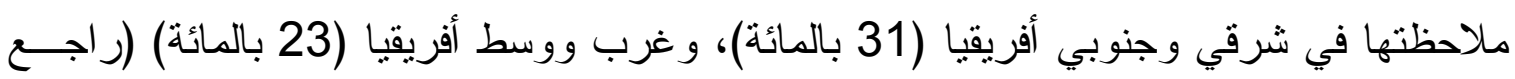

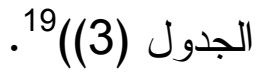

توجد بلدان بها قو انين تحظر الزواج المبكر في بداية سنوات المر اهقة، حيث لا تز ال توجد نسب

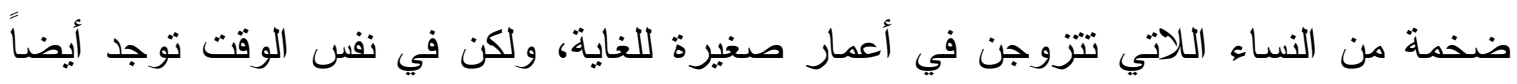

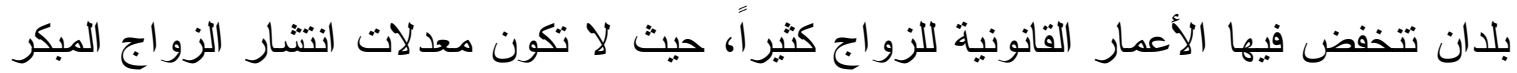

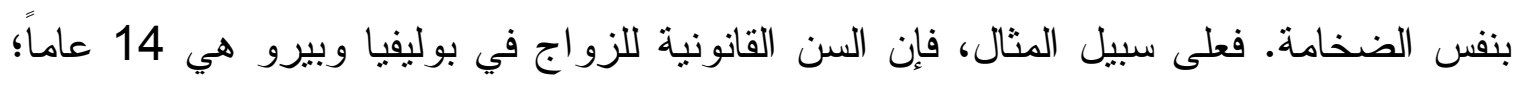

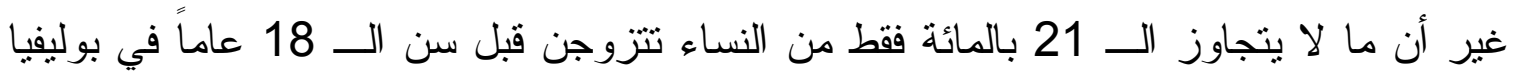

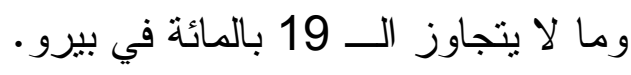

وفي بعض البلدان، تكون السن الفعلية التي تتزوج فيها كثير من النساء أقل من السن القانونية (اليونيسيف UNICEF، 2001). وفي حالة بنجلاديش، يتكهن البعض بأن الارتفاع في السن

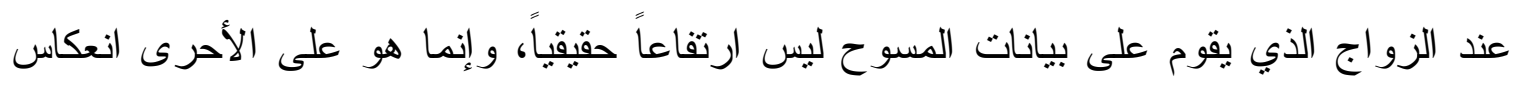

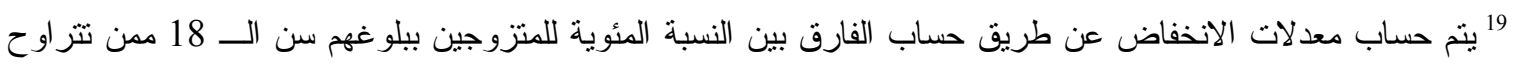

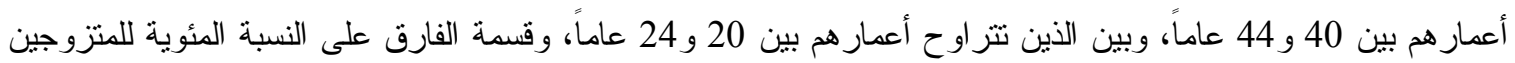

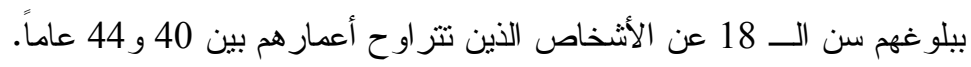


لزيادة السن عند الزواج المبلغ عنها بين مبحوثات مسح النانئات الإناث اللاتي تعرفن بزيادة الحد

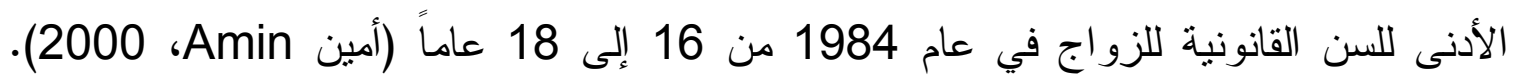

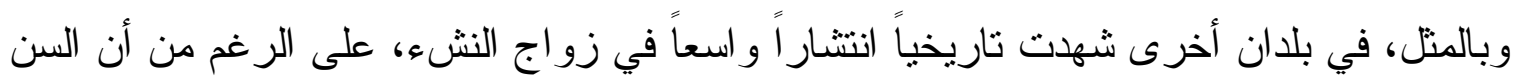

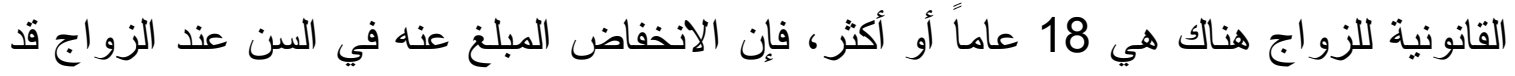
يعزى إلى خطأ في التقارير نتيجة للخوف من أن تتم مقاضاة الأسر بسبب تزويجها لبناتها في

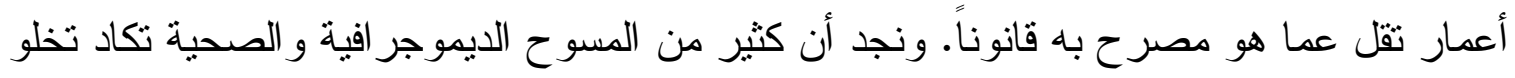

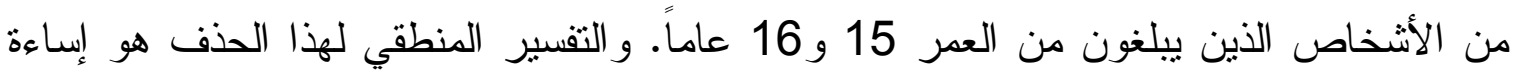

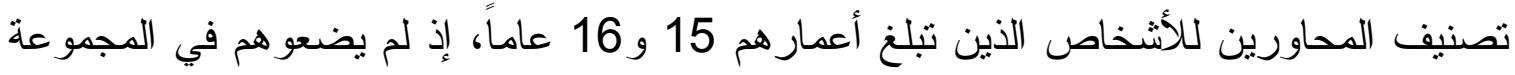

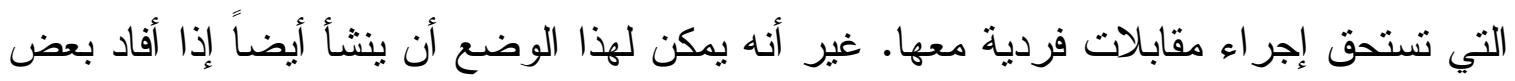
الأشخاص الذين يبلغون من العمر 15- 16 عاماً أن سنهم 17 أو 18 عاماً.

و الجدير بالذكر أنه ثبت عدم فاعلية الجهد المبذول لوضع تشريعات تحكم السن عند الزواج، ليس

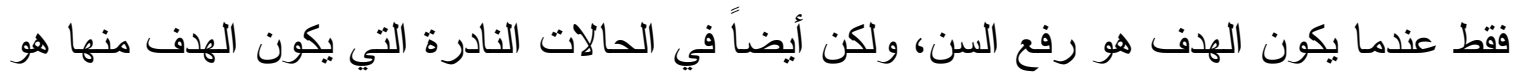

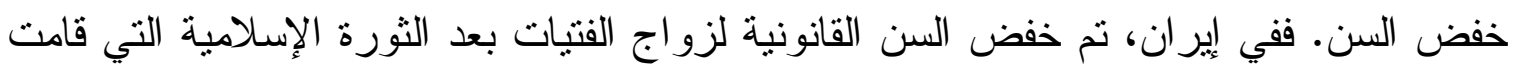

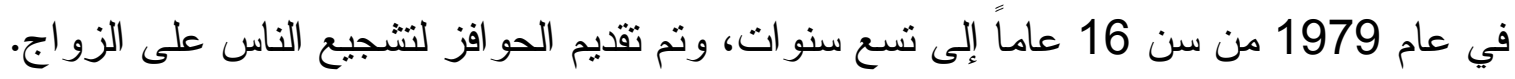

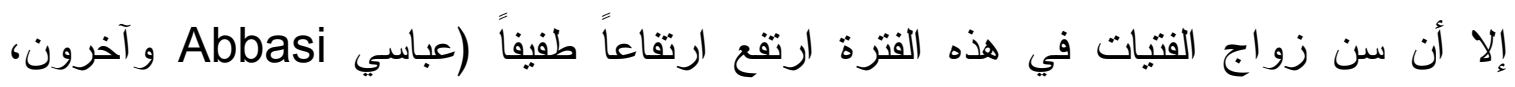
.2002

وفي السنوات الأخيرة، أدخلت كثير من البلدان النامية تعديلات في قو انينها الخاصة بالسن عنــــ

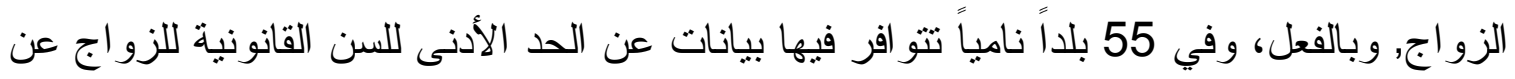

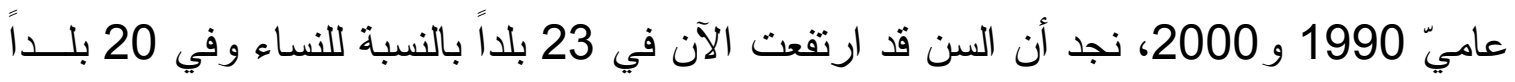

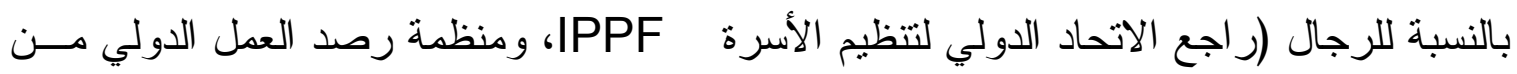

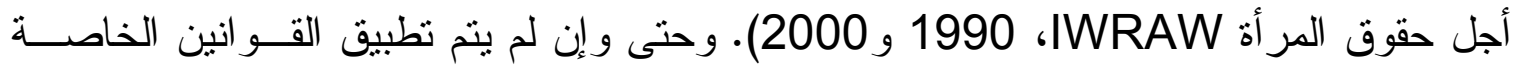

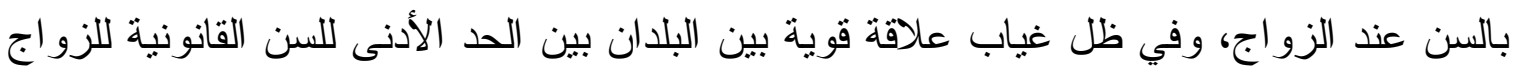
ونسبة السكان الذين يتزوجون في سن مبكرة، فإن تغيير السن القانونية للزوواج قد ينم عن تغييــر

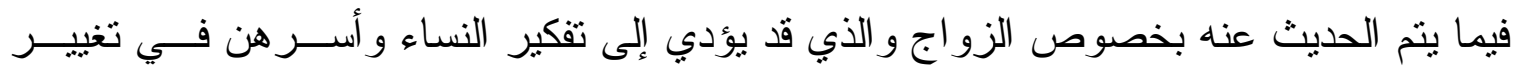


سلوكهم 20. وحقيقة أنه تم تعديل القو انين في عدد كبير من البلدان ينم عن زيادة المناقتنات التـي

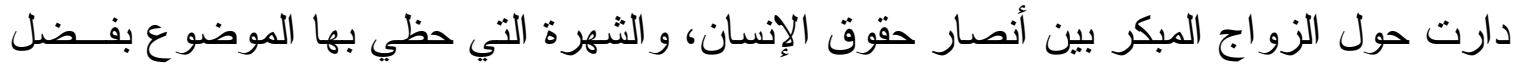

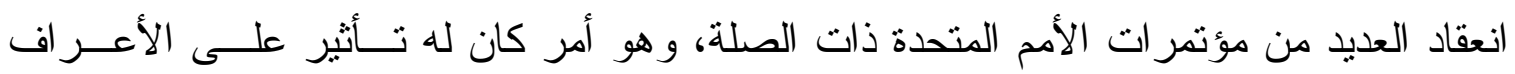

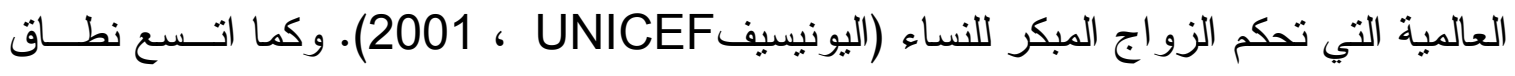

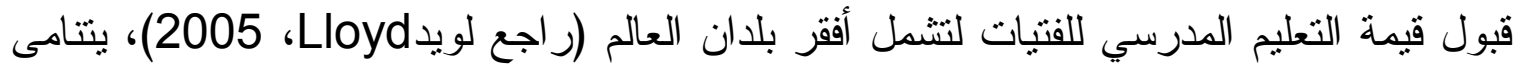

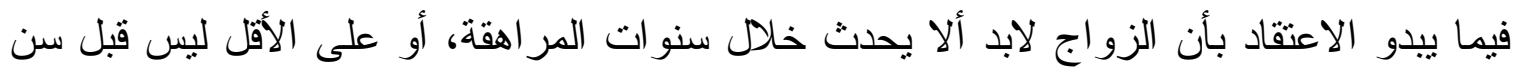

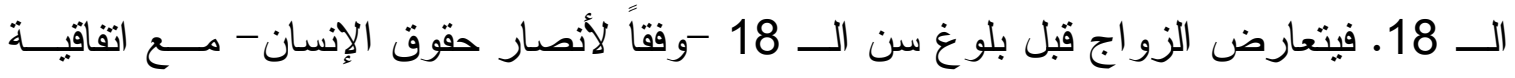

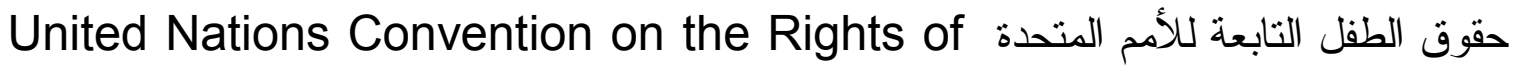

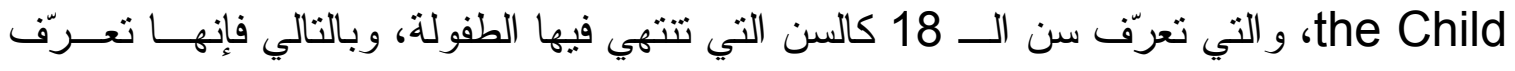

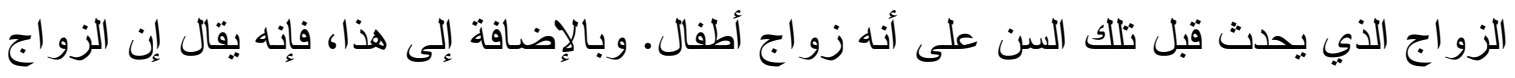

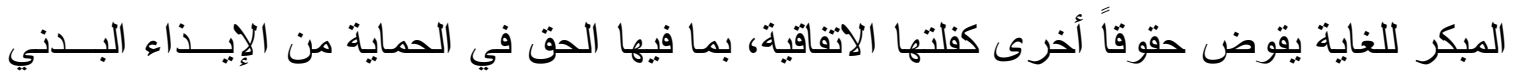

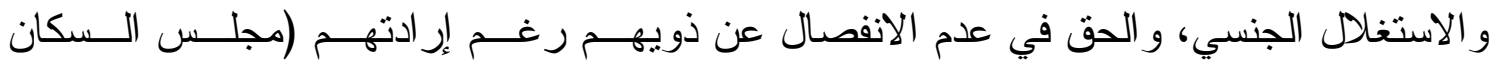
.(2002، Population Council

و عند وضع نظريات حول ارتفاع سن الزواج الأول بين النساء في أفريقيا، يجادل هرتريش Hertrich بالوضع الاجتماعي للنساء بخلاف وضع الزوجة و الأم"، على الرغم من عدم تقديم المؤلف لبيانات الاهن

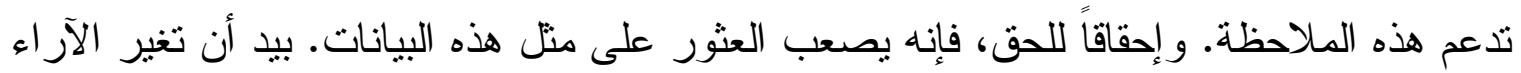

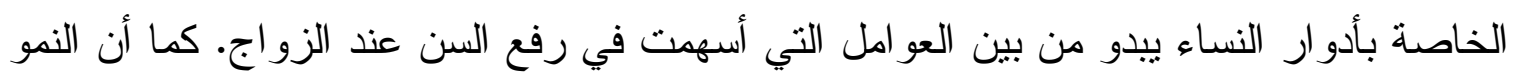
في الحركات النسائية، وما يصاحبها من حملات إعلامية تعززها العولمة -تظهر فيها النساء

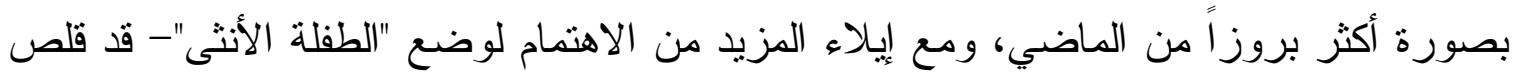
على الأرجح من الأعر اف التقليدية.

كذلك يجوز أن تكون بعض التغير ات الاجتماعية و الديموجر افية الأخرى قد أثزت على الاتجاهات

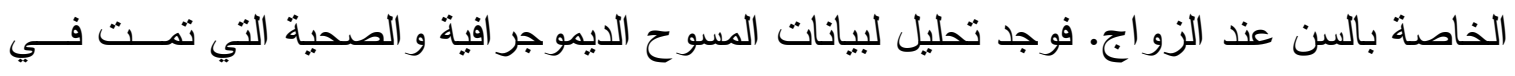

20 يمكن للزيادة في السن القانونية للزواج في بعض البلدان أن تعكس بالطبع الظروف السائدة. في تلك الحالة، نجد أن القانون يجاري التغير الحادث في السلوك. للك. 
21 من بلدان منطقة جنوب الصحر اء الأفريقية أن التحسن الذي طر أ على معدلات بقاء الأطفال

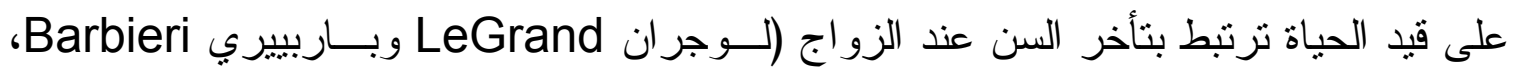

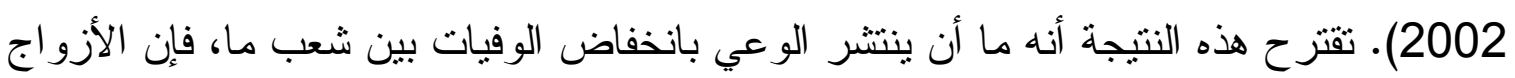

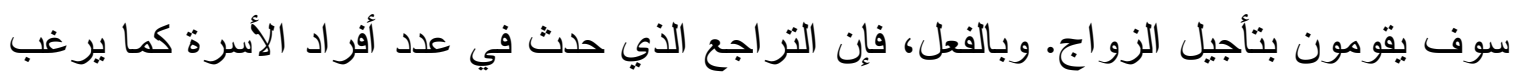

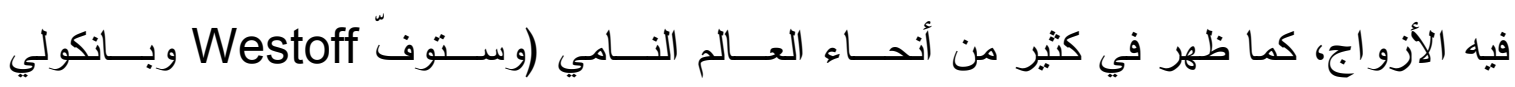
هankole

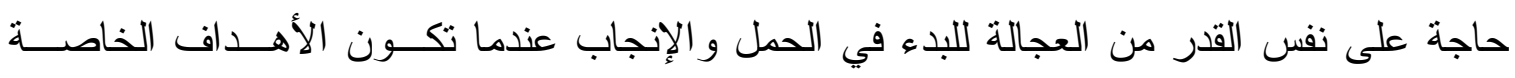

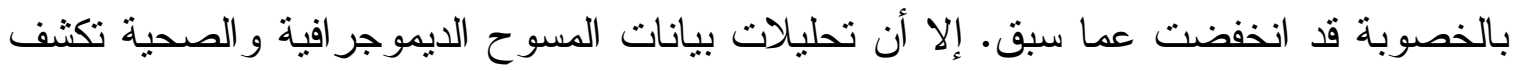

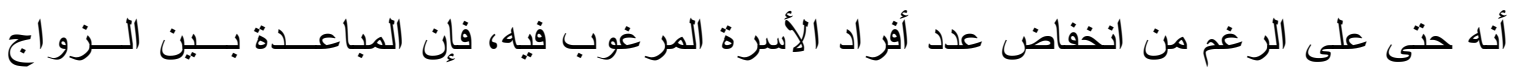

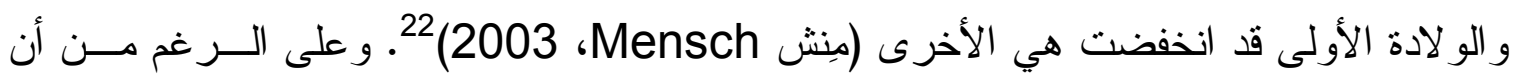

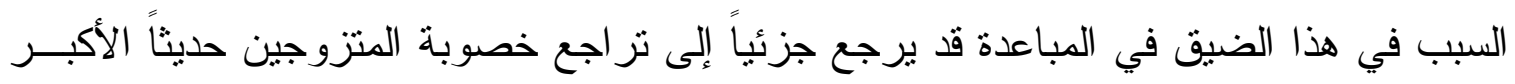

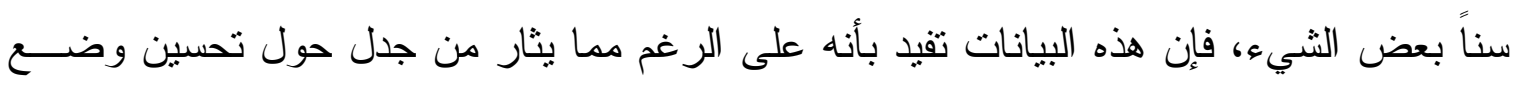

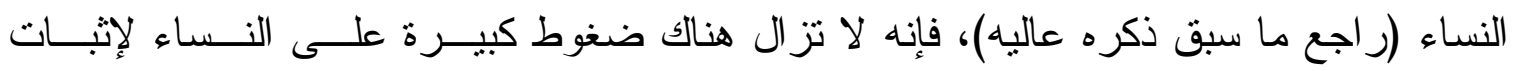

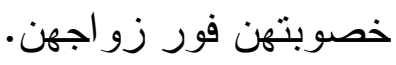

تفسير الاتجاهات بين الرجال

إذا كان الارتفاع في التحصيل الدراسي للنساء يهيمن على المناقنشات الخاصة بارتفاع سنهن عند

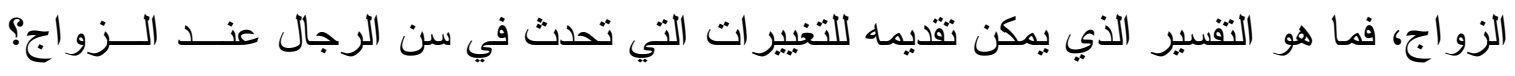

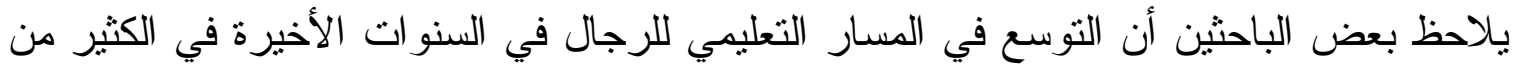

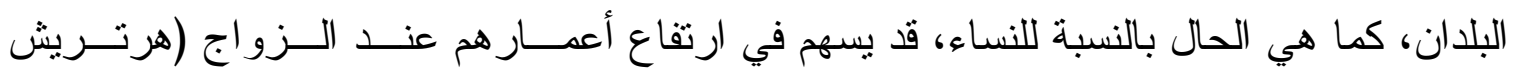
Hertrich

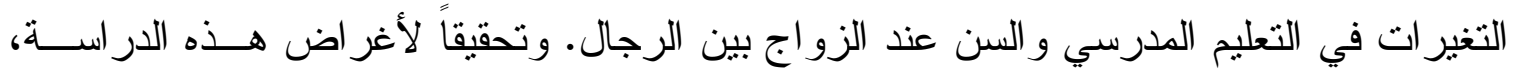

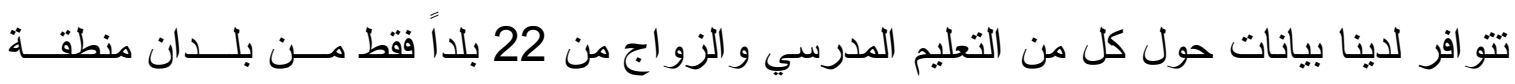
جنوب الصحر اء الأفريقية، وستة من بلدان أمريكا اللاتينية و الكاريبي، وبلدين من آسيا السوفيينية

21 غرب أفريقيا الناطقة بالفرنسية هي الاستثاء: فبخلاف توجو ، لم يحدث تغير كبير في الأفضليات الإنجابية بهذه الهنطقة

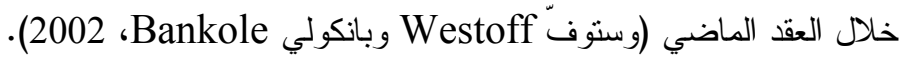
22 ظهر هذا الانخفاض بين النساء اللاتي صرن حوامل وأنجبن بعد الزواج، الأمر الذي يفيد بعدم رجوع هذا إلى زيادة

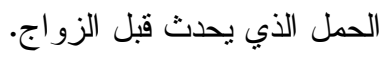


السابقة، وبلد شرق أوسطي واحد، جرت فيها مسوح ديموجر افية وصحية بين الرجال23. ويرسم

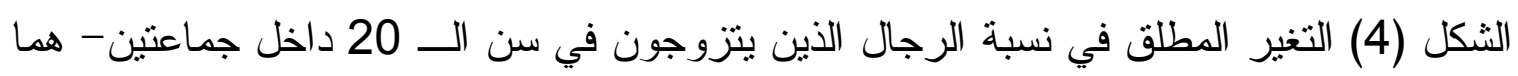

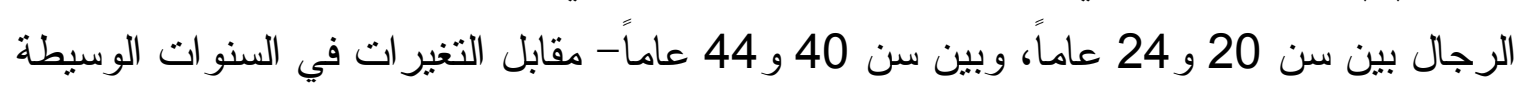

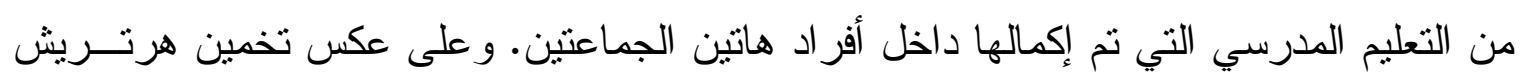
Hertrich

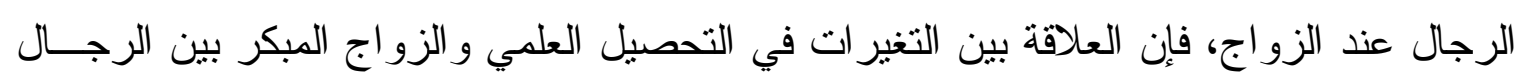
في هذه البلدان لا يكون هاماً.

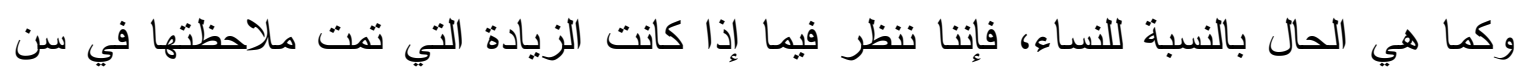

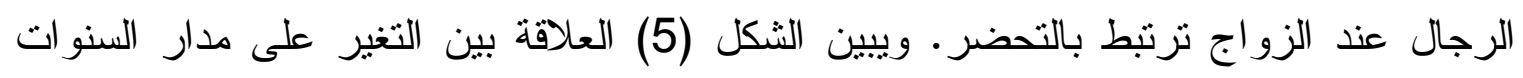

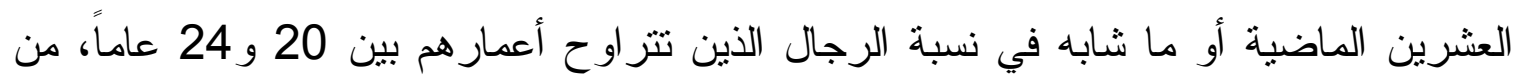

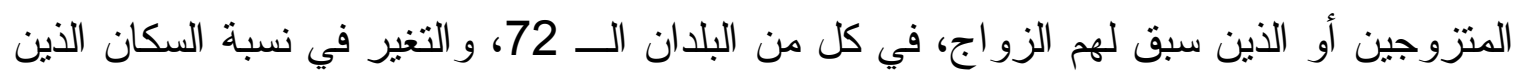

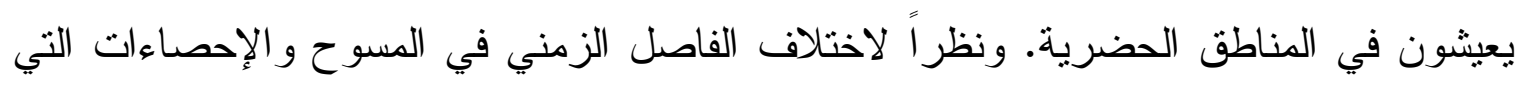
تستمد منها هذه البيانات، كما هي الحال في الثكل(3)، فئن فإننا قمنا بحساب التغير السنوي مضروباً

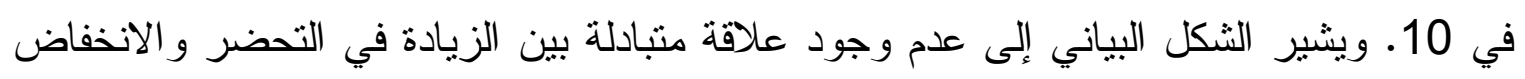
في نسبة السكان الذكور المتزوجين و الذين تتر اوح أعمار هم بين 20 و 24 عاماً.

و عادة ما تتم الإثشارة إلى البيئة الاقتصادية في البلدان النامية على أنها الـسبب الرئيسسي وراء

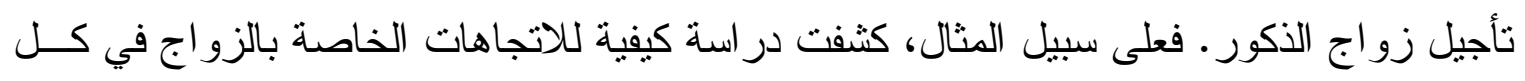

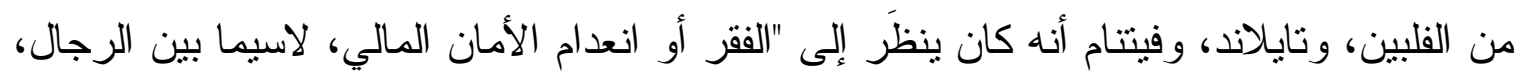

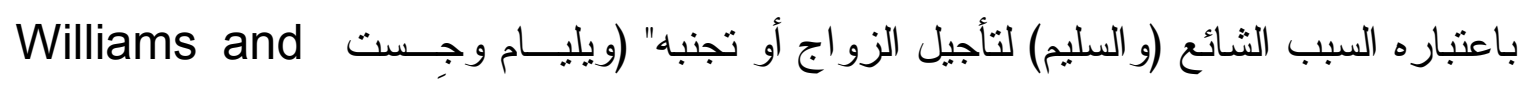
Guest

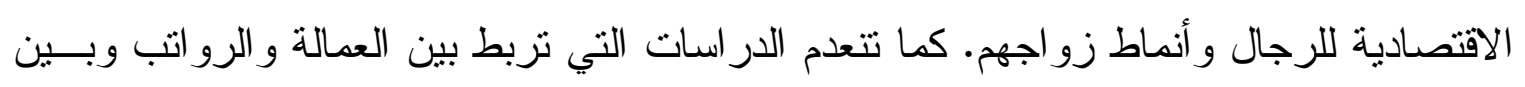

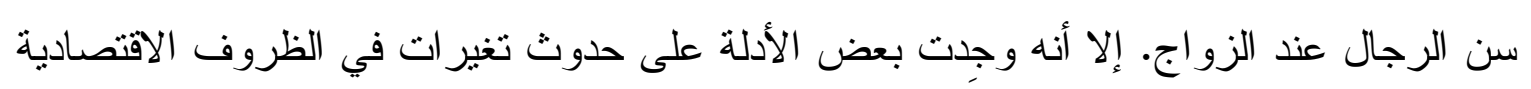

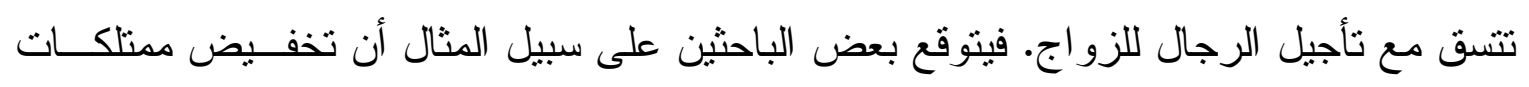

23 لا نتو افر بيانات حول الصفوف الدراسية التي ثم إكمالها بالنسبة للجابون، على الرغم من توافر بيانات حول الزواج.

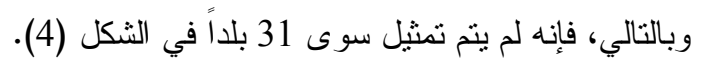


الأر اضي في ريف آسيا قد يكون من بين العو امل التي أسهمت في تأخير الزواج. فقد أجبر التزايد

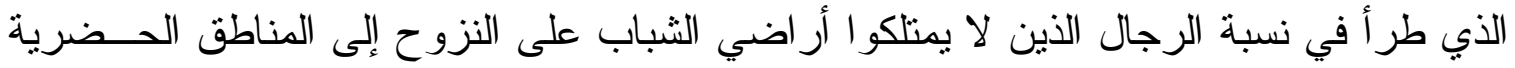

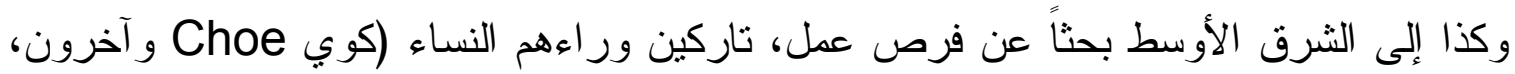

2002

أما في المجتمعات الأفريقية، فيقال إن التغير الذي حدث في طبيعة ثروة العروس، حبـــث حلـــ

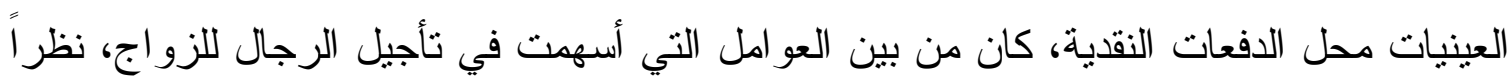

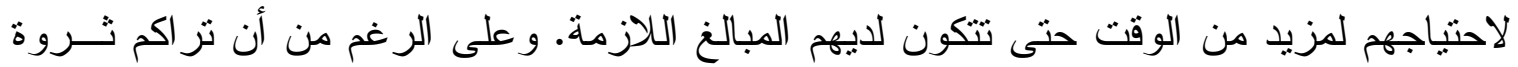

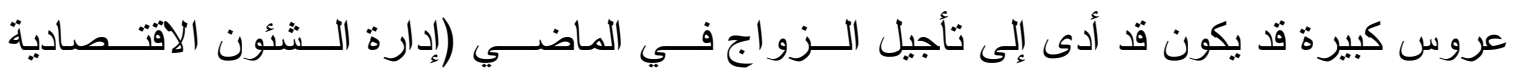

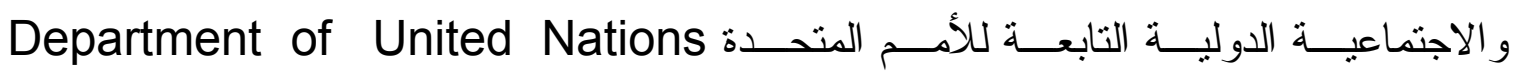
International Economic and Social Affairs

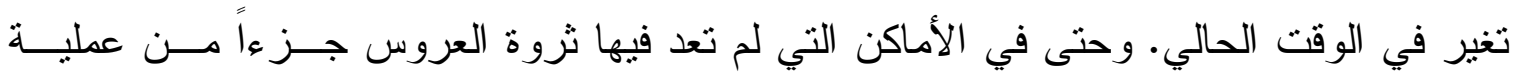

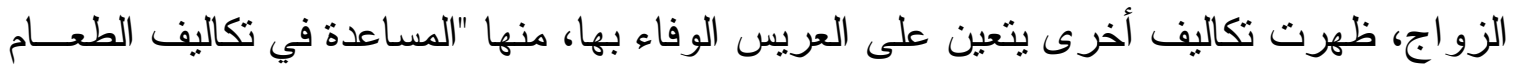

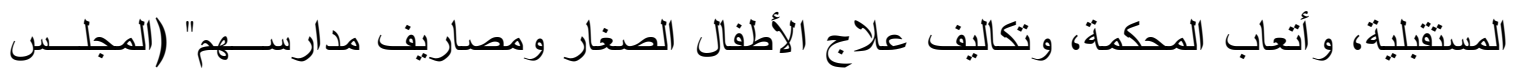

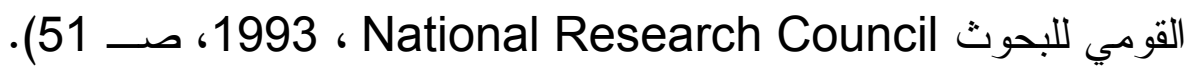

و الأهم من هذا هو التحول الذي يقال بأنه حدث في طبيعة اقتصاد الأسر المعيشية في كثير من

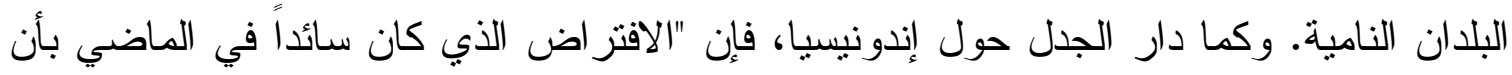

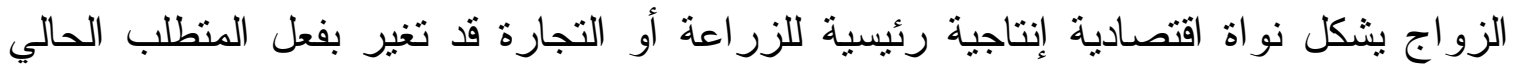

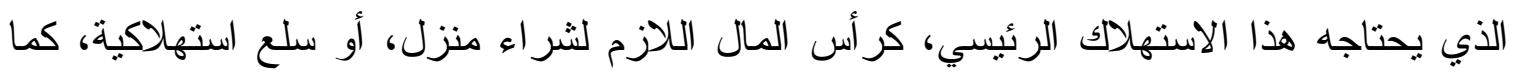

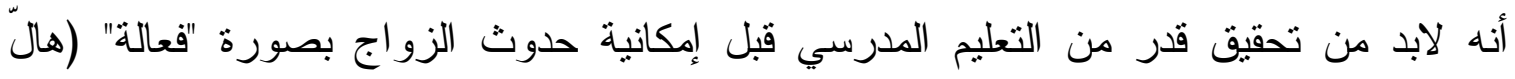
. Hull

وفي بلدان منل نيجيريا وسريلانكا، لاحظ الباحثون أن الاعتبار ات الاقتصادية اليوم صارت فيما

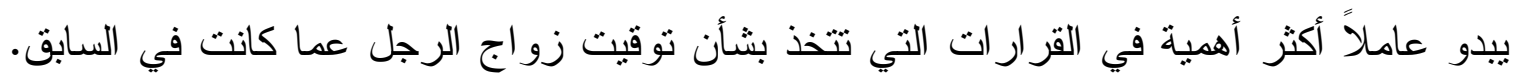

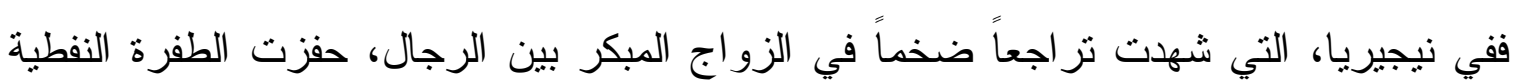

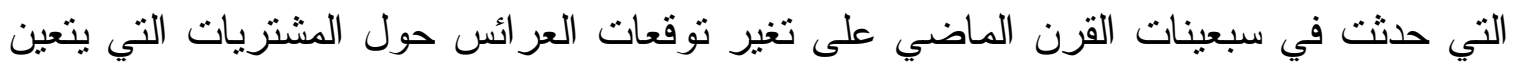


National Research لعى العرسان القيام بها قبل إتمام الزواج (المجلس القومي للبحوث Council الذي تحدده وظيفته الآن، و الذي لم تكن له أهمية كبيرة في الماضي -خاصةً في الأماكن التي لئي

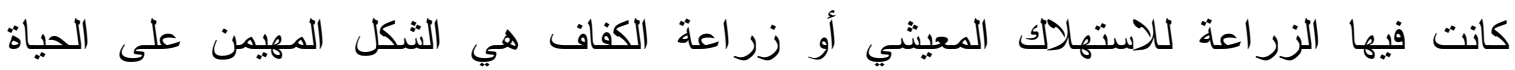

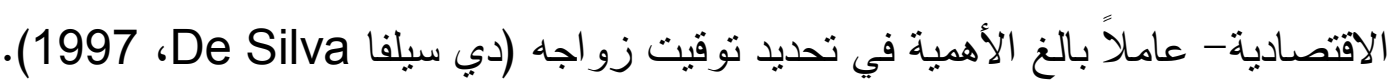

وفي مصر ، حيث يعتبر المسكن، والأثاث، والأجهزة أمور أ أساسية بالنسبة لحديثي الزو اج، وحيث

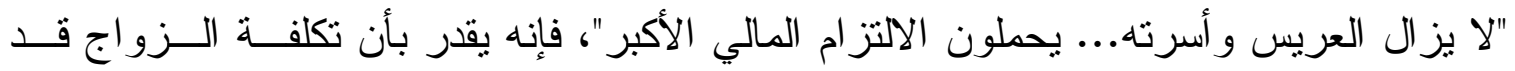

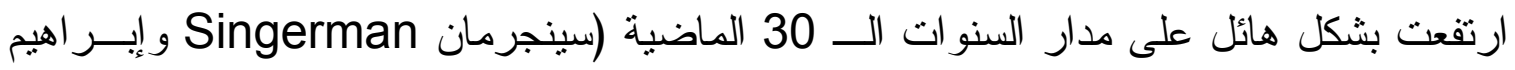
Ibrahim

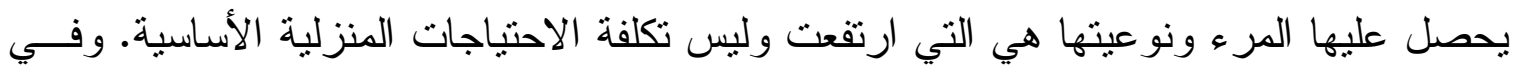

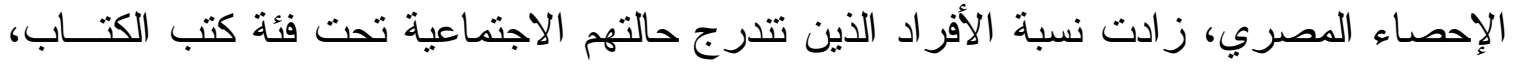

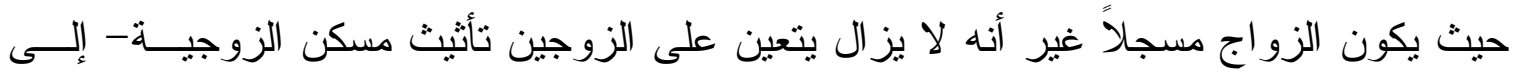

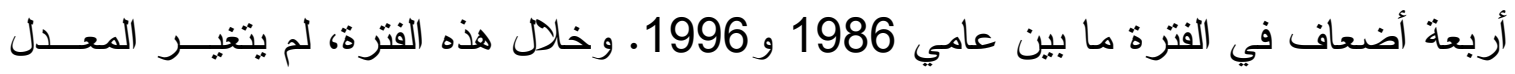

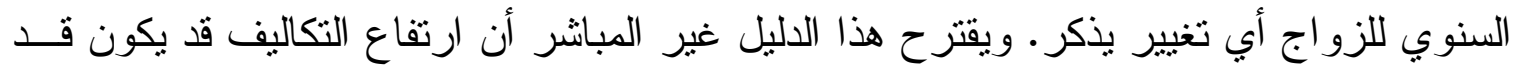

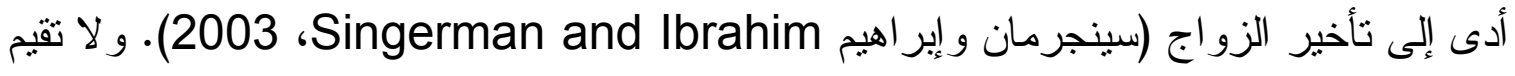

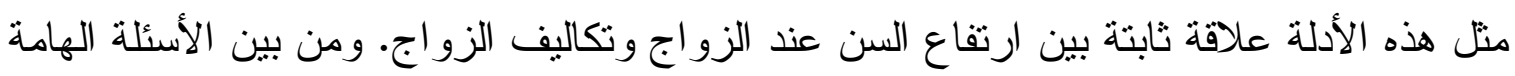

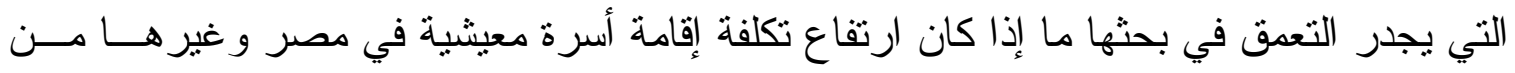

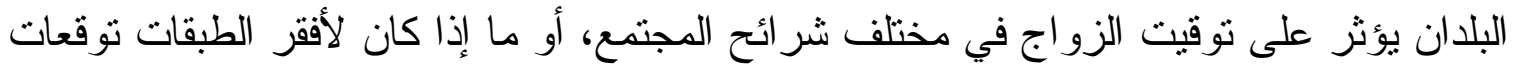

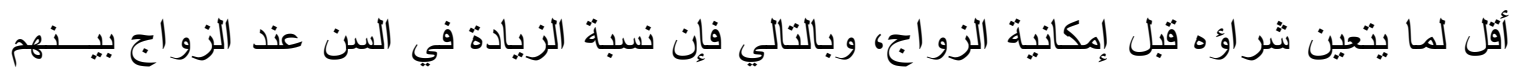
كانت أقل.

فإذا ما انتقلنا إلى النساء، فإننا نتعجب أيضاً مما إذا كانت بعض التغيرات العالمية قد طرأت وتتؤثر على توقيت الزو اج بين الرجال. وربما يكون للانفتاح المتز ايد على الإعلام الغربي تأثثر

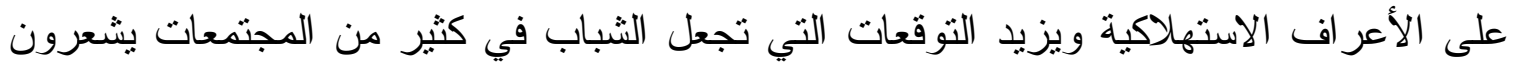

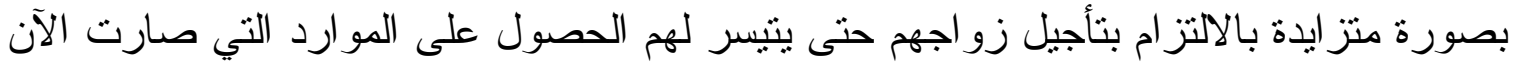

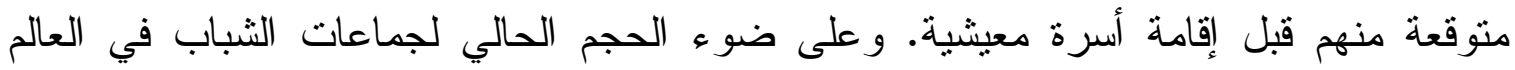


النامي وصعوبة ضمان العثور على فرص عمل ملائمة لمنل هذه الأعداد الضخمة، فإن تأجيل

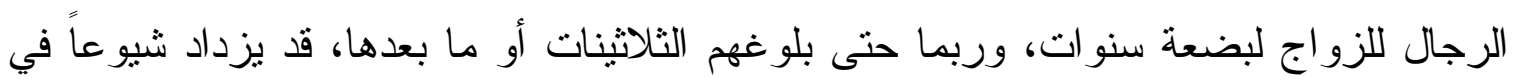

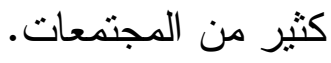

\section{تبعات ارتفاع السن عند الزواج}

على الرغم من توثيقنا وتفسيرنا للاتجاهات الخاصة بالسن عند الزو اجه، فإنتا لم نقم باختبار تأثير

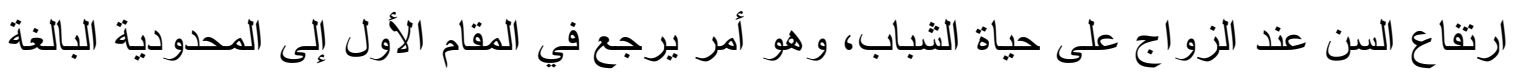

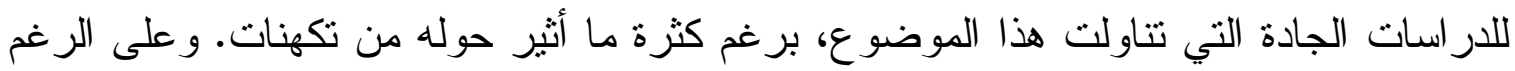

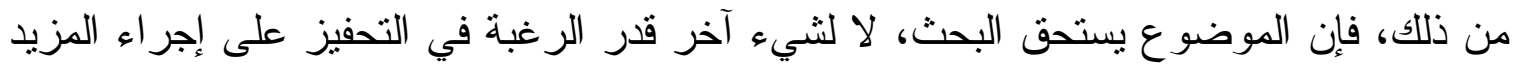

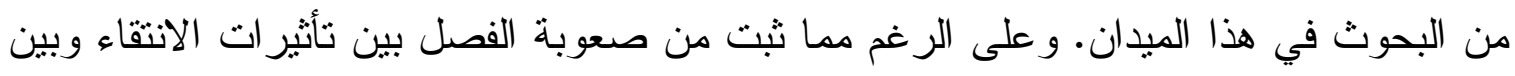

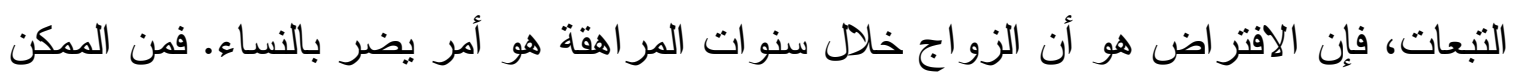

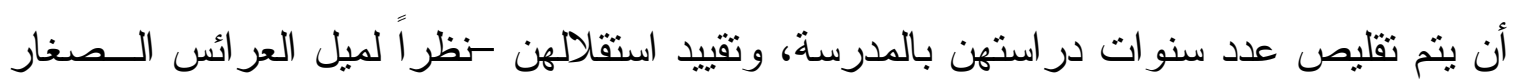

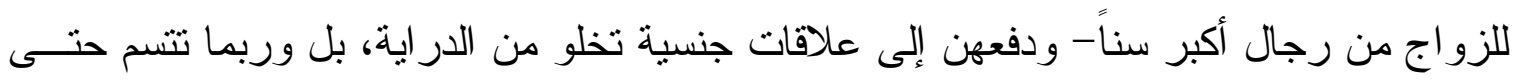

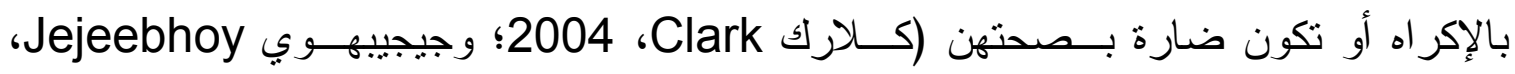
1995؛ ومينش وبروس وجرين Mensch, Bruce, and Greene، 1998؛ وسينج وسمار ا 1996؛ Singh and Samara

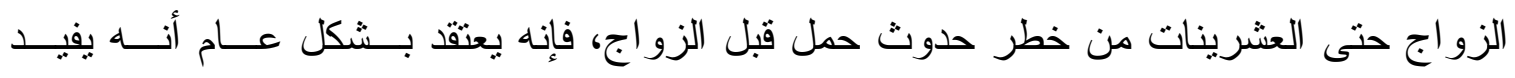
النساء

وبرغم عدم وجود دراسات حول ارتفاع الأعمار عند الزواج بين الرجال، فيبدو من المعقول أنه

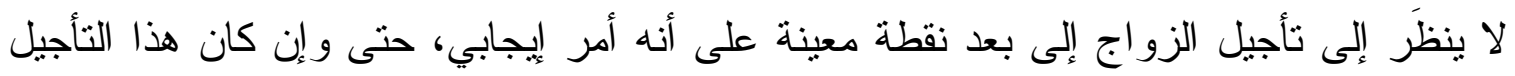

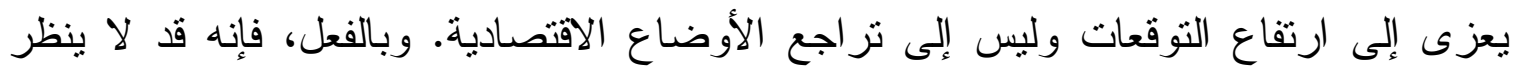

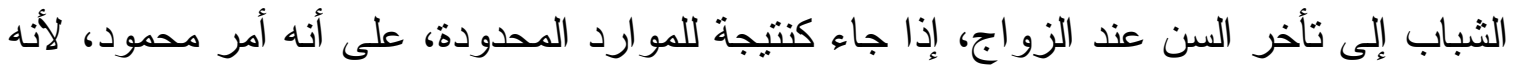

24 في المجتمعات الني تنزوج فيها النساء تقليدياً في سن صغيرة و التي تكون فيها حريتهن مقيدة إلى أقصى درجة، قد لا يكون لتـأخير

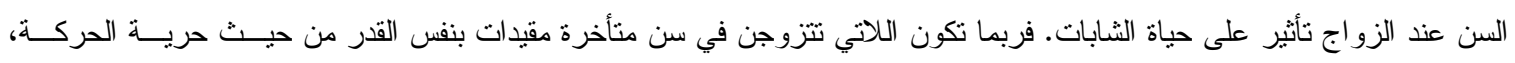

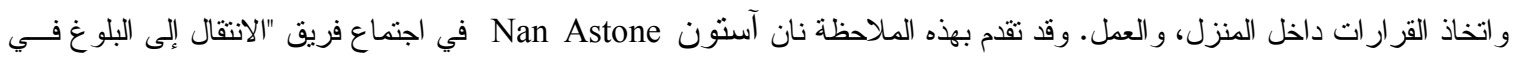

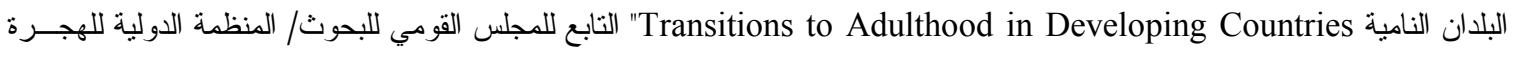
Nالذي انعقد في مارس/ آذار، 2003. 


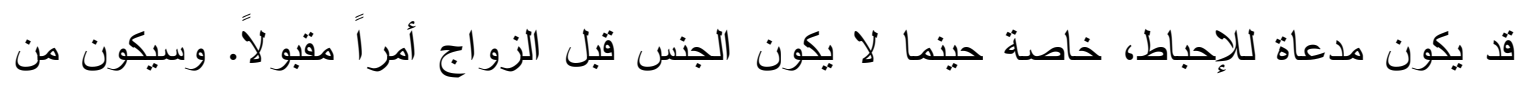

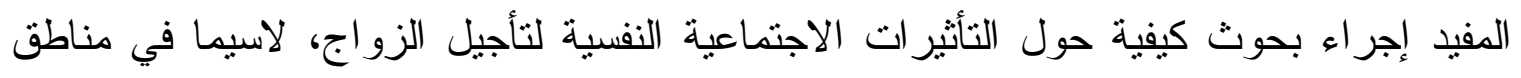
متل الثرق الأوسط، حيث يكون الاختلاط بين الرجال و النساء غير المتزوجين محدوداً.

HIVIAIDS السن عند الزواج وخطر الإصابة بمتلامة نقص المناعة البشرية

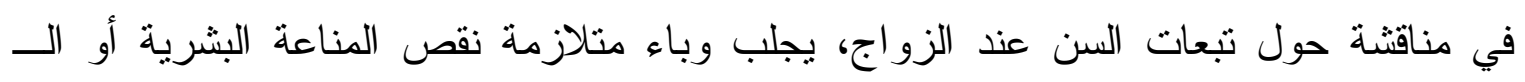

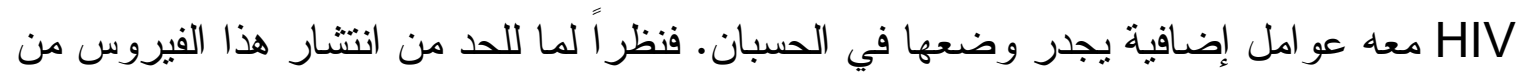

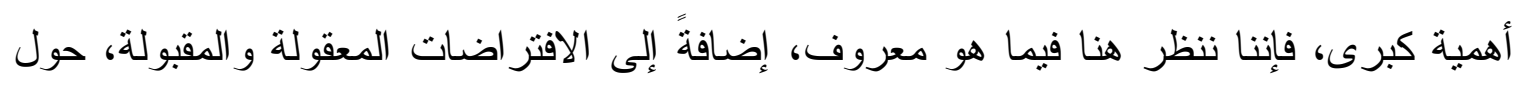

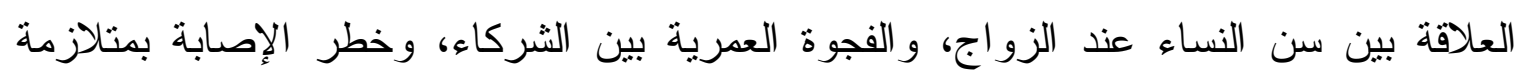

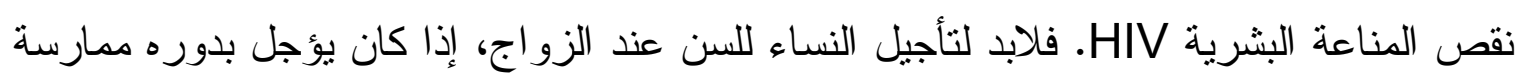

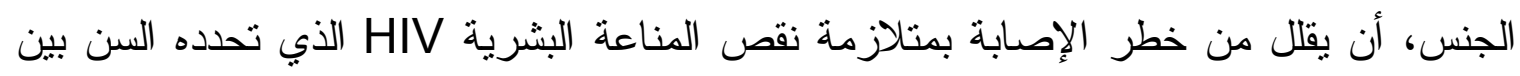

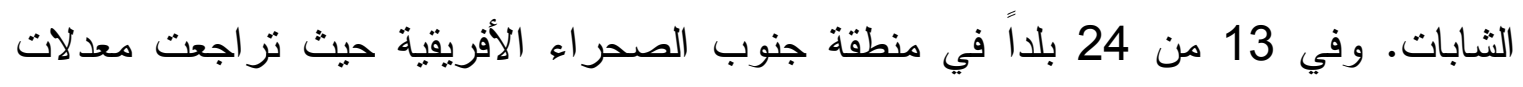

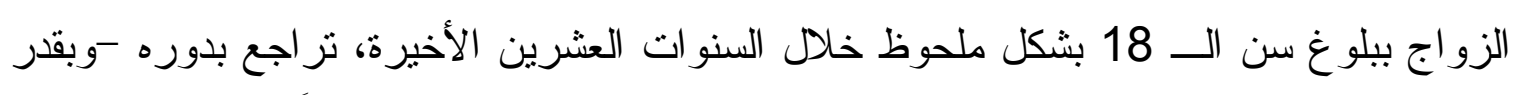

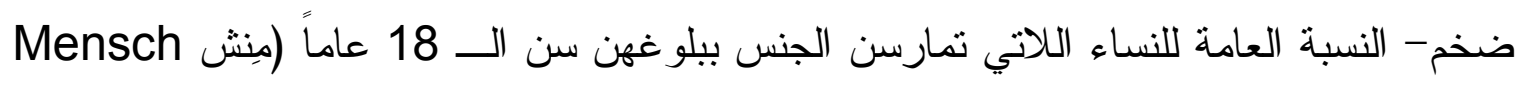

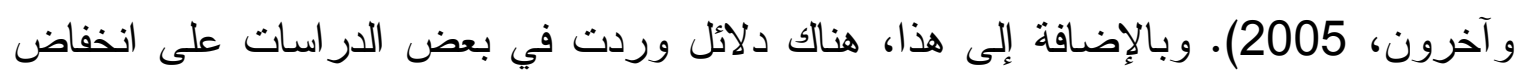

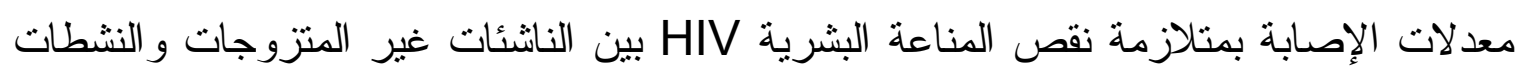

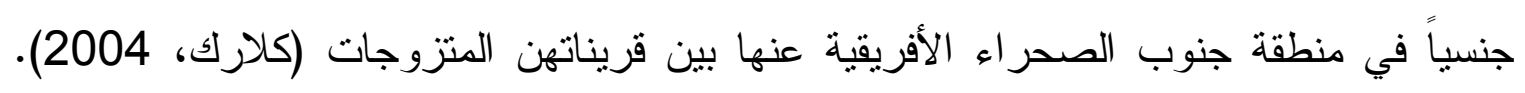

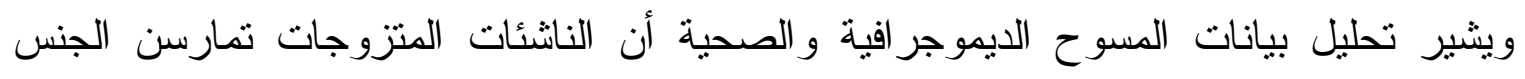

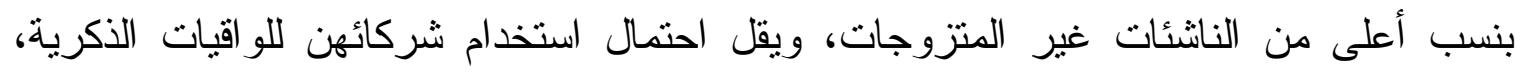

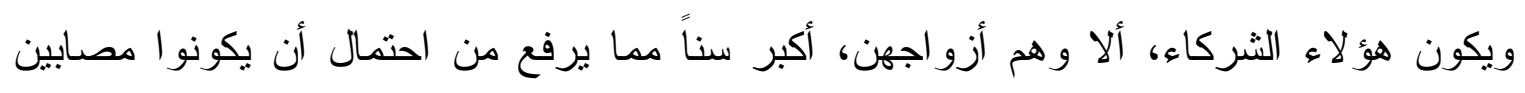

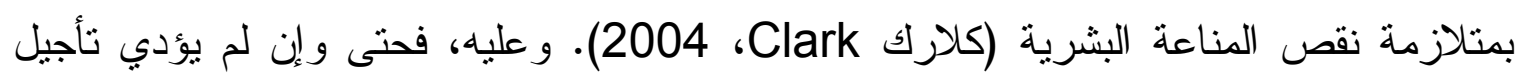

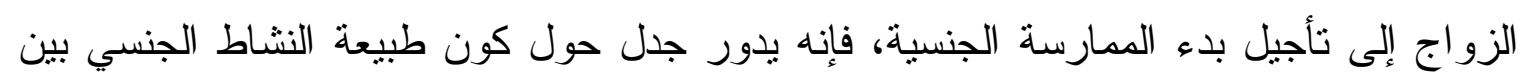

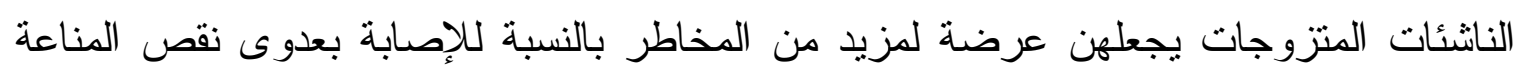
البشرية من قريناتهن غير المتزوجات.

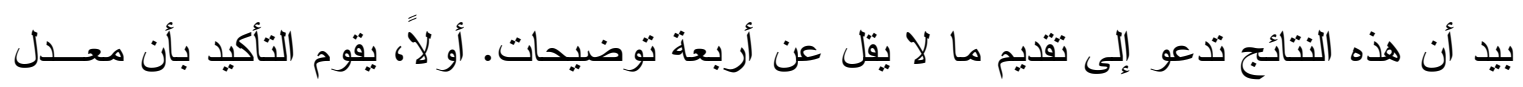

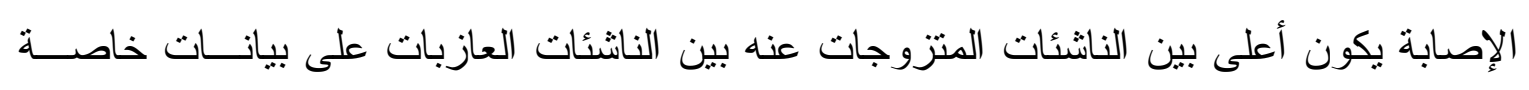


بمعدلات الانتشار وليس على بيانات معدلات حدوث الإصـابة. و المعروف أن بيانــات معــلات الانتشار تحجب احتمال أن تكون الفتيات الصغيرات المتزوجات قد التقطن العدوى قبل زوات اجهن،

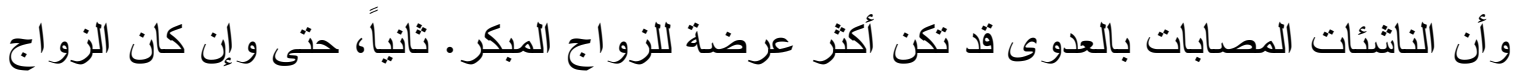

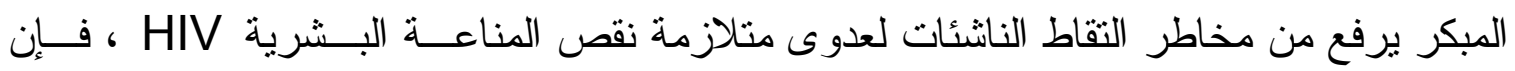
الزو اج قد يثبت على المدى الطويل أنه إجر اء أكثر حماية لهن من البقاء عازبات ونشطات جنسياً.

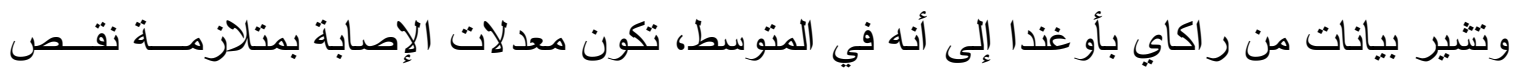

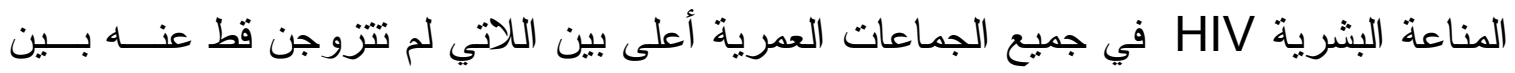

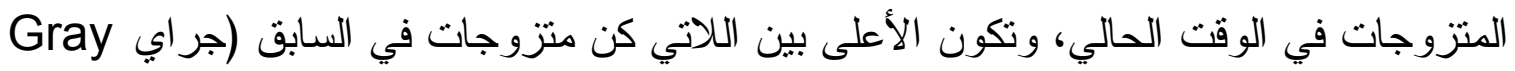
و آخرون، 2004). وفي سبيل تحديد الكيفية التي تؤثر بها الحالة الاجتماعية على خطر الإصابة بمتلازمة نقص المناعة البشرية HIV ، ينبغي إجر اء در اسات وبائية باستخدام بيانـات طوليـــة.

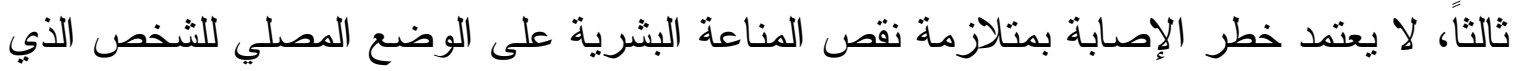

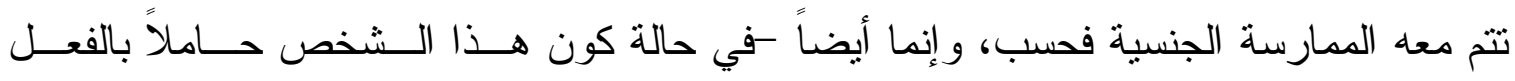

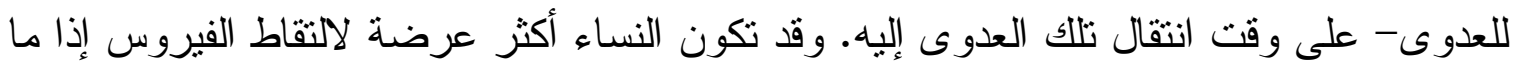

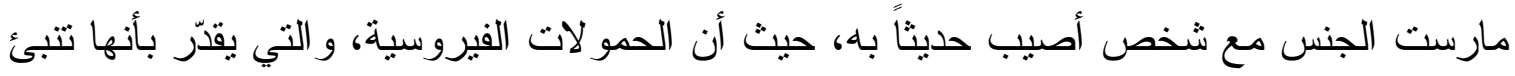

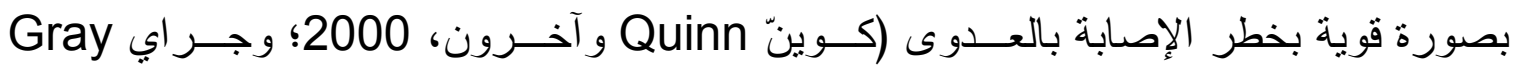
و آخرون، 2001) تكون مرتفعة في وقت الإصـابة (أندرسـون Anderson، 1996). و وعلى بـى الرغم من احتمال تباين القابلية للعدوى بصورة منظمة تبعاً لسن الرجل، فإنه لا تتوفر لدينا بيانات

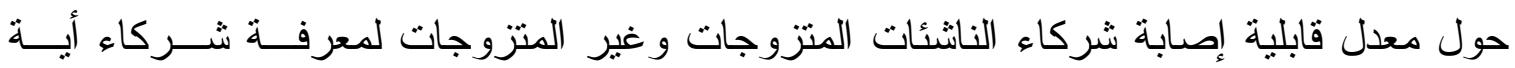
مجموعة هم الذين يعرضو هن لـخاطر أكبر بالنسبة للإصـابة بمتلازمة نقص المناعــة البـشرية.

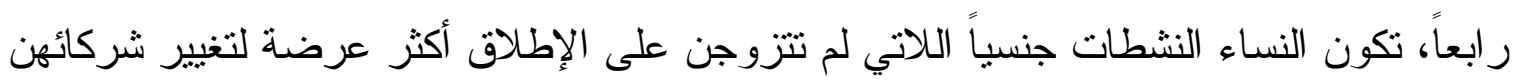
من النساء المتزوجات حالياً (معهد آلان جوتماخر Alan Guttmacher Institute،

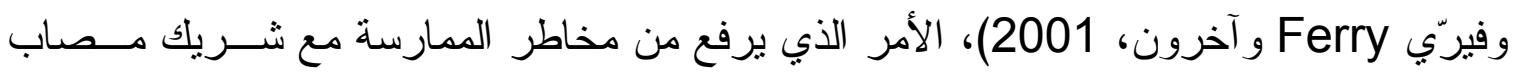

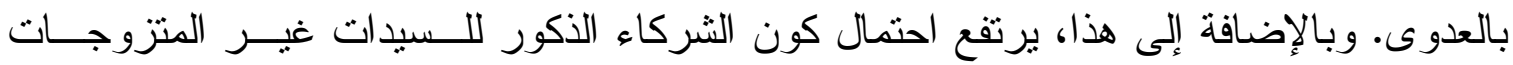

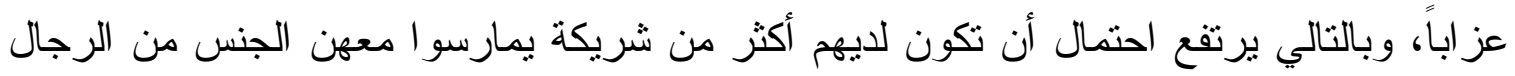

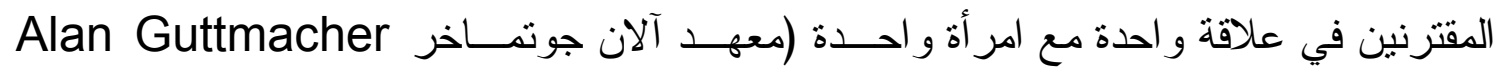
Institute، 2003). و على الرغم من ذلك، فإذا ما قمنا بتضمين الرجال الذين يمارسون الجنس

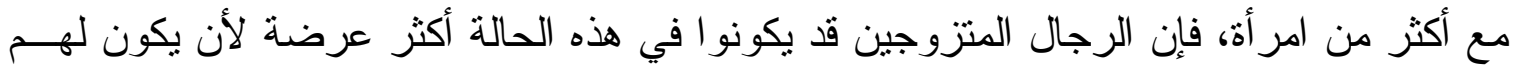


عدد أكبر من النساء الذين يمارسون معهن الجنس من الرجال العز اب، كما تمت ملاحظتـــه فــي

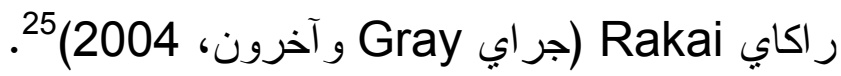

و لا يمكن الخروج بنتائج قاطعة حول تأثثر تأجيل الزواج على خطر الإصابة بمتلازمة نقص هابل

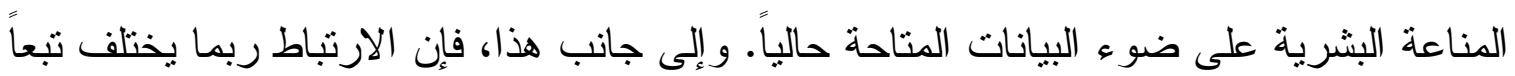

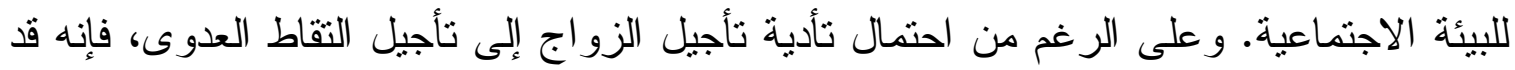

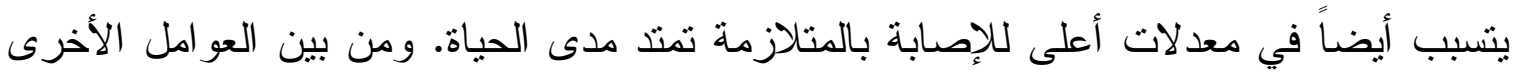

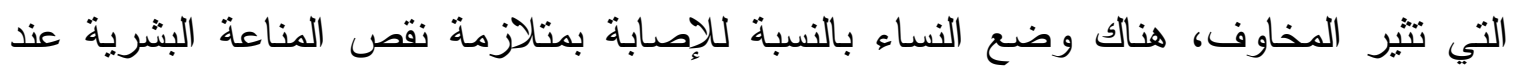

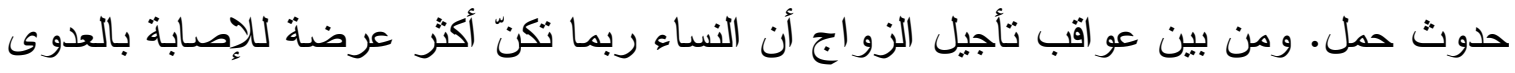
خلال الحمل، على الرغم من أن إحدى الدراسات لم تجد دليلاً يدعم هذا التخمين (كلارك Clark،

وكما هي الحال بالنسبة للنساء، فإن التبعات الصحية لتأجيل الرجال لزواجهم تكون غير معروفة. و على الرغم من أن الزواج لا يفرض خصوصية في ممارسة الجنس على الرجال، ففي البلدان

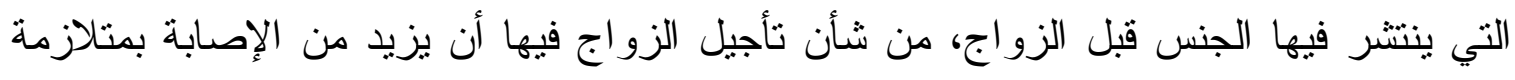

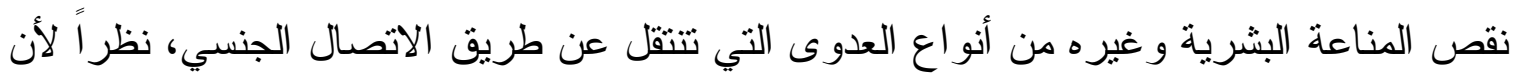

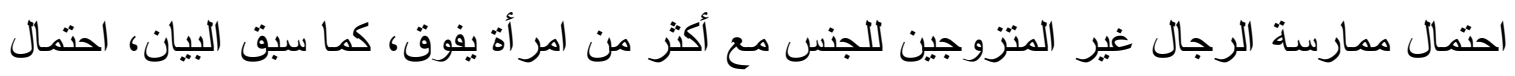

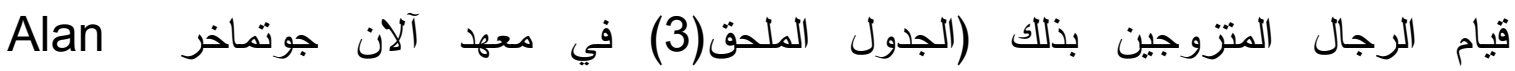
Guttmacher Institute أعراف الامتتاع عن ممارسة الجنس خلال فترة النفاس وحيث يتزوج الرجال في سن مبكرة،

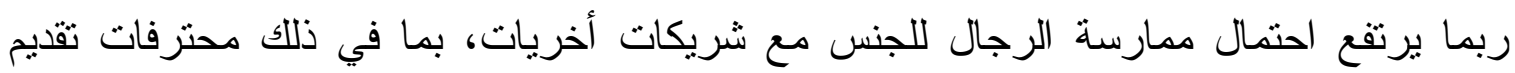
الجنس مقابل المال، خلال فترة النفاس. وتتمنل حاجة واضحة للقيام بمزيد من البحوث حول

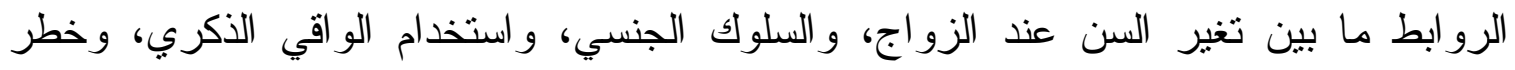
الإصابة بمتلازمة نقص المناعة البشرية بين الرجال و النساء على حد سواء.

25 يعتمد هذا التحليل لتبعات تأجيل النساء لزواجهن تحسباً من خطر الإصابة بمتلازمة نقص المناعة البشرية HIV كذلك على مناقـشات

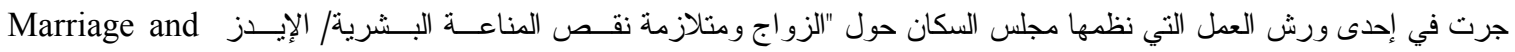

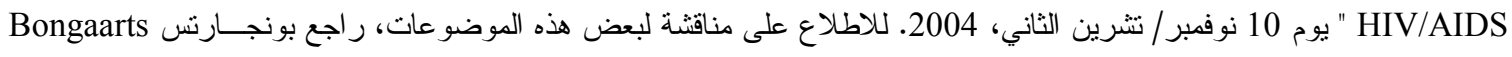




\section{الخلاصة}

على مدار السنوات الـــ 30 الماضية، حدث تر اجع كبير في معظم مناطق العالم النامي في نسبة الثباب و الثابات المتزوجين. أما الاستثناء الواضح، فهو أمريكا الجنوبية بالنسبة لكلا الجنسين، وجنوب وجنوب شرق آسيا بالنسبة للرجال فقط.

وبالنظر إلى الاختلافات في أعمار الذكور والإناث عند الزواج تبعاً لسنوات التعليم المدرسي و الإقامة، فقد قمنا بتقييم ما إذا كانت هنالك علاقة بين التز اجع في نسبة الثباب المتزوجين بالزيادة

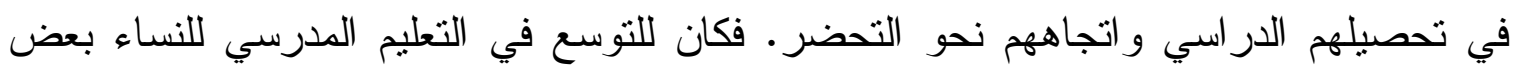

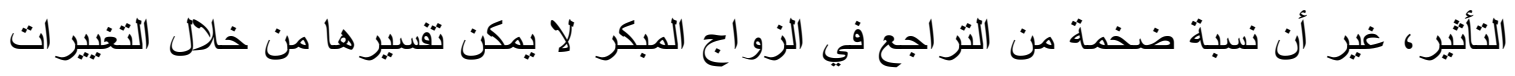

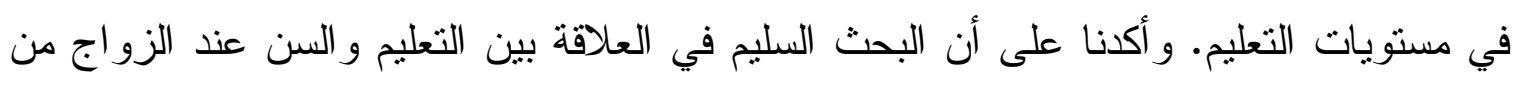
شأنها النظر فيما يتخطى عو امل منل سنوات التعليم المدرسي إلى ما يحدث داخل المدرسة نفسها، علاوة على التغيير ات في قيمة التعليم، و التي تختلف على على الأرجح من بيئة إلى أخرى.

وقد اقترحنا عو امل أخرى يمكنها أن تتسبب في بعض الزيادة التي طر أت على السن عند الزواج بين النساء، وقمنا باستعر اض عدد ضخم من الدراسات الديموجر افية. وتتضمن العوامل التي لتصني أسهمت في حدوث هذا والمبينة في المراجع والتي وضعت في الحسبان هنا تراجع الزيجات

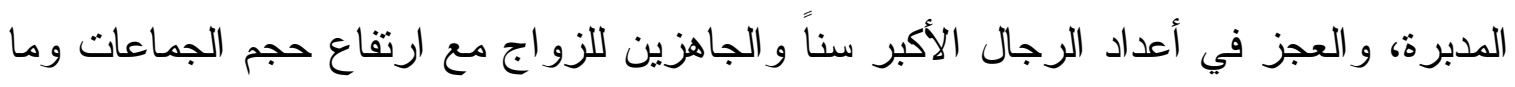

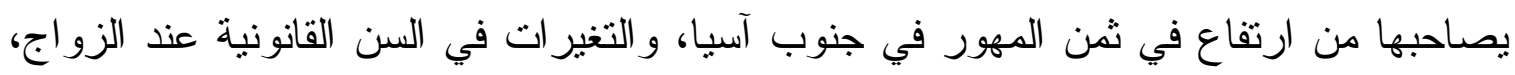
و التحول في الأعر اف العالمية حول الرغبة في الزواج المبن فئر للنساء. كما لاحظنا تو افر عدد أقل فئل بكثير من المر اجع حول سن الرجال عند الزواج. و على الرغم من الاعتقاد في أن زيادة التحصيل

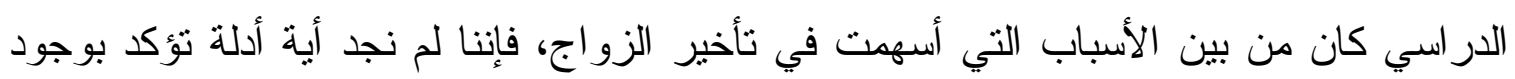

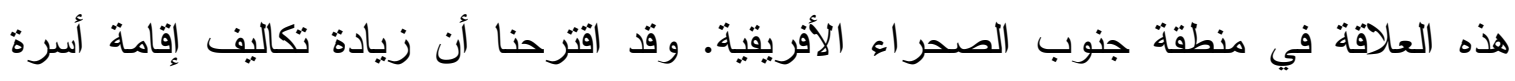
معيشية قد يدفع الرجال إلى تأجيل الزو اجه. 
وقد كثف هذا التحليل للبيانات واستعر اض المر اجع عن أنه لا يعرَف سوى القليل حول التغيرات

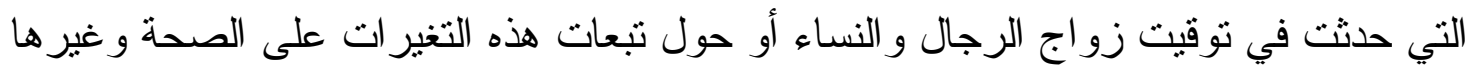

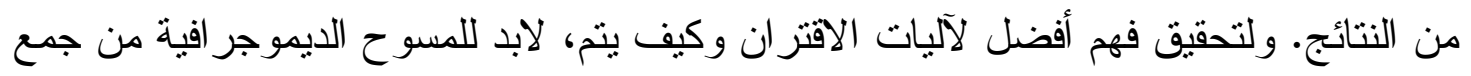

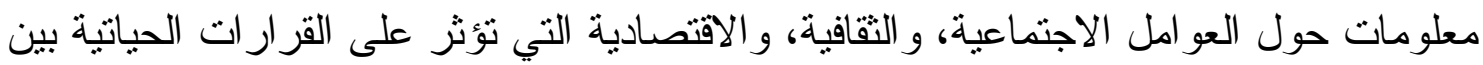

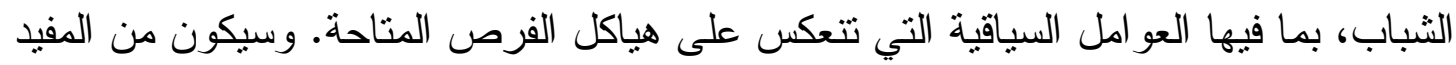

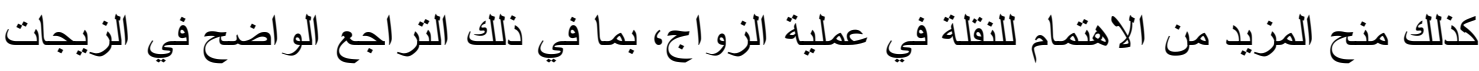

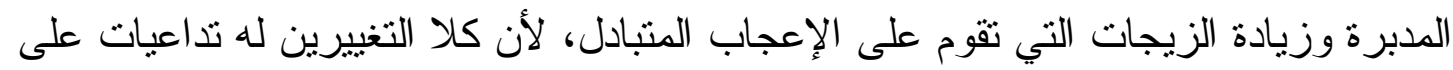

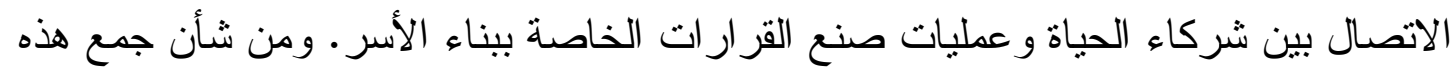

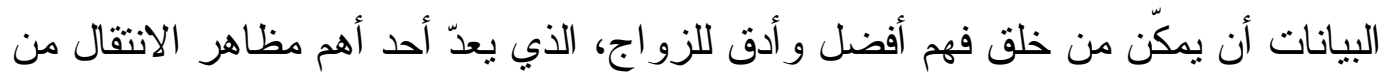

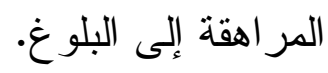

\section{REFERENCES}

Abbasi, M.J., Mehryar, A., Jones, G., and McDonald, P. 2002. "Revolution, war, and modernization: Population policy and fertility change in Iran." Journal of Population Research, 19(1), 25-46.

Ahearn, L.M. 2001. Invitations to Love: Literacy, Love Letters, and Social Change in Nepal. Ann Arbor: University of Michigan Press.

Alan Guttmacher Institute (AGI). 1998. Into a New World: Young Women's Sexual andReproductive Lives. New York and Washington, DC: AGI. 2003. In Their Own Right: Addressing the Sexual and
Reproductive Health
Needs of Men Worldwide. New York and Washington, DC:
AGI.

Amin, S. 2000. "Gender, governance and the making of a new population policy in Bangladesh." Paper presented at a panel 
discussion on Globalization and Some Aspects of Recent Social Changes in Rural Bangladesh, at the annual meeting of The American Rural Sociological Society, 14 August, Washington, DC.

Amin, S., and Cain, M. 1997. "The rise of dowry in Bangladesh." In G.W. Jones, R.M. Douglas, J.C. Caldwell, and R.M. D'Souza (eds.), The Continuing Demographic Transition (pp. 290306). Oxford, England: Clarendon Press.

Amin, S., Mahmud, S., and Huq. L. 2002. "Marriage." In Baseline Survey Report on Rural Adolescents in Bangladesh: Kishori Abhijan Project. Dhaka: UNICEF and Department of Women's Affairs, Ministry of Women and Children Affairs.

Anderson, R.M. 1996. "The spread of HIV and sexual mixing patterns." In J. Mann and

D. Tarantola (eds.), AIDS in the World II (Vol. II, pp. 71-86). New York:

Oxford University Press.

Anderson, S. 2003. "Why dowry payments declined with modernization in Europe but are rising in India." Journal of Political Economy, 111(2), 269-310.

Assaad, R., and Zouari, S. 2002. "The timing of marriage, fertility, and female labor force participation in urban Morocco." Paper presented at the Economic Research Forum Ninth Annual Conference, 26-28 October, Sharjah, UAE.

Becker, G. 1973. "A theory of marriage." In T.W. Schultz (ed.), Economics of the Family: Marriage, Children and Human Capital (pp. 299-344). Chicago: The University of Chicago for the National Bureau of Economic Research.

Bhat, P.N.M. and Halli, S.S. 1999. "Demography of brideprice and dowry: Causes and consequences of the Indian marriage squeeze." Population Studies, 53(2), 129- 148. 
Billig, M.S. 1992. "The marriage squeeze and the rise of groomprice in India's Kerala State." Journal of Comparative Family Studies, 23(2), 197-216.

Blanc, A.K. and Rutenberg, N. 1990. "Assessment of the quality of data on age at first sexual intercourse, age at first marriage and age at first birth in the Demographic and Health Surveys." In An Assessment of DHS-I Data Quality (pp. 4179). Columbia, MD: Institute of Resource Development/Macro Systems.

Bongaarts, J. 2005. "Marriage, sexual behavior, and HIV epidemics in sub-Saharan Africa." Unpublished.

Boulier, B.L. and Rosenzweig, M.R. 1984. "Schooling, search, and spouse selection: Testing economic theories of marriage and household behavior." The Journal of Political Economy, 92(4), 712-732.

Boye, A.K., Hill, K., Isaacs, S., and Gordis, D. 1991. "Marriage law and practice in the Sahel." Studies in Family Planning, 22(6), 343-349.

Brien, M.J. and Lillard. L.A. 1994. "Education, marriage, and first conception in Malaysia." The Journal of Human Resources, 34(4), $1167-1204$.

Caldwell, J., Reddy, P.H., and Caldwell, P. 1983. "The causes of marriage change in South India." Population Studies, 37(3), 343-361.

Casterline, J.B. 1994. "Fertility transition in Asia." In T. Locoh and V. Hertrich (eds.), The Onset of Fertility Transition in SubSaharan Africa (pp. 69-86). Liège, Belgium: Ordina.

Center for Reproductive Law and Policy. 1999. Adolescent Reproductive Rights: Laws and Policies to Improve Their Health and Lives. New York: Center for Reproductive Law and Policy. 
Choe, M.K., Thapa, S., and Achmad, S. 2001. Early marriage and childbearing in Indonesia and Nepal (East-West Center Working Papers Population Series, No. 108-115). Honolulu, HI: East-West Center.

Choe, M.K., Westley, S.B., and Retherford, R.D. 2002. Tradition and Change in Marriage and Family Life: The Future of Population in Asia. Honolulu, HI: East-West Center.

Clark, S. 2004. "Early marriage and HIV risks in sub-Saharan Africa." Studies in Family Planning, 35(3), 149-160.

Coale, A.J., and Treadway, R. 1986. "A summary of the changing distribution of overall

fertility, marital fertility, and the proportion married in the provinces of Europe." In A.J. Coale and S.C. Watkins (eds.), The Decline of Fertility in Europe: The Revised Proceedings of a Conference on the Princeton European Fertility Project (pp. 31-181). Princeton, NJ: Princeton University Press.

Dahal, D.R., Fricke, T., and Thornton, A. 1993. "The family contexts of marriage timing in Nepal." Ethnology, 32(4), 305-323.

Das Gupta, M. 1997. "Kinship systems and demographic regimes." In D.I. Kertzer and T. Fricke (eds.), Anthropological Demography: Toward a New Synthesis (pp. 36-52). Chicago and London: University of Chicago Press.

Deolalikar, A.B., and Rao, V. 1998. "The demand for dowries and bride characteristics in marriage: Empirical estimates for rural South-Central India." In M. Krishnaraj, R. Sudarshan, and A. Shariff (eds.), Gender, Population, and Development (pp. 122-140). Oxford, England: Oxford University Press.

De Silva, W.I. 1997. "The Ireland of Asia: Trends in marriage timing in Sri Lanka." Asia-Pacific Population Journal, 12(2), 3-24.

Ehmer, J. 2002. "Marriage." In D.I. Kertzer and M. Barbagli (eds.), Family Life in the Long Nineteenth Century 1789-1913, 
Volume two: The History of the European Family (pp. 282321). New Haven and London: Yale University Press.

Ferry, B., Caraël, M., Buvé, A., Auvert, B., Laourou, M., Kanhonou, L., de Loenzien, M., Akam, E., Chege, J., and Kaona, F., for the Study Group on Heterogeneity of HIV Epidemics in African Cities. 2001. "Comparison of key parameters of sexual behaviour in four African urban populations with different levels of HIV infection." AIDS, 15(supplement 4), S41-S50.

Fricke, T.E., Syed, S.H., and Smith, P.C. 1986. "Rural Punjabi social organization and marriage timing strategies in Pakistan." Demography, 23(4), 489-508.

Gage, A.J., and Meekers, D. 1995. "The changing dynamics of family formation: Women's status and nuptiality in Togo." In P. Makinwa-Adebusoye and A.-M. Jensen (eds.), Women and Demographic Change in Sub-Saharan Africa (pp. 15-38). Liège, Belgium: International Union for the Scientific Study of Population.

Goode, W.J. 1963. World Revolution and Family Patterns. New York: Free Press.

Gray, R.H., Wawer, M.J., Brookmeyer, R., Sewankambo, N.K., Serwadda, D., Wabwire-Mangen, F., Lutalo, T., Li, X., vanCott, T., and Quinn, T.C. 2001. "Probability of HIV-1 transmission per coital act in monogamous, heterosexual, HIV-1-discordant couples in Rakai, Uganda." The Lancet, 357(9263), 1149-1153.

Gray, R., Nalugoda, F., Serwadda, D., and Wawer, M. 2004. "Marriage and HIV risk: Data from Rakai, Uganda." Paper presented at Workshop on Marriage and HIVIAIDS, 10 November. New York: Alan Guttmacher Institute.

Guinnane, T. 1991. "Re-thinking the Western European marriage pattern: The decision to marry in Ireland at the turn of the twentieth century." Journal of Family History 16(1), 47-64. 
Gutmann, M.P. and Leboutte, R. 1984. "Rethinking protoindustrialization and the family." Journal of Interdisciplinary History 14(3), 587-607.

Hajnal, J. 1965. "European marriage patterns in perspective." In D.V. Glass and D.E.C. Eversley (eds.), Population in History: Essays in Historical Demography (pp.101-143). London: Edward Arnold.

Heaton, T.B., Forste, R., and Otterstrom, S.M. 2002. "Family transitions in Latin America: First intercourse, first union, and first birth." International Journal of Population Geography, 8, $1-15$.

Hertrich, V. 2002. "Nuptiality and gender relationships in Africa: An overview of first marriage trends over the past 50 years." Paper presented at the annual meeting of the Population Association of America, 9-11 May, Atlanta.

Hull, T.H. 2002. "The marriage revolution in Indonesia." Paper presented at the annual meeting of the Population Association of America, 9-11 May, Atlanta.

International Center for Research on Women. 2004. "Too young to wed: Child marriage in their own words." $<$ http://www.icrw.org/photoessay/html/intro.htm>. Accessed August 2004.

International Planned Parenthood Federation (IPPF) and International Women's Rights Action Watch (IWRAW). 1990. Reproductive Rights. The Hubert H. Humphrey Institute of Public Affairs at University of Minnesota. Suffolk, England: Lavenham Press.

2000. Reproductive Rights 2000. The Hubert H. Humphrey Institute of Public Affairs at University of Minnesota. London: Terracotta Press. 
Islam, M.N., and Ahmed, A.U. 1998. "Age at first marriage and its determinants in Bangladesh." Asia-Pacific Population Journal, 13(2), 73-92.

Jejeebhoy, S. 1995. "Education and women's age at marriage." In S. Jejeebhoy, Women's Education, Autonomy, and Reproductive Behaviour: Experience from Developing Countries (pp. 6077). Oxford, England: Clarendon Press.

Jejeebhoy, S.J., and Halli, S.S. 2005. "Marriage patterns in rural India: Influence of sociocultural context." In The Changing Transitions to Adulthood in Developing Countries: Selected Studies (Chapter 6). Forthcoming.

Kertzer, D.I. and Hogan, D.P. 1991. "Reflections on the European marriage pattern: Sharecropping and proletarianization in Casalecchio, Italy, 1861-1921." Journal of Family History, 16(1), 31-45.

Kishor, S. 2003. "Uses and limitations of DHS data on age and characteristics of first marriages." Paper presented at UNICEF Global Consultation on Indicators: Female Genital Mutilation/Cutting and Early Marriage, 11-13 November, New York.

LeGrand, T.K. and Barbieri, M. 2002. "The possible effects of child survival on women's ages at first union and childbirth in subSaharan Africa." European Journal of Population, 18, 361386.

Lesthaeghe, R.J., Kaufman, G., and Meekers, D. 1989. "The nuptiality regimes in sub-Saharan Africa." In R.J. Lesthaeghe (ed.), Reproduction and Social Organization in Sub-Saharan Africa (pp. 238-333). Berkeley: University of California Press.

Lindstrom, D.P., and Brambila Paz, C. 2001. "Alternative theories of the relationship of schooling and work to family formation: Evidence from Mexico." Social Biology, 48(3-4), 278-297. 
Lloyd, C.B. (ed.). 2005. "Schooling." In Growing Up Global: The Changing Transitions to Adulthood in Developing Countries (pp. 67-167). National Research Council and Institute of Medicine, Panel on Transitions to Adulthood in Developing Countries. Washington, DC: National Academies Press.

Lloyd, C.B. and Mensch, B.S. 1999. "Implications of formal schooling for girls' transitions to adulthood in developing countries." In C.H. Bledsoe, J.B.

Casterline, J.A. Johnson-Kuhn, and J.G. Haaga (eds.), Critical Perspectives on Schooling and Fertility in the Developing World (pp. 80-104). Washington, DC: National Academy Press.

Lynch, K.A. 1991. "The European marriage pattern in the cities: Variations on a theme by Hajnal." Journal of Family History, 16(1), 79-96.

Malhotra, A. 1991. "Gender and changing generational relations: Spouse choice in Indonesia." Demography, 28(4), 549-570.

- 1997. "Gender and the timing of marriage: Rural-urban differences in Java." Journal of Marriage and the Family, 59(2), 434-450.

Malhotra, A. and Tsui, A.O. 1996. "Marriage timing in Sri Lanka: The role of modern norms and ideas." Journal of Marriage and the Family, 58(2), 476-490.

Mensch, B.S., Bruce, J., and Greene, M.E. 1998. The Uncharted Passage: Girls' Adolescence in the Developing World. New York: Population Council. Mensch, B.S. 2003. "Trends in the timing of first marriage." Paper presented at the WHO, UNFPA, and Population Council Technical Consultation on Married Adolescents, 9 December, Geneva.

Mensch, B.S., Ibrahim, B.L., Lee, S.M., and El-Gibaly, O. 2003. "Gender-role attitudes among Egyptian adolescents." Studies in Family Planning, 34(1), 8-18. 
Mensch, B.S., Grant, M.J., Blanc, A.K., and Clark, S. 2005. "The changing context of sexual initiation in sub-Saharan Africa." Paper accepted for presentation at the 25th International Union for the Scientific Study of Population International Population Conference, Tours, July.

Montgomery, M.R., and Sulak, D.B. 1989. "Female first marriage in East and Southeast- Asia: A Kiefer-Neumann Model." Journal of Development Economics, 30(2), 225-240.

National Research Council, Committee on Population. 1993. "Marriage: New forms, new ambiguities." In C.H. Bledsoe and B. Cohen (eds.), Social Dynamics of Adolescent Fertility in Sub-Saharan Africa (pp. 37-68). Washington, DC: National Academy Press.

Population Council. 2002. Background document prepared for Working Group on Girls, United Nations Special Session on Children, 10 May, New York.

Preston, S.H., Heuveline, P., and Guillot, M. 2001. Demography: Measuring and Modeling Population Processes. Malden, MA: Blackwell Publishing.

Quinn, T.C., Wawer, M.J., Sewenkambo, N., Serwadda, D., Li, C., Wabwire-Mangen, F., Meehan, M.O., Lutalo, T., and Gray, R.H. 2000. "Viral load and heterosexual transmission of human immunodeficiency virus type 1." The New England Journal of Medicine, 342(13), 921-929.

Rao, V. 1993a. "Dowry 'inflation' in rural India: A statistical investigation." Population Studies, 47, 283-293.

1993b. "The rising price of husbands: A hedonic analysis of dowry increases in rural India." Journal of Political Economy, 101(4), 666-677.

Rashad, H. and Osman, M. 2003. "Nuptiality in Arab countries: Changes and implications." In N. S. Hopkins (ed.), Cairo 
Papers in Social Science: The New Arab Family (pp. 20-50). Cairo: The American University in Cairo Press.

Rosero-Bixby, L. 1996. "Nuptiality trends and fertility transition in Latin America." In J.M. Guzman, S. Singh, G. Rodriguez, and E.A. Pantelides (eds.), The Fertility Transition in Latin America (pp. 135-150). Oxford, England: Clarendon Press.

Saxena, P.C. and Kulczycki, A. 2004. "Nuptiality transition and marriage squeeze in Lebanon: Consequences of sixteen years of civil war." Journal of Comparative Family Studies, 35(2), 241-258.

Shryock, H.S., Siegel, J.S., et al. 1971. The Methods and Materials of Demography. Washington, DC: United States Bureau of the Census.

Singerman, D. and Ibrahim, B. 2003. "The costs of marriage in Egypt: A hidden dimension in the new Arab demography." In N.S. Hopkins (ed.), Cairo Papers in Social Science: The New Arab Family (pp. 80-116). Cairo: The American University in Cairo Press.

Singh, S. and Samara, R. 1996. "Early marriage among women in developing countries." International Family Planning Perspectives, 22(4), 148-157, 175.

Smith, P.C. 1983. "The impact of age at marriage and proportions marrying on fertility." In R.A. Bulatao and R.D. Lee with P.E. Hollerbach and J. Bongaarts (eds.), Determinants of Fertility in Developing Countries (pp. 473-531). New York: Academic Press.

United Nations. 2003. World Population Prospects: The 2002 Revision, Volume 1: Comprehensive Tables. New York: United Nations.

United Nations Children's Fund (UNICEF). 2001. Early Marriage: Child Spouses. Florence, Italy: UNICEF, Innocenti Research Center. 
United Nations Commission on Population and Development. 2002. Concise Report on World Population Monitoring 2002: Reproductive Rights and Reproductive Health with Special Reference to Human Immunodeficiency Virus/Acquired Immunodeficiency Syndrome (HIV/AIDS). Report of the Secretary General (E/CN.9/2002/2). Presented at the Commission on Population and Development, United Nations, New York, 1-5 April.

$<$ http://www.un.org/esa/population/cpd/comm2002.htm>Acces se d April 2005.

United Nations, Department of International Economic and Social Affairs (UNDIESA). (1990). Patterns of First Marriage: Timing and Prevalence. New York: United Nations.

United Nations, Department of Economic and Social Affairs, Population Division. 2000. Database on marriage patterns. $\mathrm{POP} / 1 / \mathrm{DB} / 2000 / 3$.

2001. World Population Prospects: The 2000 Revision (CDROM). File 1: Total population by age group, major area, region, and country, 1950-2050 (in thousands), estimates 1950-2000 (POP/DB/WPP/Rev.2000/3/F1).

2004. World Fertility Report: 2003. New York: United Nations.

van de Walle, E. 1993. "Recent trends in marriage ages." In K.A. Foote, K.H. Hill, and L.G. Martin (eds.), Demographic Change in Sub-Saharan Africa (pp. 117-152). Washington, DC: National Academy Press.

van de Walle, E. and Meekers, D. 1994. "Marriage drinks and kola nuts." In C. Bledsoe and G. Pison (eds.), Nuptiality in SubSaharan Africa: Contemporary Anthropological and Demographic Perspectives (pp. 57-73). Oxford, England: Clarendon Press.

Watkins, S.C. 1986. "Regional patterns of nuptiality in Western Europe." In A.J. Coale and S.C. Watkins (eds.), The Decline 
of Fertility in Europe: The Revised Proceedings of a Conference on the Princeton European Fertility Project (pp.314-336). Princeton, NJ: Princeton University Press.

Westoff, C.F. 2003. Trends in Marriage and Early Childbearing in Developing Countries. (DHS Comparative Reports No. 5). Calverton, MD: ORC Macro.

Westoff, C.F. and Bankole, A. 2002. Reproductive Preferences in Developing Countries at the Turn of the Century (DHS Comparative Reports No. 2). Calverton, MD: ORC Macro.

Williams, L., and Guest, M.P. 2002. Why Marry? Attitudes of Urban Middle-class Respondents in Vietnam, Thailand, and the Philippines (Population and Development Program Working Paper Series No. 01.01). Ithaca, NY: Cornell University, Department of Rural Sociology.

World Bank. 2002. World Development Indicators 2002. Washington, DC: The World Bank.

Wrigley, E.A., Davies, R.S., Oeppen, J.E., and Schofield. R.S. 1997. English Population History from Family Reconstitution 1580 1837. Cambridge, UK: Cambridge University Press.

Yabiku, S.T. 2003. Neighbors or Neighborhoods? Effects on Marriage Timing in Nepal. Paper presented at the annual meeting of the Population Association of America, Minneapolis.

Yabiku, S.T., Axinn, W.G., Ghimire, D.J., and Robinson, K.D. 2002. "School characteristics and marriage timing." Paper presented at the annual meeting of the Population Association of America, 9-11 May, Atlanta. 
جدول (1): النسبة المئوية للنساء المتزوجات أو اللاتي سبق لهن الزواج، تبعاً للسن، و الفترة الزمنية، والمنطقة ' (منوسطات مرجحة ب)

\begin{tabular}{|c|c|c|c|c|c|c|c|c|c|c|c|}
\hline \multicolumn{3}{|c|}{ الأعمار 25-25 } & \multicolumn{3}{|c|}{ الأعمار 20-24 } & \multicolumn{3}{|c|}{ 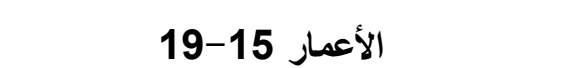 } & \multirow{2}{*}{\multicolumn{3}{|c|}{ النسبة المئوية }} \\
\hline التغير & اللفترة 2 & الفترة 1 ع & التغير & الفترة 2 & الفترة 1 ع & التغير & الفقرة 2 & الفترة 1 ع & & & \\
\hline السنوي & $\begin{array}{c}-1990 \\
2000\end{array}$ & $\begin{array}{c}-1970 \\
89\end{array}$ & السنوي & $\begin{array}{c}-1990 \\
2000\end{array}$ & $\begin{array}{c}-1970 \\
89\end{array}$ & السنوي & $\begin{array}{c}-1990 \\
2000\end{array}$ & 89-1970 & لسكان المنطقة & & \\
\hline 0.38 & 83.4 & 89.2 & -0.71 & 65.6 & 77.2 & -0.75 & 24.5 & 37.5 & 89.8 & & \\
\hline-0.05 & 92.3 & 93.5 & -0.40 & 78.6 & 85.1 & -0.89 & 38.4 & 53.0 & 30.8 & & \\
\hline 0.36 & 91.6 & 95.9 & -1.19 & 45.9 & 60.1 & -0.24 & 1.3 & 4.2 & 98.1 & & \\
\hline-0.02 & 93.4 & 93.7 & -0.30 & 77.4 & 80.6 & -0.64 & 32.3 & 39.6 & 93.3 & جنوب & ط \\
\hline-0.42 & 80.7 & 85.0 & -0.70 & 54.0 & 61.2 & 0.02 & 9.6 & 9.4 & 37.8 & السابقة & سبا السوفييتية \\
\hline & & & & & & & & & & اللاتينية & \\
\hline-0.20 & 79.3 & 81.0 & -0.35 & 56.1 & 59.4 & -0.27 & 18.1 & 20.6 & 87.5 & أمريكا & اككاريبي| \\
\hline 0.00 & 76.0 & 75.9 & 0.03 & 51.3 & 51.1 & 0.12 & 16.3 & 14.4 & 99.9 & & \\
\hline-0.58 & 81.4 & 87.7 & -0.95 & 54.6 & 64.5 & -0.59 & 14.9 & 21.0 & 62.8 & شمال & آسيا/ \\
\hline-0.18 & 89.4 & 91.6 & -0.56 & 63.9 & 70.8 & -0.48 & 20.8 & 26.6 & 86.5 & & لإجمالي \\
\hline
\end{tabular}




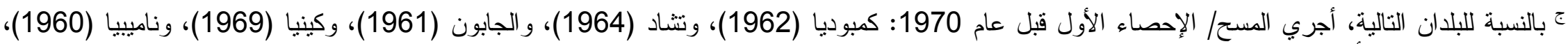

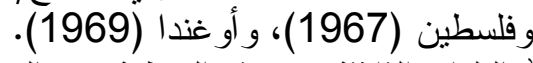

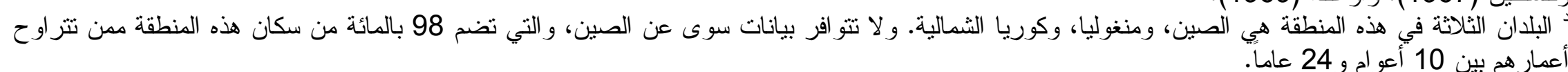

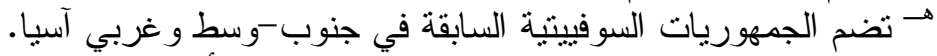

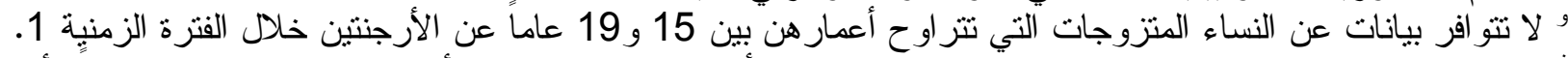

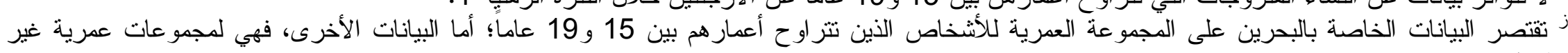

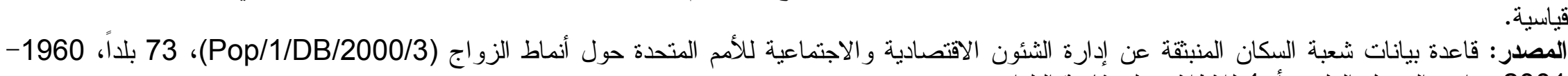
2001. راجع الجدول الملحق أسعة أبكان للاطلاع على قائمة البلدان. 
جدول (2): النسبة المئوية للرجال المتزوجين أو الذين سبق لهم الزواج، تبعاً للسن، و الفترة الزمنية، و المنطقة (متوسطات مرجحة)

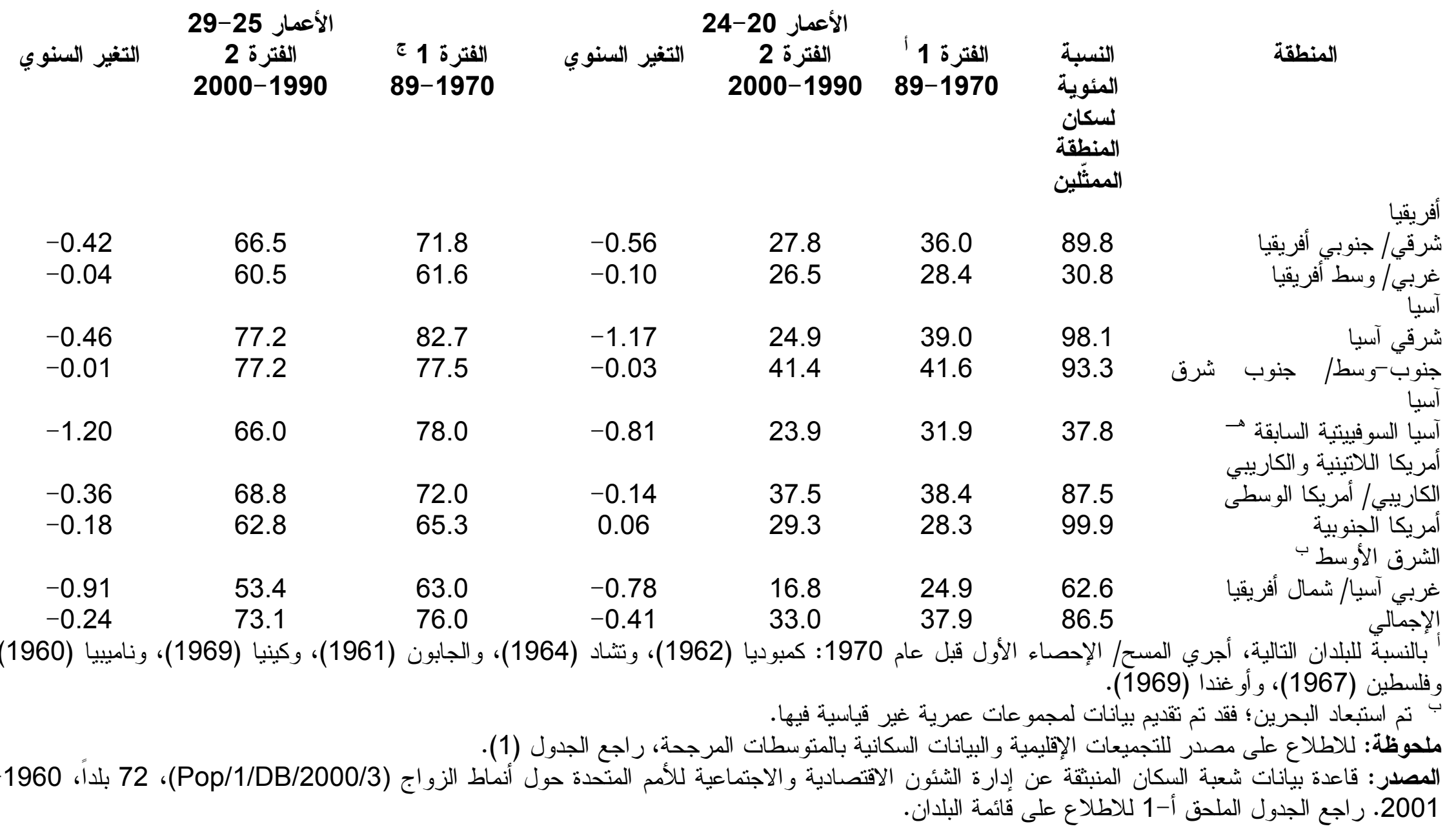


جذول(3): النسبة المئوية للنساء اللاتي تزوجن ببلو غهن سن الـــ 18 و الـــ 20 و الـــ 25 عاماً، تبعاً للسن، و الفترة الزمنية، و المنطقة (منتوسطات مرجحة)

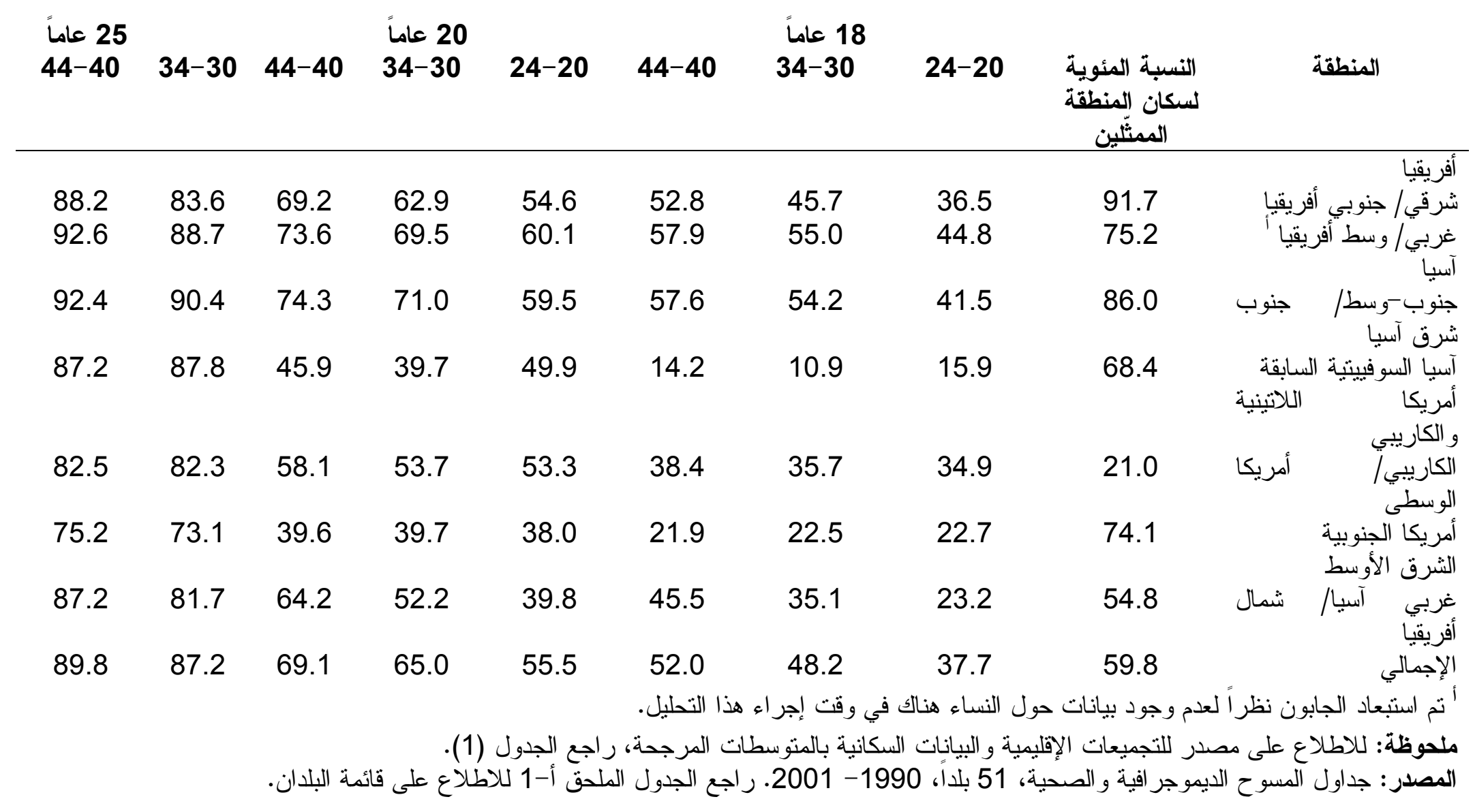


جدول (4): النسبة المئوية للرجال الذين تزوجو ا ببلو غهم سن الـــ 20 و الــ 25، و والــ 30 عاماً، تبعاً للسن في وقت إجر اء المسح، و المنطقة (منوسطات مرجحة)

\begin{tabular}{|c|c|c|c|c|c|c|c|c|}
\hline \multicolumn{2}{|c|}{30 عاماً } & \multicolumn{2}{|c|}{25 ع اما } & \multicolumn{3}{|c|}{20 عاماً } & \multirow[b]{2}{*}{ لسكان المنظية المنئة } & \multirow[b]{2}{*}{ 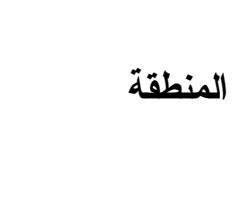 } \\
\hline $44-40$ & $34-30$ & $44-40$ & $34-30$ & $44-40$ & $34-30$ & $24-20$ & & \\
\hline 87.7 & 86.7 & 61.0 & 59.3 & 21.3 & 20.0 & 13.8 & 69.5 & نوبي أفريقيا \\
\hline 76.5 & 77.0 & 50.9 & 47.7 & 17.5 & 16.2 & 12.0 & 75.5 & نط أفريقيا \\
\hline 80.1 & 76.0 & 58.0 & 55.3 & 21.9 & 20.4 & 22.2 & 13.7 & أمريكا \\
\hline $\begin{array}{l}85.6 \\
82.7\end{array}$ & $\begin{array}{l}80.7 \\
81.1\end{array}$ & $\begin{array}{l}57.4 \\
56.2\end{array}$ & $\begin{array}{l}58.7 \\
54.8\end{array}$ & $\begin{array}{l}10.8 \\
16.9\end{array}$ & $\begin{array}{l}18.2 \\
18.1\end{array}$ & $\begin{array}{l}14.0 \\
13.5\end{array}$ & $\begin{array}{l}60.3 \\
60.5\end{array}$ & لجنوبية \\
\hline
\end{tabular}


جدول (5): النسبة المئوية للنساء اللاتي تتر اوح أعمار هن بين 20 و 24 عاماً وتزوجن ببلو غهن سن الــ 18، تبعاً لسنوات التعليم المدرسي والمنطقة (متوسطات مرجحة)

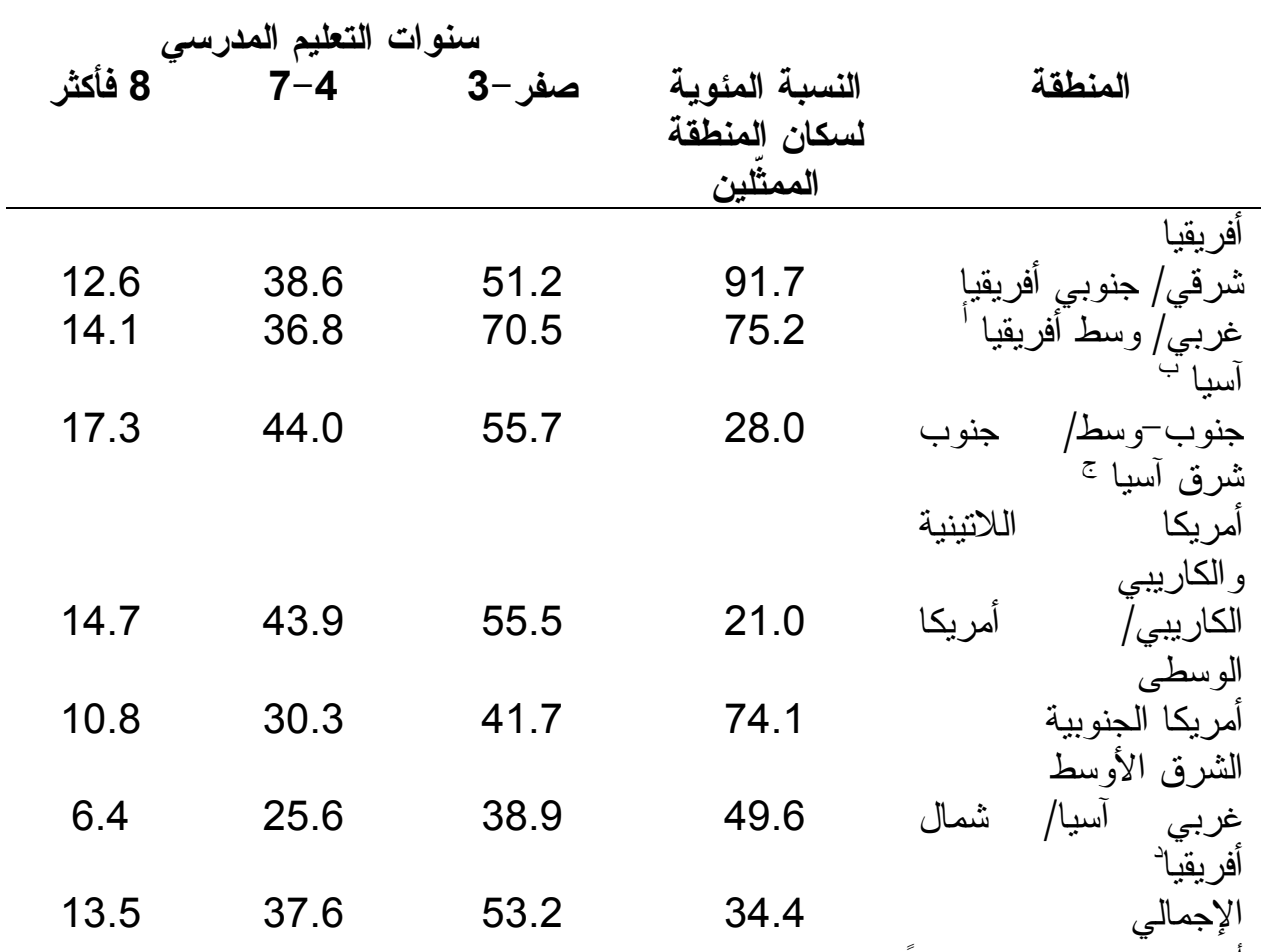

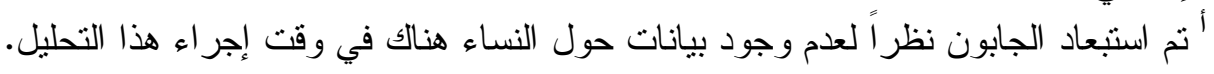

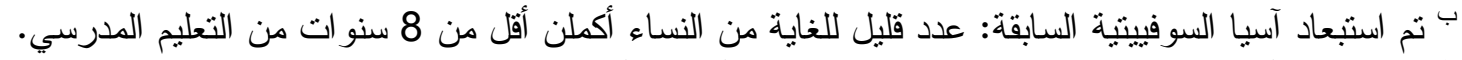

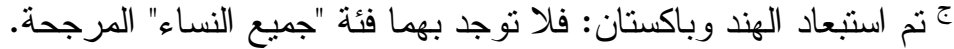

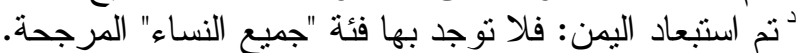

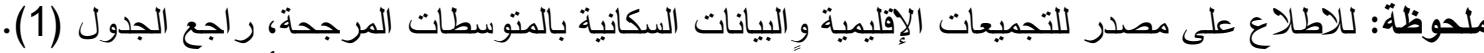

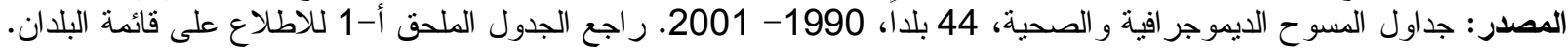


جدول (6): النسبة المئوية للنساء اللاتي تتر اوح أعمار هن بين 20 و 24 عاماً وتزوجن ببلوغهن سن الــ 18، تبعاً للإقامة في الريف أو الحضر و المنطقة (منتوسطات مرجحة)

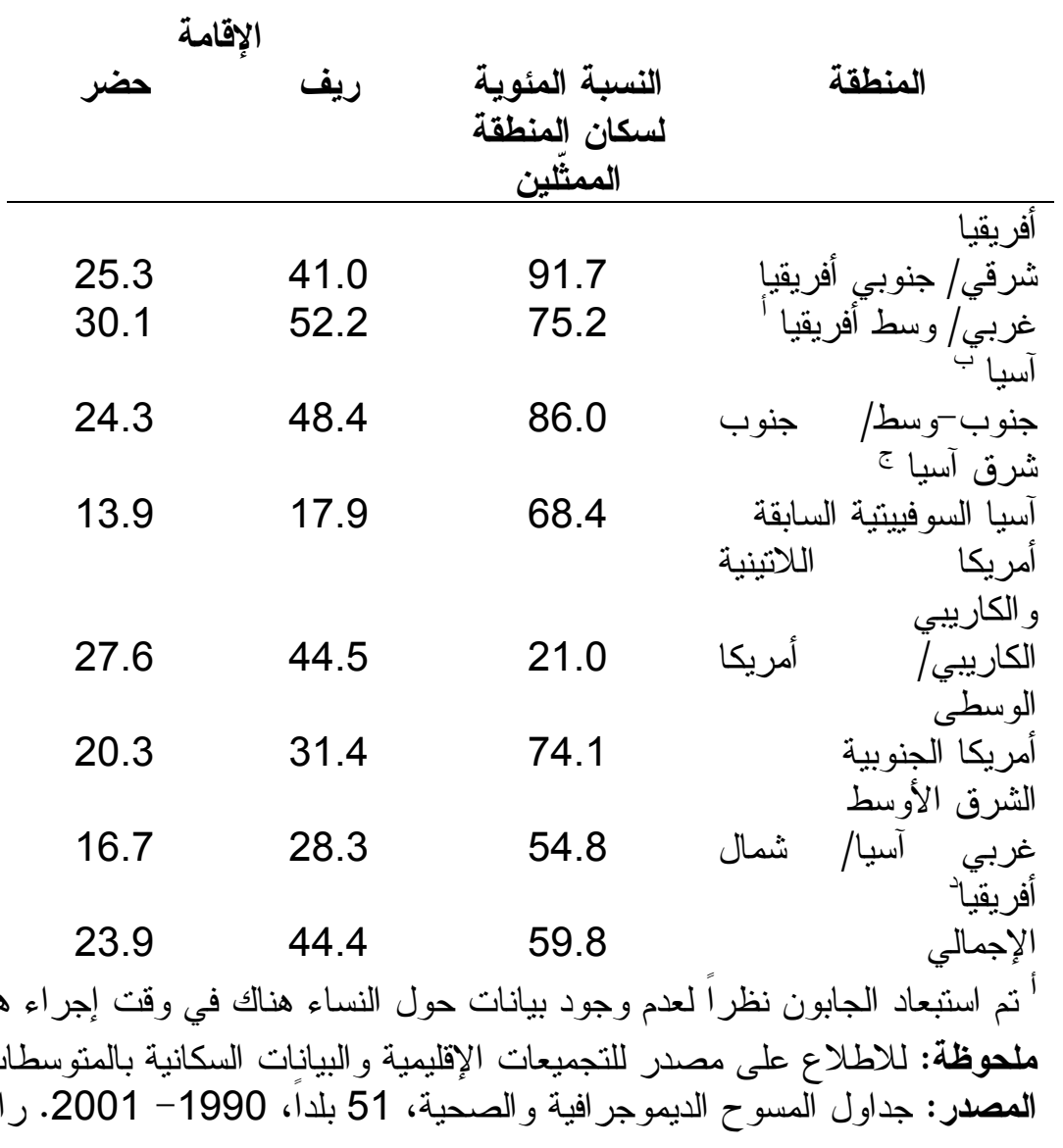




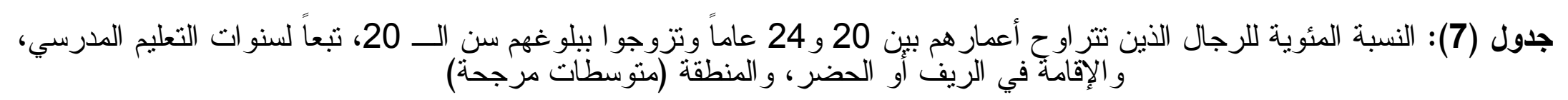

\begin{tabular}{|c|c|c|c|c|c|c|}
\hline \multicolumn{2}{|c|}{ الإقامة } & \multicolumn{3}{|c|}{ سنوات التعليم المدرسيً } & \multirow[b]{2}{*}{ لسكان المنططقة المئوية } & \multirow[b]{2}{*}{ المنطقة } \\
\hline حضر & ريف & 8 فأكثر & $7-4$ & صفر -3 & & \\
\hline 8.2 & 15.5 & 6.5 & 16.7 & 20.9 & 69.5 & \\
\hline 5.1 & 16.0 & 6.0 & 14.5 & 21.0 & 75.5 & \\
\hline 18.2 & 26.5 & 13.9 & 30.9 & 24.6 & 13.7 & أمريكا \\
\hline 14.0 & 13.4 & 10.0 & 18.0 & 20.7 & 60.3 & \\
\hline
\end{tabular}

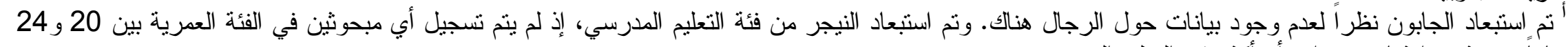

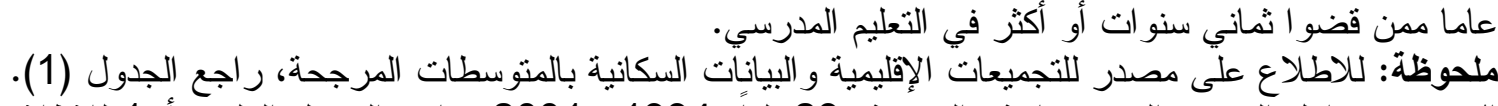

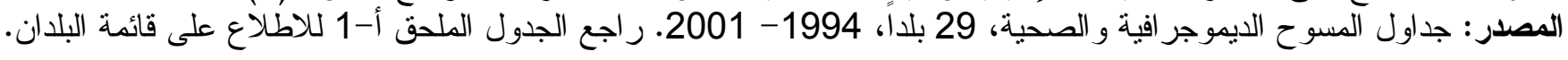


جدول (8): النسبة المئوية لتوزيع نسبة التغير المتوقعُ إلى الملاحَظ في نسبة

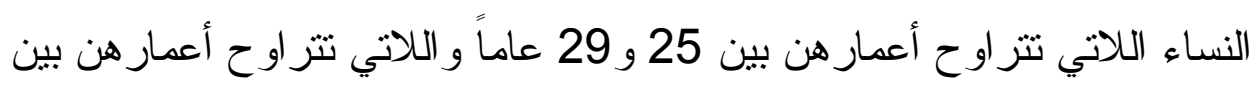

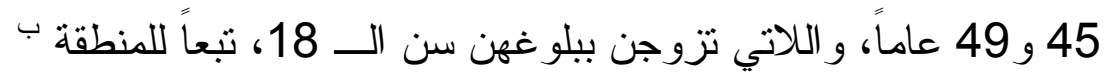

$$
\text { (متوسطات مرجحة) }
$$

نسبة التغير المتوقعُ إلى الملاحظ

\begin{tabular}{|c|c|c|c|c|c|c|}
\hline (عدد ) & الإجمالي & 1.00 فأكثر & -0.50 & أقل من & \multicolumn{2}{|c|}{ المنطقة } \\
\hline البلان ) & & ₹ & 0.99 & 0.50 & & \\
\hline (9) & 100 & 86 & 14 & صفر & اللاتينية & أمريكا \\
\hline (4) & 100 & 37 & صفر & 63 & السو فيتتية & آسبا \\
\hline & & & & & & السابقة \\
\hline (26) & 100 & 42 & 26 & 32 & جنوب & منطقة \\
\hline (39) & 100 & 56 & 21 & 23 & & جميع المش اء الص \\
\hline
\end{tabular}

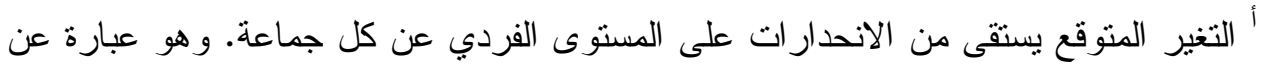

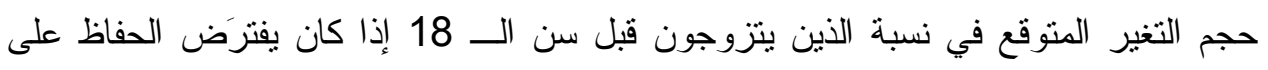

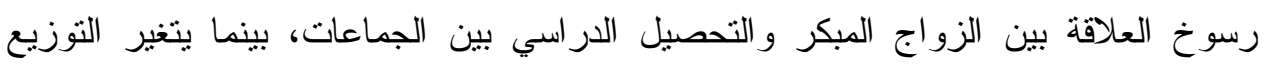

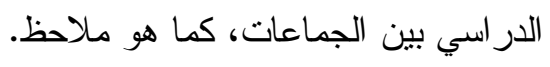
ب تم استبعاد منطقة جنوب-وسط/ جنوب شرق آنساع آسيا نظراً لاقتصار ها على عينات المتزوجات أو اللاتي سبق لهن الزواج.

ج تشمل البلدان التي ارتفع فيها الاحتمال الملاحَظ للزو اج المبكر بين الجماعتين.

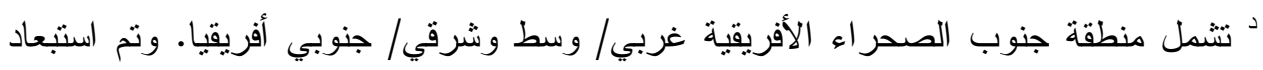

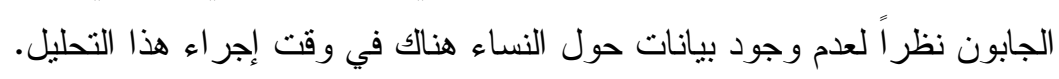

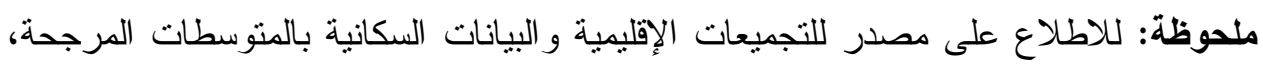
راجع الجدول (1). المصدر: جداول المسوح الديموجر افية و الصحية، 39 بلداً، 1990- 2001. الملدق أ-1 للاطلاع على قائمة البلدان. 
شكل (1): العلاقة بين التغير في النسبة المئوية للنساء اللاتي تتراوح أعمارهن

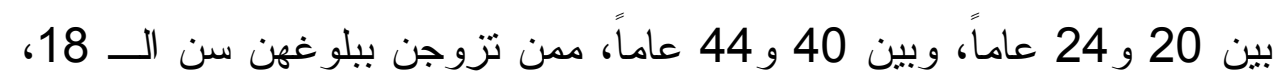
و التغير في عدد الصفوف المدرسية التي أكملنها.

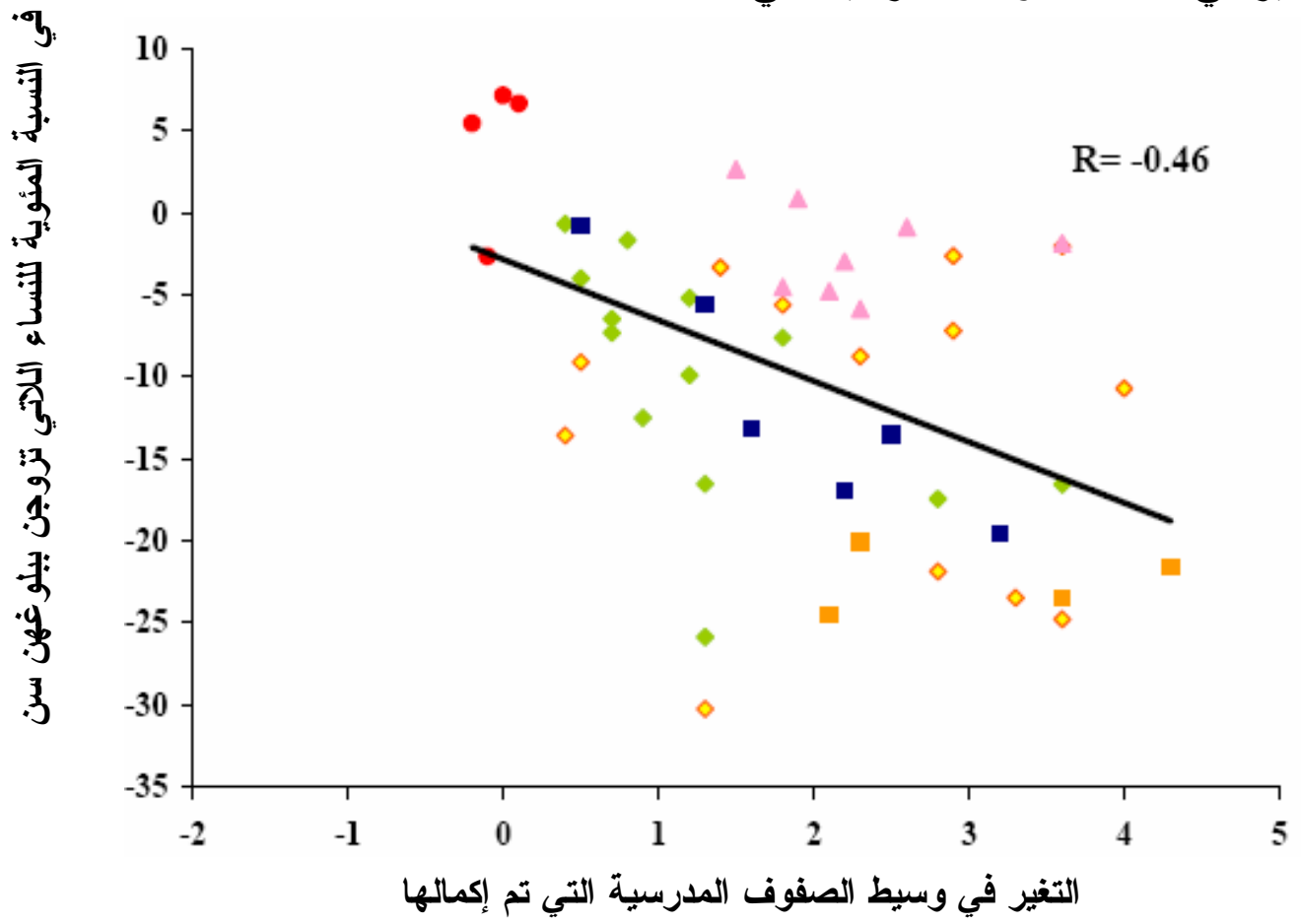

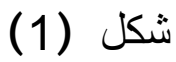

\begin{tabular}{|c|c|c|c|}
\hline • شرقيقا جنوبي & وسط & • غرب| & صآسيا السوفييتية \\
\hline [ــ الشرق الأوسط & شرقي & a & A أمريكا اللاتينية \\
\hline
\end{tabular}

المصدر: جداول المسوح الديموجر افية و الصحية، 49 بلداً، 1990- 2001. راجع الجدول

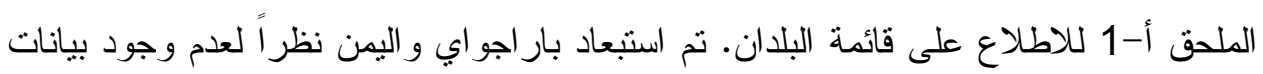

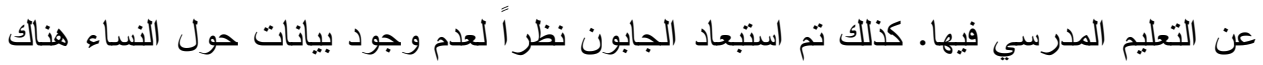

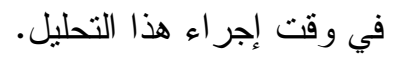


شكل (2): العلاقة بين التغير الملاحظ و المتوقع في النسبة المئوية للنساء اللاتي

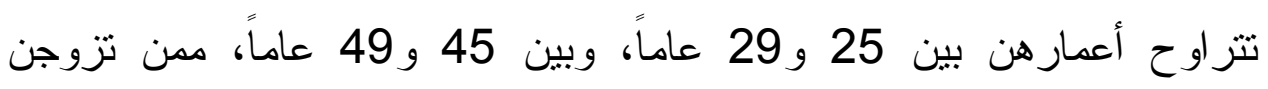

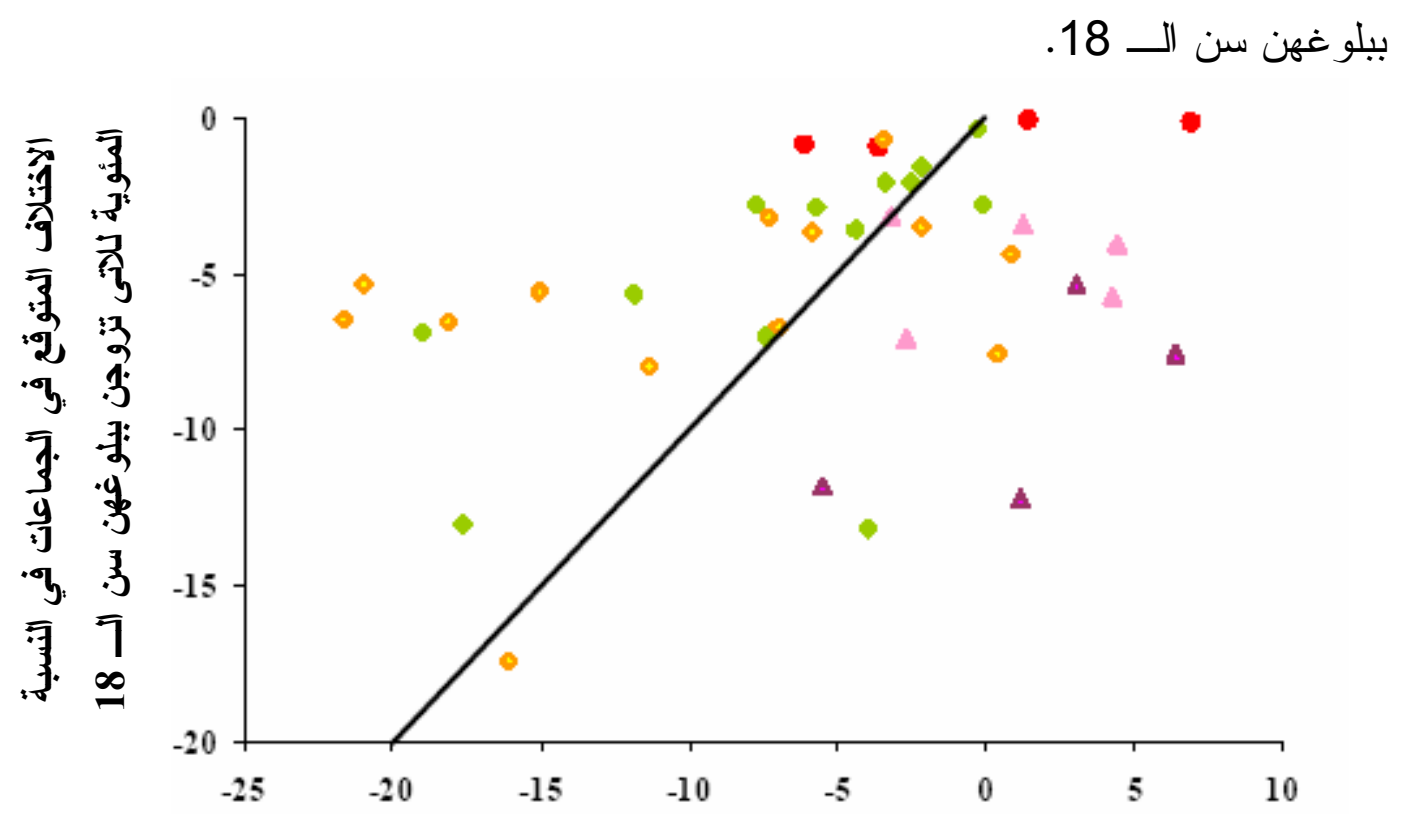

الاختلاف الملاحظّ في الجماعات في النسبة المئوية للاتي تزوجن ببلوغهن سن الـ 18

شكل (2)

\begin{tabular}{|c|c|c|}
\hline • آسيا السوفييتية السابقة & الوسطى الكاريبي/أمريكا & دأمريكا الجنوبية \\
\hline & أفريقيا & أفريقيا غرب| وسط \\
\hline
\end{tabular}

أ التغير الدنوقع هو التغير المتوقع نتيجة للاختلاف بين الجماعات من حيث التحصيل الدراسي.

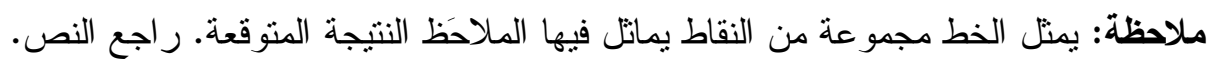

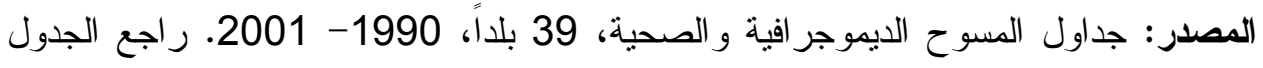

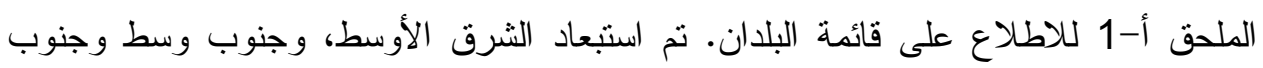

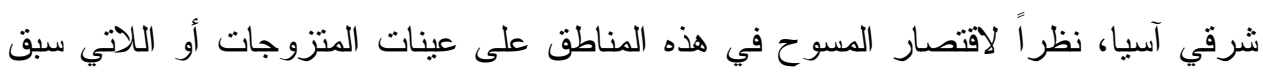

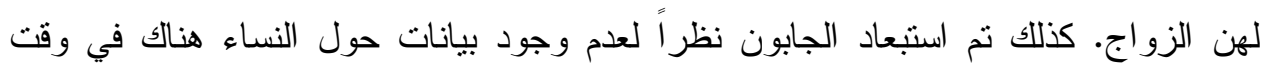
إجر اء هذا النحليل. 
شكل (3): العلاقة بين النسبة المئوية للنساء المتزوجات اللاتي تتراوح أعمار هن

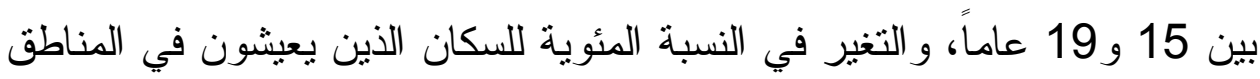
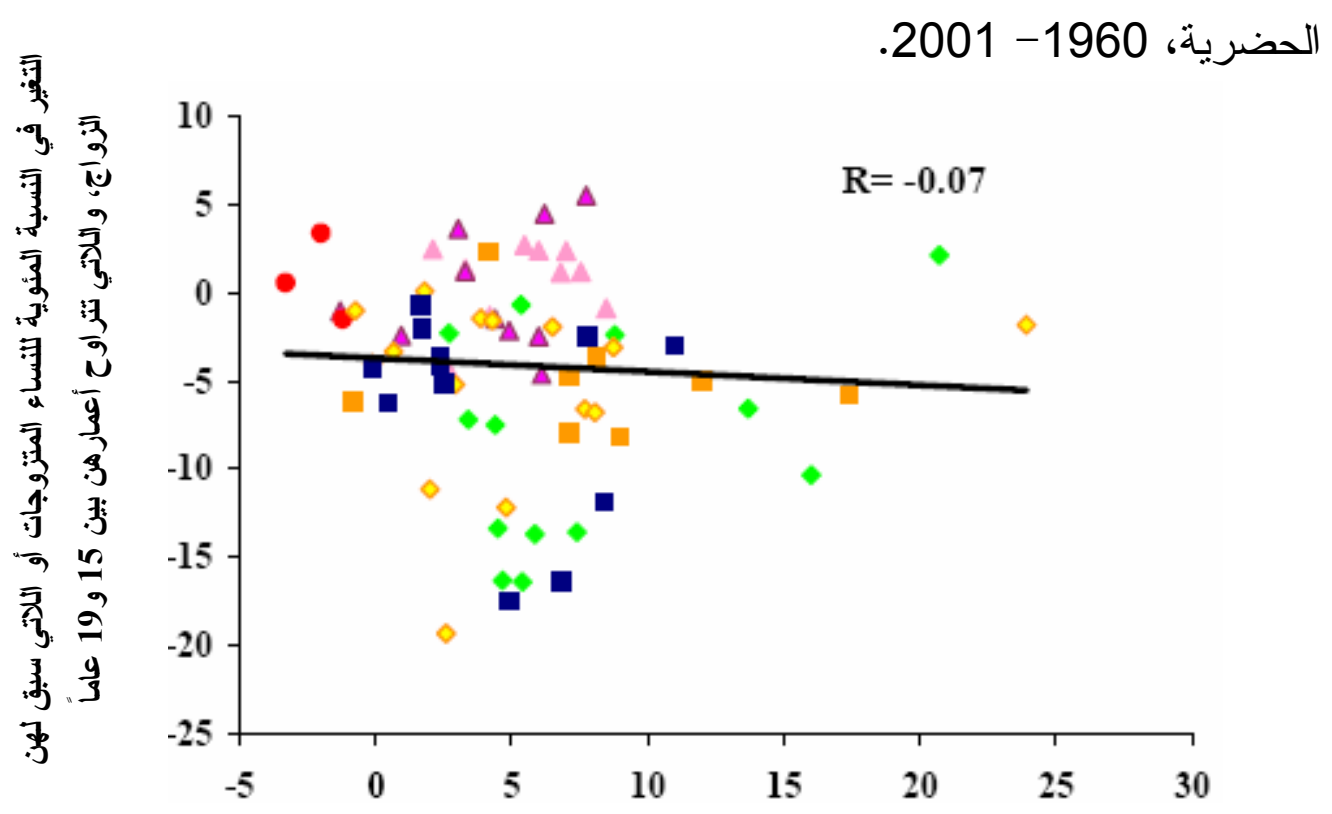

التغير في النسبة المئوية للأثخاص الأين يعيشون في المناطق الحضرية

شكل (3)

\begin{tabular}{|c|c|c|}
\hline • آسيا السوفييتية السابقة & الكاريبي/ أمريكا & أمريكا الجنوبية \\
\hline ه ش & أفريقيا & أفريقيا \\
\hline & & الثرق الأوسط \\
\hline
\end{tabular}

المصدر : قاعدة بيانات شعبة السكان المنبققة عن إدارة الثئون الاقتصادية و الاجتماعية للأهــم United Nations, Department of Economic and Social Affairs, المتحدة : Population Division database

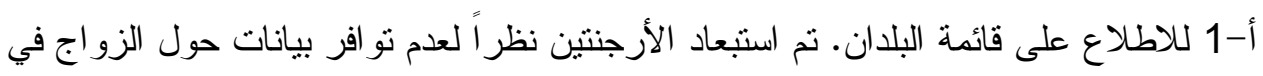
هذه الفئة العمرية خلال فترة المسح الأولى. 
شكل (4): العلاقة بين التغير في النسبة العئوية للرجال الذين تتراوح أعمارهم

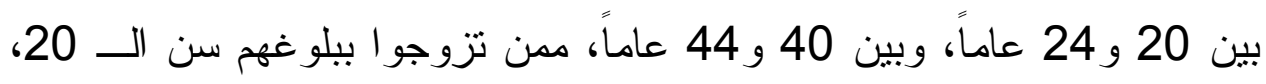
و التغير في عدد الصفوف الددرسية التي أكملوها.

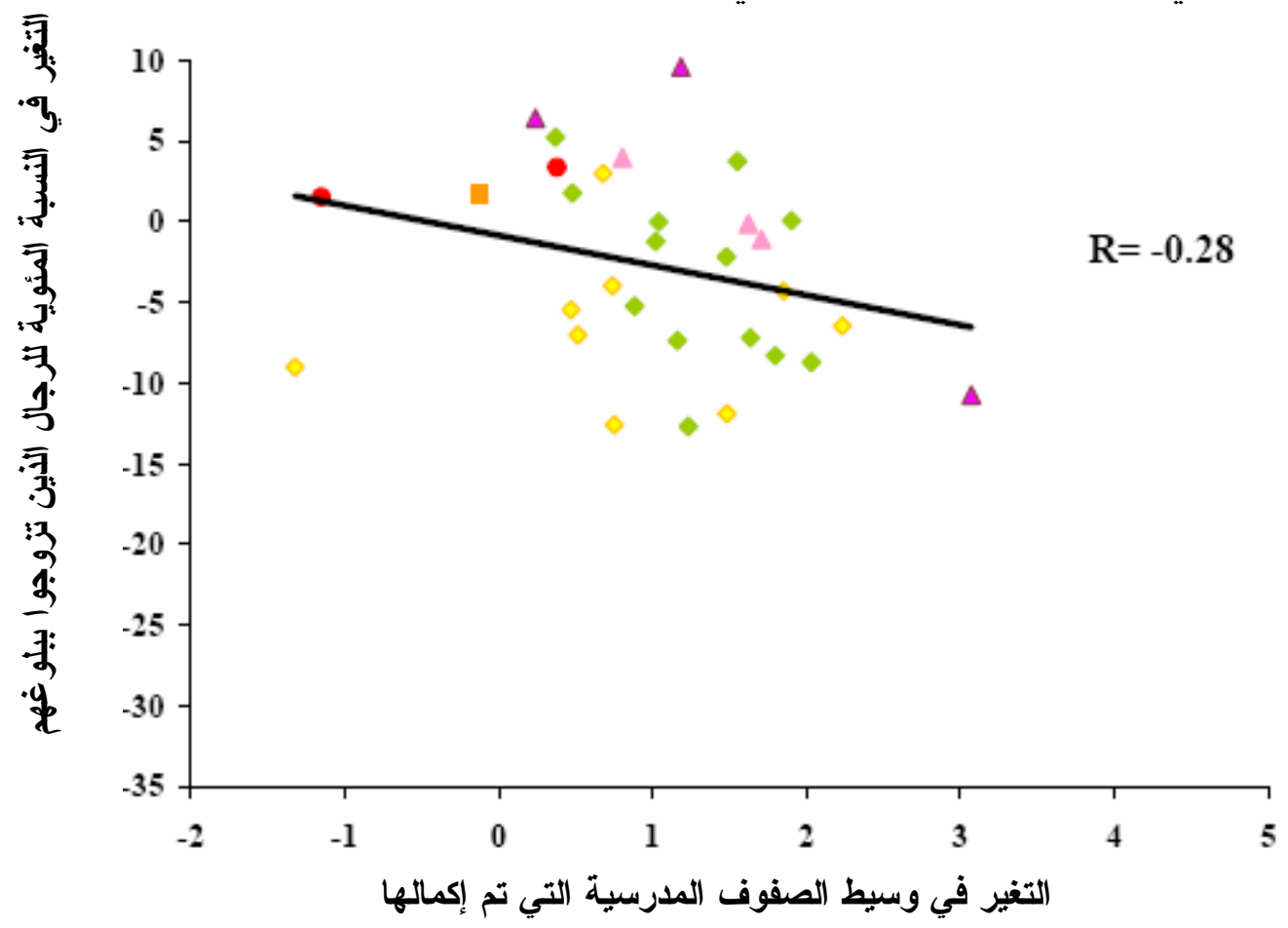

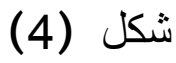

\begin{tabular}{|c|c|c|}
\hline • آسيا السوفييتية السابقة & ث الكاريبي/ أمريكا & - أمريكا الجنوبية \\
\hline - - الثرق الأوسط & أفريقيا شرقي/جنوبي & أفريقابا غرب| وسط \\
\hline
\end{tabular}

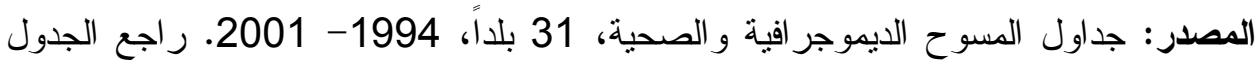
الملدق أ-1 للاطلاع على قائمة البلان. تم استبعاد الجابون نظراً لعدم وجود بيانات عن التعليم المدرسي فيها. 
شكل (5): العلاقة بين النسبة المئوية للرجال المتزوجين الذين تتراوح أعمارهم بين 20 و 24 عاماً، والتغير في النسبة المئوية للسكان الذين يعيشون في المناطق
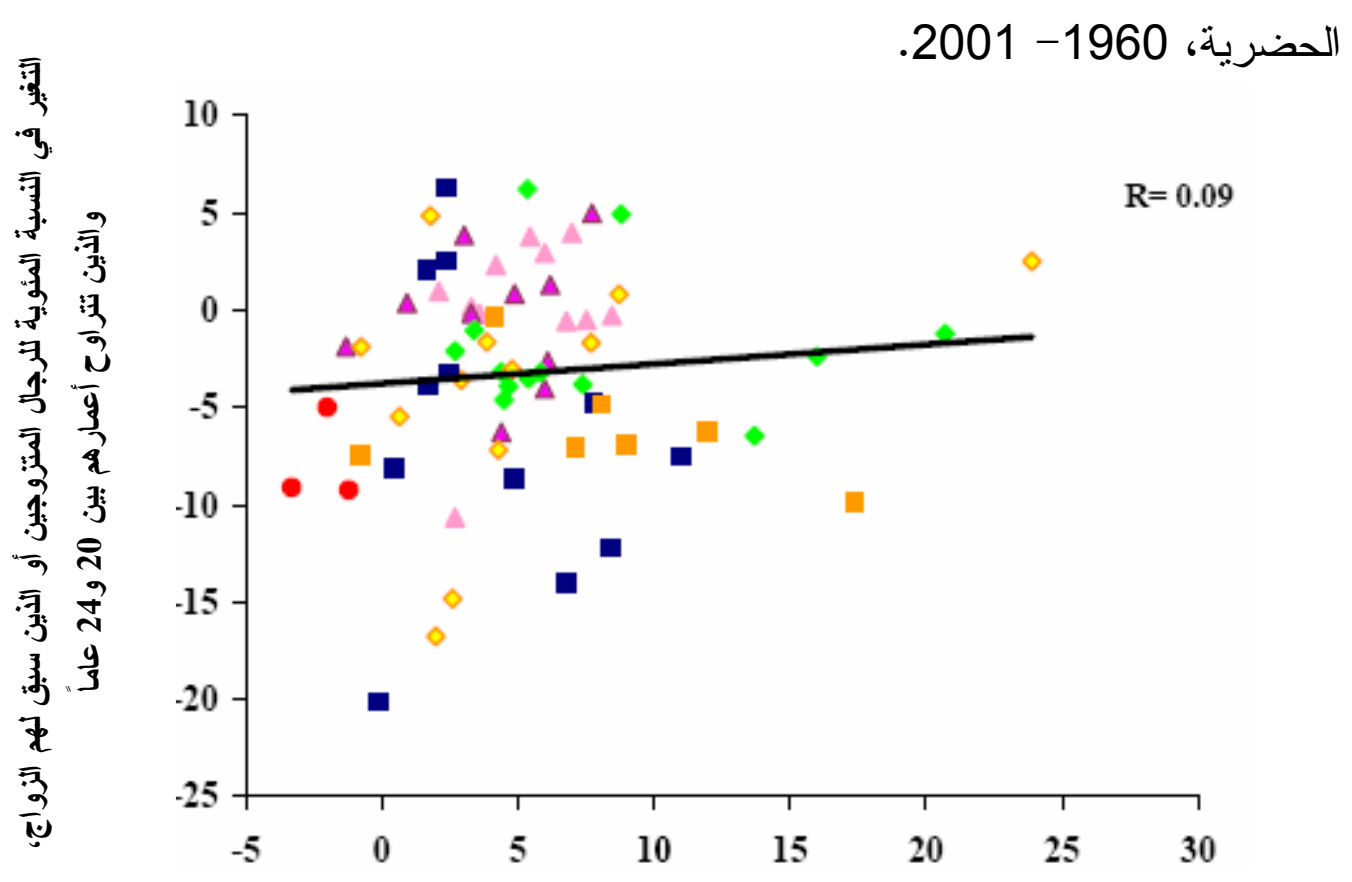

التغير في النسبة المئوية للأشخاص الذين يعيشون في المناطق الحضرية

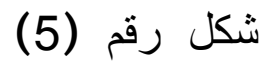

\begin{tabular}{|c|c|c|}
\hline • آسيا السوفييتية السابقة & | الكاريبي/ الوسطى & أمريكا الجنوبية \\
\hline שرق آسيا & أفريقيا & أفريقيا غرب| وسط \\
\hline & & " [ الثرق الأوسط \\
\hline
\end{tabular}

المصدر : قاعدة بيانات شعبة السكان المنبثقة عن إدارة الثئون الاقتصادية و الاجتماعية للأمم

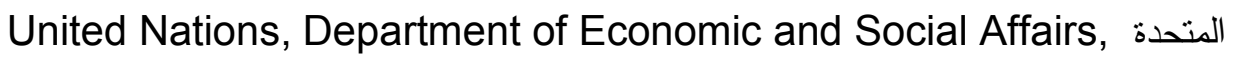
Population Division database أ-1 للاطلاع على قائمة البلدان. ثم استبعاد البحرين نظر أ لاستخدامها في مسحها لتجميعات عمرية غير قياسية. 
الجدول الملحق أ-1: البلدان تبعاً لمصدر البياتات، وفقاً للمنطقة وسنة المسح

مسوح ديموجر افية وصحية

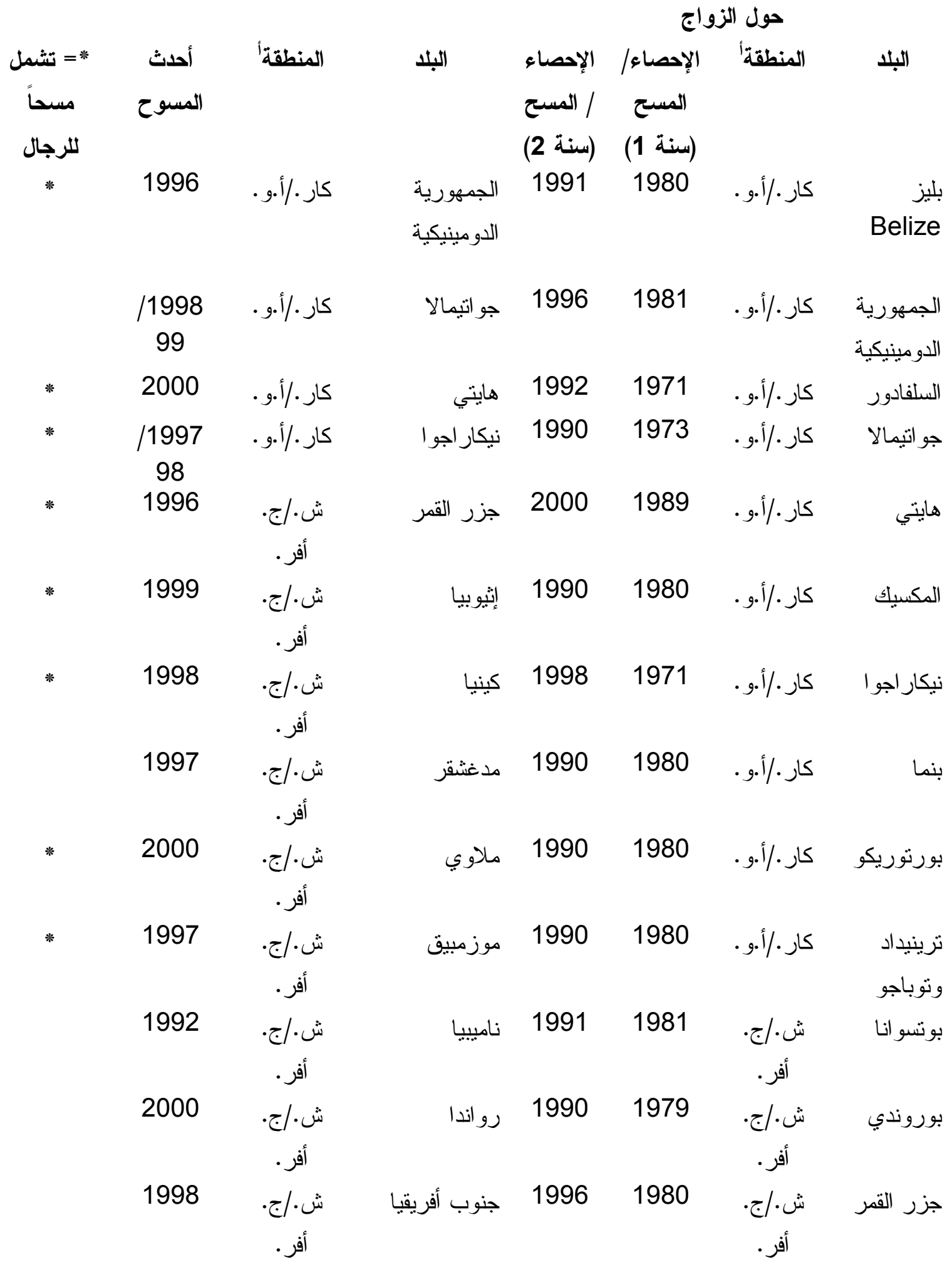

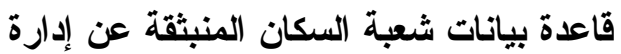

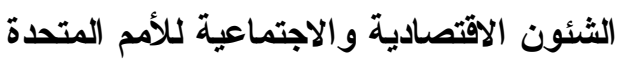

حول الزواج

بليز

Belize

الجمهورية كار./أ.و. $1981 \quad 1996 \quad$

الدومينيكية

السلفادور

جو اتيمالا كار./أ.و. $1973 \quad 1990 \quad$ كيكار اجوا

هايتي ار./أ.و. $1989 \quad 2000 \quad$

المكسيك $1980 \quad 1990 \quad$ كار.|أ.و. 1980

نيكار اجوا $\quad 1971 \quad 1998 \quad$ كار./أ.و. 1998

بنما 


\begin{tabular}{|c|c|c|c|c|c|c|c|}
\hline * & 1999 & شأفر./ج. & تنز انيا & 2000 & 1984 & ش.أفر.ج. & إثيوبيا \\
\hline * & $\begin{array}{c}/ 2000 \\
01\end{array}$ & ش. شفرج. & أو غندا & 1998 & 1969 & ش. شر/ج. & كينيا \\
\hline * & $\begin{array}{c}/ 1996 \\
97\end{array}$ & ش.فراج. & زامبيا & 2000 & 1987 & ش.أفر.ج. & ملاوي \\
\hline \multirow[t]{4}{*}{ * } & 1999 & ش.فر·. & زيمبابوي & 1990 & 1972 & ش.أفر.ج. & موريشيوس \\
\hline & 2000 & ش. أ. & مصر & 1997 & 1980 & ش. شر/ج. & موزمبيق \\
\hline & 1997 & ش. أ. & الأردن & 1991 & 1960 & ش. شُ|ج. & ناميييا \\
\hline & 1992 & ش. أ. & المغرب & 1996 & 1978 & ش. ش.|ج. & رو اندا \\
\hline \multirow[t]{2}{*}{ ب* } & 1998 & ش. أ. & تركيا & 1996 & 1985 & ش.أفر.ج. & جنوب أفريقيا \\
\hline & $\begin{array}{c}/ 1991 \\
92\end{array}$ & ش. أ. & اليمن & 1996 & 1978 & ش. شر/ج. & تنز انيا \\
\hline * & 1998 & أ. ج. & بوليفيا & 1995 & 1969 & ش.أفر·. & أو غندا \\
\hline \multirow[t]{2}{*}{ * } & 1996 & أ. ج. & البر ازيل & 1999 & 1980 & ش ش.|جر. & زامبيا \\
\hline & 2000 & أ. ج. & كولومبيا & 1999 & 1982 & شفرأف. & زيمبابوي \\
\hline \multirow[t]{4}{*}{ * } & $\begin{array}{l}1990 \\
2000\end{array}$ & ج. ج. و. ج. & بيرو اجواي & $\begin{array}{l}1999 \\
1991\end{array}$ & $\begin{array}{l}1987 \\
1981\end{array}$ & ش. ش. آس. & البحرين \\
\hline & $00 / 1999$ & ج.ش.و.| ج. & بنجلاديش & 1996 & 1986 & ش. أ. & مصر \\
\hline & $00 / 1998$ & ج.ش. ج.| & الهند & 1994 & 1979 & ش. أ. & الأردن \\
\hline & 1997 & ج. ج.و.| & إندونيسيا & 1994 & 1982 & ش. أ. & المغرب \\
\hline
\end{tabular}




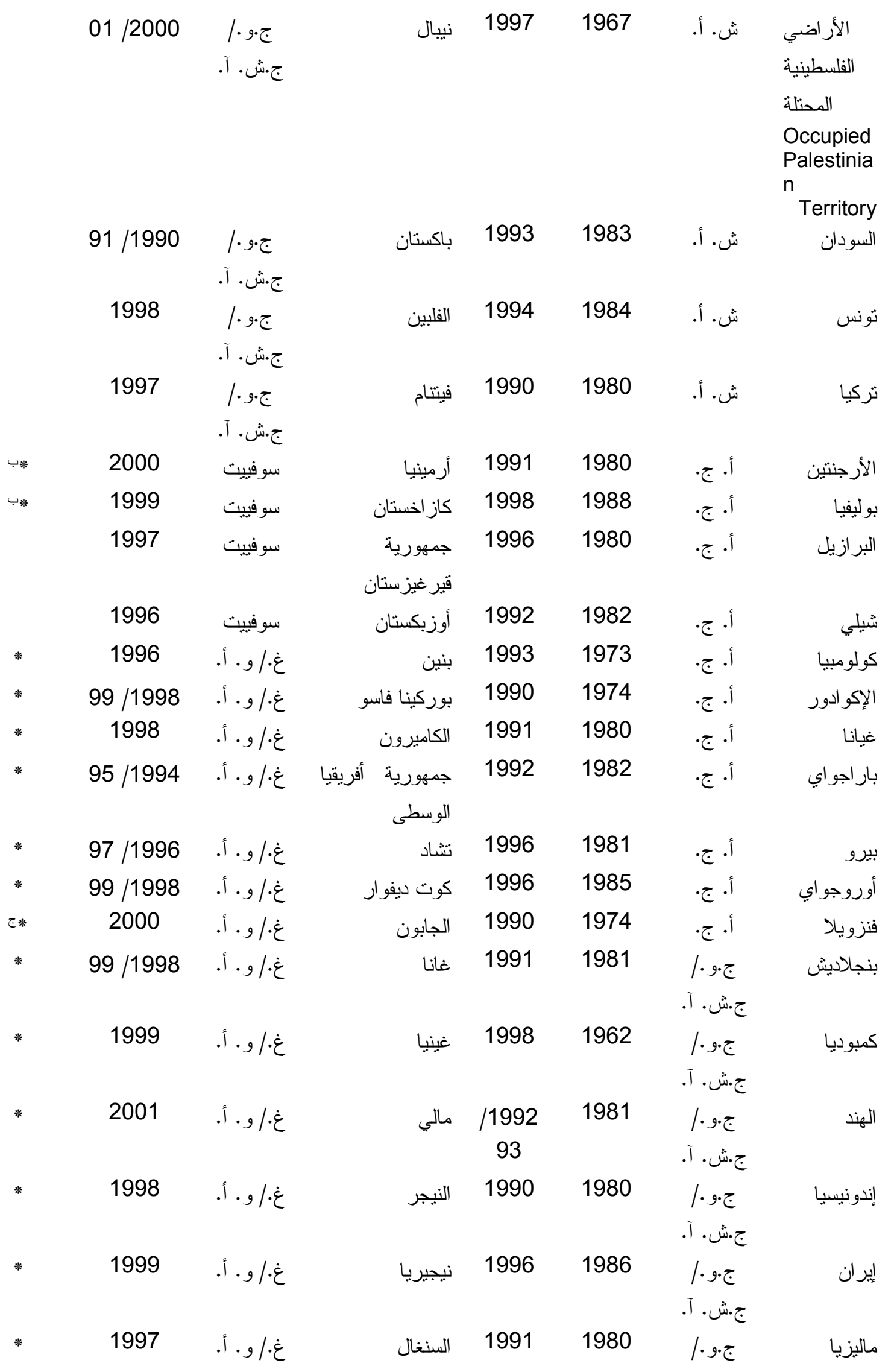




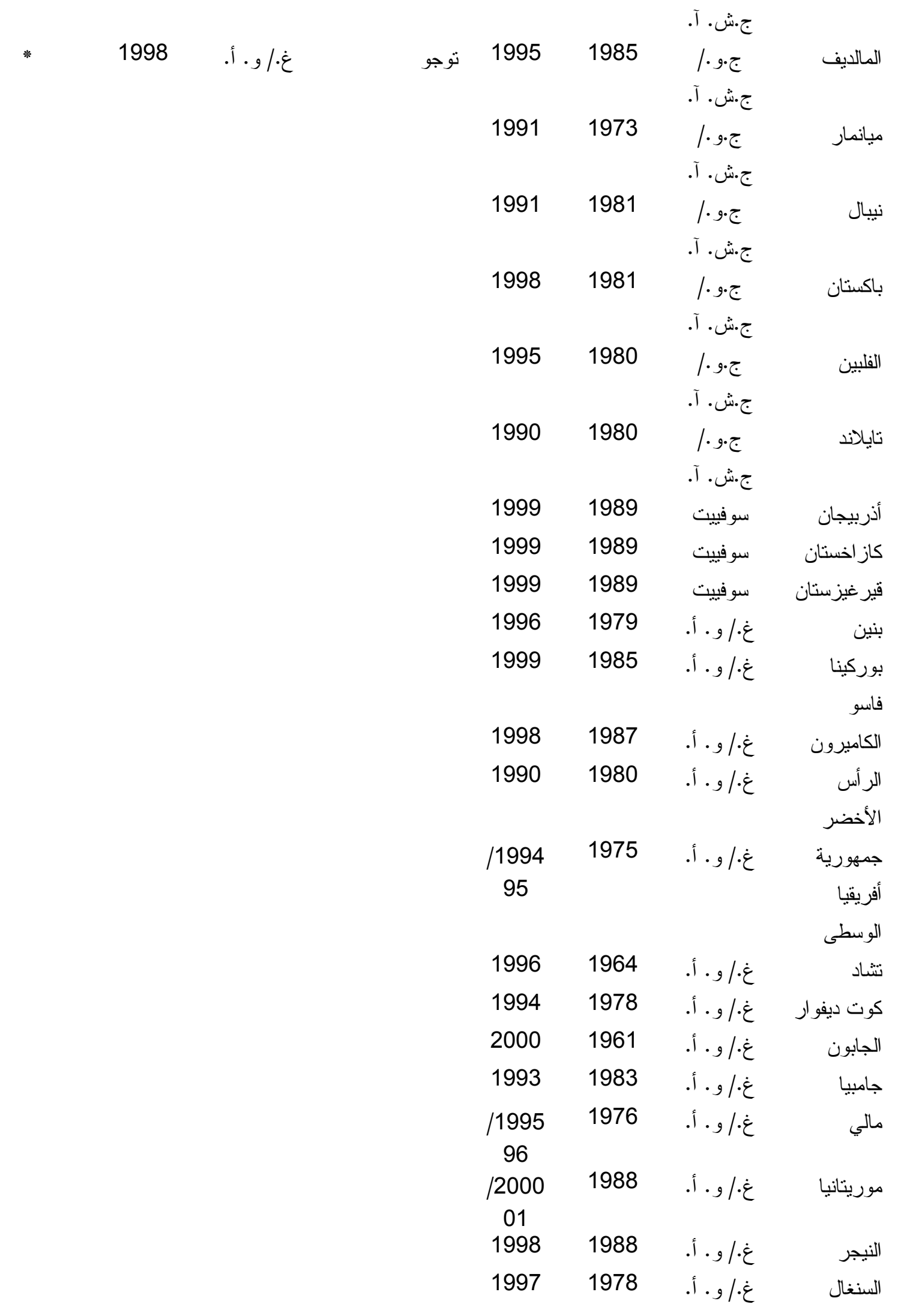




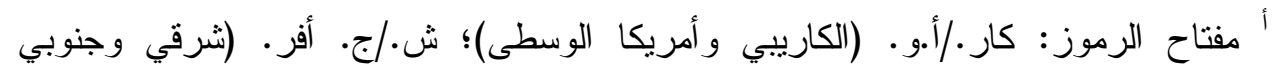

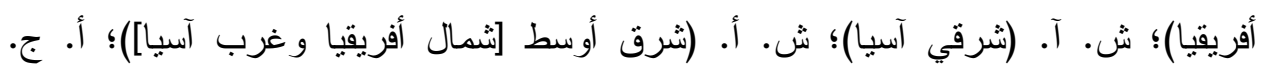

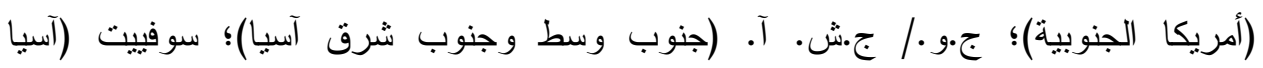

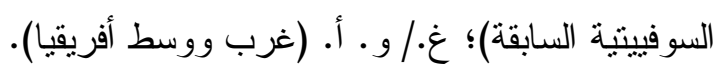

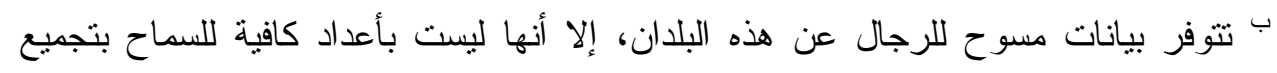
البيانات للخروج بمنوسطات إقليمية. ج لم تكن بيانات الجابون عن النساء متوفرة في وقت إجر اء هذا النحليل؛ و لا تتضمن الييانات

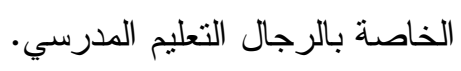

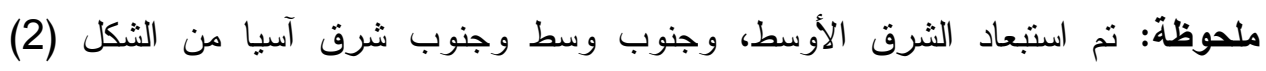
و الجدول (8) ، لأن المسوح نقوم على عينات المتزوجين أو الذين سبق لهم الزوبل واج.

أوراق عمل صدرت عن قسم بحوث السياسات 
يمكن الحصول على نسخة واحدة مما يصل إلى ثلاث ورقات عمل اعتبار أ من

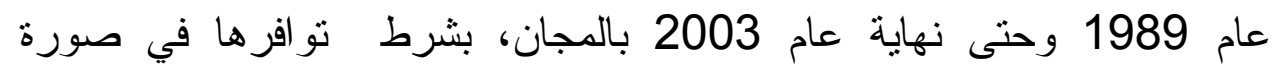
مطبو عة. - مان

و ابتداء من عام 2004، لن تكون ورقات العمل متوفرة في صورة مطبوعة.

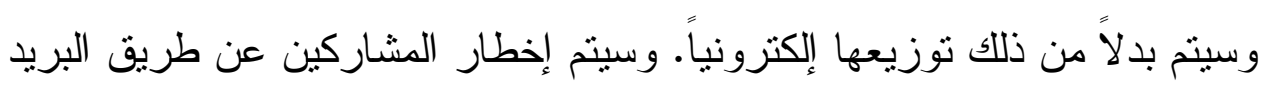
الإلكتروني فور اكتمال كل ورقة، و تعريفهم بالعنوان الإلكتروني الفرعي الذي لإني

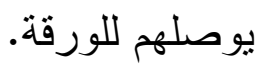

للاشتر الك في قائمة الإخطار الإلكترونية الخاصة بقسم بحوث السياسات، أو

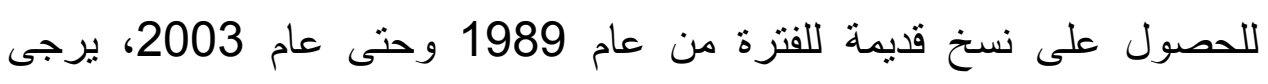
prdwp@popcouncil.org إرسال طلبك إلى العنوان كان

تتو افر إصدارات لأعداد سابقة حديثة على هيئة ملفات PDF على العنوان

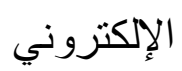
www.popcouncil.org/publications/wp/prd/rdwplist.html 
202 Barbara S. Mensch, Susheela Singh, and John B. Casterline, Trends in the timing of first marriage among men and women in the developing world."

201 Zachary Zimmer, "Active life expectancy and functional limitations among older Cambodians: Results from a 2004 survey."

200 Brian Wells Pence, Philomena Nyarko, James F. Phillips, and Cornelius Debpuur, "The effect of community nurses and health volunteers on child mortality: The Navrongo Community Health and Family Planning Project."

199 Zachary Zimmer, Linda G. Martin, Mary Beth Ofstedal, and Yi-Li Chuang, "Education of adult children and mortality of their elderly parents in Taiwan."

198 Mian Bazle Hossain, James F. Phillips, and Thomas K. LeGrand, "The impact of childhood mortality on fertility in six rural thanas

of Bangladesh."

197 Kristine R. Baker, Mary Beth Ofstedal, Zachary Zimmer, Zhe Tang, and Yi-Li Chuang, "Reciprocal effects of health and economic wellbeing among older adults in Taiwan and Beijing."

196 Mark R. Montgomery and Paul C. Hewett, "Poverty and children's schooling in urban and rural Senegal."

\section{4}

195 Luciana Suran, Sajeda Amin, Lopita Huq, and Kobita Chowdury, "Does dowry improve life for brides? A test of the bequest theory of dowry in rural Bangadesh."

194 Barbara S. Mensch, Monica J.Grant, Mary P. Sebastian, Paul C.Hewett, and Dale Huntington. "The effect of a livelihoods intervention in an urban slum in India: Do vocational counseling and training alter the attitudes and behavior of adolescent girls?" 
193 Amanda Ritchie, Cynthia B. Lloyd, and Monica Grant. "Gender differences in time use among adolescents in developing countries: Implications of rising school enrollment rates."

192 John Bongaarts. "Long-range trends in adult mortality: Models and projection methods."

191 John Koku Awoonorwilliams, Ellie Feinglass, Rachel Tobey,Maya N. VaughanSmith, Frank K. Nyonator, Tanya C. Jones, and James F. Phillips, "Bridging the gap between evidence-based innovation and national healthsector reform in Ghana."

190 Kelly Hallman, "Socioeconomic disadvantage and unsafe sexual behaviors among young women and men in South Africa."

189 Toshiko Kaneda, Zachary Zimmer, and Zhe Tang, "Differentials in life expectancy and active life expectancy by socioeconomic status among older adults in Beijing."

188 Cynthia B. Lloyd and Monica J. Grant, "Growing up in Pakistan: The separate experiences of males and females."

187 Zachary Zimmer, Xianghua Fang, Toshiko Kaneda, Zhe Tang, and Julia Kwong. "Trends and transitions in children's coresidence with older adults in Beijing municipality."

186 Sajeda Amin and Alaka M. Basu. "Popular perceptions of emerging influences on mortality and longevity in Bangladesh and West Bengal."

185 John Bongaarts. "Population aging and the rising cost of public pensions."

184 Mark R. Montgomery and Paul C. Hewett. "Urban poverty and health in developing countries: Household and neighborhood effects.

\section{3}


183 Agnes $\mathrm{R}$. Quisumbing and Kelly Hallman. "Marriage in transition: Evidence on age, education, and assets from six developing countries."

\section{Paul C. Hewett,} Barbara S. Mensch, and Annabel $S$.

Erulkar,"Consistency in the reporting of sexual behavior among adolescent girls in Kenya: A comparison of interviewing methods."

181 Zachary Zimmer, Linda G. Martin, and HuiSheng Lin, "Determinants of old-age mortality in Taiwan."

180 Frank K. Nyonator, J. Koku Awoonor-Williams, James F. Phillips, Tanya C. Jones, and Robert A. Miller, "The Ghana Community-based Health Planning and Services Initiative: $\quad$ Fostering evidence-based organizational change and development in a resourceconstrained setting."

179 John Bongaarts and Griffith

Feeney,
"Estimating

mean lifetime."

178 Elizabeth F. Jackson,Patricia Akweongo, Evelyn Sakeah,Abraham Hodgson, Rofina Asuru, and James F.Phillips, "Women's denial of having experienced female genital cutting in northern Ghana: Explanatory factors and consequences for analysis of survey data."

177 John Bongaarts, "Completing the fertility transition in the developing world: The role of educational differences and fertility preferences."

176 Cynthia B. Lloyd and Paul C. Hewett, "Primary schooling in sub-Saharan Africa: Recent trends and current challenges."

175 James F. Phillips, Tanya C. Jones,Frank K. Nyonator, and Shruti Ravikumar, "Evidencebased development of health and family planning programs in Bangladesh and Ghana." 
174 Geoffrey McNicoll, "Population

development:

introductory view."

173 Paul Demeny, "Population policy: A concise summary."

172 Zachary Zimmer, Napaporn Chayovan, HuiSheng Lin, and Josefina Natividad, "How indicators of

socioeconomic status relate to physical functioning of older adults in three Asian societies."

171 Sajeda Amin and Nagah H. Al-Bassusi, "Wage work and marriage: Perspectives of Egyptian women."

170 Ravai Marindo, Steve Pearson, and John B. Casterline, "Condom use and abstinence among unmarried young people in Zimbabwe: Which strategy, whose agenda?"

169 Zachary Zimmer and Julia Dayton, "The living arrangements of older adults in sub-Saharan Africa in a time of HIVIAIDS."
168 Paul C. Hewett, Annabel S. Erulkar, and Barbara S. Mensch, "The feasibility of computerassisted survey interviewing in Africa: Experience from two rural medistricts in Kenya." 